RICARDO CARDOSO RANGEL

SEQUÊNCIA SIMPLES DE FABRICAÇÃO DE TRANSISTORES SOI NMOSFET

São Paulo

2014 
RICARDO CARDOSO RANGEL

\section{SEQUÊNCIA SIMPLES DE FABRICAÇÃO DE TRANSISTORES SOI NMOSFET}

Dissertação apresentada à Escola Politécnica da Universidade de São Paulo para obtenção do título de Mestre em Ciências.

São Paulo 
RICARDO CARDOSO RANGEL

\title{
SEQUÊNCIA SIMPLES DE FABRICAÇÃO DE TRANSISTORES SOI NMOSFET
}

\author{
Dissertação apresentada à Escola \\ Politécnica da Universidade de São \\ Paulo para obtenção do título de \\ Mestre em Ciências.
}

Área de Concentração:

Microeletrônica.

Orientador: Prof. Dr. João Antonio Martino

São Paulo 
Este exemplar foi revisado e alterado em relação à versão original, sob responsabilidade única do autor e com a anuência de seu orientador.

São Paulo, ....... de Abril de 2014.

Assinatura do autor

Assinatura do orientador

FICHA CATALOGRÁFICA

Rangel, Ricardo Cardoso

Sequência simples de fabricação de transistores SOI

nMOSFET / R.C. Rangel. -- Edição Revisada-- São Paulo, 2014.

$147 \mathrm{p}$.

Dissertação (Mestrado) - Escola Politécnica da Universidade de São Paulo. Departamento de Sistemas Eletrônicos.

1. Transistores. 2. Microeletrônica. 3. Fabricação (Microeletrônica). 4. Dispositiovs eletrônicos. 5. Semicondutores. I. Universidade São Paulo. Escola Politécnica. Departamento de Sistemas Eletrônicos. II. t. 
Aos meus pais,

Antônio Rangel

Maria Rita Cardoso Rangel 


\section{AGRADECIMENTOS}

Ao Professor Dr. João Antonio Martino, pela orientação e pelo constante incentivo durante a realização deste trabalho.

Aos meus caros amigos do departamento de sistemas eletrônicos da escola politécnica da USP, do Laboratório de Microeletrônica, e do Laboratório de Sistemas Integráveis.

A todos os amigos do grupo SOI-CMOS, pelas valiosas discussões e apoio constante.

Ao Laboratório de Sistemas Integráveis, e ao Laboratório de Microeletrônica, ambos da Escola Politécnica da Universidade de São Paulo pela disponibilidade da infraestrutura necessária para essa atividade de pesquisa.

Aos meus pais, por seu incansável amor e dedicação.

Aos meus irmãos Felipe e Rodrigo, pela valiosa amizade.

À minha namorada Vanessa, por sua compreensão e apoio em todos os momentos.

Aos meus tios Maria Aparecida Pereira e Casemiro Pereira (in memoriam) por sua amizade e incentivo.

E a todas as pessoas que de forma direta ou indireta contribuíram para a execução deste trabalho e que foram involuntariamente omitidas. 
"Q correr da vida embrulha tuda, a vida é assim: esquenta e esfria, aperta e daí afrouxa, sassega e depois desinquieta.

Q que ela quer da gente é caragem."

(João Guimarães Rosa) 


\section{RESUMO}

Neste trabalho é desenvolvido de forma inédita no Brasil um processo simples de fabricação de transistores FD SOI nMOSFET (Fully-Depleted Silicon-On-Insulator) com porta de silício policristalino, para servir como base para futuros desenvolvimentos e, também, com finalidade de educação em microeletrônica.

É proposta uma sequência de etapas de fabricação necessárias para a obtenção do dispositivo FD SOI nMOSFET, usando apenas 3 etapas de fotogravação e usando o óxido enterrado, intrínseco à tecnologia SOI, como região de campo, objetivando a obtenção do processo mais simples possível e eficiente. São apresentados os procedimentos detalhados de todas as etapas de fabricação executadas.

Para obtenção da tensão de limiar de $1 \mathrm{~V}$ foram fabricadas amostras com 2 doses diferentes de implantação iônica, $1,0 \times 10^{13} \mathrm{~cm}^{-2}$ e $1,2 \times 10^{13} \mathrm{~cm}^{-2}$. Estas doses resultaram em tensões de limiar $\left(\mathrm{V}_{\mathrm{TH}}\right)$ de $0,72 \mathrm{~V}$ e $1,08 \mathrm{~V}$; respectivamente. Como esperado, a mobilidade independente de campo $\left(\mu_{0}\right)$ é maior na amostra com dose menor, sendo de $620 \mathrm{~cm}^{2} / \mathrm{Vs}$ e, para a dose maior, $460 \mathrm{~cm}^{2} / \mathrm{Vs}$.

A inclinação de sublimiar é calculada através da obtenção experimental do fator de acoplamento capacitivo ( $\alpha$ ) 0,22; para as duas doses, e resulta em $73 \mathrm{mV} /$ déc.

O ganho intrínseco de tensão $(A v)$ mostrou-se maior na amostra com maior dose em função da menor condutância de saída, sendo $28 \mathrm{~dB}$ contra $26 \mathrm{~dB}$ para a dose menor, no transistor com $\mathrm{L}=40 \mu \mathrm{m}$ e $\mathrm{W}=12 \mu \mathrm{m}$.

Desta forma foi possível implementar uma sequência simples de fabricação de transistores $\mathrm{SO}$, com resultados elétricos relevantes e com apenas 3 etapas de fotogravação, fato importante para viabilizar seu uso em formação de recursos humanos para microeletrônica.

Palavras-chaves: Microeletrônica. Transistores. SOI. MOSFET. Educação (Microeletrônica). 


\section{ABSTRACT}

In this work is developed in an unprecedented way in Brazil a simple process of manufacturing transistors FD SOI nMOSFET (Fully-Depleted SiliconOn-Insulator) with gate polysilicon, to serve as the basis for future developments and also with the purpose of education in microelectronics.

A sequence of manufacturing steps necessary for obtaining FD SOI nMOSFET device is proposed, using only three photolithographic steps and using the buried oxide, intrinsic to $\mathrm{SOI}$ technology such as field region, aiming to get the simplest possible and efficient process. All the detailed manufacturing steps performed procedures are presented.

To obtain the threshold voltage of $1 \mathrm{~V}$ samples with 2 different doses of ion implantation $\left(1.0 \times 10^{13} \mathrm{~cm}^{-2}\right.$ and $\left.1.2 \times 10^{13} \mathrm{~cm}^{-2}\right)$ were fabricated. These doses resulted in threshold voltages $\left(\mathrm{V}_{\mathrm{TH}}\right)$ of $0.72 \mathrm{~V}$ and $1.08 \mathrm{~V}$, respectively. As expected, mobility independent of field $(\mu 0)$ is higher in the sample with the lowest dose, $620 \mathrm{~cm}^{2} / \mathrm{Vs}$, and for the higher dose, $460 \mathrm{~cm}^{2} / \mathrm{Vs}$.

The subthreshold slope is calculated by obtaining experimental capacitive coupling factor ( $\alpha$ ) 0.22 , for both doses and results in $73 \mathrm{mV} /$ déc.

The intrinsic voltage gain (AV) was higher in the sample with a higher dose due to lower output conductance, $28 \mathrm{~dB}$ against $26 \mathrm{~dB}$ to the lowest dose, to the transistor with $\mathrm{L}=\mathrm{W}=40 \mu \mathrm{m}$ and $12 \mu \mathrm{m}$.

This made it possible to implement a simple sequence of manufacturing SOI transistors with relevant electrical results and with only 3 steps photolithographic important fact to enable their use in training human resources for microelectronics.

Keywords: Microelectronics. Transistors. SOI. MOSFET. Education (Microelectronics). 


\section{LISTA DE ILUSTRAÇÕES}

Figura 1 - Curva do número de transistores por microprocessador em função da data de lançamento deste produto [9].

Figura 2 - Guia da evolução dos tipos de transistores e materiais, ITRS 2012 [13].........................26

Figura 3 - Estrutura básica de um transistor MOSFET canal N. ..................................................31

Figura 4 - Comparação da espessura de uma estrutura básica de um transistor nMOSFET com a espessura do substrato (lâmina de silício) sobre o qual este dispositivo é construído.

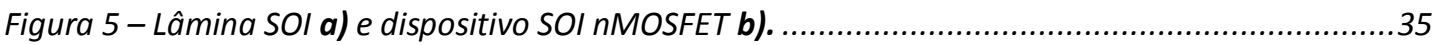

Figura 6 - Técnica Smart-Cut ${ }^{\circledR}$ de obtenção de Lâminas SOI. .................................................37

Figura 7-Seção transversal de: a) nMOSFET (Convencional), b) PD SOI nMOSFET (com implantação anti-punchthrough $P+$ ) e c) FD SOI nMOSFET. 38

Figura 8-a) vista superior de um transistor nMOSFET, em b) o corte AA (antes da construção da porta e logo após a implantação de boro), em c) o corte BB (antes da construção da porta e logo após a implantação de boro) e em d) o corte BB logo após a oxidação de campo. Observe que em d), nas laterais da ilha de silício observa-se uma faixa $P^{+}$ 40

Figura 9-a) vista superior de um transistor nMOSFET, em b) o corte AA (antes da construção da porta), em c) o corte BB (antes da construção da porta e logo após a corrosão do Si) e em d) o corte BB logo após a implantação iônica. Observe que em d), nas laterais da ilha de silício observa-se uma faixa $P^{+}$.

Figura 10 - Isolação MESA simplificada: Na figura a) observa-se uma lâmina SOI com fotorresiste marcando a região ativa, em b) observa-se a corrosão do silício, e em c) $a$ "mesa" de silício isolada devido à oxidação de porta.

Figura 11 - Diagrama de faixas de energia para os transistores A) nMOSFET convencional, B) PD SOI nMOSFET e C) FD SOI nMOSFET.

Figura 12 - Elevação abrupta da corrente na curva $I_{D S} \times V_{D S}$ de um SOI nMOSFET.

Figura 13 - Curva esquemática de um transistor SOI nMOSFET com fuga de corrente devido ao efeito de transistor lateral (Edge Transistor).

Figura 14 - Perfil da estrutura do transistor nMOSFET (convencional) após a etapa 6.....................57

Figura 15 - Perfil da estrutura do transistor nMOSFET (convencional) após a etapa 10....................57

Figura 16 - Perfil da estrutura do transistor nMOSFET (convencional) após a etapa 14...................58

Figura 17 - Perfil da estrutura do transistor nMOSFET (convencional) após a etapa 16...................58

Figura 18 - Perfil final da estrutura do transistor nMOSFET (convencional)...................................59

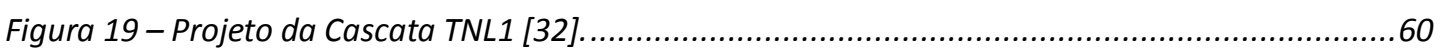

Figura 20 - Projeto do Transistor isolado T3........................................................................61

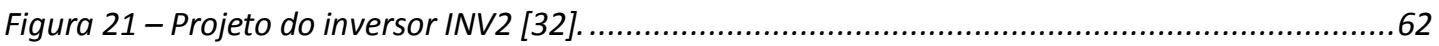


Figura 22 - Projeto do Diodo D2 [32].

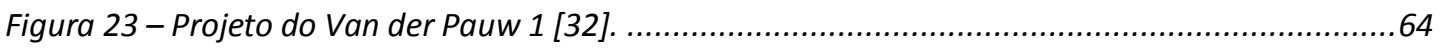

Figura 24 - Projeto da Estrutura Kelvin 2 [32]...............................................................6

Figura 25 - Projeto das marcas de alinhamento. ..................................................................6

Figura 26 - Perfil do projeto das marcas de alinhamento. ........................................................66

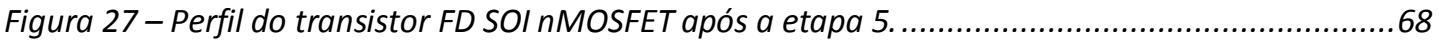

Figura 28 - Perfil do transistor FD SOI nMOSFET após a etapa 10............................................68

Figura 29 - Perfil do transistor FD SOI nMOSFET após a etapa 14.................................................69

Figura 30 - Perfil do transistor FD SOI nMOSFET após a etapa 16.............................................69

Figura 31 - Perfil final da estrutura do transistor FD SOI nMOSFET.........................................70

Figura 32 - Gráfico da corrente de porta (I GS-eixo da direita) e da corrente de dreno (IDS-eixo da esquerda) do transistor nMOSFET convencional. a) Escala linear e b) escala logarítmica. Este transistor tem dimensões $L=100 \mu \mathrm{m}$ e $W=100 \mu \mathrm{m}$.

Figura 33 - Curvas de projeto de $t_{\text {OXF }}$ e $t_{S i}$. Nestas curvas são estudadas três possíveis toxF $(30$, 50 e $70 \mathrm{~nm})$. E conclui-se que para toxF $=30 \mathrm{~nm}$ não é possível ajustar a tensão de limiar $\left(V_{T H}=1 \mathrm{~V}\right)$ e construir um dispositivo totalmente depletado ao mesmo tempo.

Figura 35 - a) Gráfico da corrente de dreno (IDS) por unidade de largura do transistor FD SOI nMOSFET e, b) Gráfico da segunda derivada de $I_{D S}$ em função de $V_{G S}$. Este é um resultado das simulações, considerando dose de $1,0 \times 10^{13} \mathrm{~cm}^{-2}$. Este transistor tem comprimento $L=5 \mu \mathrm{m}$.

Figura 36 - a) Gráfico da corrente de dreno (IDS) por unidade de largura do transistor FD SOI nMOSFET $e, \boldsymbol{b})$ Gráfico da segunda derivada de $I_{D S}$ em função de $V_{G S .}$ Este é um resultado das simulações, considerando dose de $1,2 \times 10^{13} \mathrm{~cm}^{-2}$. Este transistor tem comprimento $L=5 \mu \mathrm{m}$.

Figura 37-Curva $I_{D} \times V_{G S}$ obtida através de simulação numérica, onde está destacada a inclinação de sublimiar para as duas doses de implantação iônica de boro.

Figura 38 - Imagens no microscópio ótico após 19 litografia. a) Transistor T3, b) Cascata de transistores TNL1, c) Marca de alinhamento, e; d) Inversores.

Figura 39 - Imagens no microscópio ótico após 2 2 etapa de litografia. a) Transistor isolado T3,

b) Cascata de transistores TNL1, c) Marca de alinhamento, e; d) Inversores.

Figura 40 - Imagens no microscópio ótico após 3ạ etapa de litografia. a) Transistor isolado T3,

b) Cascata de transistores TNL1, c) Marca de alinhamento, e; d) Inversores. .91

Figura 41 - Espectro FTIR do Óxido obtido por Deposição com TEOS.

Figura 42 - Perfil final dos dispositivos construído, caso o tempo de corrosão da etapa de abertura de contato tenha sido insuficiente. ...........................................................99

Figura 43 - Medidas de resistência de folha com a estrutura Van der Pauw. 95

Figura 44 - Medidas de $I_{D} \times V_{G S}$ e $I_{G} \times V_{G S}$ para o transistor $L=100 \mu m W=100 \mu m$ na lâmina $L 29$,

a) escala linear e; b) escala logarítmica. 95 
Figura 45 - Medidas de $I_{D} \times V_{G S}$ e $I_{G} \times V_{G S}$, para o transistor $L=100 \mu m W=100 \mu m$ após metalização e sem óxido PECVD na lâmina L29. a) escala linear e b) logarítmica.

Figura 46 - Medidas de $I_{D} X V_{G S}, I_{S} X V_{G S} I_{B} X V_{G S}$ e $I_{G} X V_{G S}$, para o transistor $L=100 \mu m$ e $W=100 \mu m$ após metalização e sem óxido PECVD na lâmina L29. a) na escala linear $e$, b) na escala logarítmica.

Figura 47-a) Imagem de transistor da amostra L29; b) Perfil dos transistores da amostra L29.......98

Figura 48 - Medida $I_{D} \times V_{G S}$ e $I_{G} \times V_{G S}$ com o substrato isolado (I $I_{B}=0$ e $V_{G B}$ desconhecido), a) em escala linear $e, b)$ em escala logarítmica.

Figura 49 - Gráfico, em escala linear, de correntes em função da tensão $V_{G S}$ para o transistor de maiores dimensões da lâmina L31.

Figura 50 - Amostra $L 31$ antes da sinterização: a) Gráfico $I_{D} X V_{G S}$ para diversos comprimentos de porta e b) Comparação entre a tensão de limiar dos transistores da amostra L31 em relação ao projeto inicial.

Figura 51 - Amostra $L 31$ antes da sinterização: a) Gráfico $I_{D} X V_{G S}$ na região de sublimiar, para diversos comprimentos de porta $e, \boldsymbol{b})$ Inclinação de sublimiar para diversos comprimentos de canal.

Figura 52 - a) Corrente de dreno em função da tensão de porta; e, b) tensão de limiar em função do comprimento de porta. 104

Figura 53 - a) Corrente de dreno em função da tensão de porta; e, b) inclinação de sublimiar em função do comprimento de porta.

Figura 54 - Corrente de dreno em função da tensão de porta para as amostras L41 $\left(\right.$ Dose $\left.=1,0 \times 10^{13} \mathrm{~cm}^{-2}\right)$ e $L 42\left(\right.$ Dose $\left.=1,2 \times 10^{13} \mathrm{~cm}^{-2}\right)$ : a) Escala linear e, b) logarítmica.

Figura 55 - Gráfico da segunda derivada da corrente de dreno em função da tensão de porta. ......108

Figura 56 - Corrente de dreno em função da tensão de porta, em escala logarítmica, para as amostras: a) L41 e b) L42; para diversas polarizações de substrato.

Figura 57 - Corrente de dreno em função da tensão de porta para tensões de substrato variando de -15V até $15 \mathrm{~V}$ : a) $\left.L 41\left(1,0 \times 10^{13} \mathrm{~cm}^{-2}\right) ; e, b\right) L 42\left(1,0 \times 10^{13} \mathrm{~cm}^{-2}\right)$.

Figura 58 - Tensão de limiar $\left(V_{T H}\right)$ em função da tensão de substrato $\left(V_{G B}\right)$, para o transistor principal e para o transistor lateral parasitário, nas amostras a) $L 41\left(1,0 \times 10^{13} \mathrm{~cm}^{-2}\right)$; $e$, b) $L 42\left(1,2 \times 10^{13} \mathrm{~cm}^{-2}\right)$

Figura 59 - Figura esquemática do modo de extração da tensão de limiar $\left(V_{T H}\right)$, mobilidade $\left(\mu_{0}\right)$, e variação no comprimento de canal $(\Delta L)$.

Figura 60 - Extração dos parâmetros de mobilidade e ( $\left.\mu_{0}\right)$, e variação no comprimento de canal ( $\Delta L)$ para as amostras, a) L41 e b) L42..

Figura 61 - Transcondutância em função da tensão de porta para diferentes comprimentos de canal, para a amostra a) $L 41$ e b) $L 42$. 
Figura 62 - a) Si-Poli na região de porta do transistor de $L_{\text {máscara }}=1 \mu m$. Amostra $L 42$

(Dose $=1,2 \times 10^{13} \mathrm{~cm}^{-2}$ ) e b) Perfil esquemático do transistor, destacando a corrosão isotrópica do Si-Poli.

Figura 63 - Configuração para medida de resistência da fonte.

Figura 64 - Gráfico para extração de parâmetros: a) $V_{T H}$ e $K_{0}$; e b) $\vartheta_{1}$ e $R_{F}$. 122

Figura 65 - Gráfico para extração dos parâmetros $\vartheta_{1}$ e $R_{F}$, nas amostras a) L41 e b) L42.

Figura 66 - Gráfico IDSXV $V_{D S}$ dos transistores T3: a) L41 e; b) L42.

Figura 67 - Característica de saída dos transistores com comprimento de canal (máscara) variando de 50 m a $1 \mu \mathrm{m}$, nas amostras: $\boldsymbol{a})$ L41 e; b) L42.

Figura 68 - Gráficos da condutância de saída em função da tensão de dreno ( $\left.g_{D} x V_{D S}\right)$ para diversos comprimentos de canal, nas amostras: a) L41 e; b) L42......

Figura 69 - Ganho intrínseco de tensão em função do comprimento de canal para as amostras L41 e L42, em uma polarização fixa, $V_{G S}=2,5 \mathrm{~V}$ e $V_{D S}=2,5 \mathrm{~V}$. . 


\section{LISTA DE TABELAS}

Tabela 1 - Sequência de soluções químicas utilizadas na limpeza completa......................................78

Tabela 2 - Sequência de procedimentos para a oxidação. ........................................................... 79

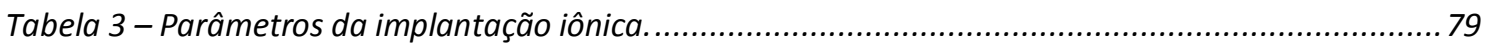

Tabela 4 - Parâmetros do processo de ativação de dopantes. .......................................................79

Tabela 5 - Sequência de soluções químicas utilizadas na limpeza completa.......................................8 80

Tabela 6 - Procedimentos para a oxidação que forma o isolante de porta. .........................................8 80

Tabela 7 - Procedimentos para a deposição de silício policristalino depositado por técnica LPCVD. .......81

Tabela 8 - Procedimentos para a dopagem de silício policristalino. ..................................................81

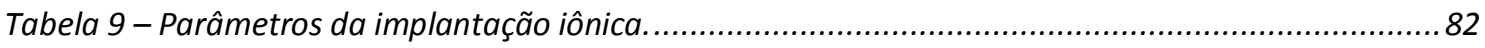

Tabela 10 - Parâmetros do processo de ativação de dopantes. ....................................................82

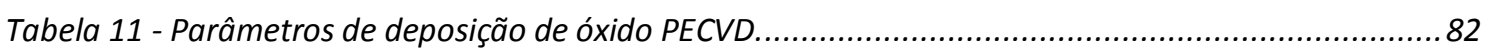

Tabela 12 - Parâmetros de deposição do Alumínio. ........................................................................83

Tabela 13 - Parâmetros de deposição do Alumínio no verso da lâmina. ...............................................84

Tabela 14 - Sequência de soluções químicas utilizadas na limpeza completa......................................85

Tabela 15 - Sequência de procedimentos para a oxidação. ..........................................................8 85

Tabela 16 - Parâmetros da implantação iônica..........................................................................86

Tabela 17 - Parâmetros do processo de ativação de dopantes. ...................................................8 86

Tabela 18 - Sequência de soluções químicas utilizadas na limpeza completa.....................................87

Tabela 19 - Procedimentos para a oxidação que forma o isolante de porta.....................................88

Tabela 20 - Procedimentos para a deposição de Si-Poli depositado no LPCVD. .....................................88

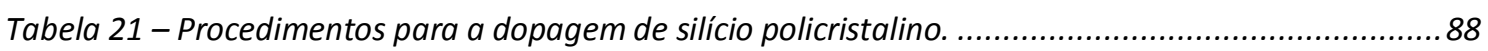

Tabela 22 - Parâmetros da implantação iônica.........................................................................90

Tabela 23 - Parâmetros do processo de ativação de dopantes. ....................................................90

Tabela 24 - Parâmetros de deposição do Alumínio. ......................................................................90

Tabela 25 - Parâmetros de deposição do Alumínio no verso da lâmina. .................................................92

Tabela 26 - Processo de sinterização realizado nas amostras $L 41$ e $L 42$. ..........................................92

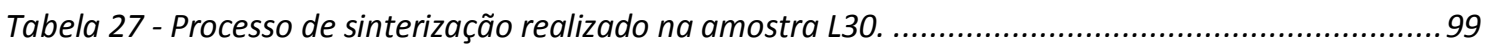

Tabela 28 - Resultados de resistência de folha e largura efetiva de linha (L31).............................. 101

Tabela 29 - Resultados de resistência de folha e largura efetiva de linha para L41 e L42. ................... 106

Tabela 30 - Comparação entre a tensão de limiar $\left(V_{T H}\right)$ obtida experimentalmente e o projeto inicial usando simulação numérica................................................................... 109

Tabela 31 - Inclinação de sublimiar do transistor lateral parasitário.............................................110

Tabela 32 - Inclinação de sublimiar do transistor principal, obtido experimentalmente, para polarização de substrato de $4 \mathrm{~V}$ e $5 \mathrm{~V}$, nas amostras $L 41$ e L42, respectivamente.

Tabela 33 - Resultado do fator de acoplamento capacitivo obtido nas amostras L41 e L42, para o transistor principal e para o transistor lateral parasitário. 
Tabela 34 - Resultados de tensão de limiar, variação do comprimento de canal e mobilidade de elétrons para baixo campo elétrico.

Tabela 35 - Transcondutância máxima $\left(g_{\operatorname{mmax}}\right)$ em função do comprimento de porta para as amostras $L 41$ e $L 42$......

Tabela 36 - Resultados da tensão de limiar $\left(V_{T H}\right)$, da resistência de fonte $\left(R_{F}\right)$ e do fator de redução da mobilidade $\left(\vartheta_{1}\right)$, para as amostras $L 41$ e L42. 


\section{LISTA DE ABREVIATURAS E SIGLAS}

\begin{tabular}{|c|c|}
\hline $\mathrm{BOE}$ & $\begin{array}{l}\text { "Buffered Oxide Etch" - Solução de corrosão } \\
\text { de óxido de Si tamponado. }\end{array}$ \\
\hline $\mathrm{Cl}$ & Circuito Integrado. \\
\hline CMOS & $\begin{array}{l}\text { Tecnologia que emprega transistores } \\
\text { MOSFET de canal } n \text { e de canal } p .\end{array}$ \\
\hline CMP & $\begin{array}{l}\text { Técnica de polimento de superfícies, } \\
\text { polimento químico-mecânico (Chemical } \\
\text { Mechanical Polishing). }\end{array}$ \\
\hline $\mathrm{IBL}$ & $\begin{array}{l}\text { Diminuição da barreira de potencial } \\
\text { fonte/substrato ocasionada pelo potencial do } \\
\text { dreno. }\end{array}$ \\
\hline PUSP & $\begin{array}{l}\text { Escola Politécnica da Universidade de São } \\
\text { Paulo. }\end{array}$ \\
\hline FD SOI & Tecnologia SOI totalmente depletada. \\
\hline FTIR & $\begin{array}{l}\text { Espectroscopia de infravermelho por } \\
\text { transformada de Fourier. }\end{array}$ \\
\hline grupo SOI-CMOS & $\begin{array}{l}\text { Grupo de pesquisas do LSI-EPUSP dedicado } \\
\text { ao estudo de transistores MOS construídos } \\
\text { em substratos SOI. }\end{array}$ \\
\hline LOCOS & Técnica de isolação local de silício. \\
\hline LPCVD & $\begin{array}{l}\text { Processo de deposição de filmes usando } \\
\text { reações de produtos em fase gasosa, } \\
\text { ativados termicamente. }\end{array}$ \\
\hline LSI-EPUSP & $\begin{array}{l}\text { Laboratório de Sistemas Integráveis da Escola } \\
\text { Politécnica da Universidade de São Paulo. }\end{array}$ \\
\hline MESA & $\begin{array}{l}\text { Técnica de isolação de silício sobre isolante } \\
\text { que consiste na separação das ilhas de silício } \\
\text { ativas, por corrosão do silício entre elas. }\end{array}$ \\
\hline F300 & $\begin{array}{l}\text { Nome comercial de produto para revelação de } \\
\text { fotorresiste. }\end{array}$ \\
\hline
\end{tabular}


MOSFET

MuGFET

nMOSFET

PD SOI

PECVD

PSI 2643

SIMOX

Si-Poli

Smart-Cut ${ }^{\circledR}$

SOI

SOI MOSFET

SOI NFD SOI

SOI-nMOSFET

TEOS

USP
Transistor de efeito de campo de tecnologia metal-óxido-semicondutor (Metal Oxide Semiconductor Field Effect Transistor). Transistor MOSFET de múltiplas portas, também conhecido como FinFET, ou 3D transistor.

Transistor MOSFET canal $\mathrm{n}$.

Tecnologia SOI parcialmente depletada.

Processo de deposição de filmes usando reações de produtos em fase gasosa enriquecidos por plasma.

Disciplina de graduação sobre construção de dispositivos em microeletrônica oferecida na EPUSP.

Técnica de obtenção de lâminas SOI consiste em: Separação por implantação de oxigênio.

Abreviatura para Silício Policristalino.

Técnica de obtenção de lâminas SOI consiste na: Adesão de lâminas oxidadas, posterior corte devido à implantação de hidrogênio e polimento da superfície.

Silício sobre isolante (Silicon On Insulator).

Transistor MOSFET construído em substrato SOI.

Dispositivo SOI de camada média.

Transistor MOSFET canal $\mathrm{n}$ construído em substrato SOI.

Sigla para TetraEthylOrthoSilicate.

Universidade de São Paulo. 


\section{LISTA DE SÍMBOLOS}

$A_{V}$

Coxb

Coxf

$\mathrm{C}_{\mathrm{Si}}$

$g_{D}$

$g_{m}$

IDS

IDSAT

IGS

k

$\mathrm{N}_{\mathrm{A}}$

$\mathrm{n}_{\mathrm{i}}$

q

QINV1

Qox1

Qox2

Qs2

$\mathrm{R}_{\mathrm{D}}$

$R_{F}$

Rs

S

$\mathrm{T}$

toxB

toxF

$\mathrm{V}_{\mathrm{FB} 1}$

$\mathrm{V}_{\mathrm{FB} 2}$

$\mathrm{V}_{\mathrm{GB}}$

$\mathrm{V}_{\mathrm{GB}, \mathrm{ACC} 2}$

$\mathrm{V}_{\mathrm{GB}, I N V 2}$

ganho intrínseco de tensão;

capacitância do óxido enterrado por unidade de área; capacitância do óxido de porta por unidade de área; capacitância da camada de silício por unidade de área; condutância de saída; transcondutância; corrente medida entre dreno e fonte; corrente de dreno quando o transistor está saturado; corrente de fuga medida entre a porta e a fonte; constante de Boltzman; concentração de impurezas aceitadoras no canal; concentração intrínseca de portadores; carga elementar do elétron; densidade de carga de inversão na primeira interface; densidade de carga efetiva no óxido de porta; densidade de carga efetiva no óxido enterrado; densidade de carga de acumulação $\left(Q_{s 2}>0\right)$ ou de inversão (Qs2<0) na segunda interface; resistência do dreno; resistência da fonte; resistência série associada ao transistor; inclinação de sublimiar; temperatura; espessura do óxido enterrado; espessura do óxido de porta; tensão de faixa plana da primeira interface; tensão de faixa plana da segunda interface; tensão aplicada ao substrato; tensão aplicada ao substrato quando a segunda interface está no limiar de acumulação; tensão aplicada ao substrato quando a segunda interface está no limiar de inversão; 


$\begin{array}{ll}\mathrm{V}_{\mathrm{GF}} & \text { tensão aplicada na porta; } \\ \mathrm{V}_{\mathrm{GS}} & \text { Tensão entre porta e fonte. } \\ \mathrm{V}_{\mathrm{TH} 1, \mathrm{ACC} 2} & \text { tensão de limiar da primeira interface quando a } \\ & \text { segunda interface está em acumulação; } \\ \mathrm{V}_{\mathrm{TH} 1, \mathrm{INV} 2} & \text { tensão de limiar da primeira interface quando a } \\ & \text { segunda interface está invertida; } \\ \mathrm{Xd}_{\mathrm{Máx}} & \text { a máxima largura da região de depleção; } \\ \alpha & \text { fator de acoplamento capacitivo; } \\ \varepsilon_{\mathrm{OX}} & \text { permissividade do óxido de silício; } \\ \varepsilon_{\mathrm{Si}} & \text { permissividade do silício; } \\ \theta_{1} & \text { coeficiente de degradação da mobilidade; } \\ \phi_{\mathrm{F}} & \text { potencial de Fermi; } \\ \Phi_{\mathrm{MS} 1} & \text { diferença de função trabalho entre o material de porta e } \\ \Phi_{\mathrm{MS} 2} & \text { o silício; } \\ \phi_{S \mathrm{SB}} & \text { diferença de função trabalho entre o substrato e o } \\ & \text { silício; } \\ & \text { potencial da segunda interface; } \\ & \text { potencial da primeira interface; }\end{array}$




\section{SUMÁRIO}

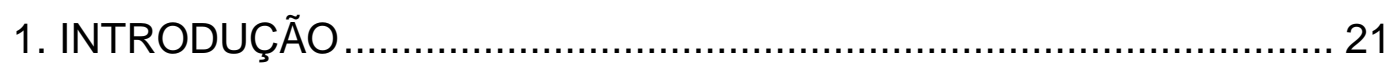

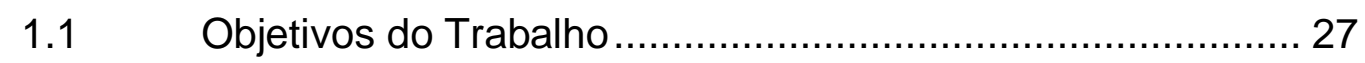

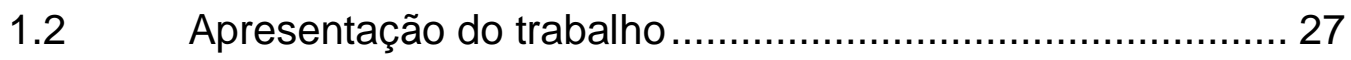

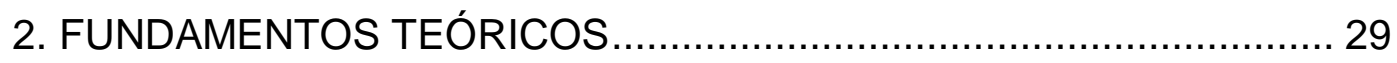

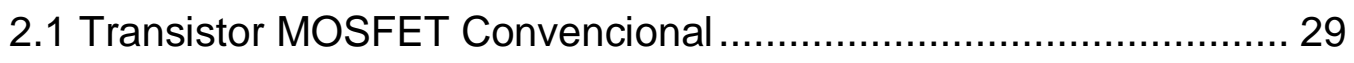

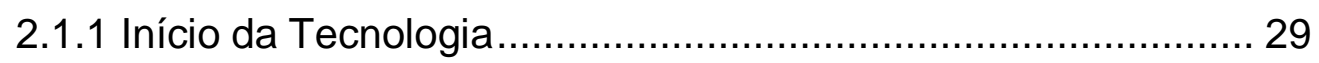

2.1.2 O desenvolvimento tecnológico ……………........................ 30

2.2 Silício Sobre Isolante - Conceito fundamental ............................. 34

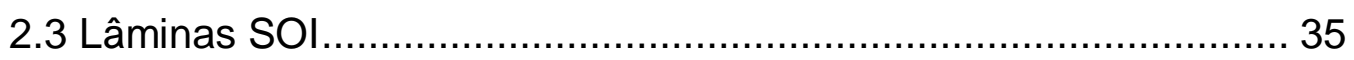

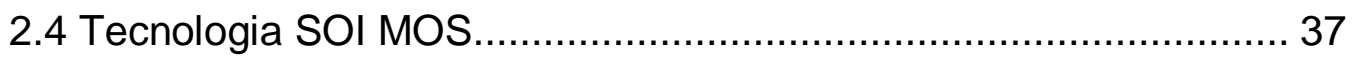

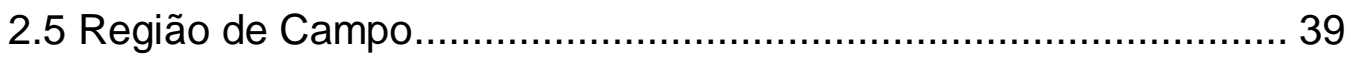

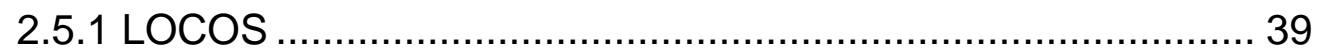

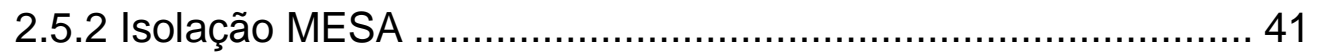

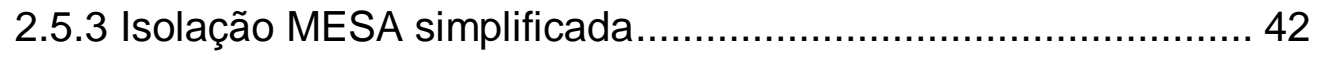

2.6 Dispositivos PD SOI e FD SOI .................................................. 43

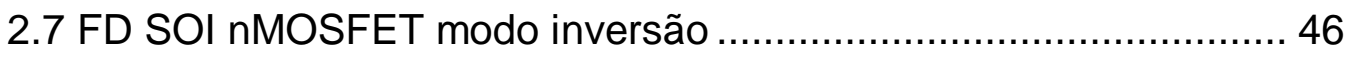

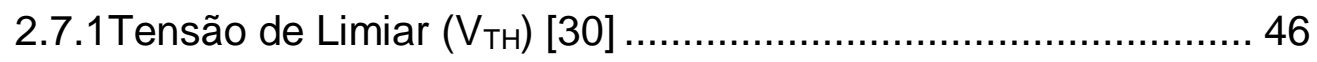

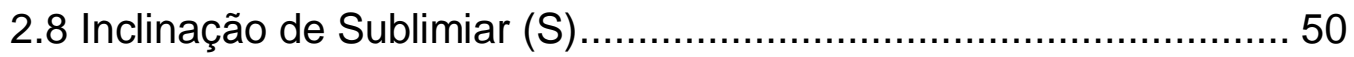

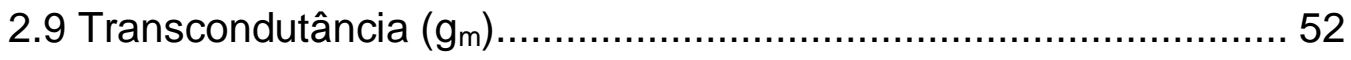

2.10 Efeito parasitário de elevação abrupta da corrente (Kink

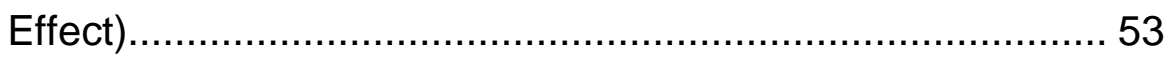

2.11 Efeito Transistor Lateral Parasitário (Edge Transistor) ................. 54

3. PROJETO E SIMULAÇÃO DE PROCESSOS.................................. 56

3.1 Sequência de Etapas de Processo do Transistor MOS

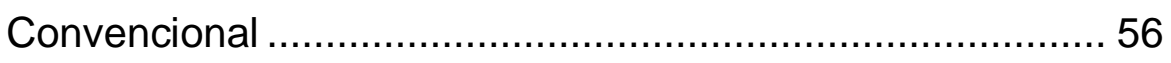

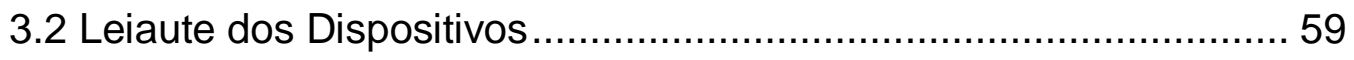

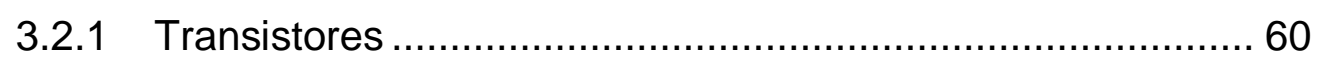

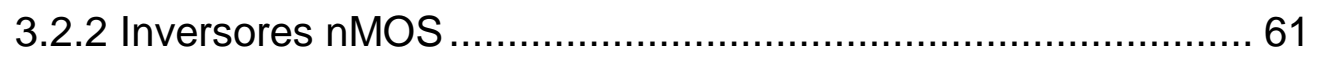




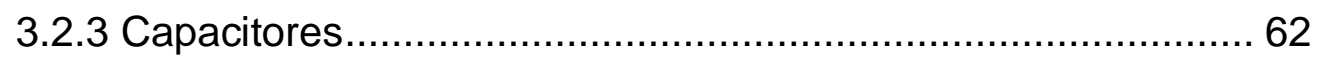

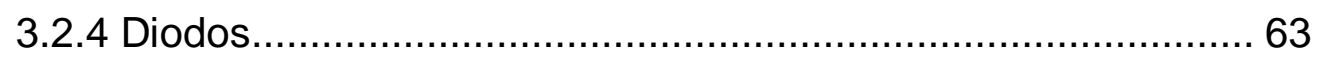

3.2.5 Estrutura Van der Pauw e 2 Resistores .................................. 63

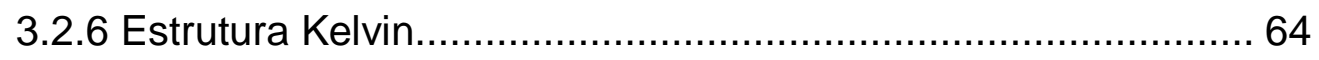

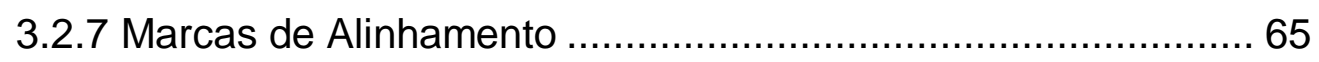

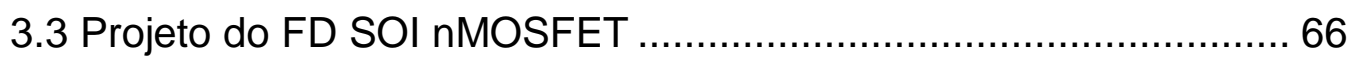

3.3.1 Sequência de Etapas de Processo do Transistor FD SOI ....... 67

3.3.2 Simulações da sequência de fabricação do Transistor FD

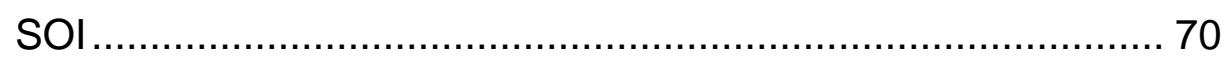

4. PROCEDIMENTO EXPERIMENTAL................................ 77

4.1 Desenvolvimento do uso do Fotorresiste AZ5214E...................... 77

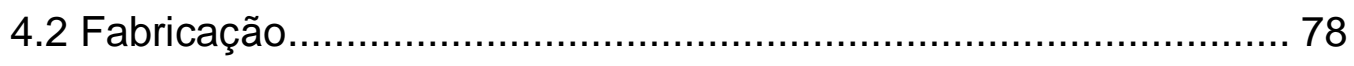

5. CARACTERIZAÇÃO ELÉTRICA E ANÁLISES ......................93

5.1 Dificuldades de caracterização elétrica da $1^{\text {a }}$ rodada de

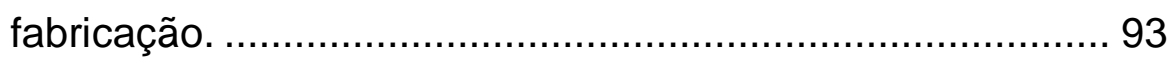

5.2 Solucionando contato elétrico com região $\mathrm{N}^{+}$.............................. 99

5.3 Caracterização elétrica da amostra L31 antes da sinterização .... 100

5.3.1 Resistência de folha, largura efetiva de linha e resistência

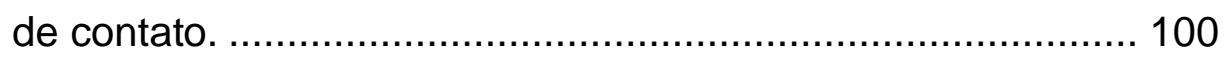

5.3.2 Curvas de transferência dos transistores das lâminas L31.... 101

5.4 Caracterização elétrica da segunda rodada de fabricação........... 105

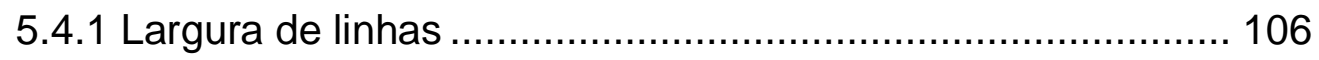

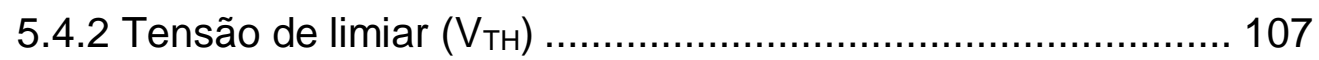

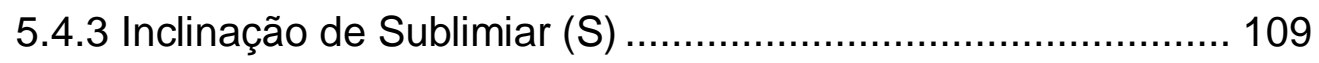

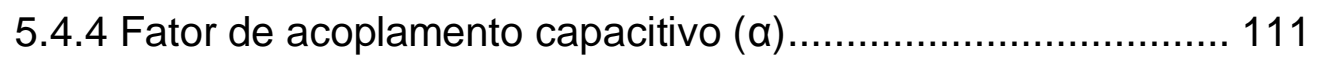

5.4.5 Mobilidade $\left(\mu_{0}\right)$ e Comprimento efetivo de canal (Leff) ........... 114

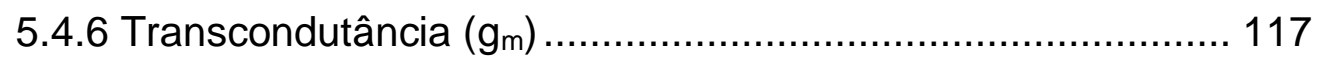

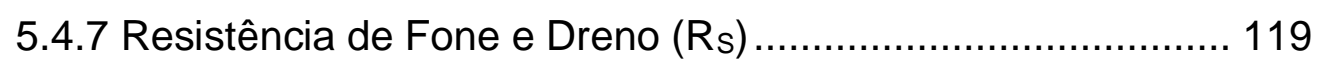

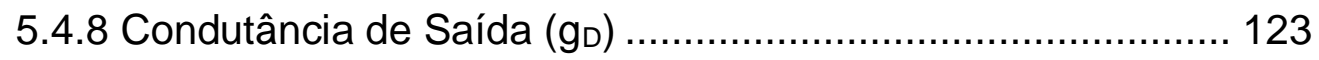

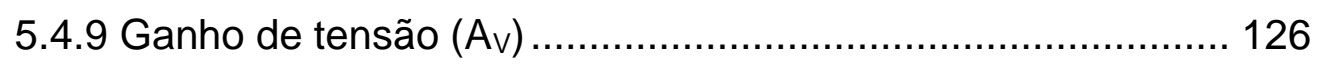

5.4.10 Resumo das Características do Processo .......................... 127 
6.

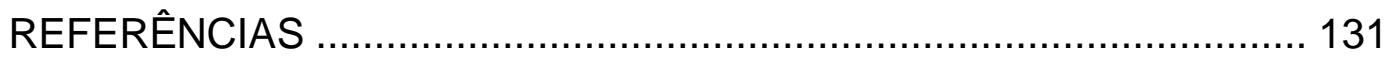

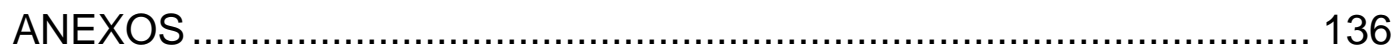

Anexo A - Lista de Publicações .................................................... 136

Anexo B - Arquivo de Simulação Athenas (Simulação de processos de fabricação do transistor FD SOI

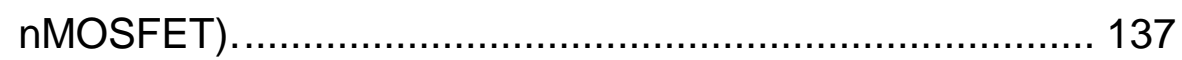

Anexo C - Arquivo de Simulação Atlas (Simulação do Dispositivo FD SOI nMOSFET)................................................... 146 


\section{INTRODUÇÃO}

A tecnologia de construção de circuitos integrados (Cl's) vem evoluindo desde os anos 60, quando foi implementada em escala industrial. Esta rápida evolução alterou significativamente a cultura humana a ponto de alguns autores se referirem ao tempo atual como a era do silício [1], em referência ao período histórico em que se define uma era através do material com o qual são confeccionados os mais importantes artefatos humanos. Pode até haver certo exagero nesta definição, por outro lado, é inegável a importância dos circuitos integrados atualmente.

Observe a quantidade de equipamentos que são usados diariamente e que dependem dos Cl's: computadores, calculadoras, telefones celulares e etc. Há também equipamentos que tem suas atividades otimizadas com a inserção de circuitos lógicos (que usam Cl's): automóveis, aviões, refrigeradores, fornos, etc.

Esta tecnologia permitiu ainda controlar de forma mais eficiente processos industriais. Equipamentos como um computador, microcontrolador, controlador lógico programável (que utilizam Cl's), substituem atividades humanas, ou em alguns casos, realizam atividades que um humano não poderia. Isto permite a redução de custos por meio da eliminação de perdas e o aumento da produtividade.

Atualmente, é realmente desafiador encontrar o mais simples objeto que não seja, em toda a sua cadeia de produção, beneficiado pela revolução tecnológica que os circuitos integrados introduziram.

A tecnologia de construção de circuitos integrados (Cl's) permitiu também uma revolução no modo de comunicação. Hoje em dia, existem diversos meios de comunicação que somente são possíveis através dos Cl's, entre eles a telefonia móvel, a internet, a captura eletrônica ou digitalização de imagens, as tecnologias de acesso remoto (sem fio, como Wi-Fi, Bluetooth, RFID) entre outras. 
Esta é a relevância atual da tecnologia de fabricação de Cl's, influenciam o modo de produção, de comunicação, enfim o modo de vida da sociedade atual.

Com toda esta importância social a indústria de semicondutores ocupa papel de destaque na economia, tendo movimentado cerca de US $\$ 298$ bilhões [2], mundialmente, no ano de 2012. Entretanto, ao contrário dos países desenvolvidos, o Brasil praticamente não possui indústria de semicondutores, importando cerca de US \$ 4,5 bilhões em semicondutores no ano de 2012 e cerca de US\$ 3,6 bilhões até agosto de 2013 [3].

O Brasil possui o terceiro maior mercado mundial de computadores pessoais, mas não tira todo o proveito que poderia dessa situação. Componentes de alto valor agregado vitais para essa indústria, os semicondutores e alguns dispositivos microeletrônicos, têm que ser trazidos de fora a preços elevados, pois não há tecnologia para produzi-los no Brasil [4]. A indústria de semicondutores permite a obtenção de produtos de alto valor agregado. "Importar um contêiner com uma tonelada de semicondutores equivale a ter que vender 14 mil toneladas de minério de ferro no exterior", afirma Virgílio Augusto Fernandes Almeida, secretário de Política de Informática do Ministério da Ciência, Tecnologia e Inovação (MCTI) [4].

Portanto, há a necessidade de desenvolvimento da indústria de semicondutores neste país. Recentemente a CEITEC S.A., empresa pública vinculada ao Ministério da Ciência, Tecnologia e Inovação (MCTI), tem o objetivo de posicionar o Brasil como um player global em microeletrônica [5]. Esta importante iniciativa vem se desenvolvendo e os resultados serão conhecidos dentro de alguns anos. Mas o próprio CEITEC coloca-se como "empresa nacional líder da cadeia produtiva do setor" [5], ou seja, existe a necessidade de uma cadeia produtiva.

Para que o país possa formar uma cadeia produtiva em semicondutores, uma grande quantidade de fatores desfavoráveis precisa ser revertida [6]. Muitos destes fatores estão fora do alcance das universidades, no entanto, a 
formação de profissionais na área de semicondutores é um destes fatores, e cabe às universidades brasileiras formar estes profissionais.

A USP, mais importante universidade brasileira, através da escola politécnica, referência nacional em formação de engenheiros, está comprometida com a formação de profissionais na área de semicondutores. Possui programa de pós-graduação na área de microeletrônica, através do qual forma mestres e doutores, além de desenvolver pesquisas e protótipos.

No que se refere à graduação, a escola possui disciplinas teóricas e de laboratório sobre semicondutores, dentre as quais se destaca a disciplina PSI 2643 - Laboratório de Fabricação de dispositivos em Microeletrônica, na qual os alunos tem a oportunidade de projetar, participar da fabricação e caracterizar um processo nMOSFET convencional (isto é fabricado em lâminas de silício convencionais). Este curso incentiva a participação efetiva dos alunos, aproximando-os aos técnicos e professores, proporcionando uma formação básica em microeletrônica e, ao mesmo tempo, convidando-os para um estudo mais aprofundado [7].

Este trabalho propõe um avanço tecnológico ao processo nMOSFET convencional da disciplina mencionada. As características da proposta serão descritas na sequência, mas antes serão discutidas as razões para este avanço tecnológico.

Há décadas a indústria de semicondutores desenvolve tecnologias para diminuir o custo e o consumo de energia, ao mesmo tempo em que aumenta a velocidade e complexidade de seus Cl's [8].

A melhoria de tais parâmetros é resultado da capacidade de redução das dimensões (escalamento) dos dispositivos que compõe os Cl's. Ao diminuir as dimensões dos dispositivos permite-se um maior número de dispositivos por circuito integrado fabricado. Deste modo é possível aumentar a capacidade dos circuitos construídos com esta tecnologia e ao mesmo tempo diminuir os custos por dispositivo fabricado. 
Esta tendência industrial (escalamento) foi descrita por Gordon Earle Moore, e ficou conhecida como lei de Moore, propõe que para ser competitiva uma indústria de semicondutores deve dobrar a quantidade de componentes por $\mathrm{Cl}$ a cada 18 meses. Até o momento a evolução tem sido exponencial, como Moore previu, embora na realidade o número de transistores por $\mathrm{Cl}$ tenha dobrado a cada 24 meses aproximadamente. A Figura 1 mostra o número de transistores em cada microprocessador em função da data de lançamento do produto.

Figura 1 - Curva do número de transistores por microprocessador em função da data de lançamento deste produto [9].

- Número de Transistores por Microprocessador 1971-2011

- Lei de Moore

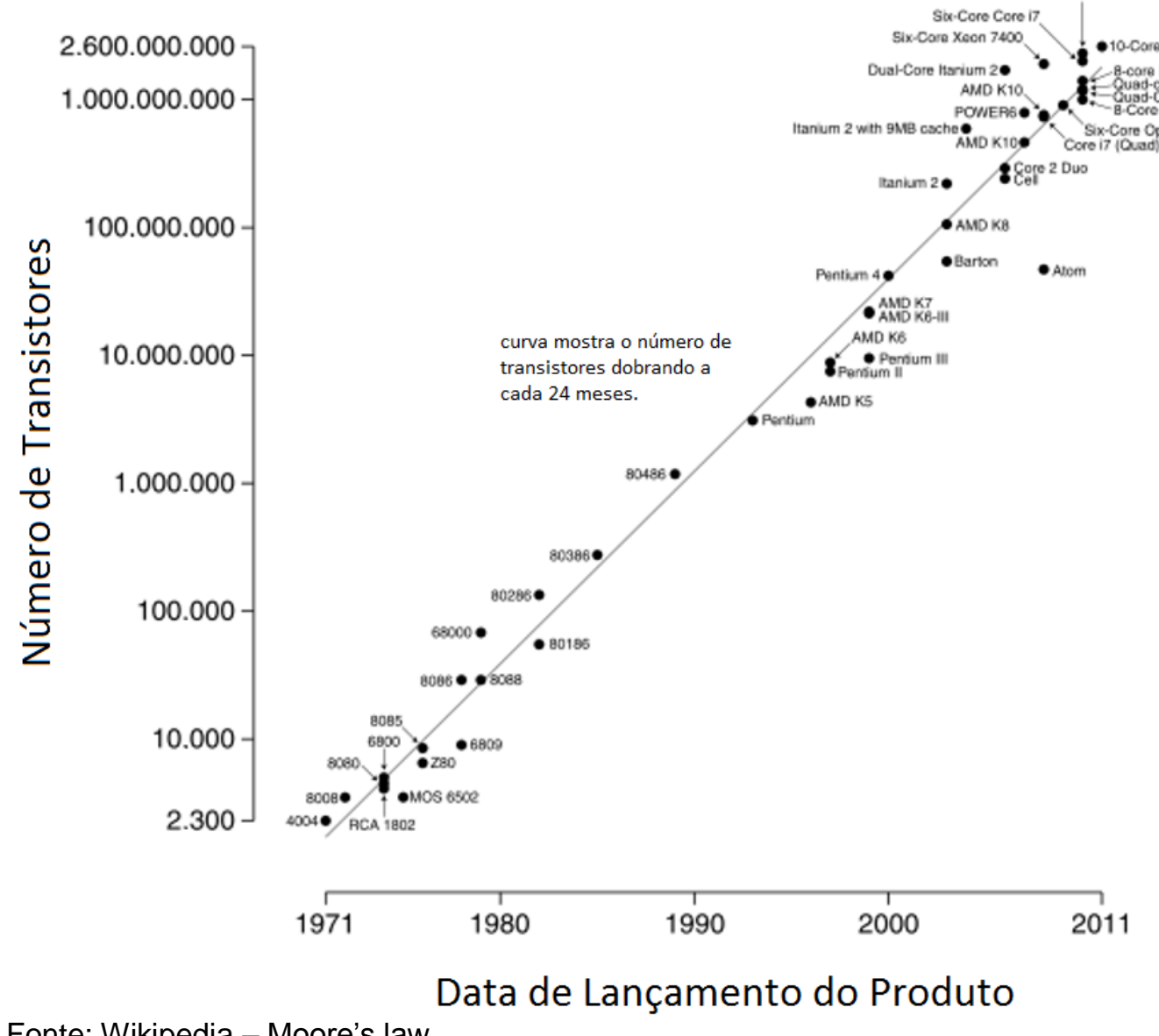

Fonte: Wikipedia - Moore's law. 
Para manter a lei de Moore há significativos desafios na construção dos dispositivos de tecnologia de transistores de efeito de campo do tipo metalóxido-semicondutor (MOSFET - metal-oxide-semiconductor field effect transistor).

A tecnologia MOSFET convencional parte de um substrato inteiramente de silício cuja espessura chega a centenas de micrometros, e os dispositivos construídos neste substrato ocupam menos de um micrometro, ou seja, somente a superfície do substrato. No entanto a interação entre o transistor e o substrato introduz uma série de efeitos parasitários [8].

Existem diversos estudos e propostas de processo de fabricação para minimizar estes efeitos, entre elas vem se destacando a tecnologia SOI (Silicon On Insulator). Nesta tecnologia propõe-se a fabricação dos transistores em uma película de silício sobre um material isolante, deste modo os dispositivos ficam isolados eletricamente do substrato. Esta solução, relativamente simples, tem apresentado resultados consistentes ao minimizar as capacitâncias de junção de fonte e dreno ou, em alguns casos (como disparo do tiristor parasitário da estrutura CMOS - Latchup), eliminar os efeitos parasitários do substrato.

A evolução da tecnologia SOI permitiu tornar a camada de silício sobre isolante cada vez mais fina, e quando esta camada é fina o suficiente de modo ao semicondutor ficar totalmente depletado, os transistores apresentam melhorias adicionais tais como aumento da mobilidade e da transcondutância [10], inclinação de sublimiar próxima ao ideal, diminuição dos efeitos de canal curto e da sensibilidade com a variação de temperatura [11]. Estes são os dispositivos totalmente depletados FD SOI (Fully Depleted Silicon on Insulator).

A evolução é contínua como mostra a Figura 2. A partir de dispositivos de tecnologia SOI estão sendo desenvolvidos dispositivos com estruturas de múltiplas portas (MuGFET) que permitem um melhor controle espacial das cargas na região de canal [12]. Em outras palavras, o fato de ter múltiplas portas permite aos transistores MUGFET minimizar efeitos provenientes da redução das dimensões. 
Figura 2 - Guia da evolução dos tipos de transistores e materiais, ITRS 2012 [13].

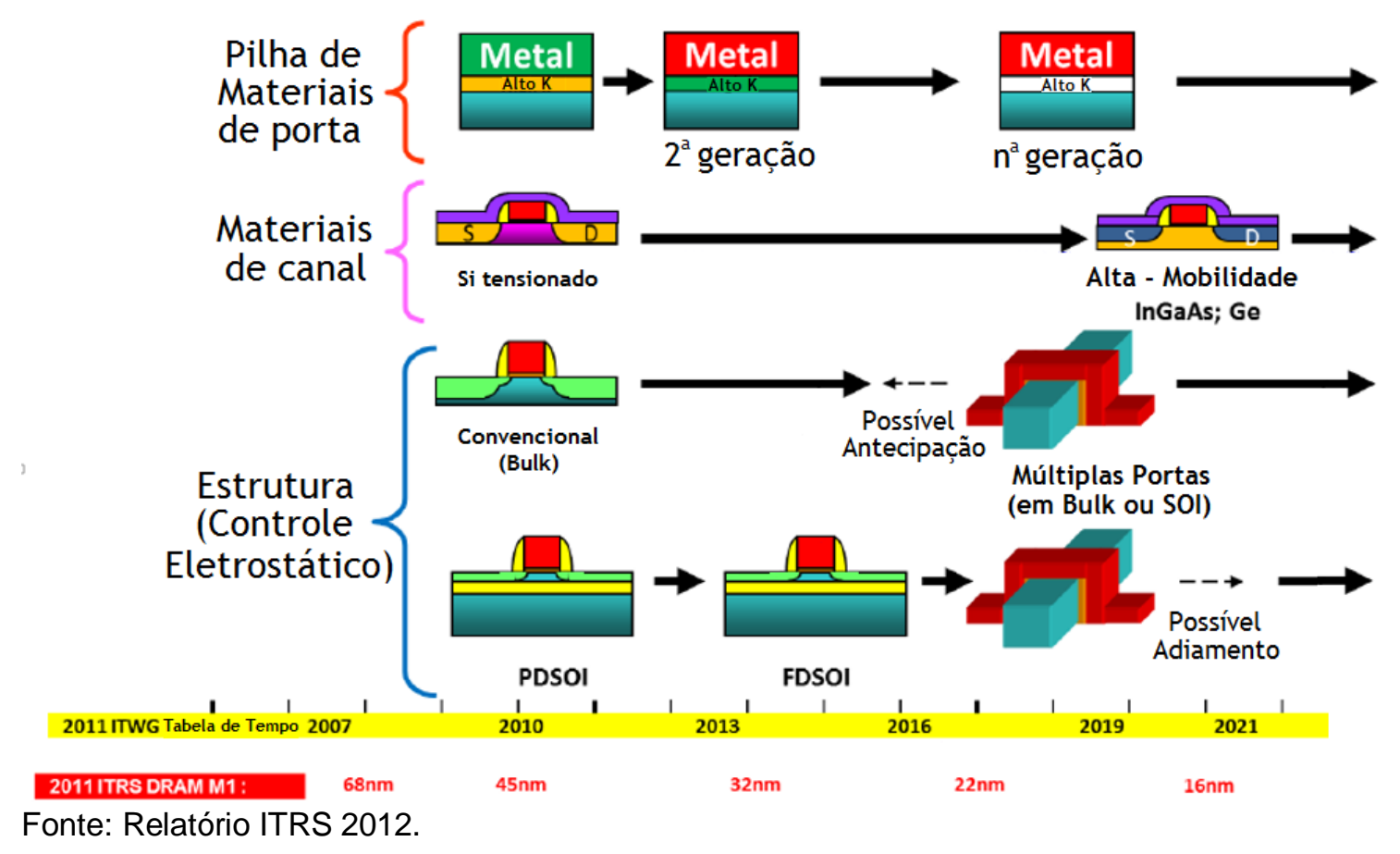

A tecnologia SOI é a opção imediata para permitir a evolução da fabricação de Cl's por mais alguns anos [14]. Atualmente empresas como a IBM, a AMD, a Freescale, a STMicroeletronics e a ST-Ericsson estão entre as empresas que já utilizam a tecnologia SOI comercialmente. Dada a importância desta tecnologia conclui-se a importância de incluí-la nas iniciativas educacionais em microeletrônica.

No Brasil o grupo SOI-CMOS do laboratório de sistemas integráveis (LSIEPUSP) da universidade de São Paulo atua há 20 anos em pesquisas na área de modelagem e caracterização elétrica de dispositivos SOI MOSFET, no entanto, sempre estudando dispositivos fabricados em outras universidades e centros de pesquisa do exterior.

A proposta deste trabalho é desenvolver um processo SOI nMOSFET nos laboratórios da Escola Politécnica da USP (EPUSP), com finalidades educacionais, vista a importância atual e a perspectiva futura de relevância da tecnologia SOI para a indústria de semicondutores. Este processo SOI será desenvolvido a partir do processo nMOSFET convencional (isto é, construídos em lâminas convencionais), também executado nos laboratórios da EPUSP e também com finalidades educacionais, através da disciplina PSI2643. 


\subsection{Objetivos do Trabalho}

O objetivo deste trabalho é obter um processo de fabricação SOInMOSFET simples. Em outras palavras, é necessário realizar três grandes tarefas:

I. Projetar um processo simples SOI nMOSFET, partindo do dispositivo "convencional" - nMOSFET projetado, construído e caracterizado para a disciplina de graduação da EPUSP "PSI 2643 - Laboratório de Fabricação de dispositivos em Microeletrônica".

II. Construir dispositivos SOI - nMOSFET, a partir do projeto executado, utilizando, sempre que possível, etapas de processamento simples e conhecidas. E desenvolvendo etapas de processo necessárias para esta nova sequência de processo.

III. Caracterizar eletricamente os dispositivos construídos estudando as características dos dispositivos obtidos.

\subsection{Apresentação do trabalho}

Este trabalho está organizado em 6 capítulos, como descrito à seguir:

Capítulo 1: Introdução - Apresenta uma breve discussão sobre tecnologia SOI e contextualização do trabalho dentro desta tecnologia, objetivos e forma de apresentação do trabalho.

Capítulo 2 - Fundamentos teóricos - Apresenta o estudo dos principais fundamentos teóricos nos quais o trabalho está embasado.

Capítulo 3 - Projeto e simulação de processos - Apresenta o processo de fabricação simplificado de um transistor SOI, utilizando conceitos e aprendizados já obtidos em processos existentes no laboratório, sobretudo o processo educacional PSI 2643. Alguns parâmetros de projeto são justificados com base em simulações realizadas. 
Capítulo 4 - Procedimento experimental - Apresenta as etapas de processo desenvolvidas, e são descritas todas as etapas utilizadas na fabricação dos dispositivos. São mostradas também algumas caracterizações de acompanhamento, tais como medidas de espessura, índice de refração e resistividade dos filmes utilizados.

Capítulo 5 - Caracterização elétrica e análises - Apresenta a caracterização elétrica dos dispositivos. A partir dos resultados elétricos medidos, das características do projeto e das medidas de acompanhamento de fabricação, são discutidos os resultados obtidos.

Capítulo 6 - Apresenta as conclusões e perspectivas do trabalho. 


\section{FUNDAMENTOS TEÓRICOS}

Este capítulo destina-se a apresentar e discutir alguns conceitos básicos sobre alguns materiais, tecnologia de fabricação de dispositivos semicondutores e parâmetros elétricos de transistores SOI nMOSFET. As discussões dos próximos capítulos estão apoiadas nestes conceitos básicos.

\subsection{Transistor MOSFET Convencional}

\subsubsection{Início da Tecnologia}

Em 1925 o físico Julius Edgar Lilienfeld patenteou o transistor, descrevendo um dispositivo similar ao transistor de efeito de campo (FET). No entanto, Lilienfeld não publicou nenhum artigo científico sobre sua descoberta nem a patente cita nenhum dispositivo construído [15].

O efeito transistor (dispositivo de estado sólido, de três terminais, que pode controlar a corrente elétrica ou tensão entre dois dos terminais através da aplicação de uma corrente elétrica ou tensão para o terceiro terminal) foi descoberto, durante os estudos de superfícies em torno de um diodo de contato puntual, nos Laboratórios Bell em 1947 por Bardeen, Brattain e Shockley [16].

Existe evidência que Shockley, o teorista que chefiava as pesquisas, estava decepcionado porque esse dispositivo não era o que estava procurando [16]. Assim, Shockley ignorou o transistor de contato puntual e continuou suas pesquisas em outras direções, que o levaram a desenvolver o transistor bipolar de junção BJT. Em meados dos anos 50 tornaram-se comercialmente viáveis transistores bipolares de junção.

Mais tarde houve a invenção do processo planar por Jean Hoerni da empresa Fairchild Semiconductor. Este processo contou com a difusão de dopantes em fase gasosa para produzir regiões do tipo $\mathrm{N}$ e do tipo $\mathrm{P}$, e contou também com a capacidade do $\mathrm{SiO}_{2}$ para mascarar esta difusão. Esta é a maior vantagem e a principal responsável pela substituição do $\mathrm{Ge}$ pelo $\mathrm{Si}$, o $\mathrm{SiO}_{2}$. $\mathrm{O}$ 
silício é o único entre os materiais semicondutores capaz de ser oxidado e formar um revestimento estável e isolante [17].

A capacidade de transferir padrões à camada de $\mathrm{SiO}_{2}$, a fotolitografia, foi essencial ao desenvolvimento do processo planar. Somada a características de material isolante e material de mascaramento à difusões, a capacidade de transferir padrões criou as bases para um novo avanço tecnológico.

Em 1959 Jack Kilby da Texas Instruments e Robert Noyce da Farchild Semiconductor criaram um "chip" contendo múltiplos componentes, integrados e interconectados, de modo a formar um circuito integrado [17]. Combinando difusões $\mathrm{P}$ e $\mathrm{N}$, camadas de passivação de $\mathrm{SiO}_{2}$ foi possível construir transistores, resistores e capacitores; e, ao interconectá-los, formar um $\mathrm{Cl}$.

Neste momento, início dos anos 1960, o transistor bipolar de junção dominava a fabricação de circuitos integrados. Mas, a partir do final da década, estudos mostraram que a instabilidade dos transistores MOS era devido a cargas na interface $\mathrm{Si} / \mathrm{SiO}_{2}$. Íns alcalinos tais como $\mathrm{Na}^{+}$e $\mathrm{K}^{+}$são móveis no filme de $\mathrm{SiO}_{2}$ a temperatura ambiente [17]. $\mathrm{O}$ fato de haver íons móveis provoca alteração no campo elétrico da estrutura MOS, tornando sua característica I-V instável.

Gradativamente melhores métodos de fabricação permitiram a redução de cargas e defeitos na interface $\mathrm{Si} / \mathrm{SiO}_{2}$, e com isto, o transistor MOS tornou-se atrativo. O transistor MOS apresenta resistência de entrada praticamente infinita, vantagem fundamental para o início do desenvolvimento da tecnologia.

\subsubsection{O desenvolvimento tecnológico}

Basicamente, o transistor MOS consiste da porta, formada por um metal (M), depositada sobre isolante $\left(\mathrm{SiO}_{2}\right.$, por exemplo) (O), crescido a partir de um substrato de silício (S). Esta estrutura central, metal-óxido-semicondutor (MOS), separa duas junções, a fonte e o dreno, a Figura 3 mostra a estrutura básica de um transistor MOSFET canal $\mathrm{N}$. 
Figura 3 - Estrutura básica de um transistor MOSFET canal N.

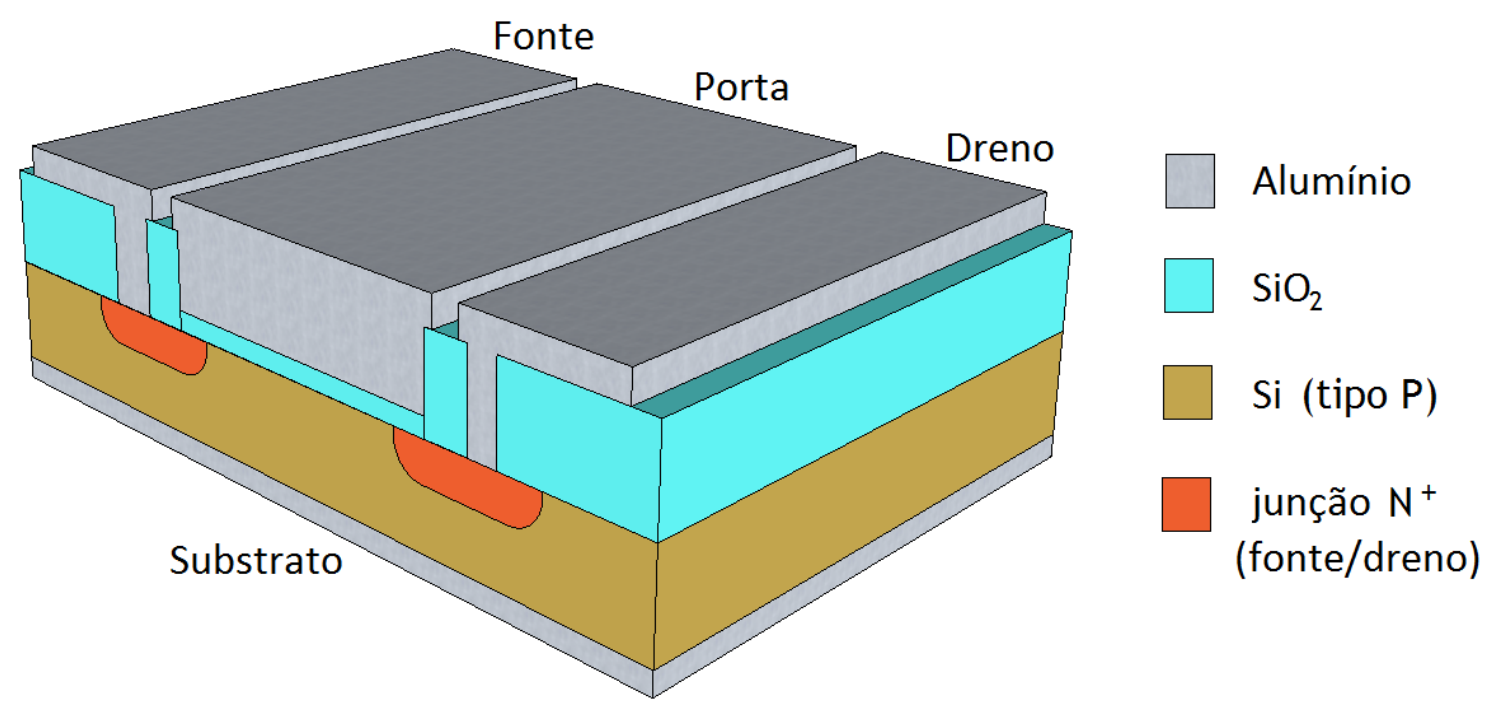

Fonte: Autor.

O potencial aplicado à porta controla a existência de cargas no canal, região imediatamente abaixo do óxido de porta $\left(\mathrm{SiO}_{2}\right)$, e com isto, controla a corrente elétrica entre fonte e dreno.

\subsubsection{Porta de Alumínio}

Historicamente o primeiro material usado como porta de transistores MOS foi o Alumínio. A sequência de processo consistia em criar as junções de fonte e dreno, e posteriormente, alinhar a porta de alumínio. Esta sequência de processo deve-se à impossibilidade de expor o filme de alumínio a temperaturas altas. Portanto, a difusão, que ocorre a altas temperaturas deveria ser realizada antes da deposição de alumínio.

Este processo necessita que o alumínio seja alinhado à fonte e dreno, e para evitar um erro de alinhamento, o alumínio é sobreposto às regiões de fonte e dreno. Esta sobre posição cria capacitâncias parasitárias entre porta e 
fonte, e entre porta e dreno, prejudicando a resposta em frequência do transistor [18].

\subsubsection{O processo Auto-Alinhado}

Como foi discutido, a sobreposição da porta sobre as regiões de fonte e dreno é prejudicial ao desempenho do transistor. Nos anos 70 , duas importantes tecnologias foram inseridas no processo de fabricação de transistores MOS, minimizando esta sobreposição.

O silício policristalino altamente dopado é um condutor razoável, no entanto, possui uma grande vantagem sobre o alumínio, quanto à utilização como material de porta, suporta altas temperaturas. Portanto a utilização deste material possibilita a definição da porta e, posterior formação de fonte e dreno.

A implantação iônica, técnica de dopagem patenteada por Shockley em 1954 [17], permite um controle muito maior sobre a dose (ou número de átomos dopantes inseridos no silício) e a profundidade da junção. Basicamente, íons dopantes são acelerados contra o substrato, inserindo-os dentro do semicondutor. Fatores como a espécie dopante e a energia de aceleração determinam a posição média que estes átomos terão dentro do semicondutor. Após um processo térmico de reconstrução da rede cristalina, que pode ser muito menor que uma etapa de difusão, os dopantes passam a fazer parte da rede, tornando-se ativos como impurezas doadoras ou aceitadores [19].

As duas técnicas somadas permitem o desenvolvimento do processo auto-alinhado. Resumidamente, significa que após a definição do silício policristalino (material de porta), íons são acelerados contra o substrato e, o SiPoli serve de máscara à implantação, protegendo o canal, e permitindo a formação das junções de fonte/dreno automaticamente alinhadas à porta.

Este processo será adotado na sequência deste trabalho. 


\subsubsection{Tecnologia CMOS}

No início do desenvolvimento da tecnologia MOS, os circuitos nMOS foram mais atrativos. Devido à simplicidade de processo, alta velocidade e alta densidade de integração [20].

Gradativamente, à medida que os circuitos tornavam-se mais complexos, a tecnologia CMOS equiparou-se à nMOS. Com a diminuição das dimensões (escalamento) a tecnologia CMOS tornou-se tão rápida quanto a nMOS, a densidade de integração tornou-se equivalente devido a simplicidade de projeto e, principalmente, a potência dissipada num chip CMOS é muito menor comparada ao nMOS [20].

Deste modo, nos anos 1980, a tecnologia CMOS tornou-se predominante, e seguiu evoluindo, para tecnologias mais velozes. Um dos principais desafios a tecnologias velozes são as capacitâncias de junção de fonte e dreno.

Para minimizar o problema das capacitâncias de junção surgiram diversos processos, entre os quais o processo com cavidade dupla (Double-Well) e com cavidade quádrupla (Quadruple Well), apenas para citar alguns.

Estes processos com múltiplas cavidades foram introduzindo etapas de processo extras, além de aumentar a complexidade e o custo de fabricação dos circuitos integrados. E mais, a grande quantidade de cavidades trouxe problemas como o efeito tiristor parasitário (latch-up), ou seja, parasitariamente ao circuito CMOS existiam estruturas PNPN (tiristor) que, em certa condição de polarização, poderia disparar danificando o circuito integrado.

O substrato SOI surge para solucionar esta dificuldade da tecnologia CMOS em substratos de silício convencionais, proporcionado um isolação entre os transistores e o substrato. 


\subsection{Silício Sobre Isolante - Conceito fundamental}

Construir dispositivos semicondutores é essencialmente uma ciência de superfície. Afinal os dispositivos ocupam cerca de $1 \mu \mathrm{m}$ da espessura de um substrato no qual eles são construídos. Estes substratos são materiais semicondutores como lâminas de silício, por exemplo. Estas lâminas, em geral, têm espessuras de centenas de micrometros, pois desta forma apresentam resistência mecânica para serem manipuladas durante as diversas etapas de processo necessárias para construção dos dispositivos. Observe a Figura 4 que mostra esquematicamente a estrutura básica de um transistor nMOSFET convencional.

Figura 4 - Comparação da espessura de uma estrutura básica de um transistor nMOSFET com a espessura do substrato (lâmina de silício) sobre o qual este dispositivo é construído.

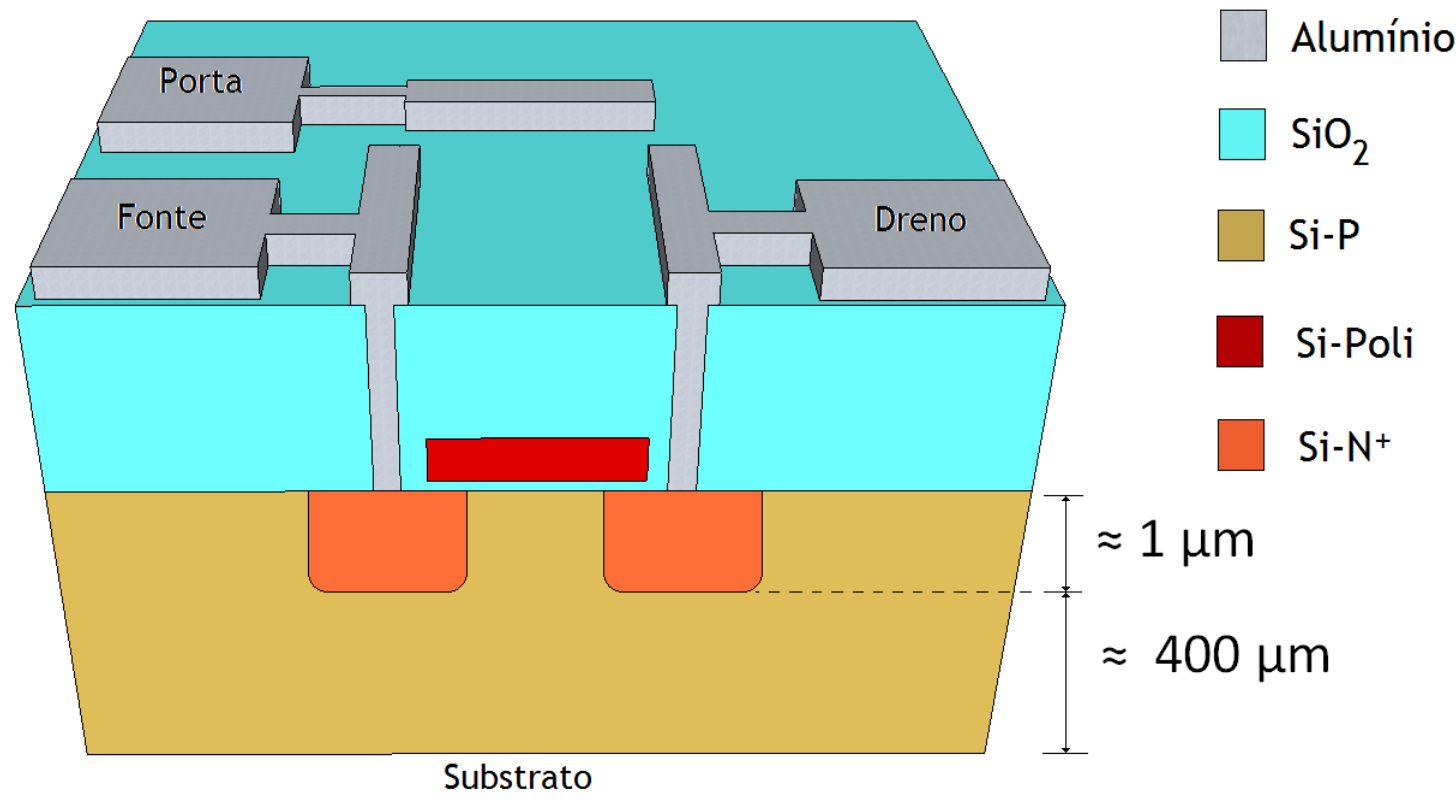

Fonte: Autor.

A Figura 4 ilustra uma dimensão aproximada de quão superficial são os dispositivos nMOSFET. Deste modo, os principais fenômenos elétricos relacionados ao funcionamento dos transistores nMOSFET ocorrem na superfície do substrato.

No entanto não se podem desprezar os fenômenos elétricos que ocorrem devido à presença do substrato semicondutor. Alguns destes fenômenos são 
considerados parasitários, ou seja, são indesejáveis e prejudicam o desempenho dos transistores, tais como capacitâncias de junção, corrente de fuga nas junções, diminuição da barreira de potencial fonte/substrato induzida pelo potencial do dreno (DIBL) [8], entre outros.

Nos dispositivos nMOSFET tradicionais a isolação entre regiões $\mathrm{N}+\mathrm{e} o$ substrato tipo $P$ é feita mantendo-se a junção reversamente polarizada. Mas considere que seja possível introduzir um material dielétrico para isolar as junções, ou seja, diminuir a área das junções. Todos os efeitos parasitários devido à presença do substrato semicondutor serão minimizados. Esta é a ideia básica de um dispositivo SOI.

\subsection{Lâminas SOI}

As lâminas SOI são compostas por uma fina camada de silício (dentro da qual os dispositivos serão construídos) sobre uma camada de material isolante [10]. Observe a Figura 5, que mostra um perfil de uma lâmina SOI a) e um dispositivo nMOSFET construído sobre esta lâmina b).

Figura 5 - Lâmina SOI a) e dispositivo SOI nMOSFET b).

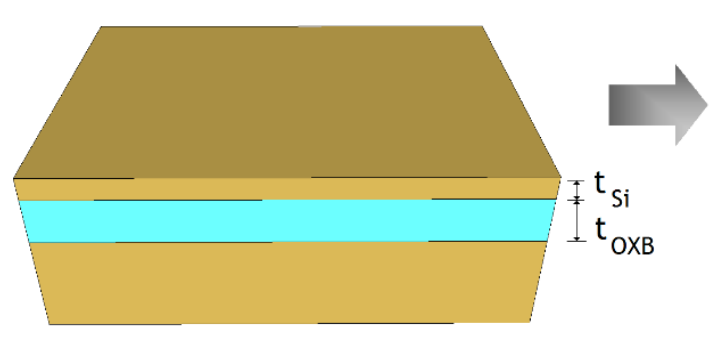

a)

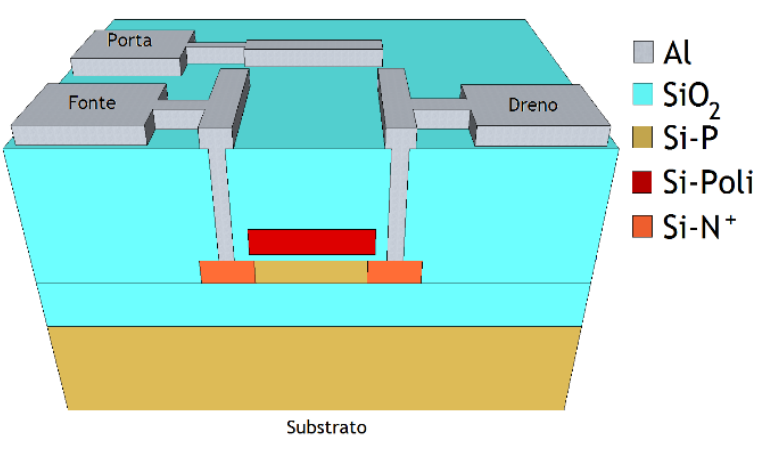

b)

Fonte: Autor.

Para obter uma lâmina com estas características existem diversas técnicas. Algumas das principais são [8]: 
1) Crescimento epitaxial de silício sobre substratos isolantes cristalinos ou lâminas de silício cobertas parcialmente por isolantes [21], [22] e [23].

2) Separação por implantação de oxigênio (SIMOX) [24]e [25].

3) Adesão de lâminas oxidadas, posterior corte devido à implantação de hidrogênio e polimento da superfície (Smart-Cut®) [26] e [27].

Em cada uma destas técnicas há características específicas que a tornam adequada para determinada aplicação. Neste trabalho serão usadas lâminas obtidas com a técnica Smart-Cut@, pois é uma técnica de grande sucesso comercial na fabricação de circuitos integrados em giga escala (GSI).

A técnica Smart-Cut ${ }^{\circledR}$ consiste na oxidação de uma lâmina de silício, na sequência esta lâmina sofre uma implantação iônica de hidrogênio $\left(\mathrm{H}^{+}\right)$que induz a criação de uma camada interna enfraquecida. A lâmina implantada e oxidada é "colada" (as lâminas são pressionadas uma contra a outra, mas não há um produto químico que as fixe) a outra lâmina de silício, e devido à camada interna enfraquecida é feito um corte na região enfraquecida, através de tratamento térmico. Posteriormente a lâmina sofre um polimento (CMP) que torna sua superfície plana. A Figura 6 ilustra a técnica Smart-Cut ${ }^{\circledR}$ para obtenção de lâminas SOI.

As lâminas que serão usadas neste trabalho têm características de espessura inicial de $100 \mathrm{~nm}$ de silício, $200 \mathrm{~nm}$ de óxido enterrado, $625 \mu \mathrm{m}$ de substrato e diâmetro inicial de 150 mm [28], mas devido à limitação de tamanho dos equipamentos disponíveis as lâminas serão cortadas em quadrados de 25 mm de lado. 
Figura 6 - Técnica Smart-Cut® de obtenção de Lâminas SOI.

\section{Lâmina A Lâmina B}
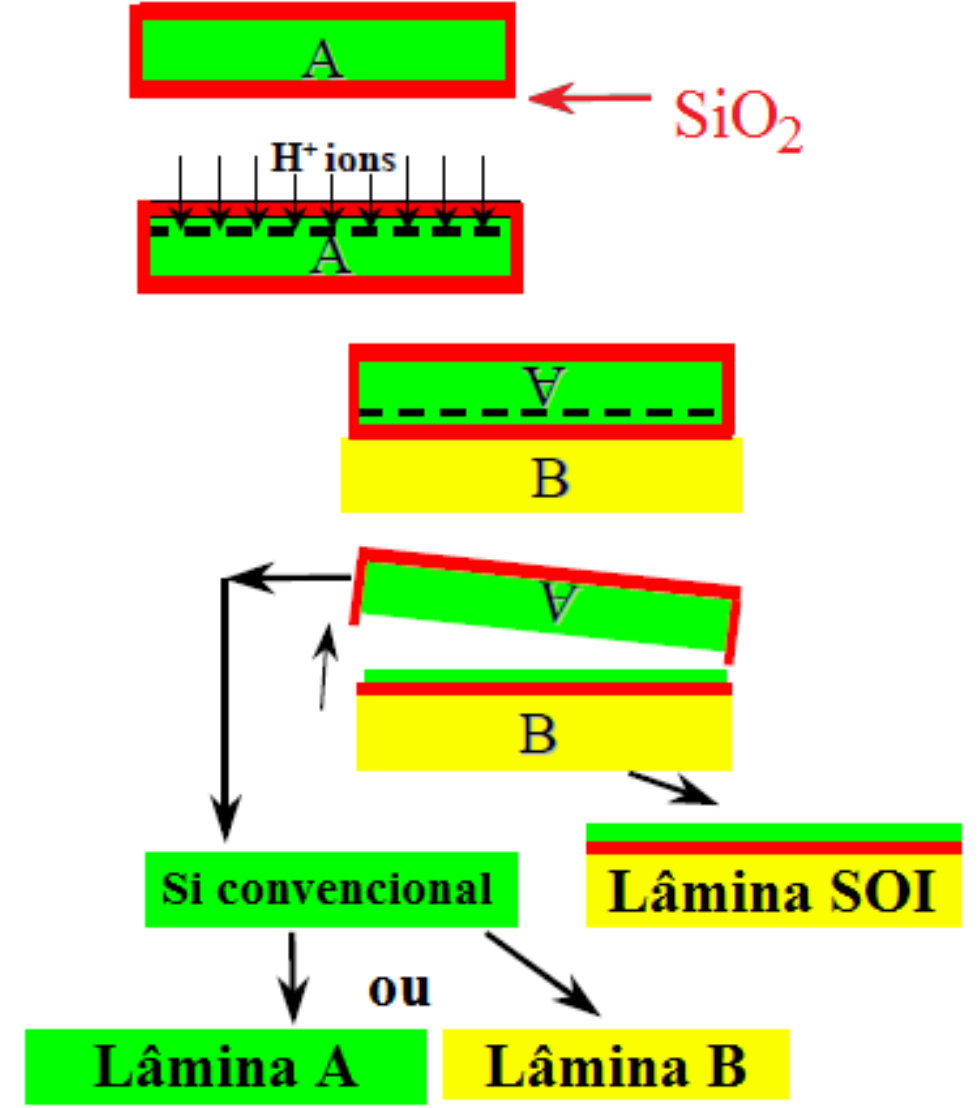

Fonte: SOITEC.

\subsection{Tecnologia SOI MOS}

Os processos de fabricação de dispositivos MOS em lâminas de silício convencionais ou SOI são muito similares [10]. Isto se deve ao fato de se construir os dispositivos na superfície do substrato. No entanto, a lâmina SOI tem vantagens, pois isola a camada superficial de silício na qual os dispositivos serão construídos.

Em tecnologia MOS convencional pode ser necessário o uso de camada epitaxial, cavidades, e outras etapas. Em tecnologia SOI parcialmente depletada (PD SOI), pode ser necessária a implantação anti-perfuração MOS 
(anti-punchthrough), para evitar corrente de fuga entre fonte e dreno na interface silício-óxido enterrado. Já a tecnologia SOI totalmente depletada (FD SOI) é ainda mais simples e o perfil total de impurezas implantadas na região de canal é determinado por uma única e rasa implantação iônica [10].

A diferença entre tecnologias SOI, PD SOI ou FD SOI, será definida mais a frente, na seção 2.6, quando será descrito o funcionamento dos dispositivos SOI, no momento é interessante ter em mente que a tecnologia PD SOI utiliza camada de silício superficial espessa (aprox. 200nm a 500nm) e a tecnologia FD SOI utiliza camada superficial de silício fina (aprox. $\leq 100 \mathrm{~nm}$ ). A Figura 7 abaixo mostra a seção transversal de transistores nMOSFET de tecnologia convencional, PD SOI e FD SOI.

Figura 7 - Seção transversal de: a) nMOSFET (Convencional), b) PD SOI nMOSFET (com implantação anti-punchthrough $\mathrm{P}+$ ) e c) FD SOI nMOSFET.

\begin{tabular}{|l|}
\hline Legenda \\
$\mathrm{Al}$ \\
$\square \mathrm{SiO}_{2}$ \\
$\square \mathrm{Si}-\mathrm{P}$ \\
$\square \mathrm{Si}-\mathrm{Poli}^{+}$ \\
$\square \mathrm{Si}-\mathrm{P}^{+}$ \\
$\square \mathrm{Si}-\mathrm{N}^{+}$ \\
\hline
\end{tabular}

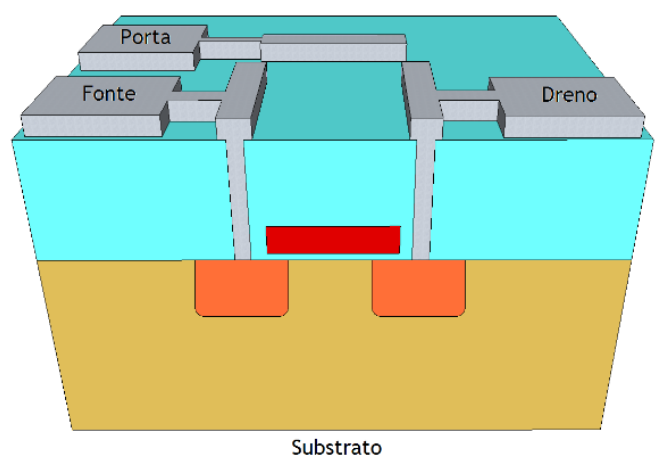

a)

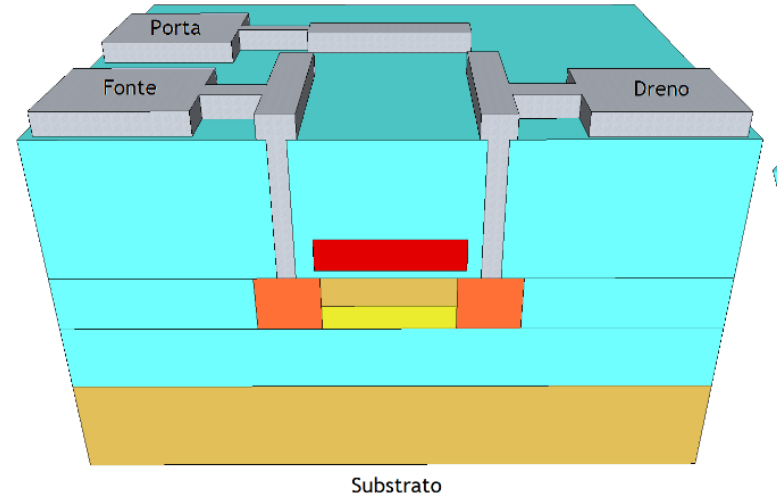

b)

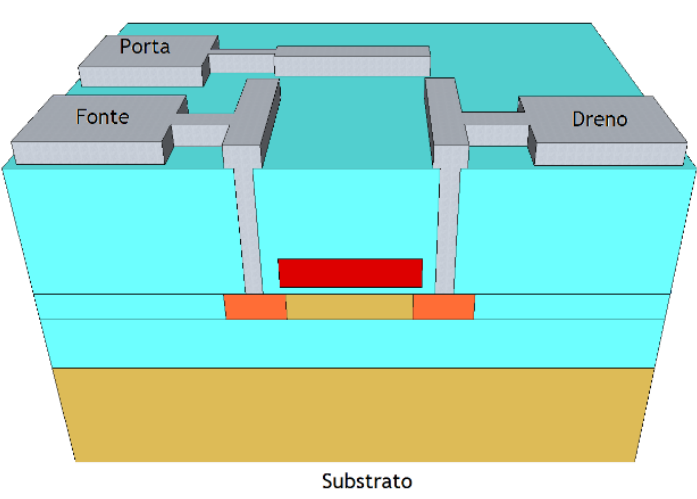

c)

Fonte: Autor. 
Por uma questão de simplicidade nos processos de fabricação optou-se por trabalhar com o FD SOI nMOSFET. Ou seja, o dispositivo terá uma única implantação na região de canal, que deverá ajustar a tensão de limiar dos transistores e minimizar o efeito de perfuração MOS.

No capítulo seguinte detalharemos a sequência de fabricação do dispositivo.

\subsection{Região de Campo}

Existem variados modos de criar as regiões de campo (regiões que isolam as regiões ativas de silício) em tecnologias SOI. Todas elas são mais simples quando comparadas às regiões de campo criadas para tecnologia MOS convencional [10], pois o óxido enterrado já proporciona uma isolação vertical intrínseca.

Serão abordados tópicos de duas das principais técnicas de isolação das regiões ativas em tecnologia SOI: o LOCOS, e a isolação MESA.

\subsubsection{LOCOS}

A técnica LOCOS foi originalmente desenvolvida para processos de tecnologia MOS convencional. Atualmente é usada tanto em tecnologias MOS convencional, como em tecnologias SOI. A isolação local de silício (LOCOS) consiste na seguinte sequência de processos:

i. Crescer uma fina camada de óxido térmico ("pad");

ii. Depositar uma camada de nitreto de silício (máscara de oxidação);

iii. Fotogravar a camada de nitreto de silício (manter $\mathrm{Si}_{3} \mathrm{~N}_{4}$ sobre a região ativa);

iv. Implantação de boro (channel-stop implant);

v. Oxidação térmica da região de campo; 
A Figura 8 mostra vista superior de um transistor nMOSFET, seus cortes longitudinal e transversal (corte AA e corte BB) logo após a implantação de boro e seu corte paralelo à porta logo depois da oxidação de campo.

Figura 8 - a) vista superior de um transistor nMOSFET, em b) o corte AA (antes da construção da porta e logo após a implantação de boro), em c) o corte BB (antes da construção da porta e logo após a implantação de boro) e em d) o corte BB logo após a oxidação de campo. Observe que em d), nas laterais da ilha de silício observa-se uma faixa $\mathrm{P}^{+}$.

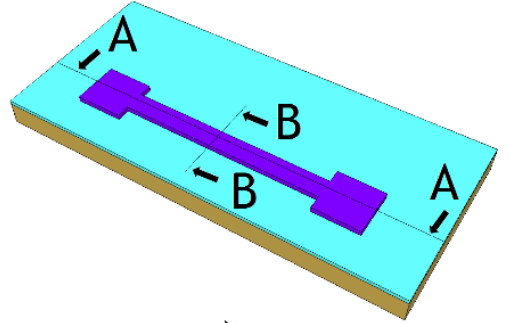

a)

Corte BB

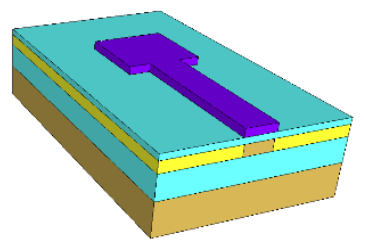

c)

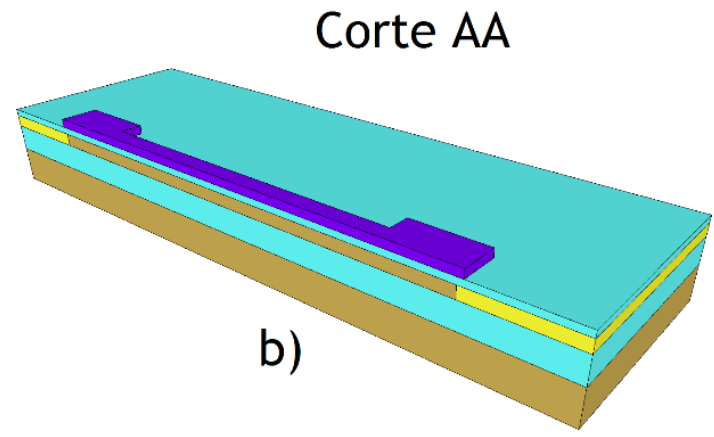

Corte BB

Oxidação de Campo

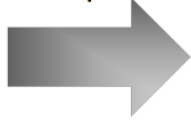

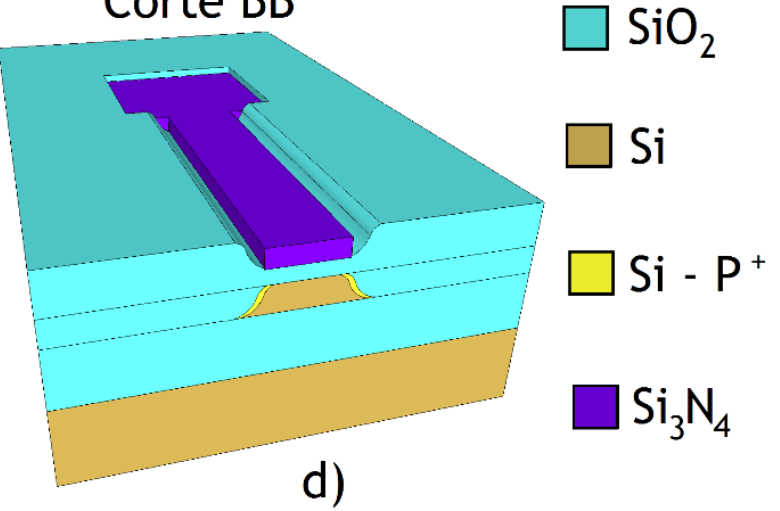

Fonte: Autor.

Não haverá crescimento de óxido nas regiões protegidas pelo nitreto de silício, logo é possível oxidar as regiões de campo promovendo a isolação das regiões ativas.

Em lâminas SOI a oxidação de campo consome todo o silício superficial, exceto região ativa. Ou seja, o óxido é crescido até encontrar o óxido enterrado. 
A implantação $\mathrm{P}^{+}$é usada para prevenir uma fuga de corrente entre fonte e dreno, pelas laterais da ilha de silício, efeito chamado transistor lateral parasitário ("edge transistor").

Para observar este efeito é necessário um corte do transistor que não é muito usual. O mais comum é observar o corte longitudinal (de fonte para 0 dreno), no entanto, nesta situação será mostrado um corte transversal à porta.

Caso esta implantação não seja feita, a oxidação de campo causará a diminuição da concentração de boro nas laterais da ilha de silício, devido à segregação do boro para o óxido [19]. Este é o chamado Transistor Lateral Parasitário ("Edge Transistor"), um efeito indesejado que degrada a curva IDS $\mathrm{X}$ $V_{G S}$ dos transistores, como será discutido na seção 2.11.

\subsubsection{Isolação MESA}

Outra técnica que possibilita a isolação de campo em tecnologia SOI é a chamada técnica MESA [10].

Esta técnica consiste em:

i. $\quad$ Crescer $\mathrm{SiO}_{2}$ ("pad");

ii. Depositar $\mathrm{Si}_{3} \mathrm{~N}_{4}$ (máscara de corrosão);

iii. Fotogravar o $\mathrm{Si}_{3} \mathrm{~N}_{4}\left(\mathrm{Si}_{3} \mathrm{~N}_{4}\right.$ permanece sobre a região ativa);

iv. Corroer o Si da região de campo;

v. Implantação de Boro (channel-stop implant);

A Figura 9 mostra vista superior de um transistor nMOSFET, seu corte longitudinal (corte $\mathrm{AA}$ ) antes da corrosão do Si e transversal (corte $\mathrm{BB}$ ) logo após a corrosão do Si. O resultado final da técnica após a implantação de boro. 
Figura 9 - a) vista superior de um transistor nMOSFET, em b) o corte AA (antes da construção da porta), em c) o corte BB (antes da construção da porta e logo após a corrosão do Si) e em d) o corte BB logo após a implantação iônica. Observe que em d), nas laterais da ilha de silício observa-se uma faixa $\mathrm{P}^{+}$.

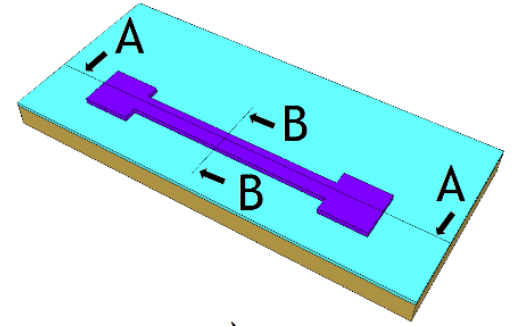

a)

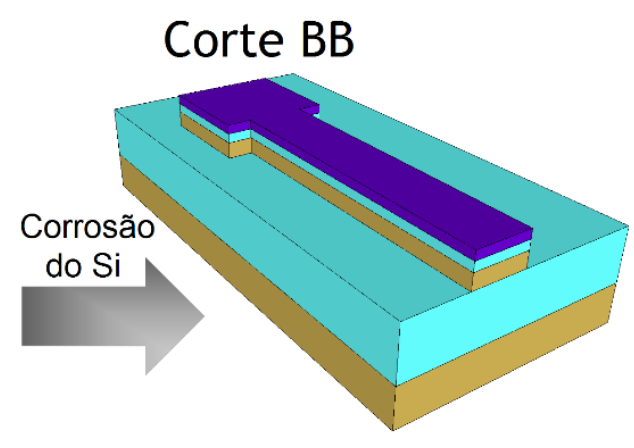

c)

\section{Corte AA}

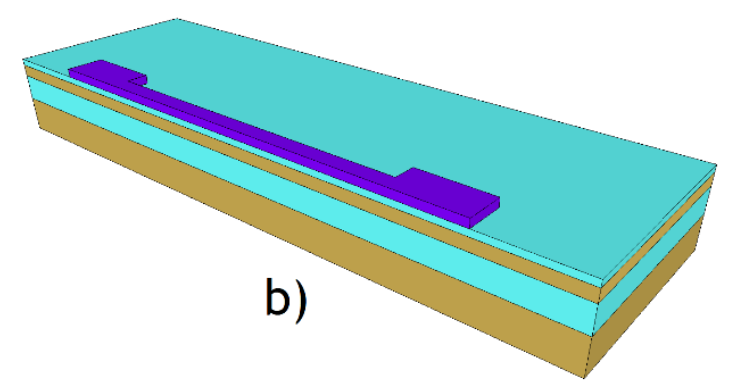

Corte BB

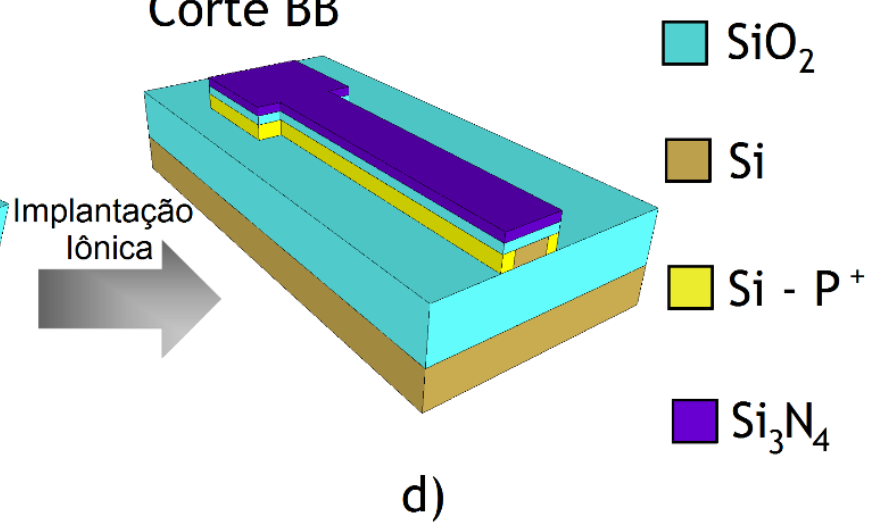

\subsubsection{Isolacão MESA simplificada}

É uma simplificação da técnica MESA e que será adotada em nosso processo.

Esta técnica consiste em:

i. Fotogravar de modo a proteger a região ativa;

ii. Corroer o silício da região de campo;

Realizando estas etapas resta uma "mesa" (ilha de silício), e após a formação do óxido de porta esta "mesa" estará isolada das outras. A Figura 10 mostra esquematicamente o resultado da isolação MESA. 
Figura 10 - Isolação MESA simplificada: Na figura a) observa-se uma lâmina SOI com fotorresiste marcando a região ativa, em b) observa-se a corrosão do silício, e em c) a "mesa" de silício isolada devido à oxidação de porta.

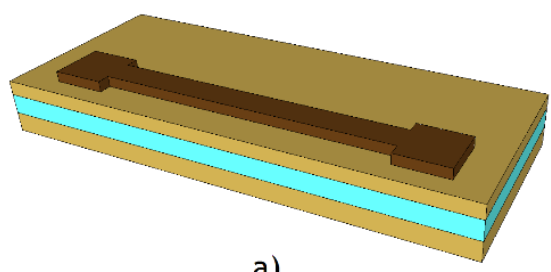

a)

Remoção do fotorresiste e oxidação

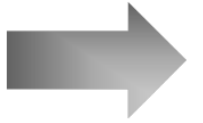

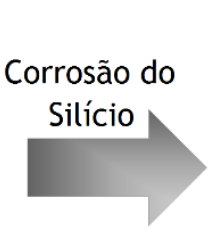

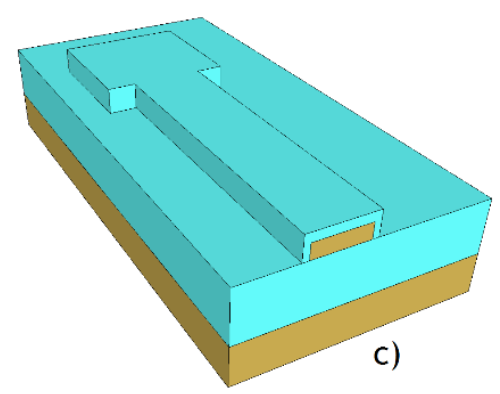

b)

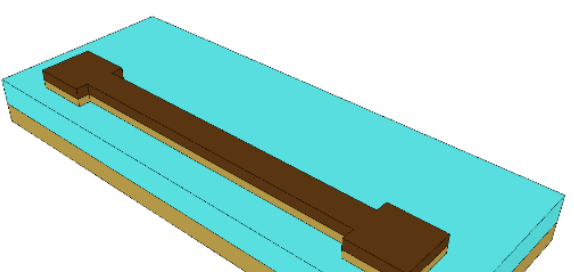

$\square \mathrm{SiO}_{2}$

$\square \mathrm{Si}$

Fotorresiste

Fonte: Autor.

Se por um lado a técnica MESA simplificada é muito atrativa por sua simplicidade, por outro traz consigo alguns problemas. Como, por exemplo, a não uniformidade do óxido crescido nos cantos de silício ou a diferença de espessura entre o óxido crescido na lateral e no topo da ilha de silício [10].

Outro problema é a fuga de corrente pelas laterais da ilha de silício, efeito também observado na isolação LOCOS. Pois ao oxidar a mesa de silício as laterais perdem dopantes para o óxido por efeito de segregação [19], o que pode resultar no chamado transistor lateral parasitário ("Edge transistor").

\subsection{Dispositivos PD SOI e FD SOI}

Anteriormente, foi dito que dispositivos PD SOI são aqueles em que a camada de silício sobre isolante ( $\mathrm{t}_{\mathrm{si}}$ ) é espessa e que dispositivos FD SOI são os que a camada de silício sobre o isolante ( $t_{s i}$ ) é fina. Este é um conceito qualitativo útil, mas agora é necessário refiná-lo. 
As características de funcionamento dos dispositivos SOI nMOSFET são fortemente dependentes da espessura da camada de silício ( $\left.t_{\mathrm{si}}\right)$ e da concentração de dopantes no silício sobre $O$ isolante $\left(N_{A}\right)$ [8]. Em outras palavras, a máxima largura da região de depleção ( $X \mathrm{~d}_{\text {Máx }}$ ) é função da concentração de dopantes $\left(\mathrm{N}_{\mathrm{A}}\right)$ e também da temperatura. É possível calcular a máxima largura de depleção ( $X d_{\text {Máx }}$ ) pela equação (2.1) [29]:

$$
X d_{M a ́ x}=\sqrt{\frac{4 \cdot \varepsilon_{S i} \cdot \phi_{F}}{q \cdot N_{A}}}
$$

sendo que:

$$
\phi_{F}=\frac{k \cdot T}{q} \cdot \ln \frac{N_{A}}{n_{i}}
$$

onde:

$\phi_{F}$ é o potencial de Fermi, $\mathrm{k}$ é a constante de Boltzman, $\mathrm{T}$ a temperatura, q a carga elementar do elétron, $\varepsilon_{S i}$ a permissividade do silício e $n_{\mathrm{i}}$ a concentração intrínseca de portadores.

Comparando a espessura da camada de silício sobre o isolante $\left(t_{\mathrm{si}}\right)$ e a máxima largura de depleção ( $\left.X d_{\text {Máx }}\right)$ tem-se duas situações limite:

1) Se $t_{s i} \geq 2 X d_{\text {Máx }} \circ$ silício sobre $o$ isolante nunca estará totalmente depletado, portanto é um dispositivo PD SOI;

2) Se $t_{s i} \leq X d_{\text {Máx }}$ neste dispositivo, na iminência da inversão, o silício sobre o isolante estará totalmente depletado, portanto é um dispositivo FD SOI.

Evidentemente é possível existirem dispositivos na situação intermediária, que dependendo das condições de polarização estarão parcialmente depletados ou totalmente depletados. São chamados SOI - MOSFET de 
camada média ou "próximos da depleção completa" (Near-fully depleted SOI NFD SOI). Estes dispositivos não serão estudados neste trabalho.

Na Figura 11 é possível observar o diagrama de faixas de energia de transistores nMOSFET convencional (A), PD SOI nMOSFET (B) e FD SOI nMOSFET (C), onde $E_{C}$ é o nível inferior da faixa de condução, $E_{v}$ é o nível superior da faixa de valência, $E_{i}$ é o nível intrínseco e $E_{F}$ é o nível de Fermi.

Observe que em um dispositivo MOS convencional há o encurvamento das bandas na interface óxido de porta-silício de canal. Em um dispositivo PD SOI há o encurvamento das bandas na interface silício-óxido de porta e também silício-óxido enterrado. Observe também que em dispositivos PD SOI há também uma região neutra, ou seja, uma região onde não há campo

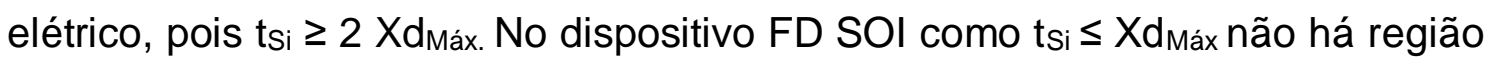
neutra no silício da região de canal.

Figura 11 - Diagrama de faixas de energia para os transistores A) nMOSFET convencional, B) PD SOI nMOSFET e C) FD SOI nMOSFET.

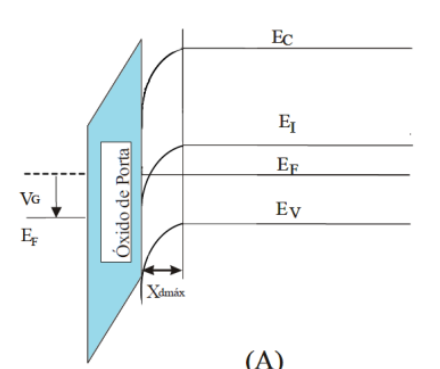

(A)

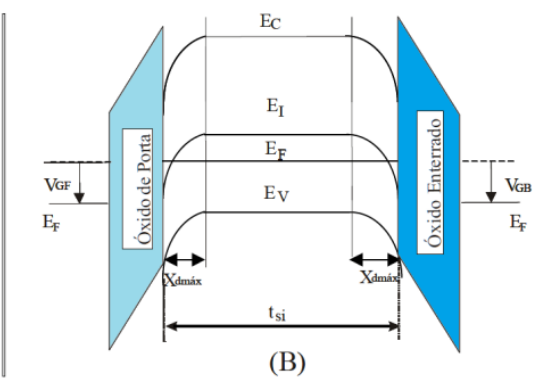

(B)

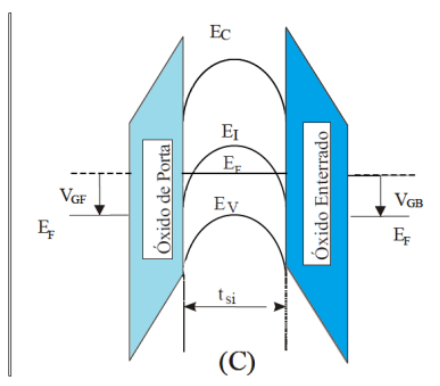

(C)

Fonte: Colinge J.P.,Silicon-on-insulator technology.

Em dispositivos PD SOI haverá uma região neutra (região não depletada) que se conectada a um terminal externo gera um dispositivo similar a um nMOSFET convencional. Quando não há este contato na região neutra ocorrem efeitos parasitários como efeito de elevação abrupta de corrente (Kink Effect) e efeito bipolar parasitário [10].

Já os dispositivos FD SOI tem mais vantagens. Por exemplo, menor inclinação de sublimiar, maior transcondutância e não apresenta o efeito parasitário de elevação abrupta de corrente (Kink Effect) [10]. Estas 
características dos dispositivos FD SOI nMOSFET serão detalhadas nos itens 2.8, 2.9 e 2.10 respectivamente.

Devido a estas características, se decidiu trabalhar com dispositivos FD SOI, para maximizar as vantagens da tecnologia SOI nMOSFET que será desenvolvida.

\subsection{FD SOI nMOSFET modo inversão}

Nesta seção serão discutidos os principais parâmetros elétricos de um dispositivo FD SOI nMOSFET modo inversão, afinal este é o dispositivo alvo deste trabalho.

\section{$\underline{\text { 2.7.1Tensão de Limiar }\left(\mathrm{V}_{\mathrm{TH}}\right)[30]}$}

A tensão de limiar de transistores FD SOI nMOSFET é obtida pelo modelo de Lim \& Fossum [30], descrito pelas equações a seguir:

$$
\begin{aligned}
& V_{G F}=V_{F B 1}+\frac{q \cdot N_{A} \cdot t_{S i}}{2 \cdot C_{O X F}}+\left(\frac{\varepsilon_{S i}}{t_{S i} \cdot C_{O X F}}+1\right) \cdot \phi_{S F}-\frac{\varepsilon_{S i}}{t_{S i} \cdot C_{O X F}} \cdot \phi_{S B}-\frac{Q_{I N V 1}}{C_{O X F}} \\
& V_{G B}=V_{F B 2}+\frac{q \cdot N_{A} \cdot t_{S i}}{2 \cdot C_{O X B}}+\left(\frac{\varepsilon_{S i}}{t_{S i} \cdot C_{O X B}}+1\right) \cdot \phi_{S B}-\frac{\varepsilon_{S i}}{t_{S i} \cdot C_{O X B}} \cdot \phi_{S F}-\frac{Q_{S 2}}{C_{O X B}}
\end{aligned}
$$

onde:

$$
V_{F B 1}=\phi_{M S 1}-\frac{Q_{O X 1}}{C_{O X F}}
$$




$$
\begin{gathered}
V_{F B 2}=\phi_{M S 2}-\frac{Q_{O X 2}}{C_{O X B}} \\
C_{O X F}=\frac{\varepsilon_{O X}}{t_{O X F}} \\
C_{O X B}=\frac{\varepsilon_{O X}}{t_{O X B}}
\end{gathered}
$$

Neste modelo observam-se os termos que representam os potenciais da primeira ( $\left.\phi_{S F}\right)$ e segunda interface $\left(\phi_{S B}\right)$ e as tensões aplicadas na porta $\left(V_{G F}\right)$ e no substrato $\left(\mathrm{V}_{\mathrm{GB}}\right)$. É necessário ter em mente que o funcionamento de um FD SOI nMOSFET depende da condição da segunda interface (se acumulada, em depleção ou invertida), portanto os termos de tensão aplicada ao substrato e potencial de superfície da segunda interface são tão importantes quanto da primeira interface.

Nas equações (2.3) a (2.8) há ainda:

- $V_{\mathrm{FB} 1}$, que é a tensão de faixa plana da primeira interface;

- $V_{\mathrm{FB} 2}$, que é a tensão de faixa plana da segunda interface;

- $N_{A}$, que é a concentração de impurezas aceitadoras no canal;

- $t_{\mathrm{S}}$, a espessura da camada de silício sobre o isolante;

- Coxf, a capacitância do óxido de porta por unidade de área;

- Cохв, a capacitância do óxido enterrado por unidade de área;

- toxf, a espessura do óxido de porta;

- toxв, a espessura do óxido enterrado;

- EOX, a permissividade do óxido de silício;

- $\Phi_{M S 1}$, a diferença de função trabalho entre o material de porta e o silício;

- $\Phi_{\mathrm{MS2}}$, a diferença de função trabalho entre o substrato e o silício;

- QInv1, a densidade de carga de inversão na primeira interface; 
- Qs2, a densidade de carga de acumulação $\left(Q_{s 2}>0\right)$ ou de inversão $\left(Q_{s 2}<0\right)$ na segunda interface;

- Qox1, a densidade de carga efetiva no óxido de porta;

- Qox2, a densidade de carga efetiva no óxido enterrado;

É possível simplificar as equações gerais da tensão de limiar (2.3) e (2.4) dependendo da condição da segunda interface, como será descrito a seguir.

\subsubsection{Segunda interface acumulada}

Uma vez que a segunda interface esteja acumulada, não há potencial de superfície nesta interface, portanto, a tensão de limiar da primeira interface $\left(V_{\mathrm{TH} 1, A C C 2}\right)$ é uma simplificação da equação (2.3) de modo que $\phi_{\mathrm{SB}}=0, \mathrm{Q}_{\mathrm{INV} 1}=0$ (pois o dispositivo encontra-se no limiar de inversão) e $\phi_{S F}=2 \phi_{F}$. Observe:

$$
V_{G F}=V_{T H 1, A C C 2}=V_{F B 1}+\frac{q \cdot N_{A} \cdot t_{S i}}{2 \cdot C_{O X F}}+\left(\frac{\varepsilon_{S i}}{t_{S i} \cdot C_{O X F}}+1\right) \cdot 2 \phi_{F}
$$

\subsubsection{Segunda Interface em depleção}

Neste caso o potencial de superfície da segunda interface depende da tensão aplicada ao substrato. Existe, portanto, uma faixa de valores de $\mathrm{V}_{\mathrm{GB}}$ tal que: $0 \leq \phi_{S B} \leq 2 \phi_{F}$. Pode-se calcular as situações limite de tensão no substrato em que a segunda interface está depletada.

Caso $\phi_{\mathrm{SB}}=0$ e $\mathrm{Qs2}_{\mathrm{s}}=0$ (segunda interface no limiar de acumulação) e $\phi_{\mathrm{SF}}=2 \phi_{\mathrm{F}}$ (primeira interface na inversão):

$$
V_{G B, A C C 2}=V_{F B 2}+\frac{q \cdot N_{A} \cdot t_{S i}}{2 \cdot C_{O X B}}-\frac{\varepsilon_{S i}}{t_{S i} \cdot C_{O X B}} \cdot 2 \phi_{F}
$$


E se $\phi_{\mathrm{SB}}=2 \phi_{\mathrm{F}}$ e $Q_{\mathrm{S} 2}=0$ (segunda interface no limiar de inversão) e $\phi_{\mathrm{SF}}=2 \phi_{\mathrm{F}}$ (primeira interface na inversão):

$$
V_{G B, I N V 2}=V_{F B 2}+\frac{q \cdot N_{A} \cdot t_{S i}}{2 \cdot C_{O X B}}+2 \phi_{F}
$$

Logo se a tensão no substrato estiver entre os valores calculados nas equações (2.10) e (2.11) é possível garantir que a segunda interface está em depleção. E agora obtem-se a tensão de limiar na porta usando as equações (2.3) e (2.4) e a condição de limiar de inversão da primeira interface, ou seja: $\phi_{\mathrm{SF}}=2 \phi_{\mathrm{F}}, \mathrm{Q}_{\mathrm{INV} 1}=0$.

$$
V_{T H 1, D E P 2}=V_{T H 1, A C C 2}-\frac{C_{S i} \cdot C_{O X B}}{C_{O X F} \cdot\left(C_{S i}+C_{O X B}\right)} \cdot\left(V_{G B}-V_{G B, A C C 2}\right)
$$

A equação (2.12) é válida na condição de depleção da segunda interface,

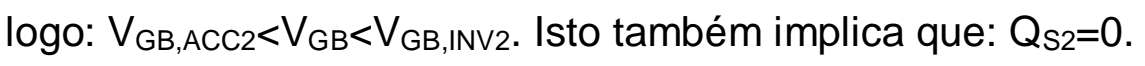

Na equação (2.12) é usado o termo $C_{S i}$ que é a capacitância da camada de silício por unidade de área. Matematicamente:

$$
C_{S i}=\frac{\varepsilon_{S i}}{t_{S i}}
$$


A análise da equação (2.12) permite dizer que com o aumento da tensão de substrato há uma diminuição da tensão de limiar. Este aumento de $\mathrm{V}_{\mathrm{GB}}$ está limitado é claro a tensão necessária para inverter a segunda interface.

É possível obter a tensão de limiar quando a segunda interface está invertida. No entanto, como não há aplicação prática para este tipo de polarização (afinal, nesta situação, independente da tensão aplicada à porta há corrente entre fonte e dreno) esta condição não será analisada.

Todas as equações apresentadas nesta seção baseiam-se no modelo de Lim \& Fossum [30].

\subsection{Inclinação de Sublimiar (S)}

Define-se a inclinação de sublimiar (S) de transistores MOSFET's como a variação da tensão de porta necessária para se aumentar a corrente de dreno em uma década, quando o dispositivo estiver operando na região de sublimiar [31]. Matematicamente:

$$
S=\frac{d V_{G F}}{d\left(\log I_{D}\right)}=\frac{k T}{q} \ln 10 \times(1+\alpha)
$$

onde:

a é o fator de acoplamento capacitivo do transistor e, portanto, depende do tipo de transistor (se convencional, PD SOI ou FD SOI) e depende também, no caso de transistores FD SOI, do estado da segunda interface (se depletada ou acumulada).

Para transistores MOSFET convencional ou PD SOI o fator de acoplamento capacitivo ( $\left.\alpha_{\text {bulk }}\right)$ fica [8]: 


$$
\alpha_{b u l k}=\frac{C_{D}+C_{i t f}}{C_{O X F}}
$$

onde:

$$
\begin{gathered}
C_{D}=\frac{\varepsilon_{S i}}{d \max } \\
C_{i t f}=q^{2} \cdot N_{i t f} \\
C_{O X F}=\frac{\varepsilon_{O X F}}{t_{O X F}}
\end{gathered}
$$

sendo:

- $C_{D}$, a capacitância de depleção por unidade de área;

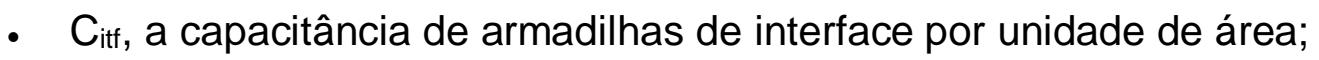

- Coxf, a capacitância do óxido de porta por unidade de área;

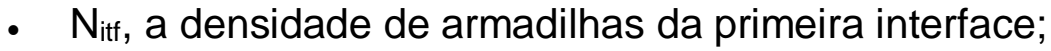

- toxf, espessura do óxido de porta.

Para transistores FD SOI MOSFET com a segunda interface depletada $\left(\alpha_{\text {depl }}\right)$ fica [8]:

$$
\alpha_{d e p l}=\frac{C_{i t f}}{C_{O X F}}+\frac{C_{S i}\left(C_{i t b}+C_{O X B}\right)}{C_{O X F}\left(C_{i t b}+C_{O X B}+C_{S i}\right)}
$$

onde:

$$
C_{i t b}=q^{2} \cdot N_{i t b}
$$

sendo: 
- Citb, a capacitância de armadilhas da segunda interface por unidade de área;

- $\quad \mathrm{N}_{\text {itb }}$, a densidade de armadilhas da segunda interface;

Para transistores FD SOI MOSFET com a segunda interface acumulada $\left(\alpha_{\text {acc }}\right)$ fica $[8]$ :

$$
\alpha_{a c c}=\frac{C_{S i}+C_{i t f}}{C_{O X F}}
$$

Deste modo $\alpha_{d e p}<\alpha_{b u l k}<\alpha_{a c c}$, logo a inclinação de sublimiar (S) de dispositivos FD SOI, com a segunda interface depletada, é a menor entre os dispositivos analisados. Este fato permite aos transistores FD SOI uma tensão de limiar menor, sem que isto implique em aumentar o valor da corrente de fuga (quando $\mathrm{V}_{\mathrm{GF}}=0$ ). Ou seja, estes dispositivos permitem circuitos com maior velocidade de comutação principalmente para baixas tensões de alimentação [10].

\subsection{Transcondutância $\left(g_{m}\right)$}

É definida como a taxa de variação da corrente de dreno em relação à tensão aplicada na porta. Em outras palavras, transcondutância $\left(g_{\mathrm{m}}\right)$ é a razão entre uma variação da corrente de dreno em função de uma variação na tensão aplicada na porta.

$$
g_{m}=\frac{d I_{D s a t}}{d V_{G F}}
$$

A transcondutância de um transistor MOSFET, usando o modelo de Lim \& Fossum [30], é: 


$$
g_{m}=\frac{\mu_{n} \cdot C_{O X F}}{(1+\alpha)} \cdot \frac{W}{L} \cdot\left(V_{G F}-V_{T H}\right)
$$

Sabendo que o fator de acoplamento capacitivo ( $\alpha$ ) é menor em dispositivos totalmente depletados e com a segunda interface depletada $\left(\alpha_{\text {depl }}<\alpha_{\text {bulk }}<\alpha_{\text {acc }}\right)$, conclui-se que o dispositivo FD SOI apresenta maior transcondutância.

\subsection{Efeito parasitário de elevação abrupta da corrente (Kink Effect)}

O efeito parasitário de elevação abrupta da corrente é caracterizado por um "salto" na característica IDSXVDS de um SOI MOSFET [10]. A Figura 12 que ilustra o efeito.

Figura 12 - Elevação abrupta da corrente na curva lDS $x$ VDS de um SOI nMOSFET.

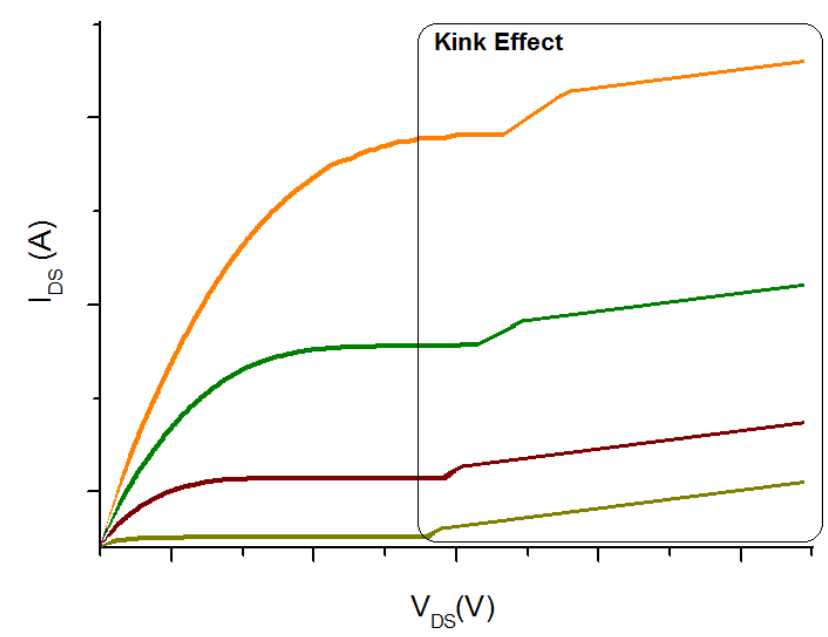

Fonte: Colinge J.P.,Silicon-on-insulator technology.

A origem da elevação abrupta da corrente é o aumento da tensão de dreno. Quando esta tensão é alta o bastante, elétrons da região de canal adquirem energia suficiente, devido ao alto campo elétrico, para criar pares elétron-lacuna através de ionização por impacto. Os elétrons gerados migram 
rapidamente para o dreno, enquanto as lacunas migram para a região de menor potencial, ou seja, a região de corpo flutuante em dispositivos PD SOI ou a fonte em dispositivos FD SOI.

Ou seja, em dispositivos PD SOI há um acúmulo de lacunas na região de corpo flutuante, o que pode elevar o potencial de corpo. Em dispositivos FD SOI as lacunas não se acumulam, pois não há uma região de corpo flutuante. Logo dispositivos FD SOI são imunes a este efeito.

O aumento do potencial de corpo em dispositivos PD SOI (desde que menor que $700 \mathrm{mV}$ ) leva a uma diminuição da tensão de limiar e esta diminuição provoca aumento na corrente de dreno. Este aumento repentino na corrente de dreno é o efeito de elevação abrupta da corrente [10].

\subsection{Efeito Transistor Lateral Parasitário (Edge Transistor)}

Sabe-se que a isolação de campo, seja ela LOCOS ou MESA, causa a diminuição da concentração de impurezas aceitadoras $\left(N_{A}\right)$ nas laterais da ilha de silício, devido à segregação do boro para o óxido de silício durante o processo de oxidação [19].

Analisando as equações (2.2), (2.3) e (2.4), percebe-se que a tensão de limiar é função de $\mathrm{N}_{\mathrm{A}}$. Quanto maior for a concentração de impurezas aceitadoras, maior a tensão de limiar.

Isto significa que a região lateral da ilha de silício, com $\mathrm{N}_{\mathrm{A}}$ menor, poderá inverter para tensões menores. Em outras palavras, é como se houvessem dois transistores em paralelo na mesma estrutura: o transistor principal e o transistor lateral. Sendo que este último permite uma corrente entre fonte e dreno para valores de tensão de porta menor que a tensão de limiar do transistor principal.

O efeito transistor lateral parasitário causa uma anomalia na curva da corrente de dreno pela tensão na porta ( $\mathrm{IDS}_{\mathrm{DS}} \mathrm{V}_{\mathrm{GF}}$ ) quando o transistor lateral conduz corrente entre fonte e dreno antes do transistor principal. O resultado é 
um salto na região de sublimiar da referida curva. A Figura 13 mostra a curva de um transistor lateral e de um transistor principal, e ainda a corrente resultante. Observe um "salto" anormal na corrente resultante, na região de sublimiar.

Figura 13 - Curva esquemática de um transistor SOI nMOSFET com fuga de corrente devido ao efeito de transistor lateral (Edge Transistor).

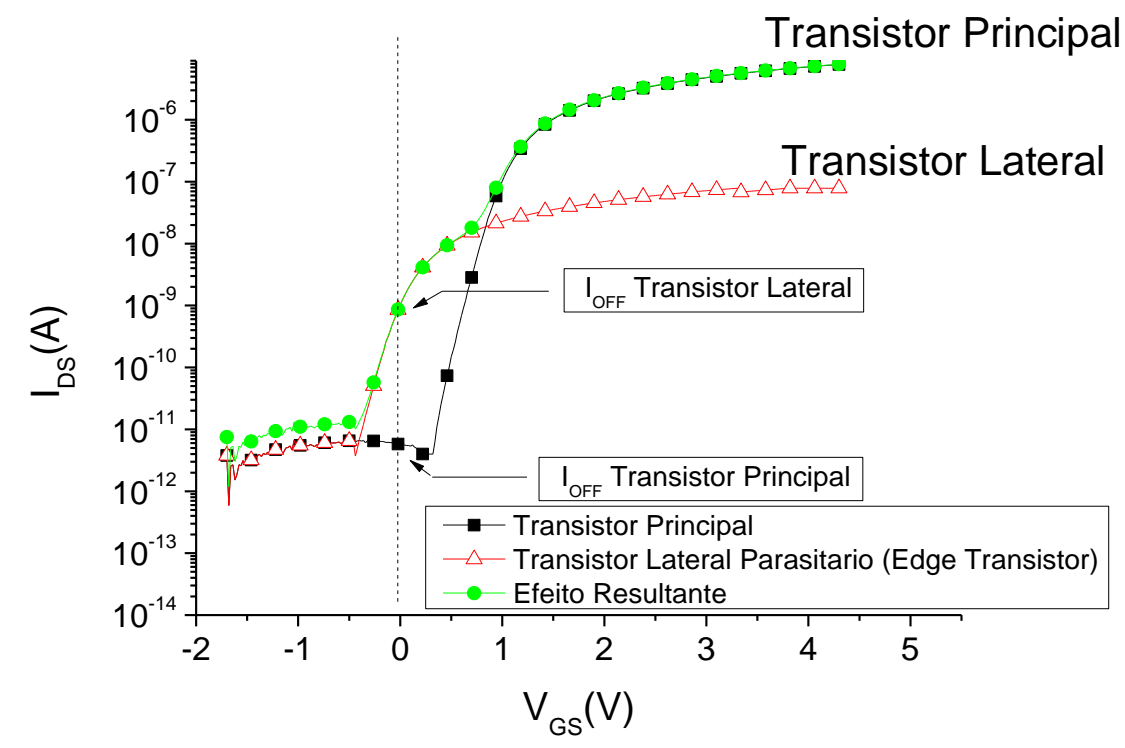

Fonte: Autor.

Este efeito é indesejado, pois piora duas características importantes dos transistores. Quando há o transistor lateral há também um aumento na inclinação de sublimiar e na corrente de fuga (OFF leakage current) [10]. 


\section{PROJETO E SIMULAÇÃO DE PROCESSOS.}

O projeto do dispositivo de tecnologia FD SOI nMOSFET desenvolvido neste trabalho baseou-se inicialmente no projeto do dispositivo nMOSFET convencional usado para finalidade didática na disciplina de graduação "PSI2643 - Laboratório de Fabricação de Dispositivos em Microeletrônica" [7].

A ideia de usar um projeto conhecido como base ao projeto FD SOI visa reduzir custos e tempo de desenvolvimento das etapas de processo.

Deste modo será apresentada a sequência de etapas do transistor convencional e será apresentado também o leiaute dos dispositivos, pois serão utilizadas as mesmas fotomáscaras para a construção do transistor FD SOI.

Posteriormente serão discutidas as mudanças necessárias no processo convencional a fim de obter o FD SOI e finalmente serão mostradas algumas simulações de fabricação.

\subsection{Sequência de Etapas de Processo do Transistor MOS Convencional}

A sequência de processos apresentada para construção do transistor convencional objetiva a obtenção de transistores com dimensão mínima de porta de $5 \mu \mathrm{m}$, embora existam transistores com dimensões de porta menores nas fotomáscaras. Isto porque estas fotomáscaras serão usadas, futuramente, em evoluções deste processo, para que dispositivos menores sejam obtidos.

Neste processo são utilizadas lâminas de silício convencionais tipo $P$, com orientação cristalina $\langle 100\rangle$, espessura de $400 \mu \mathrm{m}$ e resistividade entre 1,0 e $10,0 \Omega \mathrm{cm}$.

1) Limpeza Química;

2) Oxidação Térmica $(70 \mathrm{~nm})$;

3) Implantação lônica Boro (Ajuste de $V_{T H}$ );

4) Recozimento para ativação de dopantes; 
5) Deposição de $\mathrm{SiO}_{2}$ - PECVD (400 nm);

6) Fotogravação 1 - Região Ativa;

Figura 14 - Perfil da estrutura do transistor nMOSFET (convencional) após a etapa 6.

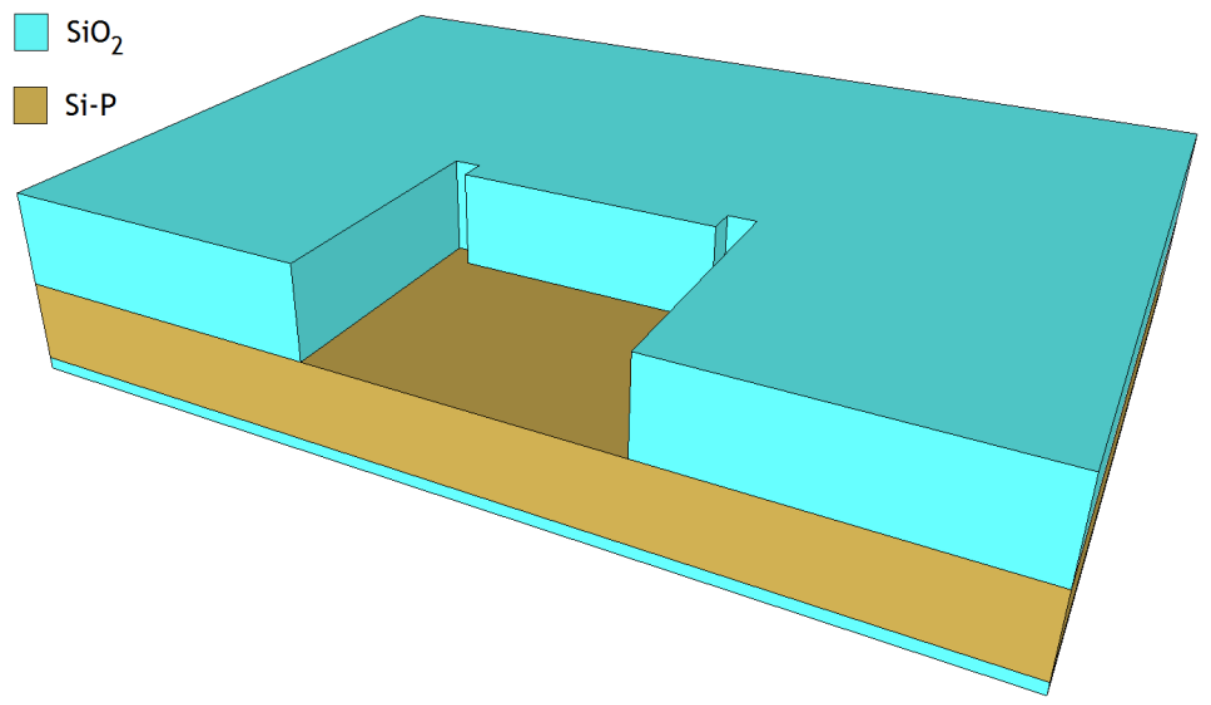

Fonte: Autor.

7) Oxidação Térmica $(70 \mathrm{~nm})$ para obtenção do óxido de porta;

8) Deposição de Silício Policristalino $(500 \mathrm{~nm})$;

9) Dopagem do Silício Policristalino por difusão de fósforo;

10) Fotogravação 2 - Definição do Si-Poli (definição de porta);

Figura 15 - Perfil da estrutura do transistor nMOSFET (convencional) após a etapa 10

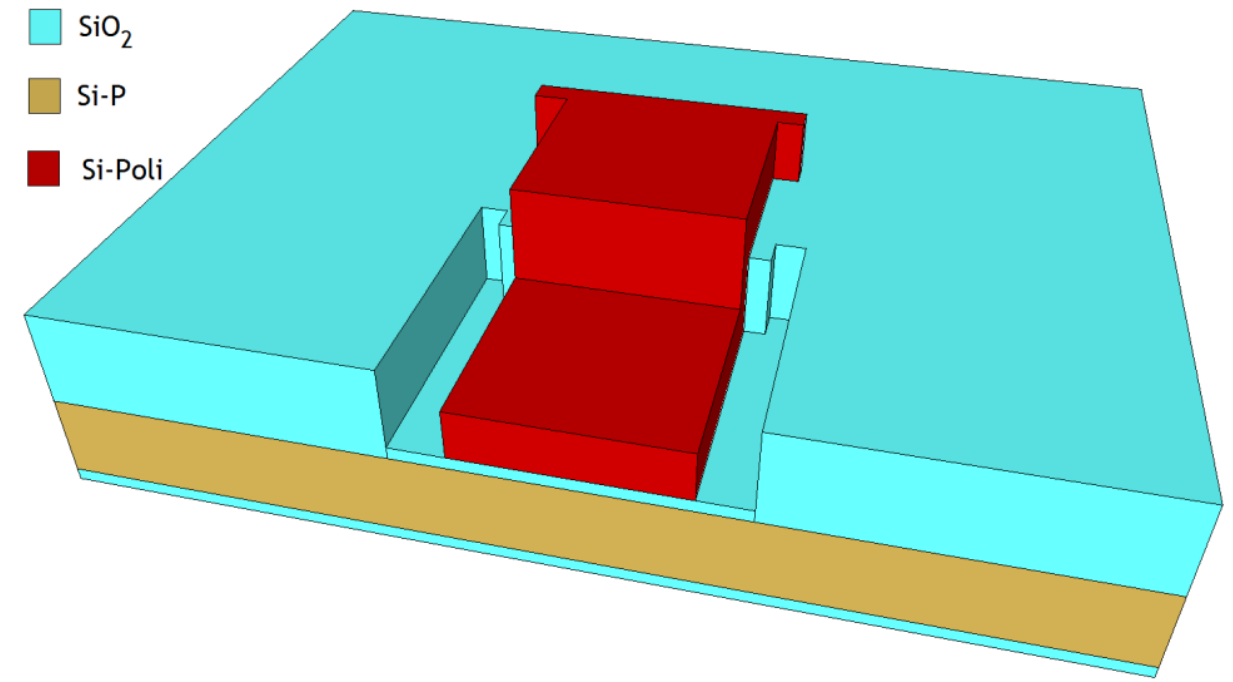

Fonte: Autor. 
11) Implantação lônica de fósforo para formação de Fonte/Dreno;

12) Recozimento para ativação de dopantes e difusão;

13) Deposição de $\mathrm{SiO}_{2}$ - PECVD (400 nm);

14)Fotogravação 3 - Abertura de Contatos;

Figura 16 - Perfil da estrutura do transistor nMOSFET (convencional) após a etapa 14.

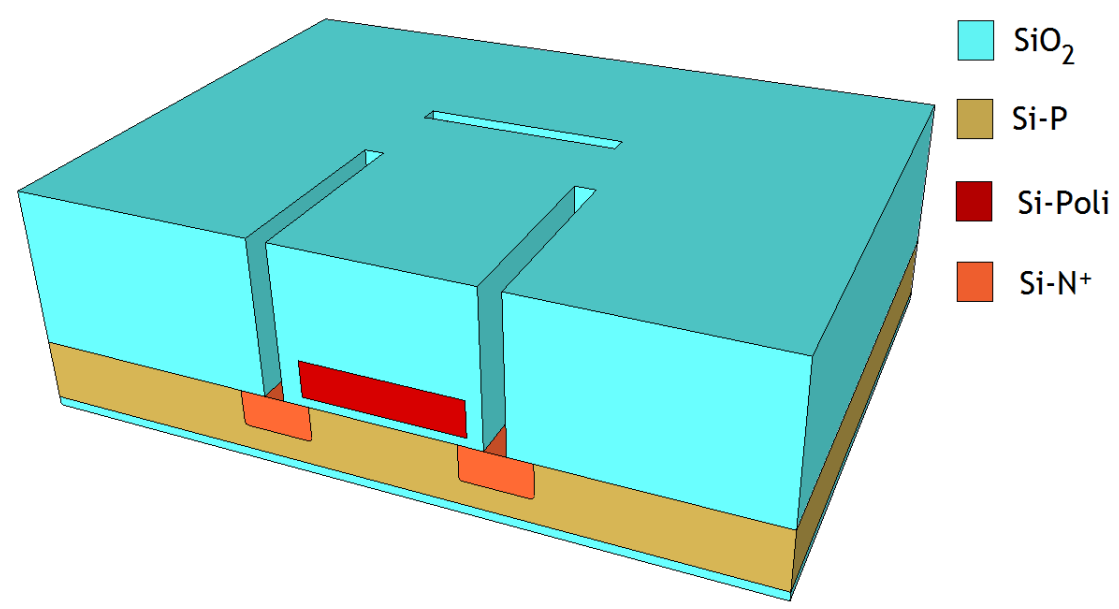

Fonte: Autor.

15)Deposição de Alumínio por evaporação (800 nm);

16)Fotogravação 4 - Definição do Alumínio;

Figura 17 - Perfil da estrutura do transistor nMOSFET (convencional) após a etapa 16.

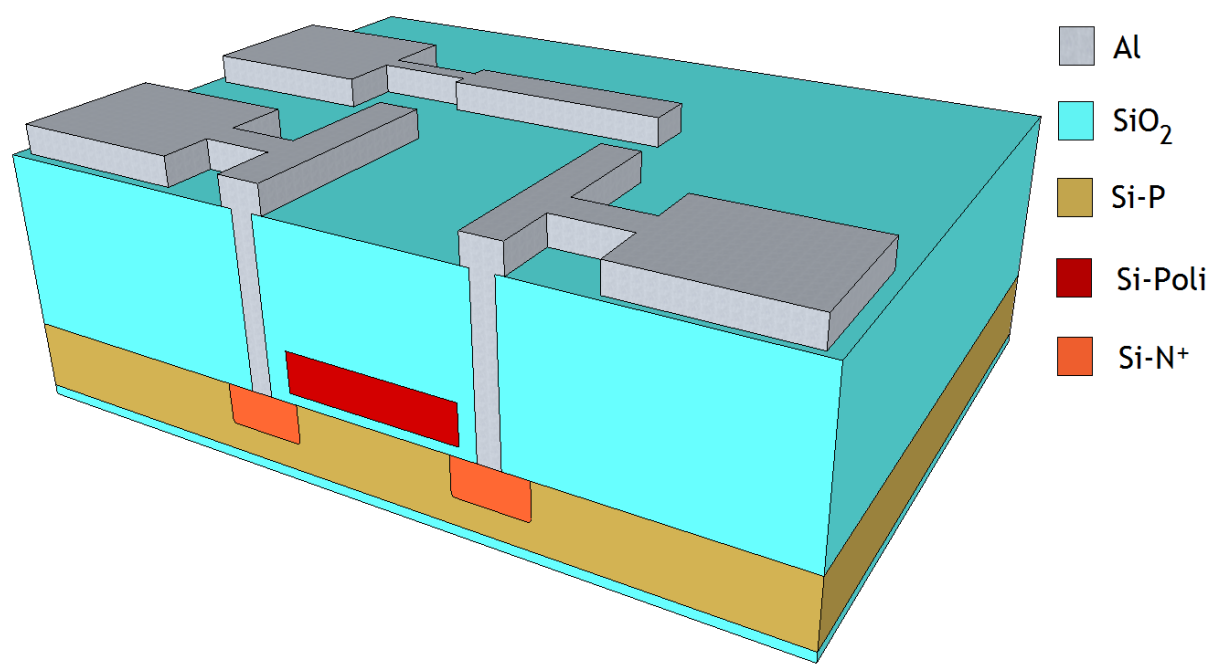

Fonte: Autor. 
17)Corrosão do $\mathrm{SiO}_{2}$ do verso da lâmina (protegendo o alumínio fotogravado com fotorresiste);

18) Metalização do verso da lâmina;

19)Sinterização do Alumínio.

Figura 18 - Perfil final da estrutura do transistor nMOSFET (convencional).

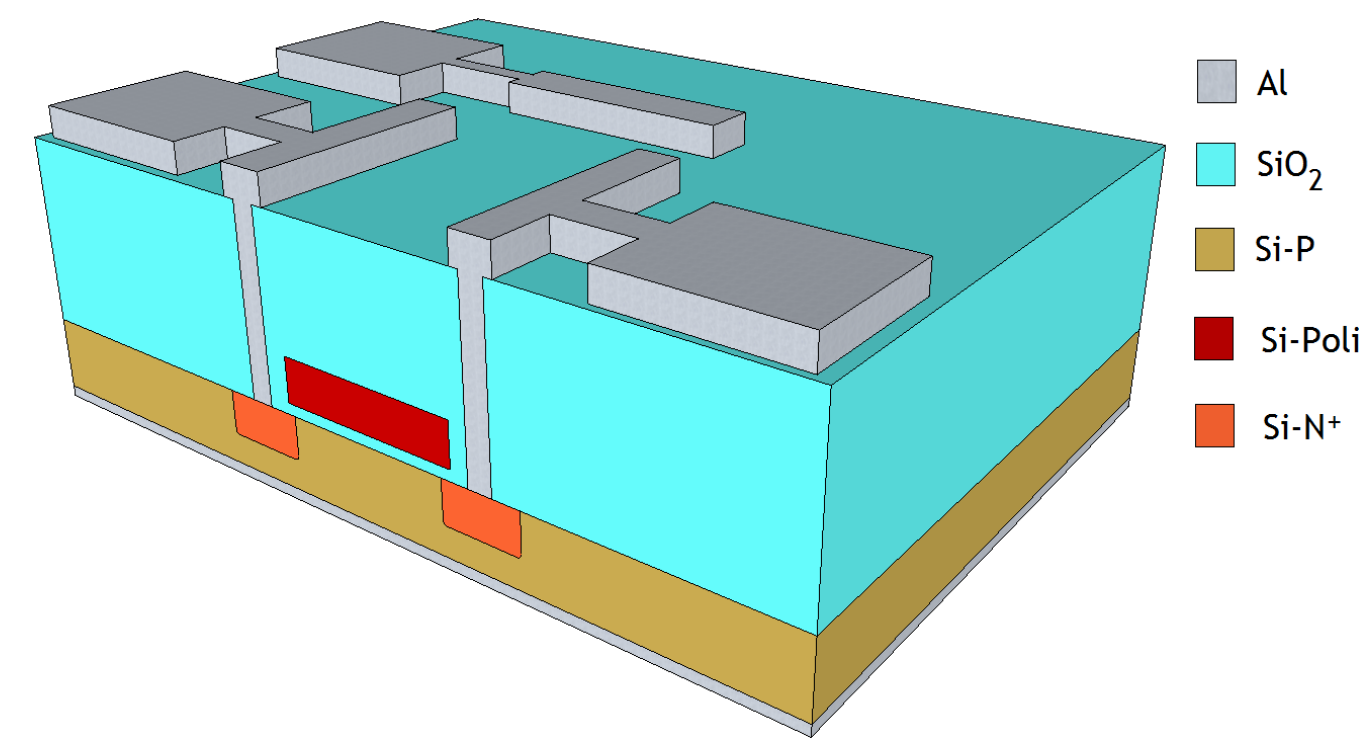

Fonte: Autor.

\subsection{Leiaute dos Dispositivos}

Nesta seção é apresentado o leiaute dos principais dispositivos contidos nas fotomáscaras usadas para fabricação da tecnologia nMOSFET convencional, cuja sequência de etapas foi apresentada na seção 3.1.

O projeto destas fotomáscaras é descrito na referência [32]. No entanto, após o projeto inicial foram necessárias algumas correções, antes que as fotomáscaras fossem confeccionadas. Devido a isto existem algumas diferenças entre o projeto inicial [32] e este trabalho. 


\subsubsection{Transistores}

Existem 4 cascatas de transistores MOS, sendo que em 3 delas se mantém constante a largura de canal $(W)$ e varia-se o comprimento $(L)$; e existem também 3 transistores isolados. Segue a descrição de cada um deles:

a) TNL1: Uma cascata composta de 6 transistores com largura de canal constante ( $\mathrm{W}=10 \mu \mathrm{m})$, e comprimento variando de $50 \mu \mathrm{m}$, $40 \mu \mathrm{m}, 30 \mu \mathrm{m}, 20 \mu \mathrm{m}, 10 \mu \mathrm{m}$ e $5 \mu \mathrm{m}$.

Figura 19 - Projeto da Cascata TNL1 [32].

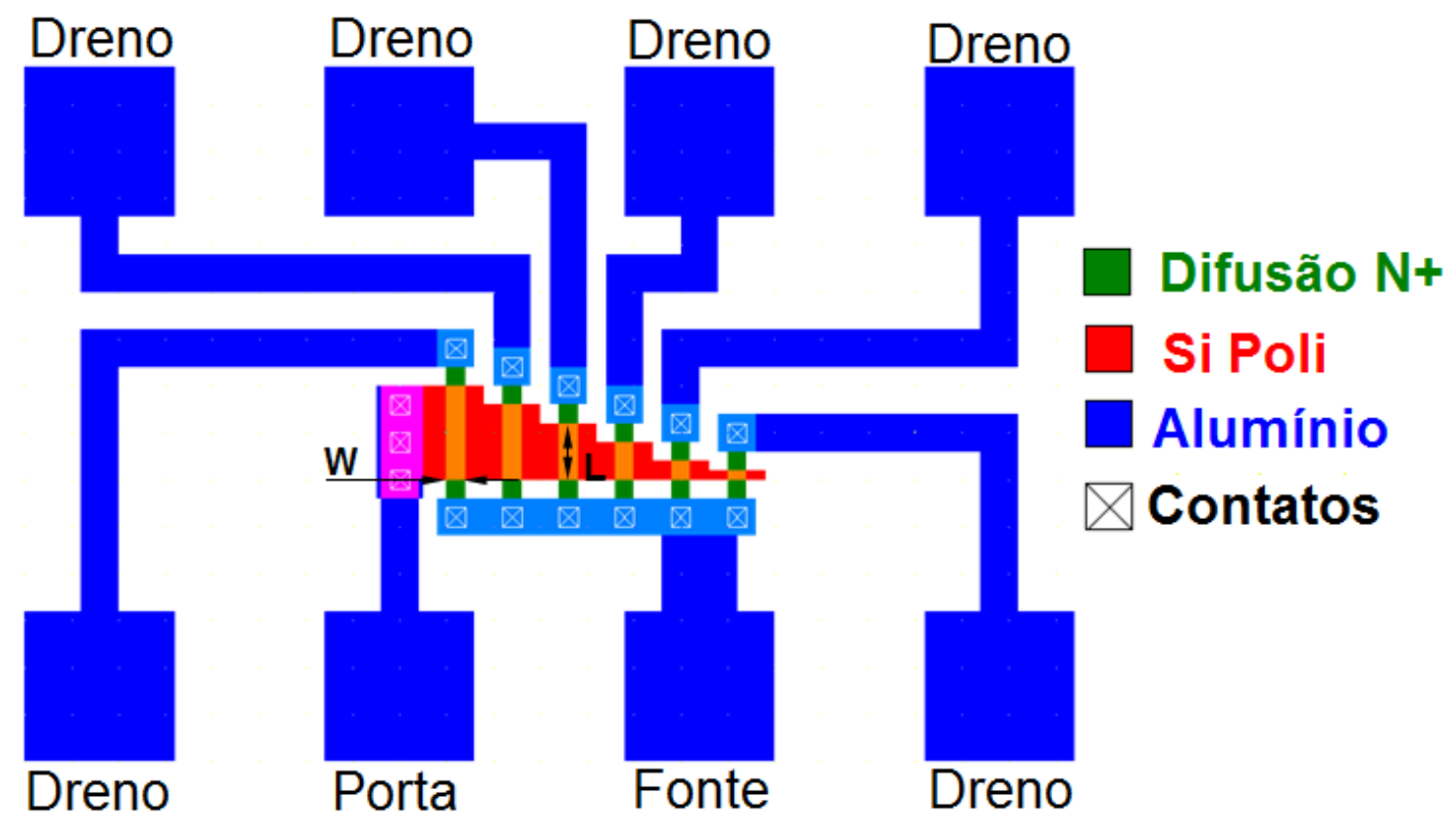

Fonte: Santos, L.P., Projeto de máscaras com dispositivos e estruturas de teste usando o microwind.

b) TNL2: Uma cascata composta de 6 transistores com largura de canal constante $(\mathrm{W}=10 \mu \mathrm{m})$, e comprimento variando de $10 \mu \mathrm{m}$, $5 \mu \mathrm{m}, 4 \mu \mathrm{m}, 3 \mu \mathrm{m}, 2 \mu \mathrm{m}$ e $1 \mu \mathrm{m}$.

c) TNL3: Uma cascata composta de 6 transistores com largura de canal constante $(\mathrm{W}=10 \mu \mathrm{m})$, e comprimento variando de $3,0 \mu \mathrm{m}$, $2,5 \mu \mathrm{m}, 2,0 \mu \mathrm{m}, 1,5 \mu \mathrm{m}, 1,0 \mu \mathrm{m}$ e $0,5 \mu \mathrm{m}$. 
d) TNW4: Uma cascata composta de 6 transistores, mas com comprimento de canal constante $(L=10 \mu \mathrm{m})$, e largura variando de $10 \mu \mathrm{m}, 8 \mu \mathrm{m}, 6 \mu \mathrm{m}, 4 \mu \mathrm{m}, 2 \mu \mathrm{m}$ e $1 \mu \mathrm{m}$.

e) T1: Transistor isolado com dimensões $\mathrm{L}=10 \mu \mathrm{m}$ e $\mathrm{W}=10 \mu \mathrm{m}$.

f) T2: Transistor isolado com dimensões $\mathrm{L}=5 \mu \mathrm{m}$ e $\mathrm{W}=10 \mu \mathrm{m}$.

g) T3: Transistor isolado com dimensões $L=100 \mu \mathrm{m}$ e $\mathrm{W}=100 \mu \mathrm{m}$.

Figura 20 - Projeto do Transistor isolado T3.

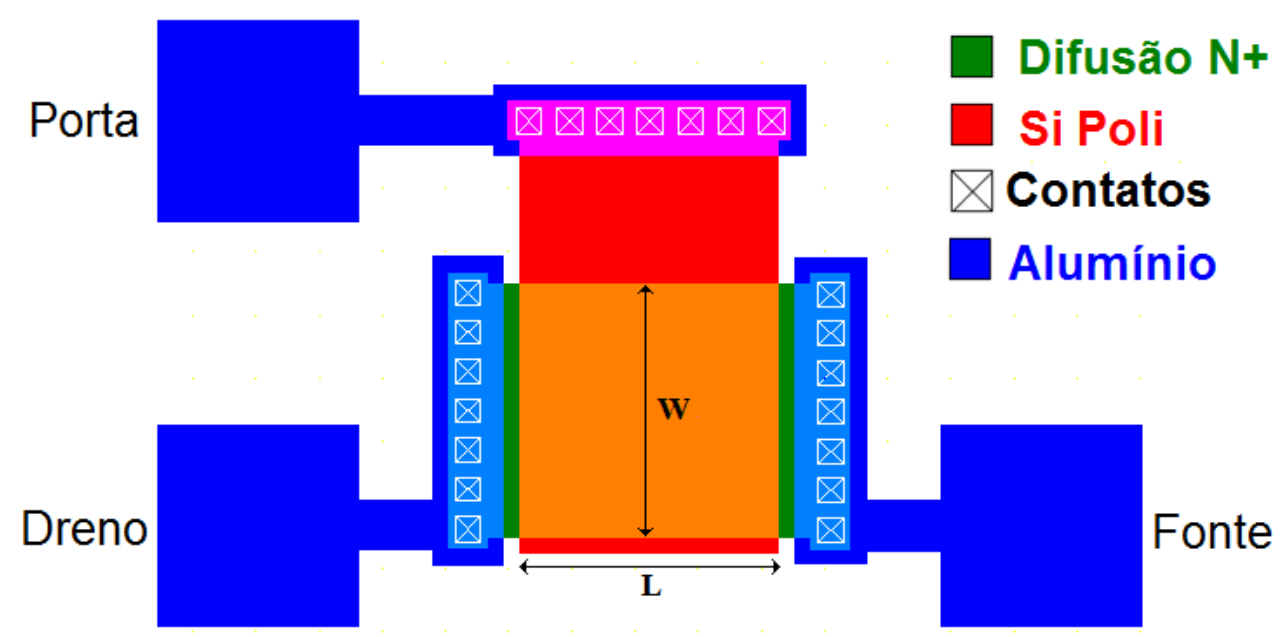

Fonte: Autor.

\subsubsection{Inversores nMOS}

Existem 2 inversores nMOS com carga saturada, com diferentes dimensões do transistor de carga.

a) INV1: Inversor nMOS com transistor de comando com dimensões $\mathrm{W}=10 \mu \mathrm{m}$ e $\mathrm{L}=10 \mu \mathrm{m}$ e transistor de carga $\mathrm{W}=40 \mu \mathrm{m}$ e $\mathrm{L}=10 \mu \mathrm{m}$.

b) INV2: Inversor nMOS com transistor de comando com dimensões $\mathrm{W}=10 \mu \mathrm{m}$ e $\mathrm{L}=10 \mu \mathrm{m}$ e transistor de carga $\mathrm{W}=10 \mu \mathrm{m}$ e $\mathrm{L}=10 \mu \mathrm{m}$. 
Figura 21 - Projeto do inversor INV2 [32].

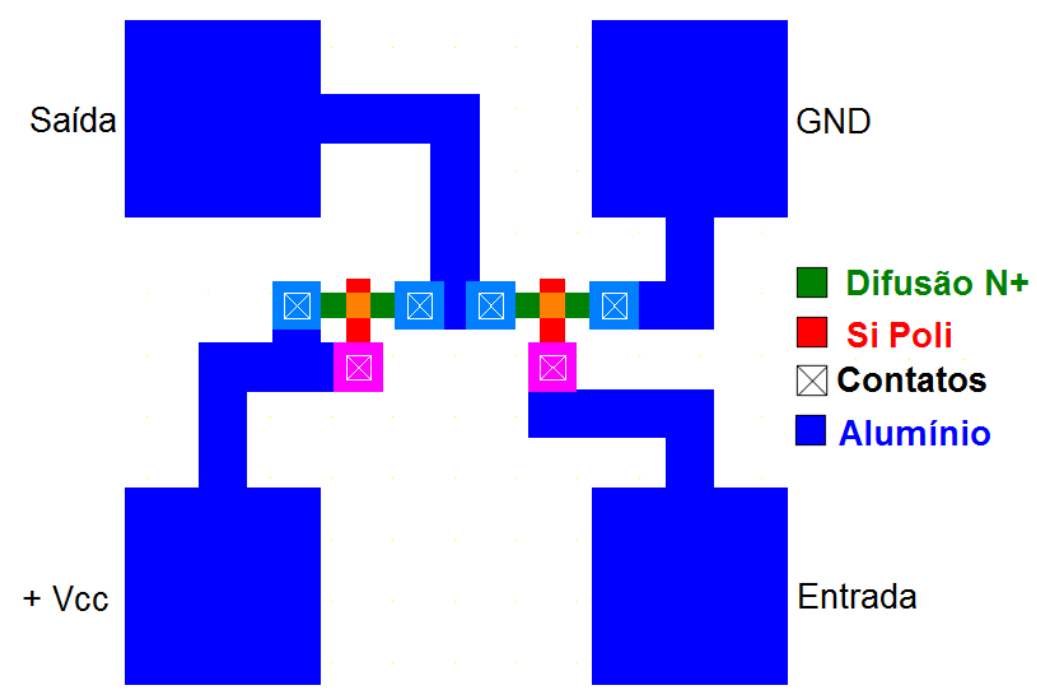

Fonte: Santos, L.P., Projeto de máscaras com dispositivos e estruturas de teste usando o microwind.

\subsubsection{Capacitores}

Foram projetados 4 tipos de capacitores, sendo que para cada tipo de

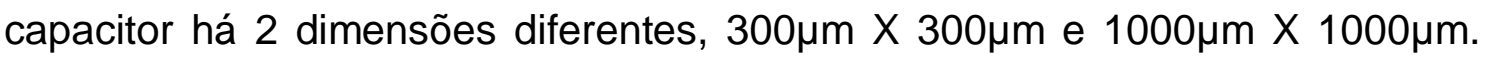
Os tipos de capacitores são:

a) C1 e C2: Capacitores de óxido de passivação (etapa 13) entre metal e silício policristalino.

b) C3 e C4: Capacitores de óxido de campo e de passivação (etapas 5 e 13) entre metal e substrato.

c) C5 e C6: Capacitor de óxido de porta entre silício policristalino e substrato com anel de guarda.

d) C7 e C8: Capacitor de óxido de campo entre silício policristalino e substrato. 


\subsubsection{Diodos}

Existem 4 diodos, sendo que:

a) D1 e D2: São diodos tipo grelha (Figura 22). O diodo D1 tem área de $1 \times 10^{-6} \mathrm{~m}^{2}$ e perímetro de $20 \mathrm{~mm}$, o diodo $\mathrm{D} 2$ tem área de $9 \times 10^{-8}$ $\mathrm{m}^{2}$ e perímetro de $6 \mathrm{~mm}$.

Figura 22 - Projeto do Diodo D2 [32].

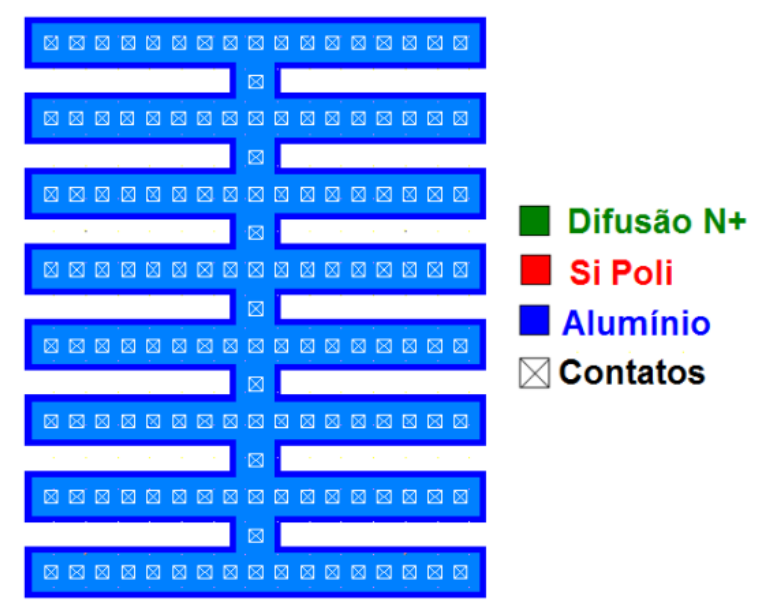

Fonte: Santos, L.P., Projeto de máscaras com dispositivos e estruturas de teste usando o microwind.

b) D3 e D4: São diodos quadrados. O diodo D3 tem área de $1 \times 10^{-6} \mathrm{~m}^{2}$ e perímetro de $4 \mathrm{~mm}$, o diodo $\mathrm{D} 2$ tem área de $9 \times 10^{-8} \mathrm{~m}^{2} \mathrm{e}$ perímetro de $1,2 \mathrm{~mm}$.

\subsubsection{Estrutura Van der Pauw e 2 Resistores}

A estrutura Van der Pauw é usada para determinar a resistência de folha e a dos resistores é a de determinar a largura efetiva de linhas [29] (região $\mathrm{N}^{+}$, Silício Policristalino e Metal). Há 3 estruturas Van der Pauw e 2 resistores:

a) VDP1: Van der Pauw de silício policristalino.

b) VDP2: Van der Pauw da região $\mathrm{N}+$.

c) VDP3: Van der Pauw de metal (Alumínio). 
Figura 23 - Projeto do Van der Pauw 1 [32].

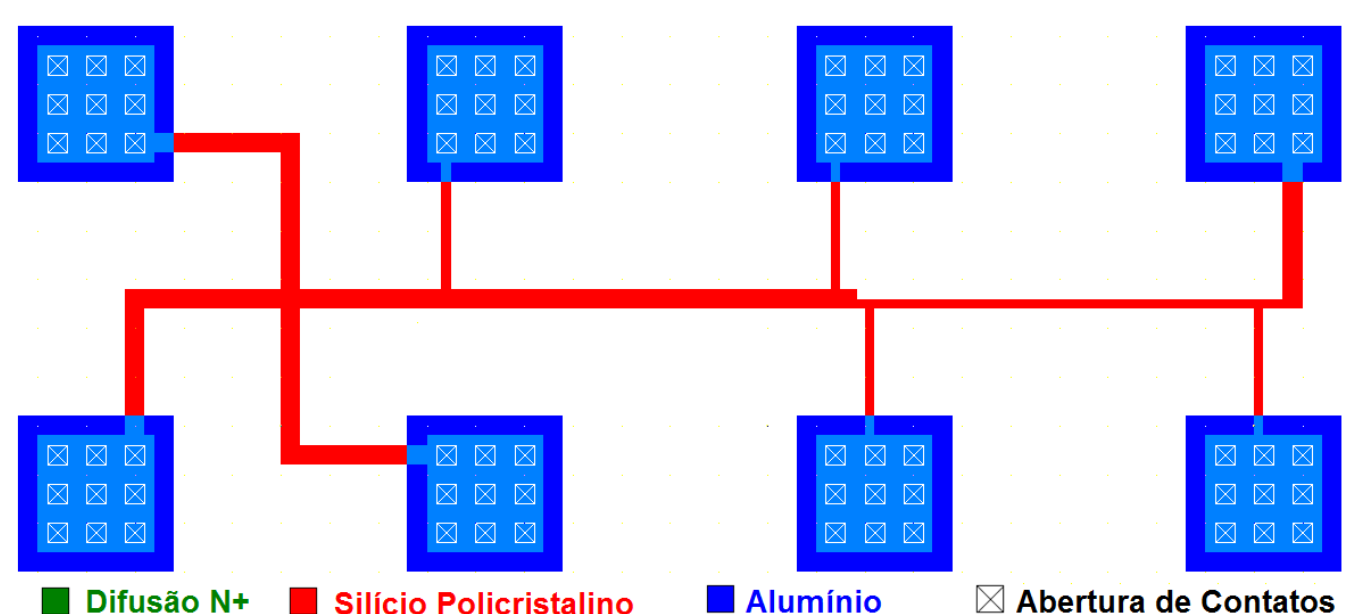

Fonte: Santos, L.P., Projeto de máscaras com dispositivos e estruturas de teste usando o microwind.

\subsubsection{Estrutura Kelvin}

A função desta estrutura é medir a resistência de contato entre duas camadas diferentes, em nosso caso há dois tipos de estruturas Kelvin: um para medir a resistência de contato entre o metal (alumínio) e o silício policristalino e outra entre o metal (alumínio) e a região $\mathrm{N}^{+}$. Deste modo:

a) K1 e K2: Estruturas Kelvin para medir a resistência de contato entre 0 metal (Alumínio) e a região $\mathrm{N}+$. Sendo que em $\mathrm{K} 1$ a área de contato é $5 \mu \mathrm{m} \times 5 \mu \mathrm{m}$, e em K2 a área de contato é $10 \mu \mathrm{m} \times 10 \mu \mathrm{m}$.

b) K3 e K4: Estruturas Kelvin para medir a resistência de contato entre o metal (Alumínio) e o silício policristalino. Sendo que em K3 a área de contato é $5 \mu \mathrm{m} \times 5 \mu \mathrm{m}$, e em K4 a área de contato é $10 \mu \mathrm{m} \times 10 \mu \mathrm{m}$. 
Figura 24 - Projeto da Estrutura Kelvin 2 [32].

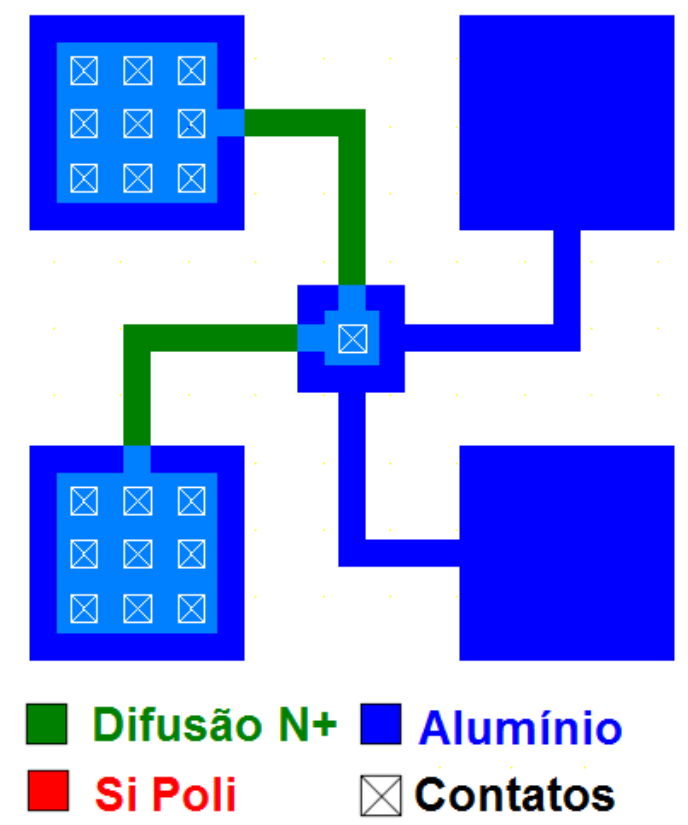

Fonte: Santos, L.P., Projeto de máscaras com dispositivos e estruturas de teste usando o microwind.

\subsubsection{Marcas de Alinhamento}

As marcas de alinhamento permitem alinhar os diferentes processos litográficos. Esta é uma estrutura, de pequenas dimensões, fundamental; sem a qual não é possível construir os dispositivos. Apesar de sua importância durante a fabricação, uma vez que o processo de fabricação esteja concluído, esta estrutura não será utilizada.

É importante cuidado ao projetar as marcas de alinhamento, pois o operador da fotoalinhadora necessita observar as marcas na lâmina através da fotomáscara, e há fotomáscaras de campo claro e de campo escuro num processo completo. Nas fotomáscaras de campo escuro é necessário abrir a região ao redor da marca de alinhamento, para que o operador possa visualizar as marcas da lâmina, e fazer o correto alinhamento.

A Figura 25 mostra o leiaute da estrutura de alinhamento e a Figura 26 mostra o perfil da marca de alinhamento utilizada neste trabalho. 
Figura 25 - Projeto das marcas de alinhamento.

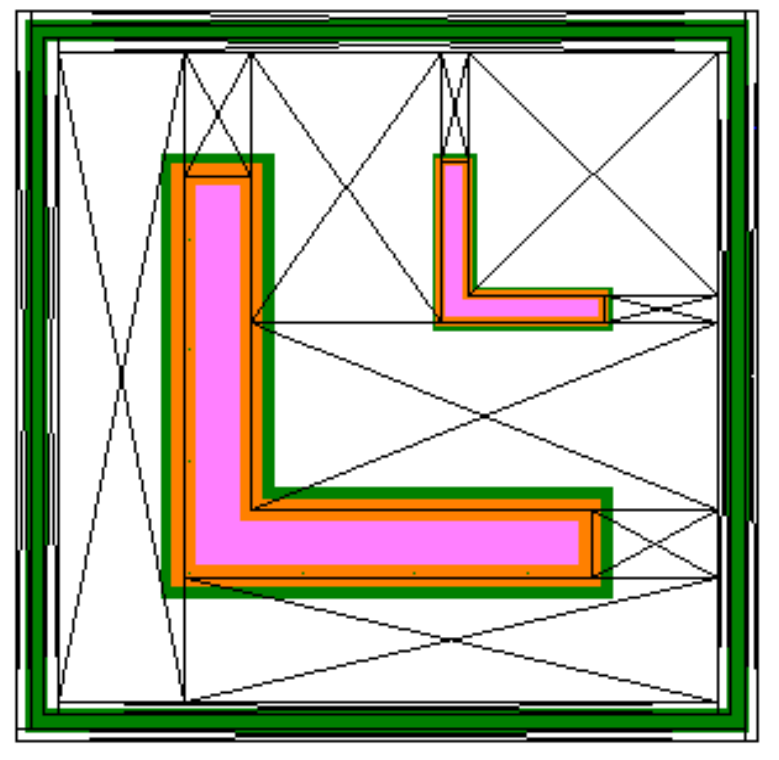

$\square$ Difusão $\mathrm{N+}$

$\square$ Si Poli

alumínio $\bigotimes$ Contatos

Fonte: Autor.

Figura 26 - Perfil do projeto das marcas de alinhamento.

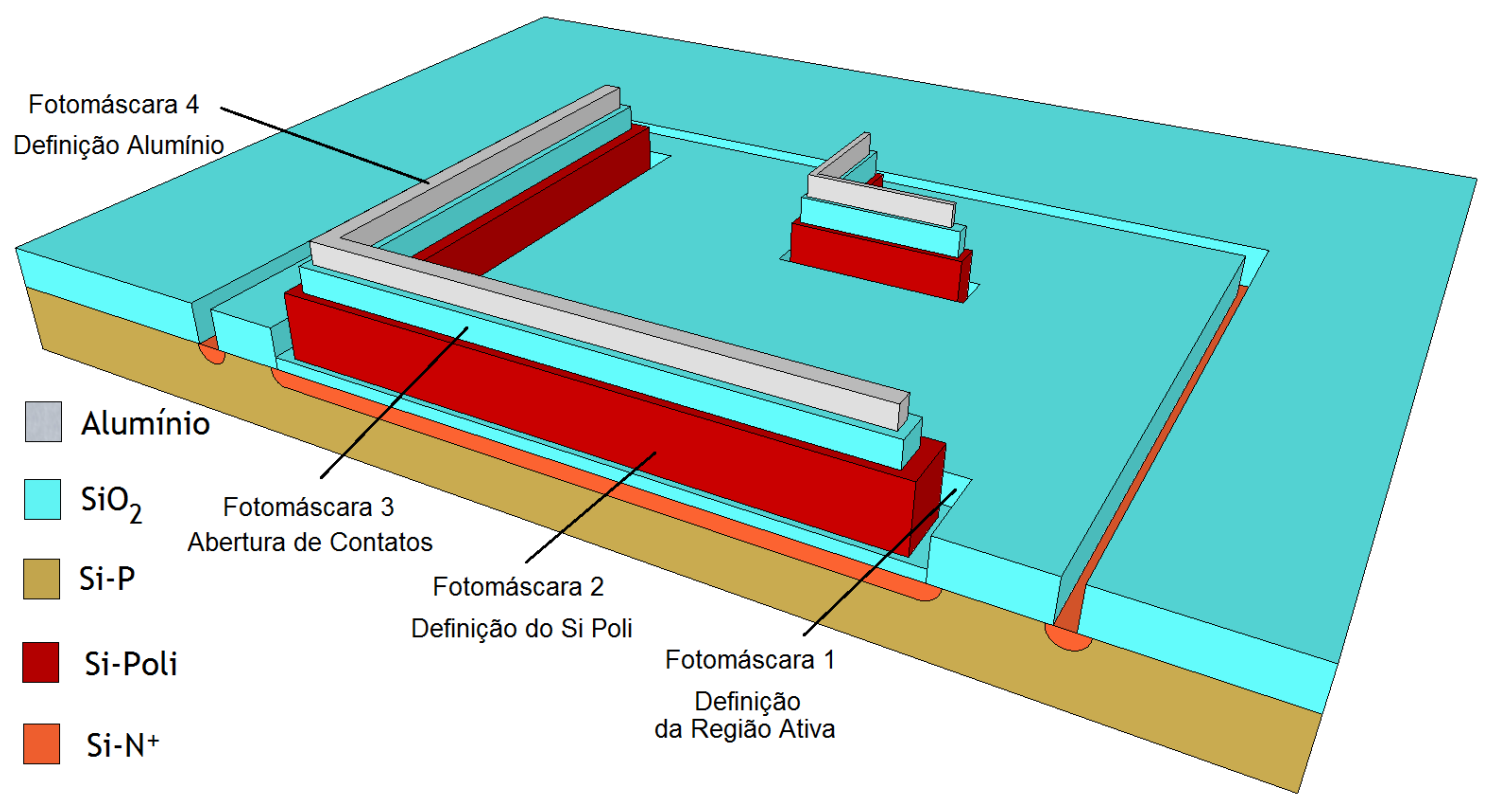

Fonte: Autor.

\subsection{Projeto do FD SOI nMOSFET}

Nesta seção é apresentado o projeto de uma sequência de processo simples capaz de produzir um transistor FD SOI nMOSFET. Serão utilizadas as mesmas fotomáscaras do processo nMOSFET convencional já descrito, por 
isso será necessário alterar parâmetros de algumas etapas de processo e desenvolver outras etapas.

\subsubsection{Sequência de Etapas de Processo do Transistor FD SOI}

A sequência de processos apresentada para construção do transistor FD SOI objetiva a obtenção de transistores com características de funcionamento superiores aos nMOS convencionais, principalmente com relação às correntes de fuga nas junções e inclinação de sublimiar.

Para usar as mesmas fotomáscaras do processo convencional a $1^{\text {a }}$ fotogravação deve ser feita com FR negativo, de modo que o resiste proteja a região ativa e exponha a região de campo. Então será realizada a corrosão do silício exposto, e assim a isolação MESA está concluída.

No processo são utilizadas lâminas SOI tipo $\mathrm{P}$, com orientação cristalina $<100$, espessura de $625 \mu \mathrm{m}$, ao todo; sendo que há 100nm de silício sobre isolante e $200 \mathrm{~nm}$ de óxido enterrado; e resistividade entre 13,5 e $22,5 \Omega \mathrm{cm}$ [28].

1) Limpeza Química;

2) Oxidação Térmica $(50 \mathrm{~nm})$;

3) Implantação lônica Boro (Ajuste de $V_{T H}$ );

4) Recozimento para ativação de dopantes;

5) Fotogravação 1 - Corrosão do silício da região de campo; 
Figura 27 - Perfil do transistor FD SOI nMOSFET após a etapa 5.

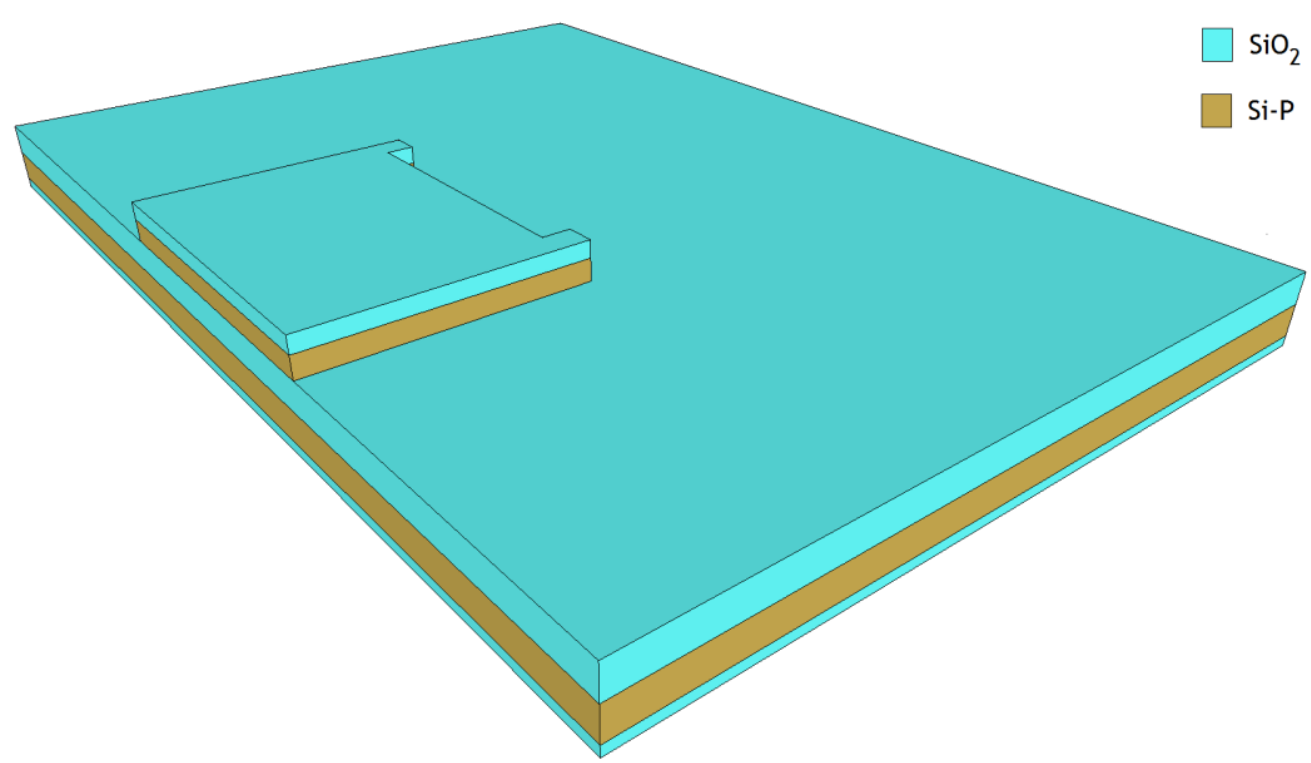

Fonte: Autor.

6) Corrosão do óxido de silício;

7) Oxidação Térmica $(50 \mathrm{~nm})$ para formação do óxido de porta;

8) Deposição de Silício Policristalino (500 nm);

9) Dopagem do Silício Policristalino por difusão de fósforo;

10) Fotogravação 2 - Definição do Si-Poli (definição de porta);

Figura 28 - Perfil do transistor FD SOI nMOSFET após a etapa 10.

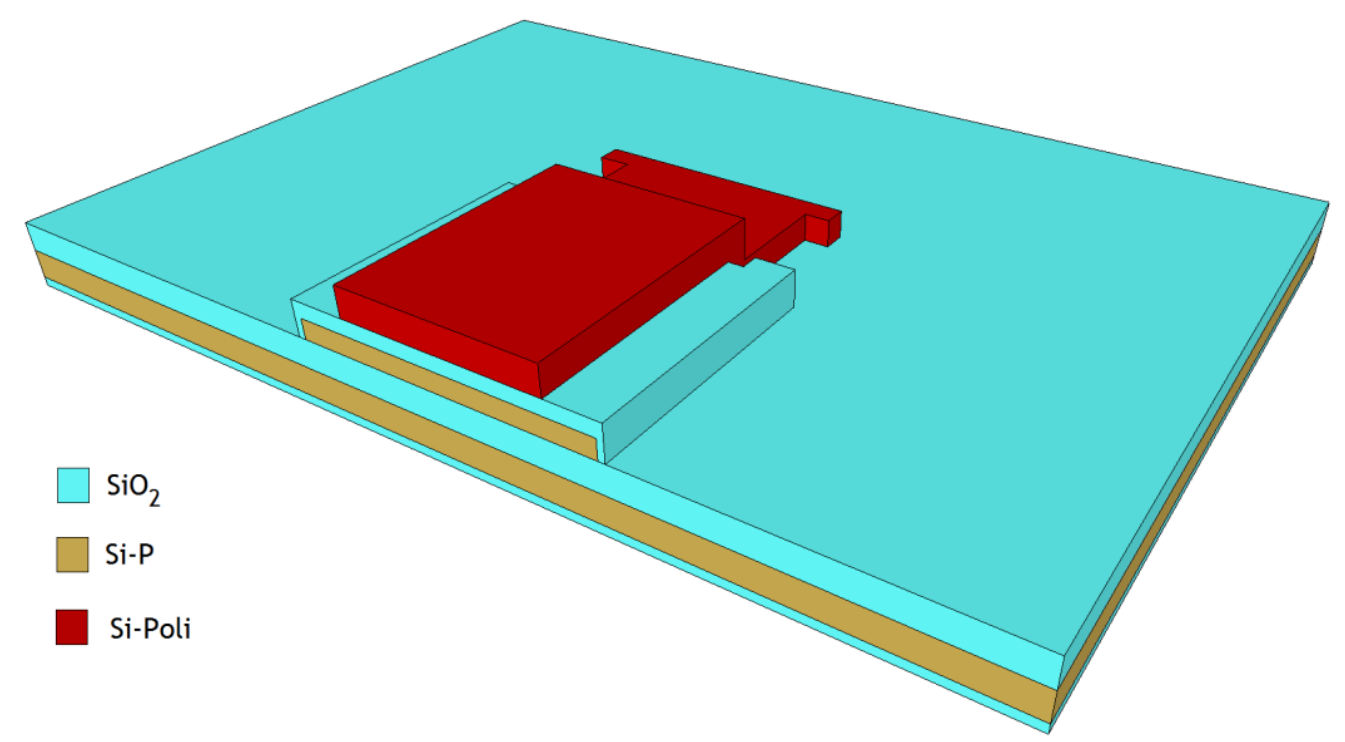

Fonte: Autor. 
11)Implantação lônica de fósforo para formação de Fonte/Dreno;

12)Recozimento para ativação de dopantes e difusão;

13) Deposição de $\mathrm{SiO}_{2}$ - PECVD (400 nm);

14)Fotogravação 3 - Abertura de Contatos;

Figura 29 - Perfil do transistor FD SOI nMOSFET após a etapa 14.

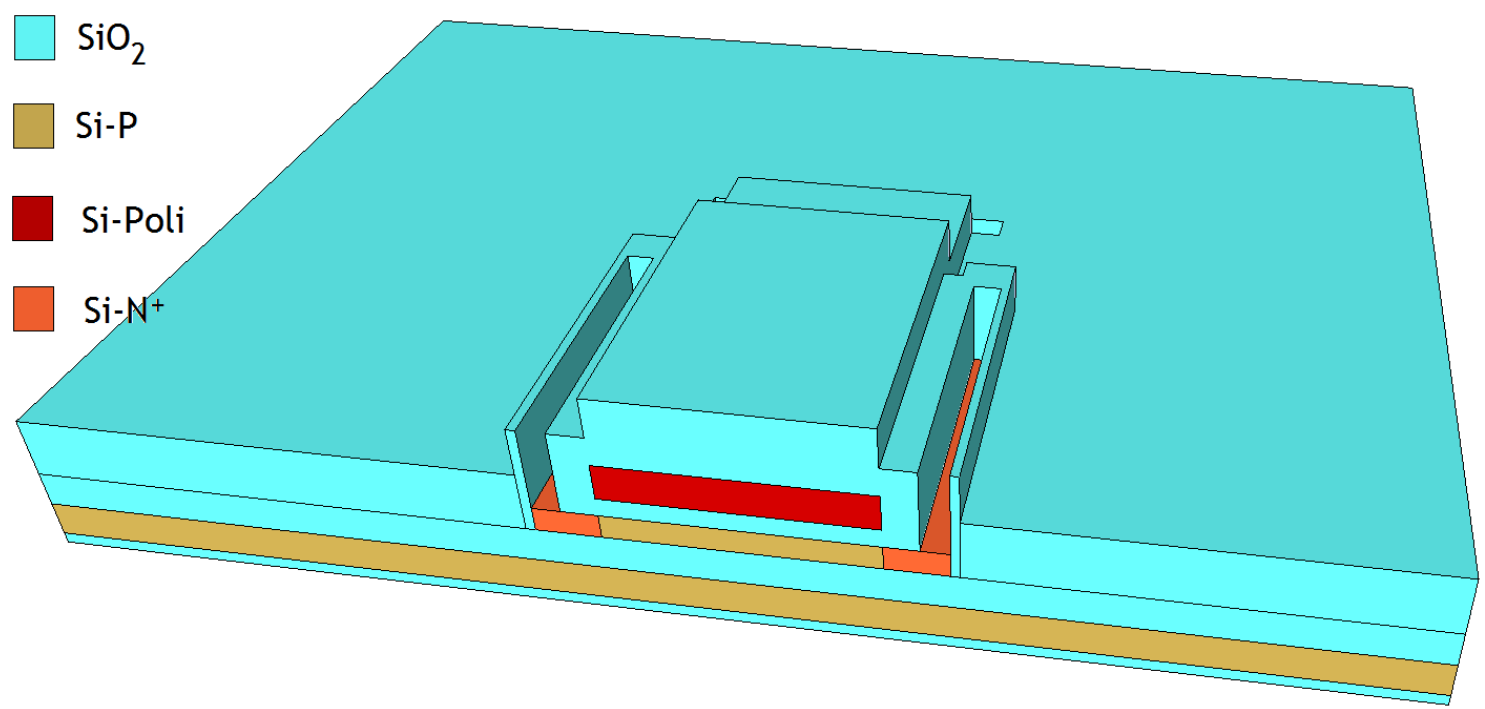

Fonte: Autor.

15)Deposição de Alumínio por evaporação (800 nm);

16)Fotogravação 4 - Definição do Alumínio;

Figura 30 - Perfil do transistor FD SOI nMOSFET após a etapa 16.

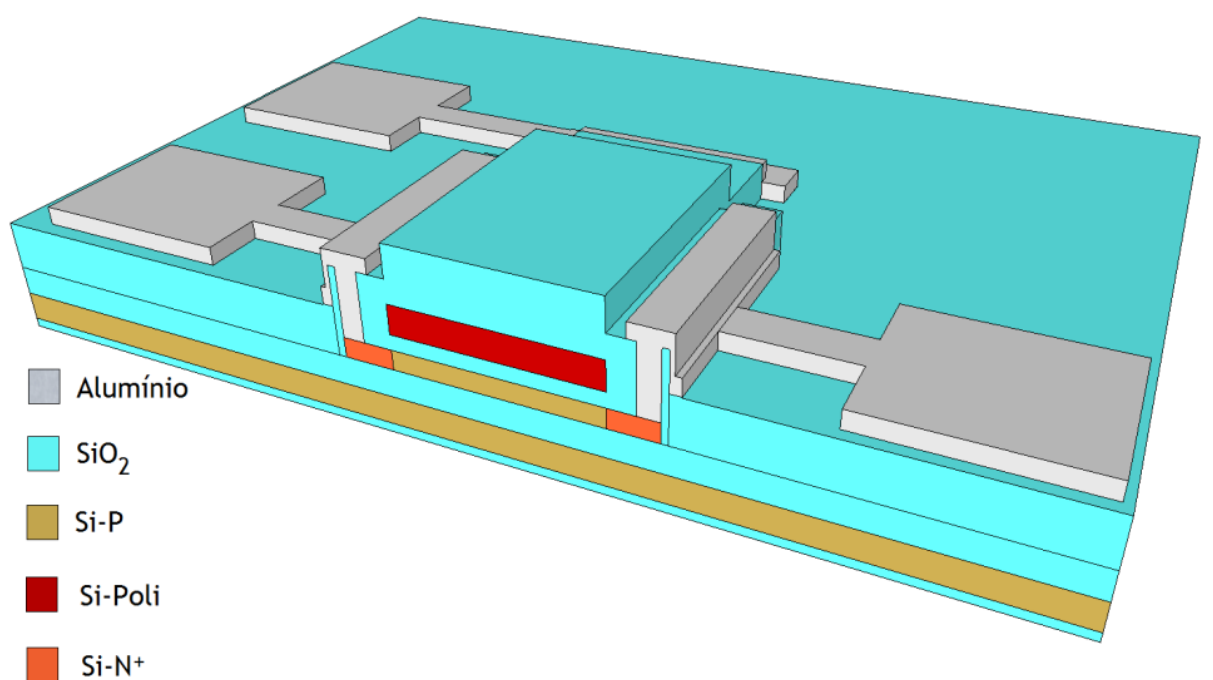

Fonte: Autor. 
17) Corrosão do $\mathrm{SiO}_{2}$ do verso da lâmina;

18) Metalização do verso da lâmina;

19)Sinterização do Alumínio.

Figura 31 - Perfil final da estrutura do transistor FD SOI nMOSFET.

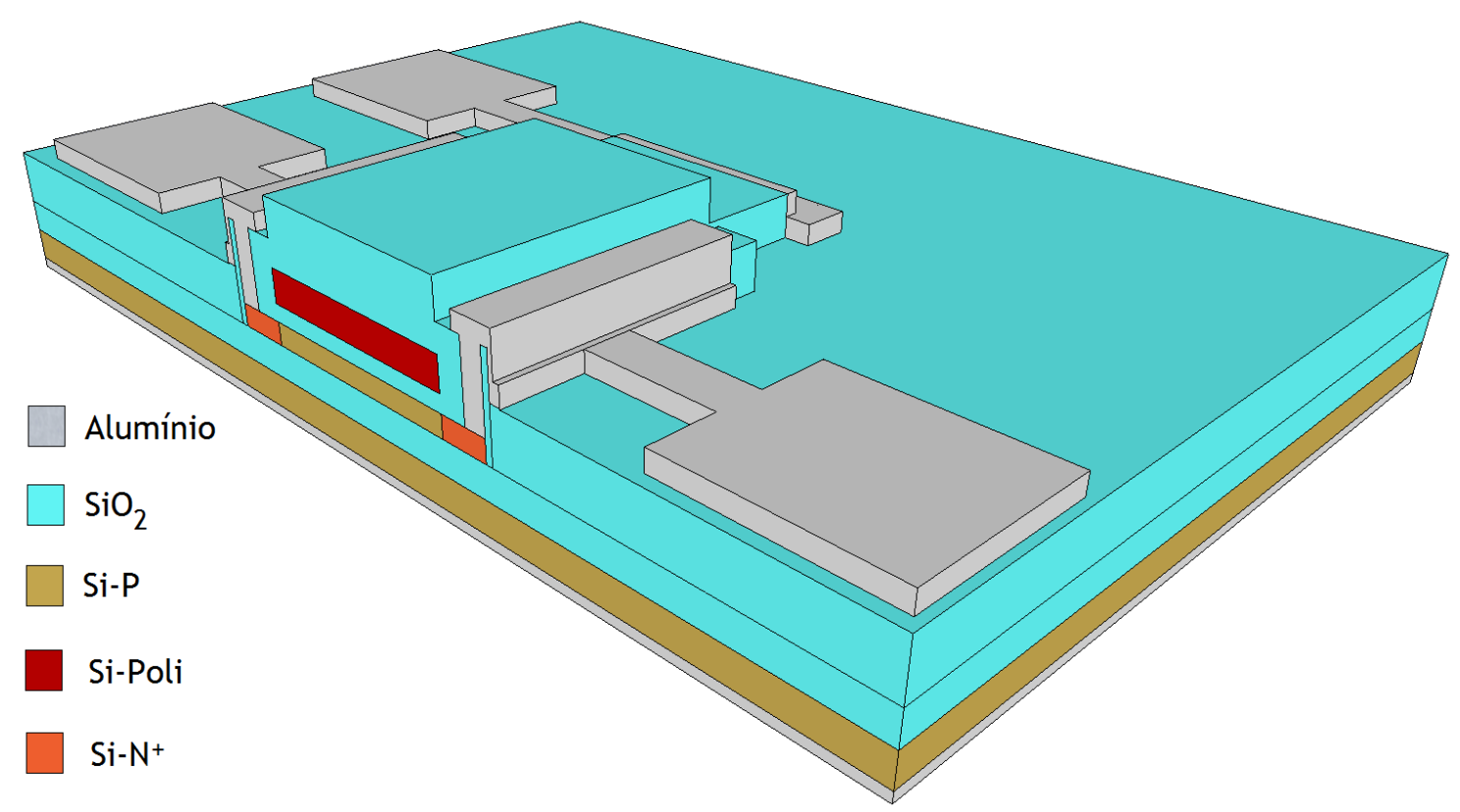

Fonte: Autor.

Para que este processo atinja os objetivos desejados foram projetados parâmetros de processo como as doses e energias usadas nas implantações iônicas, usando simulação de processos e dispositivos. E são estas simulações que são descritas a seguir.

\subsubsection{Simulacões da sequência de fabricacão do Transistor FD SOI}

Utilizando o simulador Athena da Silvaco (versão 5.20.0.R), simularam-se as etapas de processo propostas na seção 3.3.2. Esta primeira etapa das simulações objetiva entender o processo de fabricação dos dispositivos. Posteriormente, com o arquivo de construção dos dispositivos pronto, iniciou-se a simulação de dispositivos, com o Atlas (versão 5.18.3.R) da Silvaco. 
Como o objetivo é construir um transistor FD SOI nMOSFET inicialmente projetou-se qual deveria ser a espessura final da camada de silício sobre o isolante. Conforme descrito anteriormente, a espessura do silício sobre isolante deve ser menor que a espessura máxima de depleção ( $\left.t_{s i} \leq X d_{M a ́ x}\right)$.

A espessura de silício sobre o óxido tsi $=100 \mathrm{~nm}$ será afinada (consumida) no processo proposto, pois há duas etapas de oxidação térmica, que acabam por diminuir a espessura final do silício sobre isolante. Se por um lado é desejável que o silício seja fino o suficiente para que o dispositivo seja totalmente depletado (FD SOI), por outro não é desejável que seja fino demais, pois isto pode custar elevada resistência nas regiões de fonte e dreno.

Neste momento não estão disponíveis etapas como crescimento seletivo epitaxial (SEG) [33] ou a formação de silicetos [34] técnicas que diminuem a resistência das regiões $\mathrm{N}+$ e de contato entre metal e regiões de fonte e dreno, respectivamente. Por isto, torna-se ainda mais importante o cuidado com a espessura final do silício, para que o efeito de resistência série (o qual não será possível eliminar) seja o menor possível.

Há ainda a preocupação para que o óxido de porta não seja fino demais, pois nosso transistor poderia apresentar elevada corrente de porta. Efeito parasitário que se deseja evitar, principalmente ao trabalhar com transistores de grandes dimensões.

\subsubsection{Espessura do Óxido de Porta (toxF) e do Silício sobre Isolante ( $\left.t_{s i}\right)$}

Optou-se por estabelecer uma espessura de óxido de porta segura. De modo que nosso dispositivo não deverá apresentar elevada corrente de porta. Sabe-se que no processo nMOSFET convencional apresentado a espessura do óxido de porta de $70 \mathrm{~nm}$ torna a corrente de porta muito pequena (aprox. 80pA). Observe o gráfico da Figura 32, em que a curva IDS $\times V_{G S}$ e IGS $X V_{G S}$ de um transistor nMOSFET convencional $(\mathrm{L}=100 \mu \mathrm{m}$ e $\mathrm{W}=100 \mu \mathrm{m})$ construído com óxido de porta de $70 \mathrm{~nm}$ é mostrada. 
Figura 32 - Gráfico da corrente de porta (IGS-eixo da direita) e da corrente de dreno (IDS-eixo da esquerda) do transistor nMOSFET convencional. a) Escala linear e b) escala logarítmica. Este transistor tem dimensões $\mathrm{L}=100 \mu \mathrm{m}$ e W=100 $\mu \mathrm{m}$.

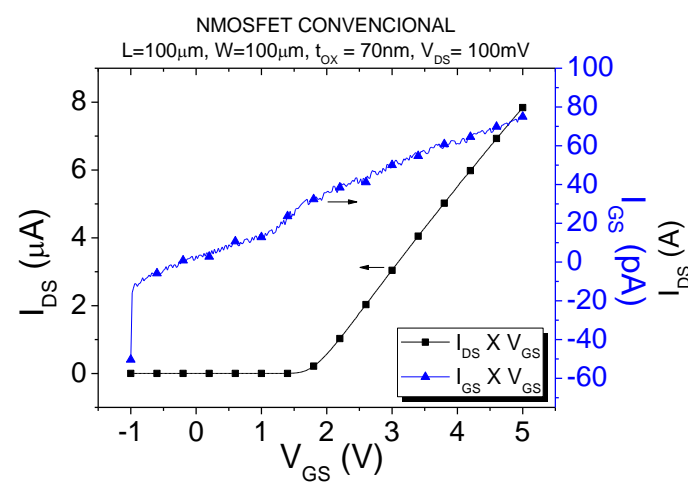

a)

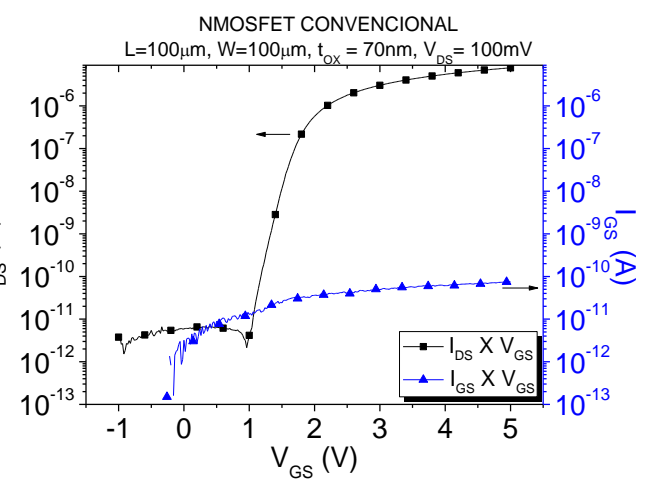

b)

Fonte: Autor.

Conclui-se que usar espessuras de óxido de porta (toxf) desta ordem de grandeza $(\sim 70 \mathrm{~nm})$ resultam em correntes de fuga suficientemente baixas $(\sim 100 \mathrm{pA})$.

Para o transistor FD SOI nMOSFET há uma relação entre toxF, a espessura final de silício sobre isolante $\left(t_{s i}\right)$, a concentração de dopantes $\left(N_{A}\right)$ e a tensão de limiar $\left(\mathrm{V}_{\mathrm{TH}}\right)$ desejada. Portanto não se pode projetar toxf somente em função da corrente de fuga pelo óxido de porta. É necessário relacionar estas variáveis.

É bem conhecido que ao oxidar o silício, há uma diminuição da espessura da camada de silício; e que da espessura final de óxido crescido, cerca de $44 \%$ é a espessura do silício consumido [19].

Neste processo serão feitas duas oxidações, uma antes da implantação de boro (implantação esta que deverá ajustar a tensão de limiar), e outra oxidação que irá formar o isolante de porta. As duas oxidações usarão exatamente o mesmo procedimento, ou seja, é possível estabelecer uma relação entre a espessura do toxf e tsi, como mostra a equação (3.1).

$$
t_{S i}=t_{\text {Si_inicial }}-2 \cdot\left(0.44 \cdot t_{\text {OXF }}\right)
$$


Ainda é necessário considerar variáveis como $\mathrm{N}_{\mathrm{A}}, \mathrm{Xd}_{\mathrm{Máx}}$ e $\mathrm{V}_{\mathrm{TH}}$. Usando a equação (2.1) é possível calcular X $d_{\text {Máx }}$ em função de $N_{A}$, considerando $N_{A}$ constante ao longo do canal. E neste caso, também é possível calcular a tensão de limiar com a segunda interface em depleção ( $\left.\mathrm{V}_{\text {TH1,DEP2 }}\right)$ em função de $\mathrm{N}_{\mathrm{A}}$, para determinadas espessuras toxF e $t_{\mathrm{Si}}$. Deste modo podemos traçar um gráfico que relaciona todas estas variáveis, e estudar toxf e tsi são mais adequados, observe as curvas da Figura 33.

Figura 33 - Curvas de projeto de toxf e tsi. Nestas curvas são estudadas três possíveis toxf (30, 50 e $70 \mathrm{~nm}$ ). E conclui-se que para toxf $=30 \mathrm{~nm}$ não é possível ajustar a tensão de limiar $\left(\mathrm{V}_{\mathrm{TH}}=1 \mathrm{~V}\right)$ e construir um dispositivo totalmente depletado ao mesmo tempo.

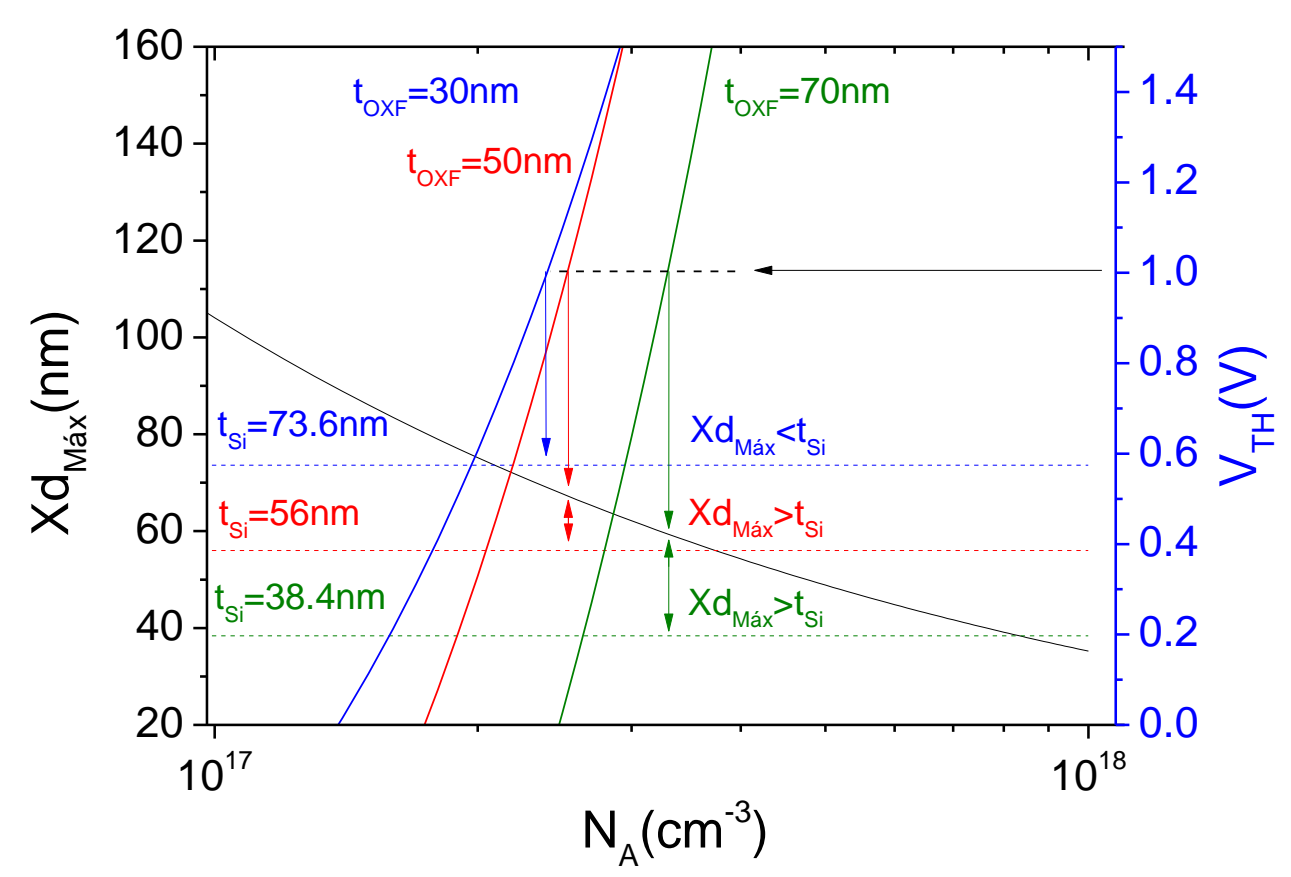

Fonte: Autor.

Analisando as curvas fica claro que a espessura do óxido não pode ser 30 nm, pois neste caso não é possível obter um dispositivo nas condições desejadas. É necessário um toxF maior, e possivelmente entre 50 e $70 \mathrm{~nm}$.

Considerando a necessidade de minimizar a resistência das regiões de fonte e dreno, é desejável obter os transistores FD SOI com a maior espessura tsi possível. Neste caso, a escolha lógica consiste em toxf $=50 \mathrm{~nm}$ e tsi= $56 \mathrm{~nm}$. 


\subsubsection{Ajuste da Tensão de Limiar}

As tensões de limiar de transistores nMOSFET são tipicamente iguais a $0,2 x V_{\mathrm{DD}}$ [20]. Como serão construídos transistores de grandes dimensões adotou-se $\mathrm{V}_{\mathrm{DD}}=5 \mathrm{~V}$ e portanto é desejável obter uma tensão de limiar de aproximadamente $1 \mathrm{~V}$.

Entretanto, é conhecido da equação (2.5) que a tensão de faixa plana $\left(\mathrm{V}_{\mathrm{FB}}\right.$ ) depende da densidade de cargas efetivas no óxido de porta (Qox1). E este parâmetro tecnológico pode variar entre um processo e outro. Por sua vez, a tensão de limiar $\left(\mathrm{V}_{\mathrm{TH}}\right)$ é dependente da tensão de faixa plana $\left(\mathrm{V}_{\mathrm{FB}}\right)$.

No processo do transistor nMOSFET convencional o valor de densidade de cargas efetivas no óxido é da ordem de $4.5 \times 10^{11} \mathrm{~cm}^{-2}$.

Este valor será adotado como referência nas simulações para obter dois valores de tensão de limiar. Um valor um pouco abaixo de $1 \mathrm{~V}$ e um valor um pouco acima de $1 \mathrm{~V}$, de modo a garantir que ainda que o valor de Qox1 varie ligeiramente, algum dos transistores terá valor de $\mathrm{V}_{\mathrm{TH}}$ próximo ao projetado.

Através das simulações, cujos arquivos de simulação podem ser vistos nos anexos $A$ e $B$, determinaram-se duas doses para a implantação iônica da etapa 3. A primeira dose $\left(1,0 \times 10^{13} \mathrm{~cm}^{-2}\right)$ nos leva a uma tensão de limiar de 0,68 V. Na Figura 34 observam-se os gráficos das simulações realizadas para esta dose. No item a) vê-se a variação da corrente de dreno em função da tensão de porta, para um transistor de comprimento $L=5 \mu \mathrm{m}$ e $W=1 \mu \mathrm{m}$. $O$ item b) mostra a segunda derivada da corrente de dreno em função da tensão de porta, para o transistor de mesmas dimensões. Neste caso, o valor máximo da função permite identificar a tensão de limiar $\left(\mathrm{V}_{\mathrm{TH}}\right)$ do transistor.

As simulações para determinação de $\mathrm{V}_{\mathrm{TH}}$ estão admitindo tensão de substrato (back gate) igual à zero $\left(\mathrm{V}_{\mathrm{GB}}=0 \mathrm{~V}\right)$.

A segunda dose $\left(1,2 \times 10^{13} \mathrm{~cm}^{-2}\right)$ nos leva a uma tensão de limiar de 1,26V. $\mathrm{Na}$ Figura 35 observam-se os gráficos das simulações realizadas para esta dose. No item a) vê-se a variação da corrente de dreno em função da tensão 
de porta, para um transistor de comprimento $L=5 \mu \mathrm{m}$ e $\mathrm{W}=1 \mu \mathrm{m}$. $\mathrm{O}$ item b) mostra a segunda derivada da corrente de dreno em função da tensão de porta, para o transistor de mesmas dimensões.

Figura 34 - a) Gráfico da corrente de dreno (IDS) por unidade de largura do transistor FD SOI nMOSFET e, b) Gráfico da segunda derivada de IDs em função de VGs. Este é um resultado das simulações, considerando dose de $1,0 \times 10^{13} \mathrm{~cm}^{-2}$. Este transistor tem comprimento $\mathrm{L}=5 \mu \mathrm{m}$.

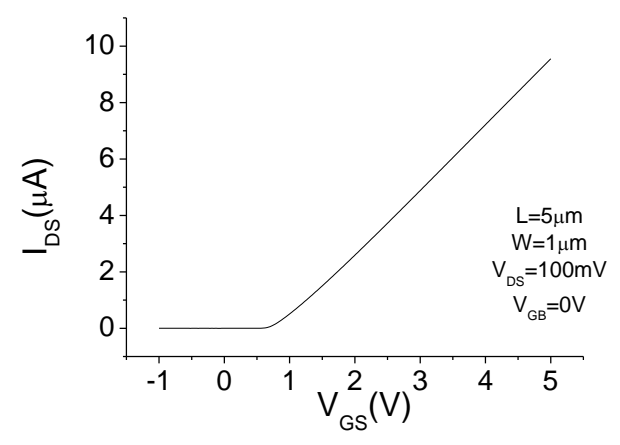

a)

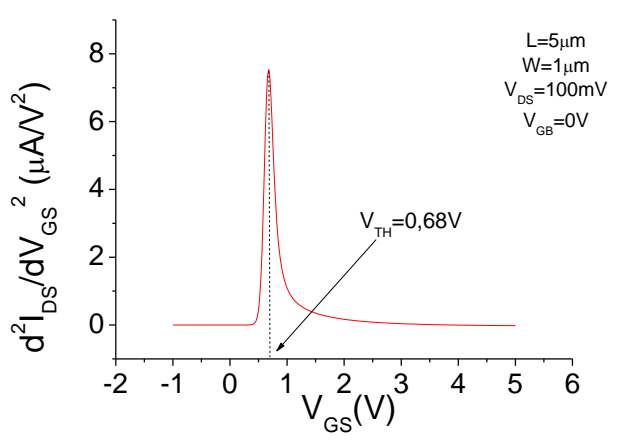

b)

Fonte: Autor.

Deste modo há dois tipos de dispositivos sendo construídos simultaneamente, um em que a implantação iônica de ajuste da tensão de limiar terá dose de $1,0 \times 10^{13} \mathrm{~cm}^{-2}$ e outro em que a dose será $1,2 \times 10^{13} \mathrm{~cm}^{-2}$.

Figura 35 - a) Gráfico da corrente de dreno (IDS) por unidade de largura do transistor FD SOI nMOSFET e, b) Gráfico da segunda derivada de IDs em função de VGs. Este é um resultado das simulações, considerando dose de $1,2 \times 10^{13} \mathrm{~cm}^{-2}$. Este transistor tem comprimento $\mathrm{L}=5 \mu \mathrm{m}$.

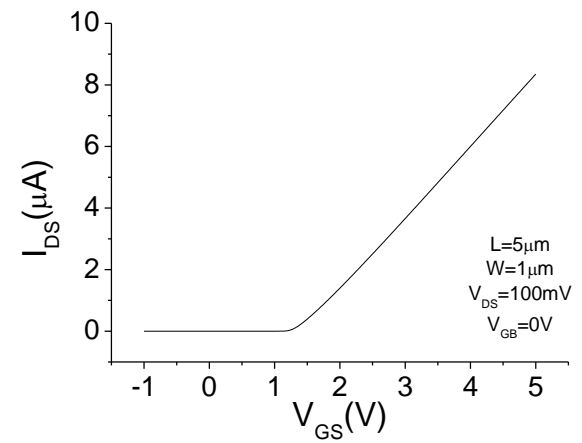

a)

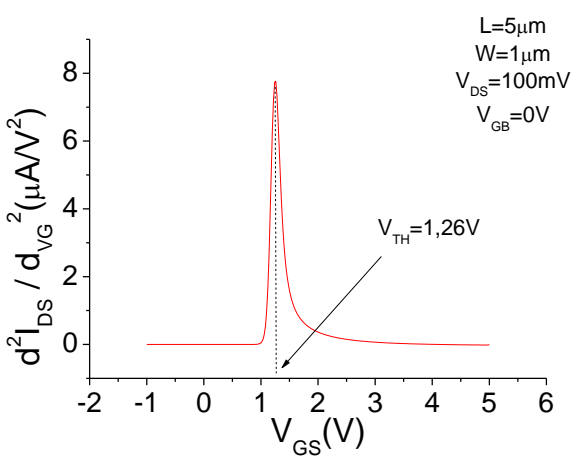

b)

Fonte: Autor. 


\subsubsection{Inclinação de sublimiar (S)}

Como foi discutido na seção 2.8 a inclinação de sublimiar é um parâmetro importante de transistores MOS. Os transistores FD SOI apresentam inclinação de sublimiar menor quando comparado a transistores PD SOI, ou convencionais (bulk) [10]. Portanto, a inclinação de sublimiar constitui uma das principais vantagens da tecnologia FD SOI.

As simulações realizadas permitem obter uma estimativa da inclinação de sublimiar. Os dados da simulação podem diferir dos valores experimentais em função das capacitâncias de interface $\left(\mathrm{C}_{\text {itt }}\right)$. Os dados obtidos da simulação supõem que estas sejam desprezíveis, o que pode não acontecer no experimento. $O$ gráfico da Figura 36 mostra a inclinação de sublimiar, obtida através de simulação, para as duas doses de implantação iônica.

Os valores de inclinação de sublimiar obtido para os dois processos é $73 \mathrm{mV} / \mathrm{dec}$. Este valor considera desprezíveis as capacitâncias de interface $\left(\mathrm{C}_{\text {itt }}\right)$ e, portanto, o valor obtido experimentalmente pode ser um pouco maior.

Figura 36 - Curva IDXVGS obtida através de simulação numérica, onde está destacada a inclinação de sublimiar para as duas doses de implantação iônica de boro.

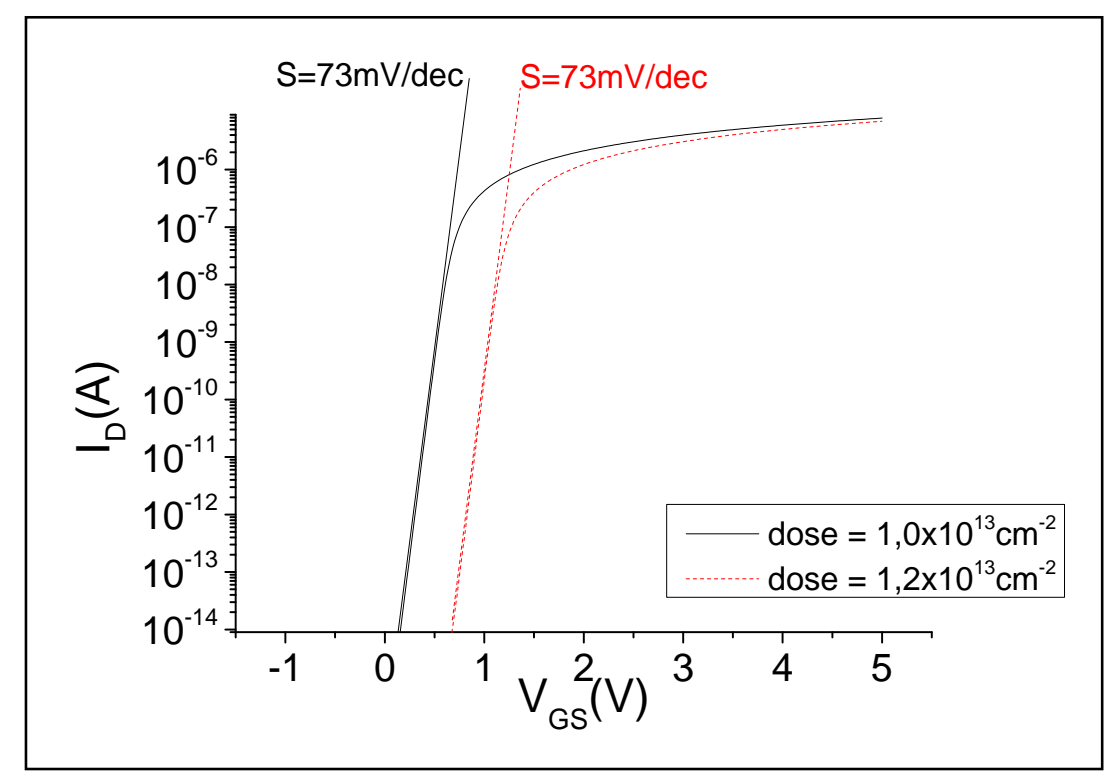

Fonte: Autor. 


\section{PROCEDIMENTO EXPERIMENTAL.}

Neste capítulo será apresentado o desenvolvimento das etapas de processo necessárias à execução dos transistores FD SOI nMOSFET tal como projetado no capítulo anterior.

\subsection{Desenvolvimento do uso do Fotorresiste AZ5214E.}

O fotorresiste AZ5214E é especialmente destinado a técnicas de "lift-off" que exigem uma parede com perfil negativo. Embora seja um FR positivo é capaz de realizar inversão da imagem, devido a sua composição [35].

A capacidade de inversão da imagem é obtida por um agente de reticulação especial na formulação do resiste que se torna ativo em temperaturas acima de $110^{\circ} \mathrm{C}$ e - o que é ainda mais importante - só em áreas expostas à luz ultravioleta [35].

O agente de reticulação exposto à luz ultravioleta em conjunto com o recozimento de inversão conduz a um produto quase insolúvel no revelador e nenhuma substância sensível à luz, enquanto as áreas não expostas ainda se comportam como um fotorresiste positivo normal não exposto. Após uma exposição de inundação (sem necessidade de máscara) as áreas que não sofreram a primeira exposição UV são dissolvidos em revelador padrão para fotorresiste positivo, as áreas reticuladas permanecem. O resultado global é uma imagem negativa do padrão de máscara [35].

Deste modo a fotolitografia de inversão, que permitirá construir os dispositivos SOI usando as mesmas máscaras usadas para o processo educacional PSI2643 (nMOSFET convencional), apresentou bons resultados com os seguintes passos:

$\checkmark$ Deposição: 3500 rpm por 40 seg; 
$\checkmark$ Pré-cura(hot plate): $110^{\circ} \mathrm{C}$ por 50 seg;

$\checkmark$ 1aㅡ Exposição (com máscara): 3 seg;

$\checkmark$ Reversal Bake: $110^{\circ} \mathrm{C}$ por $2 \mathrm{~min}$;

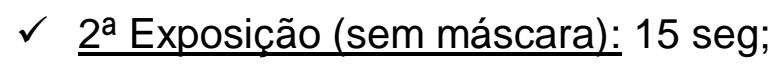

$\checkmark$ Revelação (MIF300 puro): 50 seg;

$\checkmark$ Pós-cura (hot plate): $110^{\circ} \mathrm{C}$ por $2 \mathrm{~min}$;

\subsection{Fabricação}

À seguir será descrita a sequência de fabricação, de forma detalhada, para a primeira rodada de amostras, apresentando ao mesmo tempo os resultados de medidas de acompanhamento realizadas.

1) Limpeza Química Completa:

A limpeza é descrita na tabela 1 . Em relação à limpeza química tradicionalmente usada para processos convencionais, como o PSI 2643, foi suprimida a etapa da solução piranha $\left(\mathrm{H}_{2} \mathrm{SO}_{4}+\mathrm{H}_{2} \mathrm{O}_{2}\right)$ e também se reduziu a concentração de hidróxido de amônia na solução, as duas alterações visam diminuir a rugosidade superficial após a limpeza [36]. Todos os produtos utilizados possuem grau de pureza MOS.

Tabela 1 - Sequência de soluções químicas utilizadas na limpeza completa.

\begin{tabular}{ccc}
\hline Solução & Temperatura & Tempo \\
\hline Água DI & Temp. Ambiente & $5 \mathrm{~min}$ \\
$8 \mathrm{H}_{2} \mathrm{O}+2 \mathrm{H}_{2} \mathrm{O}_{2}+1 \mathrm{NH}_{4} \mathrm{OH}$ & $80^{\circ} \mathrm{C}$ & $10 \mathrm{~min}$ \\
Água DI & Temp. Ambiente & $5 \mathrm{~min}$ \\
$4 \mathrm{H}_{2} \mathrm{O}+1 \mathrm{HCl}$ & $80^{\circ} \mathrm{C}$ & $10 \mathrm{~min}$ \\
Água DI & Temp. Ambiente & $5 \mathrm{~min}$ \\
$100 \mathrm{H}_{2} \mathrm{O}+1 \mathrm{HF}$ & Temp. Ambiente & $80 \mathrm{seg}$ \\
Água DI & Temp. Ambiente & $5 \mathrm{~min}$ \\
\hline
\end{tabular}


2) Oxidação térmica seca:

A oxidação sempre é realizada imediatamente após a limpeza química completa, para minimizar as cargas no óxido.

Tabela 2 - Sequência de procedimentos para a oxidação.

\begin{tabular}{cccc}
\hline Etapa & Temperatura & Tempo & Fluxo de Gases \\
\hline Inserção das amostras no forno & $\sim 100^{\circ} \mathrm{C} / \mathrm{min}$ & $10 \mathrm{~min}$ & 2,4 litros $/ \mathrm{min}_{2}$ \\
Oxidação & $1000^{\circ} \mathrm{C}$ & $60 \mathrm{~min}$ & 2,0 litros $/ \mathrm{min}_{2}$ \\
Remoção das amostras do forno & $\sim-100^{\circ} \mathrm{C} / \mathrm{min}$ & $10 \mathrm{~min}$ & 2,4 litros $/ \mathrm{min}_{2}$ \\
\hline
\end{tabular}

A etapa de oxidação sofreu caracterização de espessura e índice de refração através de medidas de elipsometria. A medida foi realizada com comprimento de onda de $632,8 \mathrm{~nm}$. Os resultados obtidos são espessura média de $(48 \pm 9)$ nm e índice de refração $(1,454 \pm 0,005)$.

3) Implantação lônica de Boro:

A implantação iônica de boro para ajuste da tensão de limiar foi realizada com os seguintes parâmetros:

Tabela 3 - Parâmetros da implantação iônica.

\begin{tabular}{cccc}
\hline Lâmina & Elemento & Dose & Energia \\
\hline$L 29$ & $B$ & $1,0 \times 10^{13} \mathrm{~cm}^{-2}$ & $30 \mathrm{keV}$ \\
$L 30$ & $B$ & $1,0 \times 10^{13} \mathrm{~cm}^{-2}$ & $30 \mathrm{keV}$ \\
$L 31$ & $B$ & $1,2 \times 10^{13} \mathrm{~cm}^{-2}$ & $30 \mathrm{keV}$ \\
$L 32$ & $B$ & $1,2 \times 10^{13} \mathrm{~cm}^{-2}$ & $30 \mathrm{keV}$ \\
\hline
\end{tabular}

4) Ativação de dopantes:

O processo de ativação de dopantes foi realizado do seguinte modo:

Tabela 4 - Parâmetros do processo de ativação de dopantes.

\begin{tabular}{cccc}
\hline Etapa & Temperatura & Tempo & Fluxo de Gases \\
\hline Inserção das amostras no forno & $\sim 90^{\circ} \mathrm{C} / \mathrm{min}$ & $10 \mathrm{~min}$ & 2,4 litros $/ \mathrm{min}_{2}$ \\
Recozimento & $900^{\circ} \mathrm{C}$ & $30 \mathrm{~min}$ & 2,0 litros $/ \mathrm{min}_{2}$ \\
$\begin{array}{c}\text { Remoção das amostras do } \\
\text { forno }\end{array}$ & $\sim-90^{\circ} \mathrm{C} / \mathrm{min}$ & $10 \mathrm{~min}$ & 2,4 litros $/ \mathrm{min} \mathrm{N}_{2}$ \\
\hline
\end{tabular}


5) Fotogravação 1 (inversão da máscara):

A fotogravação 1 é realizada com o fotorresiste AZ5214E e usa o processo descrito na seção 4.1 .

6) Corrosão por plasma do Si sobre isolante:

Gás: SF6 Fluxo: 26 SCCM Pressão: 68 mtorr Potência 100 W

Tempo: $20 \mathrm{~s}$

DCBIAS: $-141 \mathrm{~V}$

7) Limpeza Química Completa:

Tabela 5 - Sequência de soluções químicas utilizadas na limpeza completa.

\begin{tabular}{ccc}
\hline$\underline{\text { Solução }}$ & $\underline{\text { Temperatura }}$ & $\underline{\text { Tempo }}$ \\
\hline Água DI & Temp. Ambiente & $5 \mathrm{~min}$ \\
$8 \mathrm{H}_{2} \mathrm{O}+2 \mathrm{H}_{2} \mathrm{O}_{2}+1 \mathrm{NH}_{4} \mathrm{OH}$ & $80^{\circ} \mathrm{C}$ & $10 \mathrm{~min}$ \\
Água DI & Temp. Ambiente & $5 \mathrm{~min}$ \\
$4 \mathrm{H}_{2} \mathrm{O}+1 \mathrm{HCl}$ & $80^{\circ} \mathrm{C}$ & $10 \mathrm{~min}$ \\
Água DI & Temp. Ambiente & $5 \mathrm{~min}$ \\
$100 \mathrm{H}_{2} \mathrm{O}+1 \mathrm{HF}$ & Temp. Ambiente & $80 \mathrm{seg}$ \\
Água DI & Temp. Ambiente & $5 \mathrm{~min}$ \\
\hline
\end{tabular}

8) Oxidação térmica seca (formação do dielétrico de porta):

A oxidação para formação do óxido de porta segue os parâmetros descritos a seguir, na tabela 6 .

Tabela 6 - Procedimentos para a oxidação que forma o isolante de porta.

\begin{tabular}{cccc}
\hline Etapa & Temperatura & $\underline{\text { Tempo }}$ & Fluxo de Gases \\
\hline Inserção das amostras no forno & $\sim 100^{\circ} \mathrm{C} / \mathrm{min}$ & $10 \mathrm{~min}$ & 2,4 litros $/ \mathrm{min}_{2}$ \\
Oxidação & $1000^{\circ} \mathrm{C}$ & $60 \mathrm{~min}$ & 2,0 litros $/ \mathrm{min} \mathrm{O}_{2}$ \\
Remoção das amostras do forno & $\sim-100^{\circ} \mathrm{C} / \mathrm{min}$ & $10 \mathrm{~min}$ & 2,4 litros $/ \mathrm{min}_{2}$ \\
\hline
\end{tabular}

Usando o elipsômetro obteve-se espessura $(49 \pm 8) \mathrm{nm}$ e o índice de refração foi fixado em 1,462. 
9) Deposição de silício policristalino:

O Si-Poli foi depositado em um equipamento LPCVD, usando um cilindro de mistura gasosa contendo $97 \% \mathrm{He}$ e $3 \% \mathrm{SiH}_{4}$, com os parâmetros da Tabela 7. O filme de silício policristalino apresentou aspecto visual brilhante e espessura, medida por perfilometria, de $(431 \pm 9) \mathrm{nm}$.

Tabela 7 - Procedimentos para a deposição de silício policristalino depositado por técnica LPCVD.

\begin{tabular}{cccc}
\hline Temperatura do Forno & Pressão & Fluxo de Gases & Tempo \\
\hline $650^{\circ} \mathrm{C}$ & $680 \mathrm{mtorr}$ & $350 \mathrm{SCCM}$ & $45 \mathrm{~min}$ \\
\hline
\end{tabular}

10)Dopagem do silício policristalino:

O silício policristalino foi dopado por difusão, com temperatura do forno ajustada para $925^{\circ} \mathrm{C}$ e usando os parâmetros descritos na tabela 8 .

Tabela 8 - Procedimentos para a dopagem de silício policristalino.

\begin{tabular}{cccccc}
\hline Etapa & Entrada & Estabilização & Difusão de Dopantes & Densificação & Saída \\
Ambiente & $\mathrm{N}_{2}$ & $\mathrm{~N}_{2}$ & $\mathrm{~N}_{2}+\mathrm{O}_{2}+\mathrm{POCl}_{3}$ & $\mathrm{~N}_{2}$ & $\mathrm{~N}_{2}$ \\
Fluxo (I/min) & 0,9 & 0,9 & $\mathrm{O}_{2}=0,06 \mathrm{e}$ & 0,9 & 0,9 \\
Tempo (min) & 5 & 5 & $\mathrm{~N}_{2}+\mathrm{POCl}_{3}=0,02$ & 5 & 5 \\
\hline
\end{tabular}

11)Fotogravação 2 (definição do silício policristalino):

A fotogravação 2 é realizada com o fotorresiste AZ1518 e usa o processo descrito a seguir [37]:

$\checkmark$ Deposição: 3500 rpm por 40 seg;

$\checkmark$ Pré-cura (hot plate): $100^{\circ} \mathrm{C}$ por $50 \mathrm{seg}$;

$\checkmark$ 1를 Exposição (com máscara): $15 \mathrm{seg}$;

$\checkmark$ Revelação (MIF300 diluído em áqua 4:1): 40 seg;

$\checkmark$ Pós-cura (hot plate): $115^{\circ} \mathrm{C}$ por $2 \mathrm{~min}$;

A solução de corrosão do silício policristalino é:

$50 \mathrm{HNO}_{3}+20 \mathrm{H}_{2} \mathrm{O}+1 \mathrm{BOE}$.

Tempo de corrosão: 50 seg. 
12) Implantação lônica (formação de fonte/dreno):

Tabela 9 - Parâmetros da implantação iônica.

\begin{tabular}{cccc}
\hline Lâmina & Elemento & Dose & Energia \\
\hline$L 29$ & $P$ & $5,0 \times 10^{15} \mathrm{~cm}^{-2}$ & $40 \mathrm{keV}$ \\
$L 30$ & $P$ & $5,0 \times 10^{15} \mathrm{~cm}^{-2}$ & $40 \mathrm{keV}$ \\
$L 31$ & $P$ & $5,0 \times 10^{15} \mathrm{~cm}^{-2}$ & $40 \mathrm{keV}$ \\
$L 32$ & $P$ & $5,0 \times 10^{15} \mathrm{~cm}^{-2}$ & $40 \mathrm{keV}$ \\
\hline
\end{tabular}

13)Ativação de Dopantes:

O processo de ativação de dopantes foi realizado do seguinte modo:

Tabela 10 - Parâmetros do processo de ativação de dopantes.

\begin{tabular}{cccc}
\hline Etapa & Temperatura & Tempo & Fluxo de Gases \\
\hline $\begin{array}{c}\text { Inserção das amostras no forno } \\
\text { Recozimento }\end{array}$ & $\sim 90^{\circ} \mathrm{C} / \mathrm{min}$ & $10 \mathrm{~min}$ & 2,4 litros $/ \mathrm{min} \mathrm{N}_{2}$ \\
$\begin{array}{c}\text { Remoção das amostras do } \\
\text { forno }\end{array}$ & $900^{\circ} \mathrm{C}$ & $30 \mathrm{~min}$ & 2,0 litros $/ \mathrm{min} \mathrm{N}_{2}$ \\
\hline
\end{tabular}

14)Deposição de Óxido PECVD:

Tabela 11 - Parâmetros de deposição de óxido PECVD.

\begin{tabular}{cccccc}
\hline $\begin{array}{c}\text { Temperatura do } \\
\text { Substrato }\end{array}$ & Pressão & $\frac{\text { Fluxo de }}{\underline{\mathbf{O}}_{2}}$ & $\frac{\text { Fluxo de }}{\text { PEOS }}$ & Potência & Tempo \\
\hline $100^{\circ} \mathrm{C}$ & $200 \mathrm{mtorr}$ & $75 \mathrm{SCCM}$ & $3 \mathrm{SCCM}$ & $200 \mathrm{~W}$ & $35 \mathrm{~min}$ \\
\hline
\end{tabular}

Usando o perfilômetro obteve-se espessura $(450 \pm 50) \mathrm{nm}$.

15)Fotogravação 3 (abertura de contatos):

A fotogravação 3 é realizada com o fotorresiste AZ1518 e usa o processo descrito a seguir [37]:

$\checkmark$ Deposição: 3500 rpm por 40 seg;

$\checkmark$ Pré-cura (hot plate): $100^{\circ} \mathrm{C}$ por $50 \mathrm{seg}$;

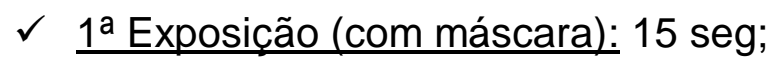

$\checkmark$ Revelação (MIF300 diluído em água 4:1): $40 \mathrm{seg}$;

$\checkmark$ Pós-cura (hot plate): $115^{\circ} \mathrm{C}$ por $2 \mathrm{~min}$; 
A solução de corrosão do óxido de silício: BOE.

Tempo de corrosão: 40 seg.

16)Deposição de Alumínio (evaporação):

Tabela 12 - Parâmetros de deposição do Alumínio.

\begin{tabular}{ccc}
\hline Material do Filamento & Pressão & Massa de Al \\
\hline W & $1 \times 10^{-5} \mathrm{mbar}$ & $190 \mathrm{mg}$ \\
\hline
\end{tabular}

Resistência de folha do alumínio depositado (medida 4 pontas):

$0,0504 \Omega$ /quadrado.

Espessura da camada de alumínio (medida por perfilometria):

$(570 \pm 60) \mathrm{nm}$.

17)Fotogravação 4 (Definição do Alumínio):

A fotogravação 4 é realizada com o fotorresiste AZ1518 e usa o processo descrito a seguir [37]. Basicamente é a mesma receita de fotogravação que utilizamos nas etapas anteriores, exceto pela exposição que é por um tempo um pouco menor:

$\checkmark$ Deposição: 3500 rpm por 40 seg;

$\checkmark$ Pré-cura (hot plate): $100^{\circ} \mathrm{C}$ por $50 \mathrm{seg}$;

$\checkmark \quad 1$ ax Exposição (com máscara): $10 \mathrm{seg}$;

$\checkmark$ Revelação (MIF300 diluído em água 4:1): 40 seg;

$\checkmark$ Pós-cura (hot plate): $115^{\circ} \mathrm{C}$ por $2 \mathrm{~min}$;

A solução de corrosão do alumínio é:

$175 \mathrm{H}_{3} \mathrm{PO}_{4}+70 \mathrm{H} 2 \mathrm{O}+15 \mathrm{HNO}_{3}$ aquecida a $40^{\circ} \mathrm{C}$.

Tempo de corrosão: 3 min.

18)Corrosão de $\mathrm{SiO}_{2}$ e deposição de $\mathrm{Al}$ no verso da lâmina: 
A parte frontal da lâmina foi protegida por uma camada de AZ1518 e a lâmina foi imersa em solução de corrosão de $\mathrm{SiO}_{2}(\mathrm{BOE})$ até que a superfície tornar-se hidrofóbica.

Posteriormente procedeu-se a remoção do AZ1518 por solução aquecida de acetona e isopropanol. E então a amostra foi encaminhada para a evaporação de alumínio.

A evaporação térmica de alumínio foi realizada com os parâmetros:

Tabela 13 - Parâmetros de deposição do Alumínio no verso da lâmina.

\begin{tabular}{ccc}
\hline Material do Filamento & Pressão & Massa de Al \\
\hline W & $1 \times 10^{-5} \mathrm{mbar}$ & $170 \mathrm{mg}$ \\
\hline
\end{tabular}

Espessura da camada de alumínio (medida por perfilometria):

$(510 \pm 50) \mathrm{nm}$.

Neste ponto do processo optou-se por iniciar algumas medidas elétricas na amostra, antes da sinterização do alumínio.

Posteriormente verificou-se que este processo não atingiu os objetivos desejados, como será discutido na seção 5.1, e a sinterização foi realizada com o objetivo de solucionar parte dos problema verificados.

Foram realizadas as medidas elétricas e outras considerações, baseadas principalmente em simulações, para que as causas dos problemas na primeira rodada de fabricação fossem identificadas e corrigidas numa segunda rodada.

Para a segunda rodada de fabricação decidiu-se excluir a etapa de deposição de óxido PECVD, por considerar esta etapa crítica e perceber a possibilidade de simplificar ainda mais o processo. Ao excluir esta etapa podese suprimir também a etapa de litografia para abertura de contatos. Por outro lado, a perda de performance dos dispositivos pode ser considerada pequena, tendo em vista sua aplicação educacional. A perda de performance está relacionada ao aumento da capacitância entre os terminais de contato e o substrato.

A seguir será descrita a sequência de fabricação realizada, para a segunda rodada de amostras, apresentando ao mesmo tempo os resultados de medidas de acompanhamento realizadas. 
1) Limpeza Química Completa:

Tabela 14 - Sequência de soluções químicas utilizadas na limpeza completa.

\begin{tabular}{ccc}
\hline$\underline{\text { Solução }}$ & $\underline{\text { Temperatura }}$ & $\underline{\text { Tempo }}$ \\
\hline Água DI & Temp. Ambiente & $5 \mathrm{~min}$ \\
$8 \mathrm{H}_{2} \mathrm{O}+2 \mathrm{H}_{2} \mathrm{O}_{2}+1 \mathrm{NH}_{4} \mathrm{OH}$ & $80^{\circ} \mathrm{C}$ & $10 \mathrm{~min}$ \\
Água DI & Temp. Ambiente & $5 \mathrm{~min}$ \\
$4 \mathrm{H}_{2} \mathrm{O}+1 \mathrm{HCl}$ & $80^{\circ} \mathrm{C}$ & $10 \mathrm{~min}$ \\
Água DI & Temp. Ambiente & $5 \mathrm{~min}$ \\
$100 \mathrm{H}_{2} \mathrm{O}+1 \mathrm{HF}$ & Temp. Ambiente & $80 \mathrm{seg}$ \\
Água DI & Temp. Ambiente & $5 \mathrm{~min}$ \\
\hline
\end{tabular}

2) Oxidação térmica seca:

A oxidação sempre é realizada imediatamente após a limpeza química completa, para minimizar as cargas no óxido.

Tabela 15 - Sequência de procedimentos para a oxidação.

\begin{tabular}{cccc}
\hline Etapa & Temperatura & Tempo & Fluxo de Gases \\
\hline $\begin{array}{c}\text { Inserção das amostras no forno } \\
\text { Oxidação }\end{array}$ & $\sim 100^{\circ} \mathrm{C} / \mathrm{min}$ & $10 \mathrm{~min}$ & 2,4 litros $/ \mathrm{min}_{2}$ \\
$\begin{array}{c}1000^{\circ} \mathrm{C} \\
\begin{array}{c}\text { Remoção das amostras do } \\
\text { forno }\end{array}\end{array}$ & $\sim-100^{\circ} \mathrm{C} / \mathrm{min}$ & $10 \mathrm{~min}$ & 2,0 litros $/ \mathrm{min} \mathrm{O}_{2}$ \\
\hline
\end{tabular}

A etapa de oxidação sofreu caracterização de espessura e índice de refração através de medidas de elipsometria. A medida foi realizada com comprimento de onda de $632,8 \mathrm{~nm}$. Os resultados obtidos são espessura média de $(47 \pm 6)$ nm e índice de refração $(1,459 \pm 0,004)$.

3) Implantação lônica de Boro:

A implantação iônica de boro para ajuste da tensão de limiar foi realizada com os seguintes parâmetros: 
Tabela 16 - Parâmetros da implantação iônica.

\begin{tabular}{cccc}
\hline Lâmina & Elemento & Dose & Energia \\
\hline$L 41$ & $B$ & $1,0 \times 10^{13} \mathrm{~cm}^{-2}$ & $30 \mathrm{keV}$ \\
$L 42$ & $B$ & $1,2 \times 10^{13} \mathrm{~cm}^{-2}$ & $30 \mathrm{keV}$ \\
\hline
\end{tabular}

4) Ativação de dopantes:

O processo de ativação de dopantes foi realizado do seguinte modo:

Tabela 17 - Parâmetros do processo de ativação de dopantes.

\begin{tabular}{cccc}
\hline Etapa & Temperatura & Tempo & Fluxo de Gases \\
\hline Inserção das amostras no forno & $\sim 90^{\circ} \mathrm{C} / \mathrm{min}$ & $10 \mathrm{~min}$ & 2,4 litros $/ \mathrm{min} \mathrm{N}_{2}$ \\
Recozimento & $900^{\circ} \mathrm{C}$ & $30 \mathrm{~min}$ & 2,0 litros $/ \mathrm{min} \mathrm{N}_{2}$ \\
$\begin{array}{c}\text { Remoção das amostras do } \\
\text { forno }\end{array}$ & $\sim-90^{\circ} \mathrm{C} / \mathrm{min}$ & $10 \mathrm{~min}$ & $2,4 \mathrm{litros} / \mathrm{min} \mathrm{N}_{2}$ \\
\hline
\end{tabular}

5) Fotogravação 1 (inversão da máscara):

A $1^{\text {a }}$ fotogravação é realizada com o AZ5214E e usa o processo descrito na seção 4.1 .

6) Corrosão por plasma do Si sobre isolante:

Gás: SF 6 Fluxo: 26 SCCM Pressão: 68 mtorr Potência $100 \mathrm{~W}$

Tempo: $20 \mathrm{~s}$

DCBIAS: $-143 \mathrm{~V}$

Após a corrosão foram feitas algumas imagens das amostras no microscópio ótico. A Figura 37 à seguir mostra algumas destas imagens. 
Figura 37 - Imagens no microscópio ótico após 1a litografia. a) Transistor T3, b) Cascata de transistores TNL1, c) Marca de alinhamento, e; d) Inversores.

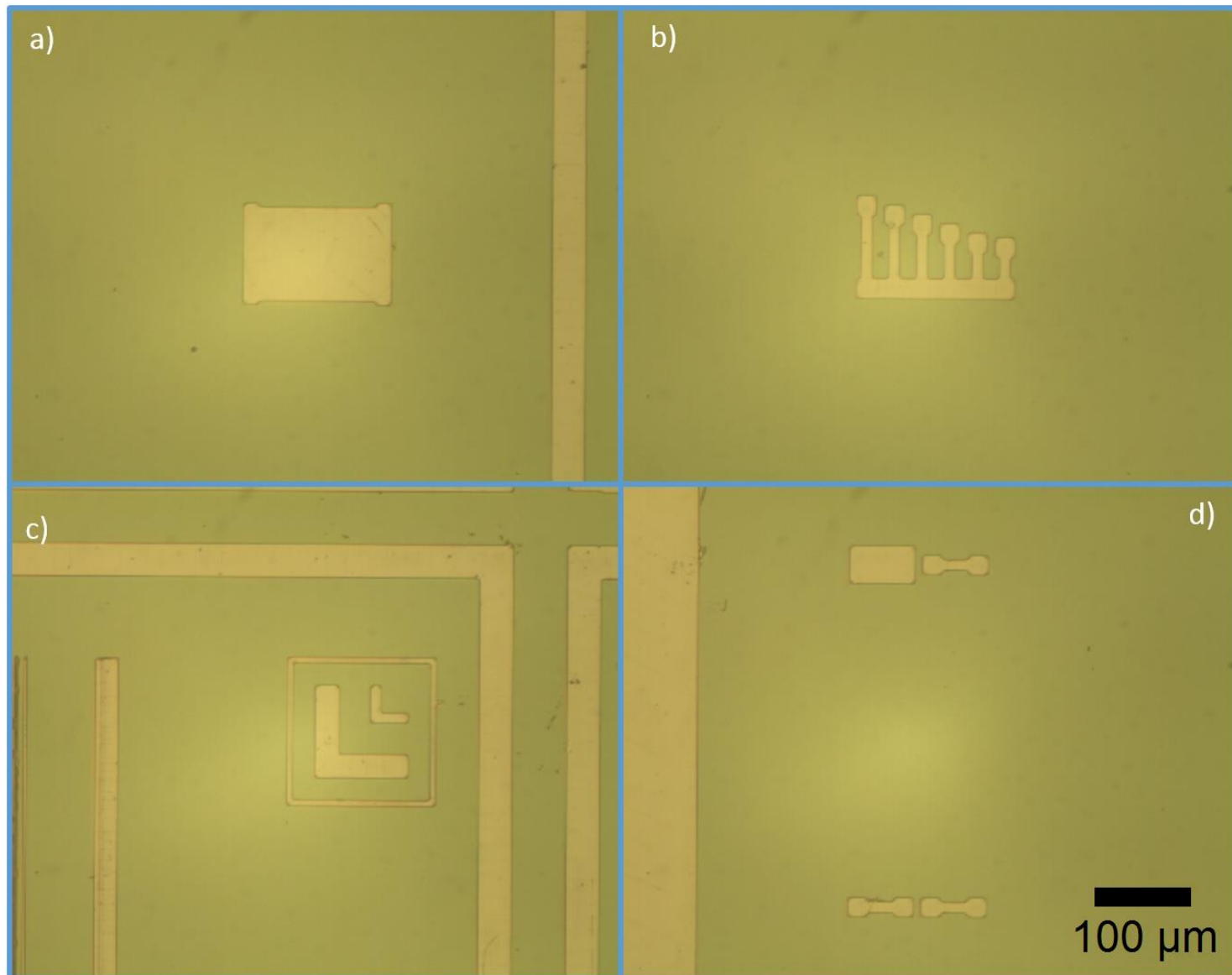

Fonte: Autor.

7) Limpeza Química Completa:

Tabela 18 - Sequência de soluções químicas utilizadas na limpeza completa.

\begin{tabular}{ccc}
\hline Solucão & Temperatura & Tempo \\
\hline Água DI & Temp. Ambiente & $5 \mathrm{~min}$ \\
$8 \mathrm{H}_{2} \mathrm{O}+2 \mathrm{H}_{2} \mathrm{O}_{2}+1 \mathrm{NH}_{4} \mathrm{OH}$ & $80^{\circ} \mathrm{C}$ & $10 \mathrm{~min}$ \\
Água DI & Temp. Ambiente & $5 \mathrm{~min}$ \\
$4 \mathrm{H}_{2} \mathrm{O}+1 \mathrm{HCl}$ & $80^{\circ} \mathrm{C}$ & $10 \mathrm{~min}$ \\
Água DI & Temp. Ambiente & $5 \mathrm{~min}$ \\
$100 \mathrm{H}_{2} \mathrm{O}+1 \mathrm{HF}$ & Temp. Ambiente & $80 \mathrm{seg}$ \\
Água DI & Temp. Ambiente & $5 \mathrm{~min}$ \\
\hline
\end{tabular}


8) Oxidação térmica seca (formação do dielétrico de porta):

A oxidação para formação do óxido de porta segue os parâmetros descritos a seguir, na Tabela 19.

Tabela 19 - Procedimentos para a oxidação que forma o isolante de porta.

\begin{tabular}{|c|c|c|c|}
\hline Etapa & Temperatura & Tempo & Fluxo de Gases \\
\hline Insercão das amostras no forno & $\sim 100^{\circ} \mathrm{C} / \mathrm{min}$ & $10 \min$ & 2,4 litros/min $N_{2}$ \\
\hline Oxidação & $1000^{\circ} \mathrm{C}$ & $60 \min$ & 2,0 litros $/ \mathrm{min} \mathrm{O}_{2}$ \\
\hline $\begin{array}{c}\text { Remoção das amostras do } \\
\text { forno }\end{array}$ & $\sim-100^{\circ} \mathrm{C} / \mathrm{min}$ & $10 \min$ & 2,4 litros/min $N_{2}$ \\
\hline
\end{tabular}

Usando o elipsômetro obtive-se espessura $(48 \pm 5) \mathrm{nm}$ e 0 índice de refração foi fixado em 1,462.

9) Deposição de silício policristalino:

O si-poli foi depositado em um equipamento LPCVD, usando um cilindro de mistura gasosa contendo $97 \% \mathrm{He}$ e $3 \% \mathrm{SiH}_{4}$, com os seguintes parâmetros:

Tabela 20 - Procedimentos para a deposição de Si-Poli depositado no LPCVD.

\begin{tabular}{ccccc}
\hline Temperatura do Forno & Pressão & Fluxo de SiH $_{4}$ & Fluxo de N $_{2}$ & $\underline{\text { Tempo }}$ \\
\hline $630^{\circ} \mathrm{C}$ & $500 \mathrm{mtorr}$ & $450 \mathrm{SCCM}$ & $204 \mathrm{SCCM}$ & $90 \mathrm{~min}$ \\
\hline
\end{tabular}

O filme de silício policristalino apresentou espessura, medida por perfilometria, de $(790 \pm 10) \mathrm{nm}$.

10)Dopagem do silício policristalino:

O silício policristalino foi dopado por difusão, com temperatura do forno ajustada para $925^{\circ} \mathrm{C}$ e usando os parâmetros descritos na Tabela 21 .

Tabela 21 - Procedimentos para a dopagem de silício policristalino.

\begin{tabular}{|c|c|c|c|c|c|}
\hline Etapa & ada & Estabilização & Difusão de Dopantes & Densificação & Saída \\
\hline Ambiente & $\mathrm{N}_{2}$ & $\mathrm{~N}_{2}$ & $\mathrm{~N}_{2}+\mathrm{O}_{2}+\mathrm{POCl}_{3}$ & $\mathrm{~N}_{2}$ & $\mathrm{~N}_{2}$ \\
\hline Fluxo(l/min) & 0,9 & 0,9 & $\begin{array}{c}\mathrm{O}_{2}=0,06 \mathrm{e} \\
\mathrm{N}_{2}+\mathrm{POCl}_{3}=0,02\end{array}$ & 0,9 & 0,9 \\
\hline Tempo(min) & 5 & 5 & 25 & 5 & 5 \\
\hline
\end{tabular}


11)Fotogravação 2 (definição do silício policristalino):

A fotogravação 2 usa o AZ1518 e os seguintes parâmetros [37]:

$\checkmark$ Deposição: 3500 rpm por 40 seg;

$\checkmark$ Pré-cura (hot plate): $100^{\circ} \mathrm{C}$ por $50 \mathrm{seg}$;

$\checkmark$ 1를 Exposição (com máscara): $15 \mathrm{seg}$;

$\checkmark$ Revelação (MIF300 diluído em água 4:1): 40 seg;

$\checkmark$ Pós-cura (hot plate): $115^{\circ} \mathrm{C}$ por $2 \mathrm{~min}$;

A solução de corrosão do silício policristalino é:

$50 \mathrm{HNO}_{3}+20 \mathrm{H}_{2} \mathrm{O}+1 \mathrm{BOE}$.

Tempo de corrosão: 50 seg.

Figura 38 - Imagens no microscópio ótico após $2^{2}$ etapa de litografia. a) Transistor isolado T3, b) Cascata de transistores TNL1, c) Marca de alinhamento, e; d) Inversores.

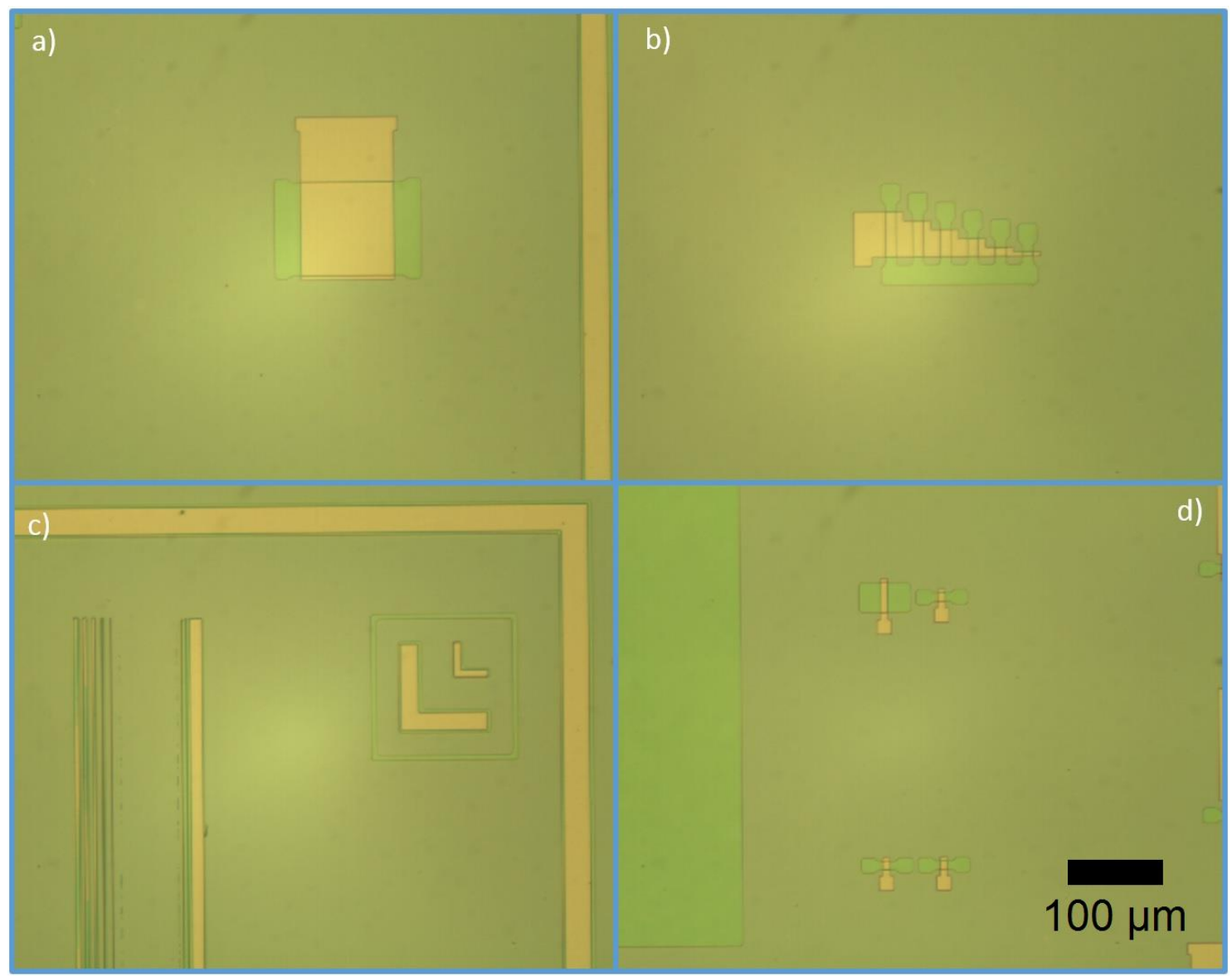

Fonte: Autor. 
A Figura 38 mostra imagens da amostra após a segunda fotogravação, corrosão do silício policristalino e remoção do fotorresiste. Comparando estas imagens com as imagens da Figura 37, observa-se o silício policristalino sobreposto à região ativa, formando a porta dos transistores.

12)Implantação lônica (formação de fonte/dreno):

Tabela 22 - Parâmetros da implantação iônica.

\begin{tabular}{cccc}
\hline Lâmina & Elemento & Dose & Energia \\
\hline$L 41$ & $P$ & $5,0 \times 10^{15} \mathrm{~cm}^{-2}$ & $40 \mathrm{keV}$ \\
$L 42$ & $P$ & $5,0 \times 10^{15} \mathrm{~cm}^{-2}$ & $40 \mathrm{keV}$ \\
\hline
\end{tabular}

13)Ativação de Dopantes:

O processo de ativação de dopantes foi realizado do seguinte modo:

Tabela 23 - Parâmetros do processo de ativação de dopantes.

\begin{tabular}{cccc}
\hline Etapa & Temperatura & $\underline{\text { Tempo }}$ & Fluxo de Gases \\
\hline Inserção das amostras no forno & $\sim 90^{\circ} \mathrm{C} / \mathrm{min}$ & $10 \mathrm{~min}$ & 2,4 litros $/ \mathrm{min}_{2}$ \\
Recozimento & $900^{\circ} \mathrm{C}$ & $30 \mathrm{~min}$ & 2,0 litros $/ \mathrm{min}_{2}$ \\
Remoção das amostras do forno & $\sim-90^{\circ} \mathrm{C} / \mathrm{min}$ & $10 \mathrm{~min}$ & 2,4 litros $/ \mathrm{min}_{2}$ \\
\hline
\end{tabular}

14)Corrosão do $\mathrm{SiO}_{2}$ sobre Fonte/Dreno:

A solução de corrosão do óxido de silício: BOE.

Tempo de corrosão: 40 seg.

15)Deposição de Alumínio (evaporação):

Tabela 24 - Parâmetros de deposição do Alumínio.

\begin{tabular}{ccc}
\hline Material do Filamento & Pressão & Massa de Al \\
\hline $\mathrm{W}$ & $2 \times 10^{-5} \mathrm{mbar}$ & $210 \mathrm{mg}$ \\
\hline
\end{tabular}

Resistência de folha do alumínio depositado (medida 4 pontas):

$0,0348 \Omega$ /quadrado.

Espessura de alumínio (medida por perfilometria): $(620 \pm 70) \mathrm{nm}$. 
16)Fotogravação 3 (Definição do Alumínio):

A fotogravação 3, basicamente, é a mesma receita utilizada anteriormente [37], exceto pelo tempo de exposição que é menor:

$\checkmark$ Deposição: 3500 rpm por 40 seg;

$\checkmark$ Pré-cura (hot plate): $100^{\circ} \mathrm{C}$ por $50 \mathrm{seg}$;

$\checkmark$ 1를 Exposição (com máscara): 10 seg;

$\checkmark$ Revelação (MIF300 diluído em água 4:1): 40 seg;

$\checkmark$ Pós-cura (hot plate): $115^{\circ} \mathrm{C}$ por $2 \mathrm{~min}$;

A solução de corrosão do alumínio é:

$175 \mathrm{H}_{3} \mathrm{PO}_{4}+70 \mathrm{H} 2 \mathrm{O}+15 \mathrm{HNO}_{3}$ aquecida a $40^{\circ} \mathrm{C}$.

Tempo de corrosão: 3 min.

Figura 39 - Imagens no microscópio ótico após $3^{3}$ etapa de litografia. a) Transistor isolado T3,

b) Cascata de transistores TNL1, c) Marca de alinhamento, e; d) Inversores.

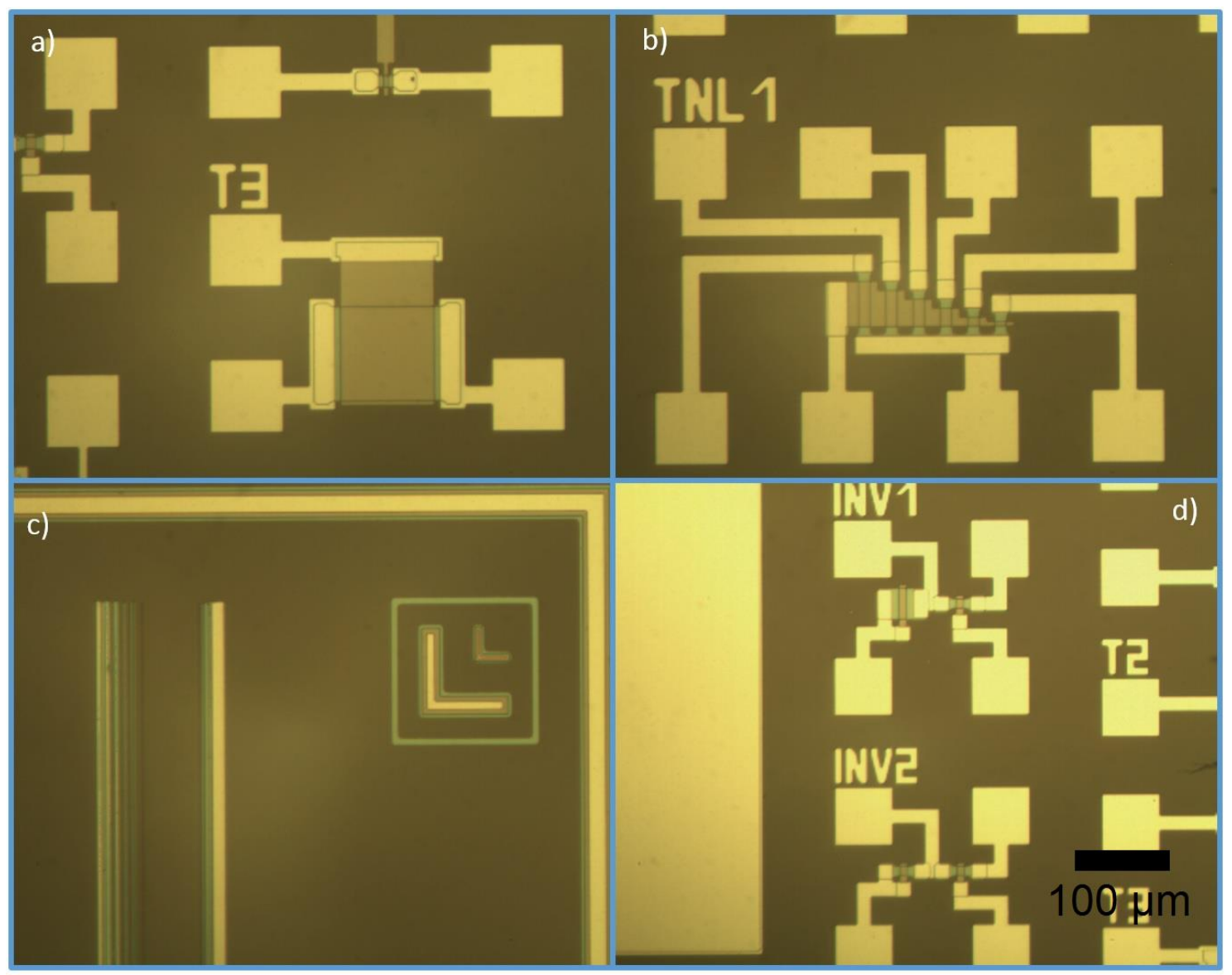

Fonte: Autor. 
A Figura 39 mostra imagens da amostra após a terceira fotogravação, corrosão do alumínio e remoção do fotorresiste. Comparando estas imagens com as imagens da Figura 38, observa-se o alumínio formando os contatos nos dispositivos construídos.

17)Corrosão de $\mathrm{SiO}_{2}$ e deposição de Al no verso da lâmina:

A parte frontal da lâmina foi protegida por uma camada de AZ1518 e a lâmina foi imersa em solução de corrosão de $\mathrm{SiO}_{2}(\mathrm{BOE})$ até que a superfície tornar-se hidrofóbica.

Posteriormente procedeu-se a remoção do AZ1518 por solução aquecida de acetona e isopropanol. E então a amostra foi encaminhada para a evaporação de alumínio.

A evaporação de alumínio foi realizada com os seguintes parâmetros:

Tabela 25 - Parâmetros de deposição do Alumínio no verso da lâmina.

\begin{tabular}{ccc}
\hline Material do Filamento & Pressão & Massa de Al \\
\hline W & $1 \times 10^{-5} \mathrm{mbar}$ & $170 \mathrm{mg}$ \\
\hline
\end{tabular}

Espessura da camada de alumínio (medida por perfilometria): $(480 \pm 40) \mathrm{nm}$.

18) Sinterização do Alumínio:

Tabela 26 - Processo de sinterização realizado nas amostras L41 e L42.

\begin{tabular}{cccc}
\hline Etapa & Temperatura & Tempo & Fluxo de Gases (Gases) \\
\hline Inserção no forno & $\sim 90^{\circ} \mathrm{C} / \mathrm{min}$ & $5 \mathrm{~min}$ & $2,0 \mathrm{litros} / \mathrm{min}\left(\mathrm{N}_{2}\right)$ \\
Sinterização & $350^{\circ} \mathrm{C}$ & $30 \mathrm{~min}$ & $\begin{array}{c}1,0 \mathrm{litros} / \mathrm{min} \\
\left(90 \% \mathrm{~N}_{2}+10 \% \mathrm{H}_{2}\right)\end{array}$ \\
Remoção do forno & $\sim-90^{\circ} \mathrm{C} / \mathrm{min}$ & $5 \mathrm{~min}$ & $2,0 \mathrm{litros} / \mathrm{min}\left(\mathrm{N}_{2}\right)$ \\
\hline
\end{tabular}




\section{CARACTERIZAÇÃO ELÉTRICA E ANÁLISES}

\subsection{Dificuldades de caracterização elétrica da $1^{\mathrm{a}}$ rodada de fabricação.}

A primeira rodada de fabricação dos dispositivos foi executada, exceto a sinterização, e iniciou-se a caracterização elétrica.

Entretanto não havia contato entre a camada de metal e do silício $\mathrm{N}^{+}$. No entanto foi possível observar contato entre a camada de alumínio e de si-poli.

Esta é uma dificuldade que impede a realização de medidas elétricas nos dispositivos. É necessário entender o motivo da dificuldade, para solucioná-la. A primeira hipótese é haver algum material isolante entre o metal e o silício $\mathrm{N}^{+}$.

A etapa de abertura de contato foi realizada de modo diferente do usual. Nos processos convencionais utilizamos a deposição de $\mathrm{SiO}_{2}$ com técnica PECVD utilizando o gás $\mathrm{SiH}_{4}$. No entanto, neste processo usou-se técnica PECVD e vapor de TEOS (TetraEthylOrthoSilicate), pois o equipamento $P E C V D$ com gás $\mathrm{SiH}_{4}$ estava indisponível. Devido à técnica de deposição do óxido usada obteve-se um óxido com o espectro FTIR indicado na Figura 40.

Figura 40 - Espectro FTIR do Óxido obtido por Deposição com TEOS.

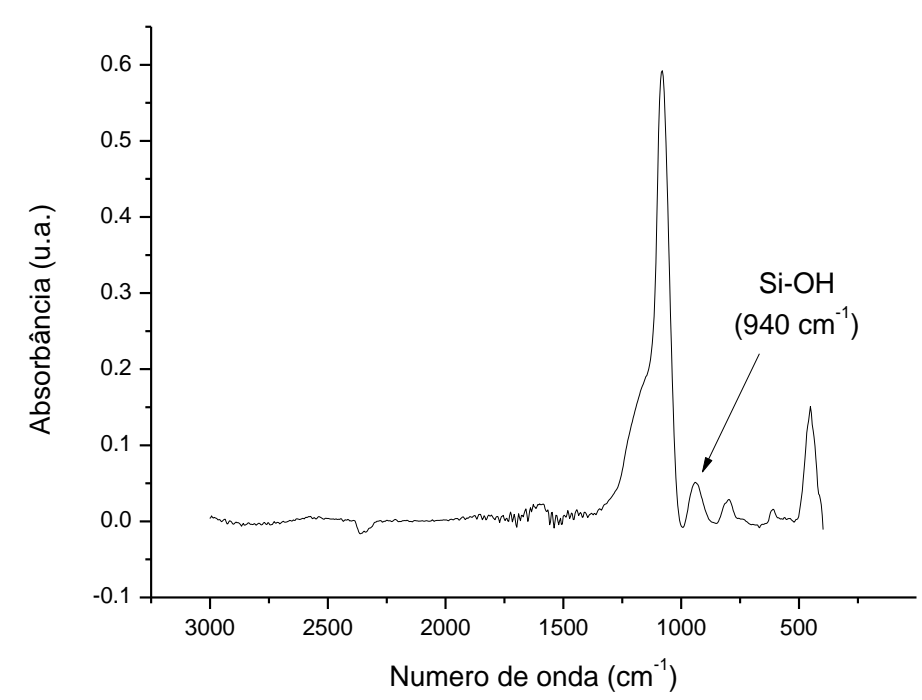

Fonte: Autor. 
O espectro indica um pico em $940 \mathrm{~cm}^{-1}$ que indica a presença de ligações $\mathrm{Si}-\mathrm{OH}$ no filme. A taxa de corrosão do filme é de $11,7 \mathrm{~nm} / \mathrm{s}$. Cerca de 3 vezes maior que a taxa de corrosão do óxido térmico, esta elevada taxa de corrosão indica um filme poroso. Este fato, e a ausência de contato entre a camada de metal e a região $\mathrm{N}^{+}$, formaram base para formulação de uma hipótese: $\mathrm{O}$ tempo de corrosão, da etapa de abertura de contato, foi insuficiente para remover o óxido térmico que havia sobre a camada $\mathrm{N}^{+}$, afinal as taxas de corrosão do óxido térmico e depositado com TEOS são muito diferentes.

Deste modo o perfil final dos dispositivos construídos deve ter ficado como o mostrado na Figura 41.

Figura 41 - Perfil final dos dispositivos construído, caso o tempo de corrosão da etapa de abertura de contato tenha sido insuficiente.

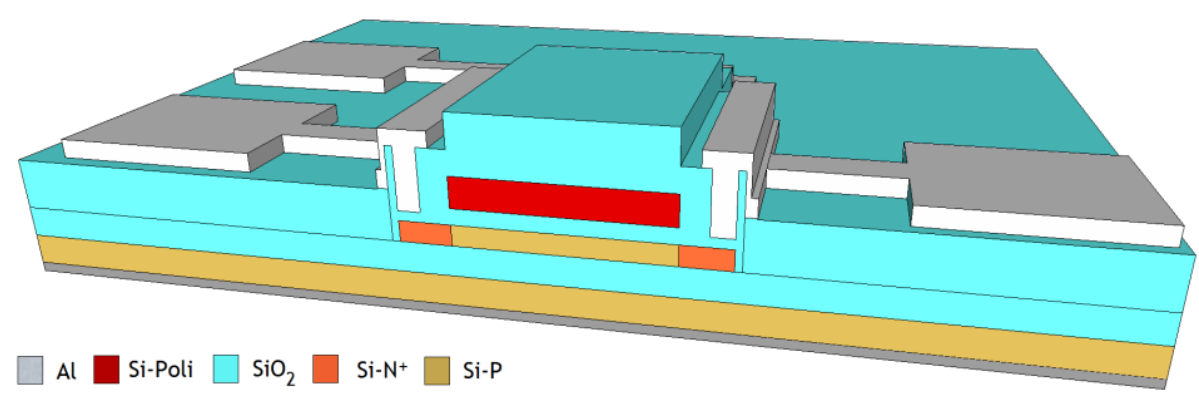

Fonte: Autor.

Para testar esta hipótese a camada de alumínio foi removida, e a amostra foi inserida na solução BOE por 1 minuto, para remover a camada de óxido.

Na sequência realizaram-se medidas na amostra fazendo a ponta de prova entrar em contato direto com o semicondutor. E, usando a estrutura Van der Pauw [29], obtiveram-se as medidas mostradas na Figura 42, para a amostra L29: 
Figura 42 - Medidas de resistência de folha com a estrutura Van der Pauw.

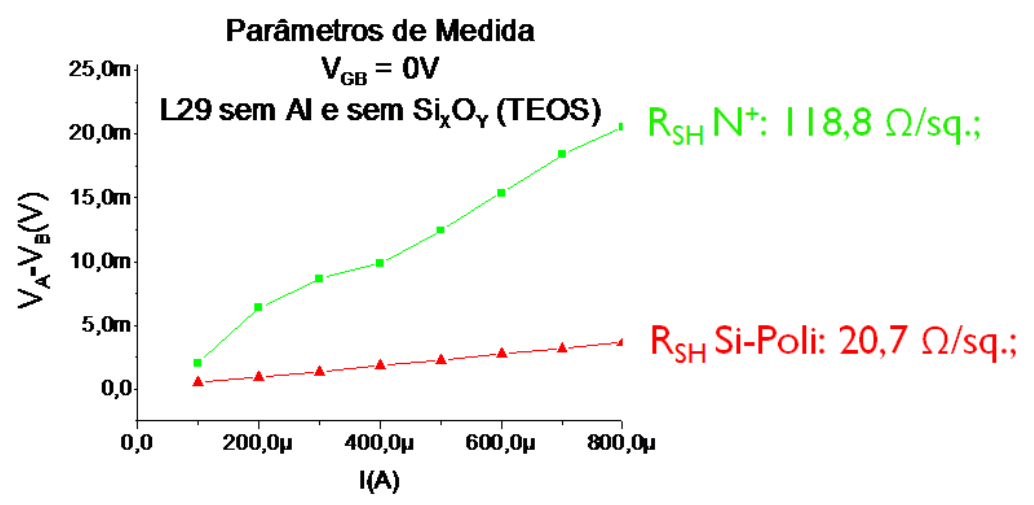

Fonte: Autor.

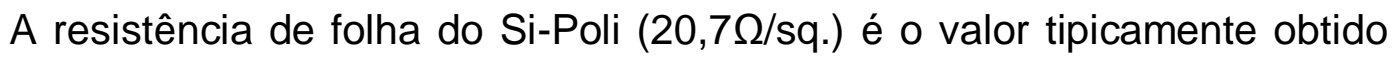
no processo MOS convencional da disciplina PSI 2643. Já o valor obtido com a região $\mathrm{N}^{+}$está alto quando comparado com o processo convencional, mas justifica-se em função da reduzida espessura de silício sobre isolante ( 56nm).

A seguir realizou-se uma medida $I_{D} X V_{G S}$ para o transistor de maior dimensão na lâmina. Durante esta medida avaliou-se também a corrente de porta $I_{G} X V_{G s}$. O gráfico da Figura 43 a) mostra os resultados desta medida em escala linear, na Figura 43 b) observam-se os mesmos dados, mas os eixos das correntes estão em escala logarítmica e, para que os dados da corrente de porta possam ser vistos, IG está em módulo.

Figura 43 - Medidas de $I_{D} \times V_{G S}$ e $I_{G} \times V_{G S}$ para o transistor $L=100 \mu m \mathrm{~W}=100 \mu m$ na lâmina $L 29$, a) escala linear e; b) escala logarítmica.

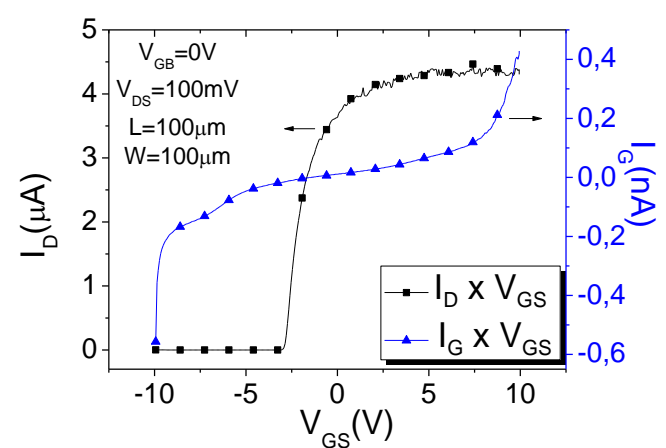

a)

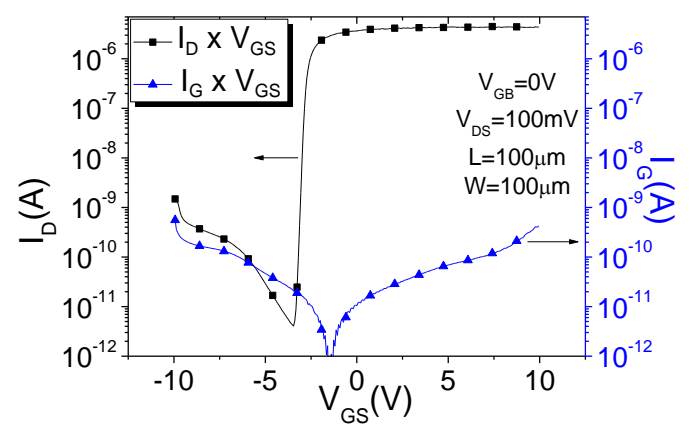

b)

Fonte: Autor. 
Com estes últimos dados observa-se um comportamento característico de transistor, com corrente de porta $I_{G}$ variando dentro de faixa aceitável (até 100pA para $-5 \mathrm{~V}<\mathrm{V}_{\mathrm{GS}}<5 \mathrm{~V}$ ), mas há um efeito inesperado na tensão de limiar ( $\mathrm{V}_{\mathrm{TH}}$ é negativo, diferentemente do projetado).

A curva linear de ID $\times V_{G S}$, como pode ser observada na Figura 43 a), apresenta comportamento anormal para valores de $\mathrm{V}_{\mathrm{GS}}$ altos (maiores que $2 \mathrm{~V}$ ). Para explicar este comportamento adotou-se por hipótese inicial que este fenômeno estaria relacionado ao fato de a medida ter sido realizada com a ponta de prova diretamente sobre o semicondutor.

Para testar tal hipótese optou-se por depositar alumínio na amostra L29, sem óxido pré-abertura de contatos, e realizar a mesma medida e obteve-se o resultado mostrado nos gráficos da Figura 44.

Figura 44 - Medidas de $\mathrm{I}_{\mathrm{D}} \mathrm{XV} \mathrm{V}_{\mathrm{GS}}$ e $\mathrm{I}_{\mathrm{G}} \mathrm{XV} \mathrm{V}_{\mathrm{GS}}$, para o transistor $\mathrm{L}=100 \mu \mathrm{m} \mathrm{W}=100 \mu \mathrm{m}$ após metalização e sem óxido PECVD na lâmina L29. a) escala linear e b) logarítmica.

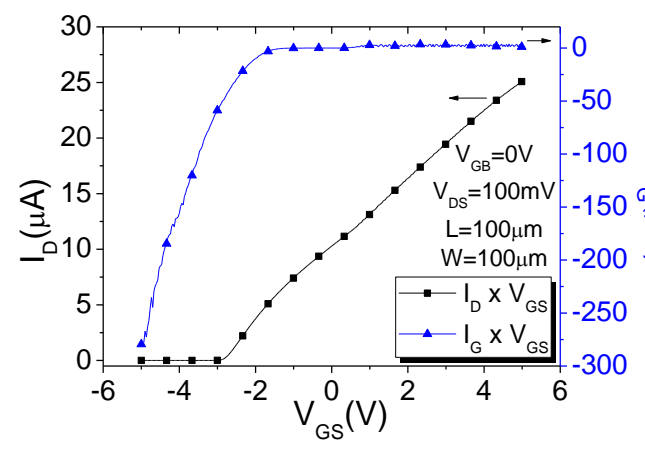

a)

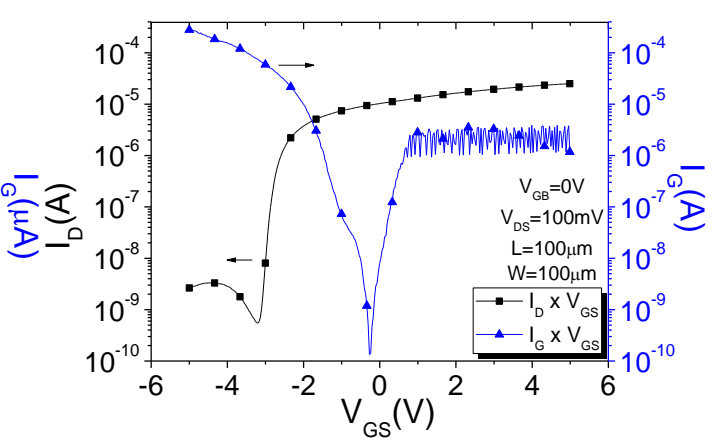

b)

Fonte: Autor.

As medidas confirmam a hipótese inicial, que de fato a curva $I_{D} \times V_{G s}$ não apresenta a mesma anomalia para valores de $\mathrm{V}_{\mathrm{GS}}$ maiores que $2 \mathrm{~V}$. Portanto há a necessidade de realizar a deposição de alumínio para um contato ôhmico.

No entanto estas medidas apresentam uma surpresa. Com a deposição de alumínio a corrente de porta ficou substancialmente maior, e principalmente para valores negativos de $V_{G s}$. Para entender este fenômeno é necessário observar os dados de todas as correntes do dispositivo na Figura 45. 
É possível perceber uma relação entre a corrente de dreno e de fonte $\left(I_{D}\right.$ e $I_{S}$ ) e entre a corrente de porta e de substrato $\left(I_{G}\right.$ e $\left.I_{B}\right)$. Isto significa que não há corrente de porta para fonte significativa, mas uma corrente entre o alumínio que faz contato com a porta e o substrato. Em outras palavras significa que o óxido enterrado está danificado.

Figura 45 - Medidas de IDXVGS, IsXVGS, IBXVGS e IGXVGS, para o transistor $L=100 \mu \mathrm{m}$ e $W=100 \mu \mathrm{m}$ após metalização e sem óxido PECVD na lâmina L29. a) na escala linear e, b) na escala logarítmica.

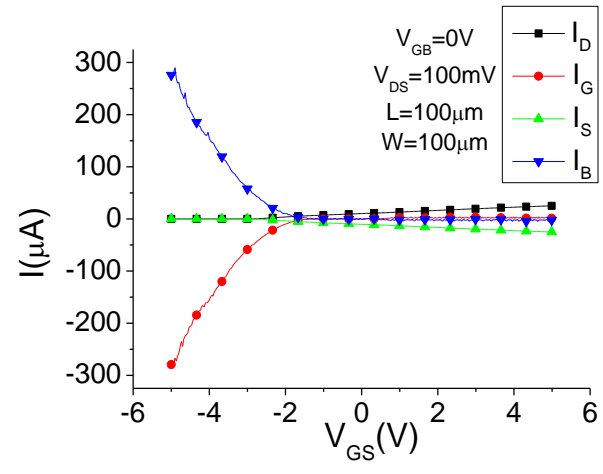

a)

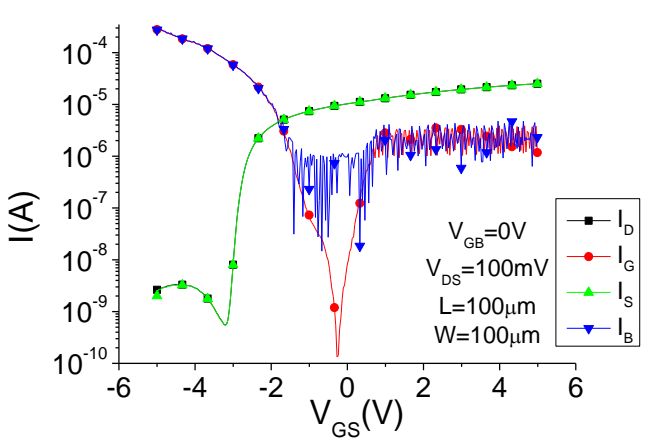

b)

Fonte: Autor.

Provavelmente o óxido enterrado foi danificado durante os testes com a amostra L29. Ao submeter esta amostra à remoção do óxido que impedia o contato com as regiões $\mathrm{N}^{+}$removeu-se também parte do óxido enterrado, permitindo o contato entre o alumínio depositado sobre a porta, e o substrato. Além disso, pelo resultado da corrente de porta na Figura 44 a), a implantação de fósforo que formou fonte e dreno, criou também uma região $\mathrm{N}+$ no substrato. Esta hipótese considera o perfil mostrado na Figura 46 para os transistores a amostra L29.

Para confirmar esta hipótese realizaram-se as medidas com o substrato isolado. Ou seja, corrente de substrato inexistente $\left(I_{B}=0\right)$ e tensão de substrato desconhecida ( $\mathrm{V}_{\mathrm{GB}}$ flutuando). O resultado destas medidas é observado nos gráficos das Figura 47 a) e b), onde podem ser vistos na escala linear e logarítmica, respectivamente.

É notável a queda na corrente de porta $\left(\mathrm{I}_{\mathrm{G}}\right)$ quando comparado à situação das Figura 45 a) e b). Isto confirma a hipótese de que não há uma corrente alta 
(impeditiva) através do dielétrico de porta, como indicava a primeira medida da Figura 43. Mas há um dano ao óxido enterrado, provocado pelos testes realizados na amostra $L 29$.

Figura 46 - a) Imagem de transistor da amostra L29; b) Perfil dos transistores da amostra L29.

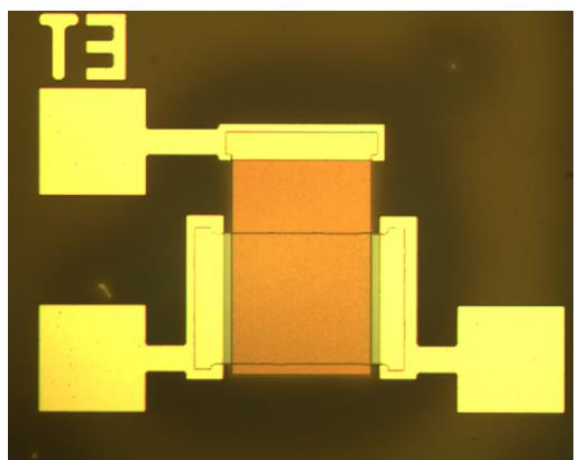

a)

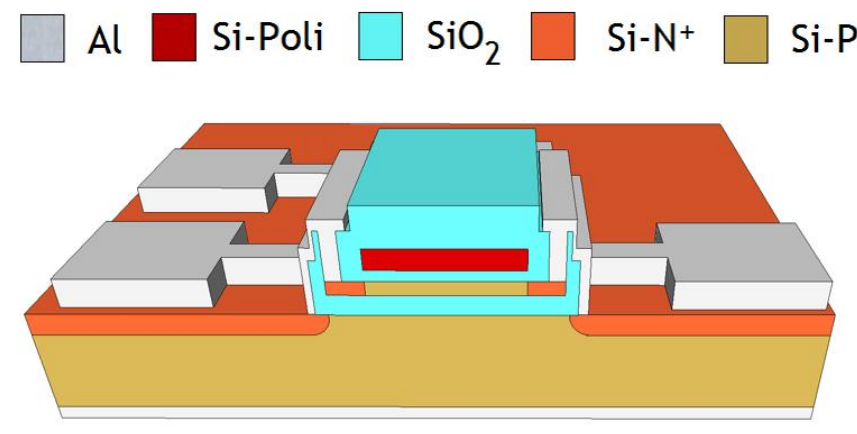

b)

Fonte: Autor.

A amostra L29 está, portanto, danificada. Mas os testes realizados nesta amostra forneceram informações importantes. O processo como um todo parece ter funcionado bem, embora existam dois problemas principais: a dificuldade de contato com as regiões $\mathrm{N}_{+}$(que impedem a caracterização elétrica) e a tensão de limiar (que está bastante deslocada).

Figura 47 - Medida $I_{D X} V_{G S}$ e $I_{G X} X V_{G S}$ com o substrato isolado ( $I_{B}=0$ e $V_{G B}$ desconhecido), a) em escala linear e, b) em escala logarítmica.

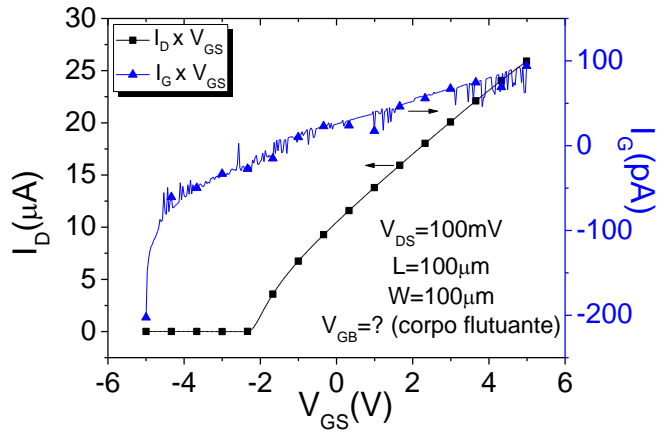

a)

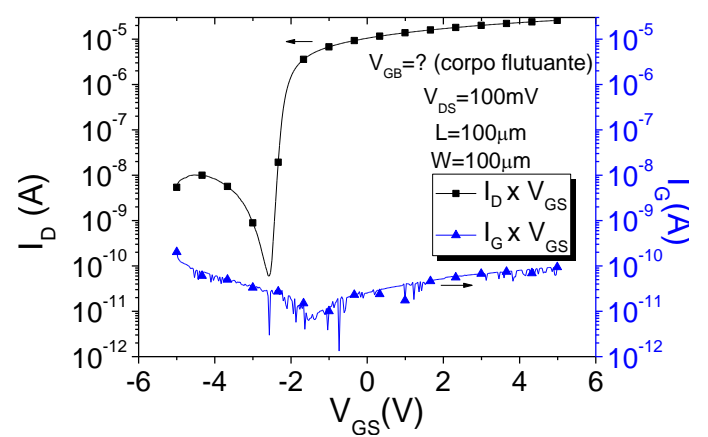

b)

Fonte: Autor. 
Foram processadas nesta rodada inicial outras 3 amostras (L30, L31 e L32). Estas amostras serão submetidas a testes para que as causas dos dois problemas principais fiquem esclarecidas e sejam eliminadas na próxima rodada de fabricação.

\subsection{Solucionando contato elétrico com região $\mathrm{N}^{+}$.}

A amostra L30 foi submetida a um processo de sinterização para testar a possibilidade de solucionar o contato com a região $\mathrm{N}^{+}$, sem a necessidade de remover a camada de alumínio. Realizaram-se medidas de resistência de contato antes e depois da sinterização. A sinterização foi realizada com os seguintes parâmetros da Tabela 27.

Tabela 27 - Processo de sinterização realizado na amostra L30.

\begin{tabular}{cccc}
\hline Etapa & Temperatura & Tempo & Fluxo de Gases (Gases) \\
\hline Inserção no forno & $\sim 90^{\circ} \mathrm{C} / \mathrm{min}$ & $5 \mathrm{~min}$ & $2,0 \mathrm{litros} / \mathrm{min}\left(\mathrm{N}_{2}\right)$ \\
Sinterização & $450^{\circ} \mathrm{C}$ & $30 \mathrm{~min}$ & $1,0 \mathrm{litros} / \mathrm{min}$ \\
$\left(90 \% \mathrm{~N}_{2}+10 \% \mathrm{H}_{2}\right)$ \\
Remoção do forno & $\sim-90^{\circ} \mathrm{C} / \mathrm{min}$ & $5 \mathrm{~min}$ & $2,0 \mathrm{litros} / \mathrm{min}\left(\mathrm{N}_{2}\right)$ \\
\hline
\end{tabular}

A resistência de contato entre 0 alumínio e a região $\mathrm{N}^{+}$não pôde ser determinada, pois nas medidas realizadas apresentou valor maior que $10^{9} \Omega$ que o limite de medida do equipamento utilizado, antes da sinterização e também depois da sinterização. Já a resistência de contato entre o alumínio e o silício policristalino foi reduzida no processo de sinterização, de $376,9 \Omega$ para $14,3 \Omega$. As medidas de resistência de contato foram executadas com a estrutura Kelvin [29].

O processo de sinterização ocorreu como o esperado, reduzindo a resistência de contato, no entanto não foi suficiente para promover um bom contato elétrico entre a camada de alumínio e a região $\mathrm{N}^{+}$.

A solução adotada para análise da amostra L29; remover a camada de alumínio, corroer óxido de silício nos contatos e então depositar alumínio novamente; será aplicada nas lâminas L31 e L32. No entanto, o tempo de 
corrosão do óxido de silício será reduzido, para que o óxido enterrado não seja irremediavelmente danificado.

Nas lâminas L31 e L32 procedeu-se a seguinte sequência:

- Remoção completa das camadas de alumínio;

- Corrosão de óxido em BOE por 40 segundos;

- Deposição de alumínio;

- Litografia: Definição do alumínio;

- Deposição de alumínio na face não polida (verso da lâmina).

Após estas etapas a lâmina L31 foi submetida à caracterização elétrica, ainda sem a etapa final de sinterização e os resultados são mostrados na seção 5.3 a seguir.

\subsection{Caracterização elétrica da amostra L31 antes da sinterização}

\subsubsection{Resistência de folha, larqura efetiva de linha e resistência de contato.}

A resistência de folha foi medida nas estruturas Van der Pauw, descritas na seção 3.2.5, para a região $\mathrm{N}^{+}$, o Si-Poli, e o alumínio. E utilizando o resistor anexo à estrutura Van der Pauw foi possível determinar a largura efetiva das linhas destas camadas [29]. Os resultados estão expressos como $\Delta \mathrm{W}$, que consiste na diferença entre a largura projetada ( $\left.W_{\text {máscara }}\right)$ e a efetiva ( $\left.W_{\text {efetiva }}\right)$, $\left(\Delta W=W_{\text {máscara }}-W_{\text {efetivo }}\right)$.

Foram medidas 5 estruturas Van der Pauw para cada material, e os valores são o resultado de medidas em 5 estruturas da lâmina e seu desvio padrão. Observe a Tabela 28. 
Tabela 28 - Resultados de resistência de folha e largura efetiva de linha (L31).

\begin{tabular}{cccccc}
\hline \multicolumn{2}{c}{ Região N+ } & \multicolumn{2}{c}{ Si-Poli } & \multicolumn{2}{c}{ Alumínio } \\
\hline R. folha $(\Omega / \square)$ & $\Delta \mathrm{W}(\mu \mathrm{m})$ & R. folha $(\Omega / \square)$ & $\Delta \mathrm{W}(\mu \mathrm{m})$ & R. folha $(\Omega / \square)$ & $\Delta \mathrm{W}(\mu \mathrm{m})$ \\
$102,6 \pm 13,3$ & $3,7 \pm 0,6$ & $23,7 \pm 1,9$ & $-0,7 \pm 0,2$ & $0,07 \pm 0,01$ & $0,4 \pm 0,1$ \\
\hline
\end{tabular}

Nestes dados destaca-se a região $\mathrm{N}^{+}$ter ficado $3,7 \mu \mathrm{m}$ mais estreita que 0 projetado inicialmente. Isto indica problemas com a etapa de litografia com inversão do resiste AZ5214. É necessário aprimorar esta etapa no próximo processo.

\subsubsection{Curvas de transferência dos transistores das lâminas L31.}

A curva de transferência típica ( $\left.\mathrm{I}_{D} \mathrm{X} \mathrm{V}_{G S}\right)$ obtida com a lâmina L31 é mostrada no gráfico da Figura 48, na sequência. Neste gráfico são mostradas também as correntes de porta $\left(\mathrm{I}_{\mathrm{G}}\right)$, de substrato $\left(\mathrm{I}_{\mathrm{B}}\right)$ e de fonte $\left(\mathrm{I}_{\mathrm{S}}\right)$. Observando o comportamento das correntes deste dispositivo fica claro que a amostra L31 não apresenta os mesmos problemas de óxido enterrado danificado que ocorreram com a amostra L29. Afinal as correntes de porta e de substrato são desprezíveis em relação à corrente de dreno.

Figura 48 - Gráfico, em escala linear, de correntes em função da tensão $V_{G S}$ para o transistor de maiores dimensões da lâmina L31.

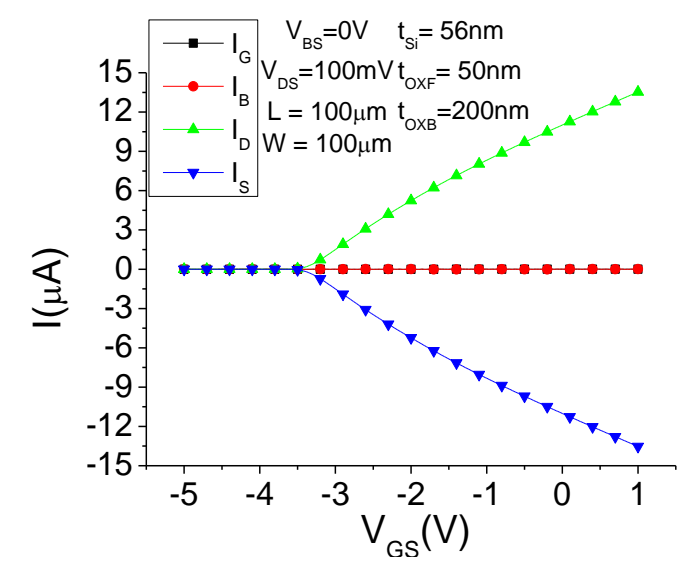

Fonte: Autor.

Embora o problema de contato com a região $\mathrm{N}^{+}$tenha sido solucionado para a amostra L31, sem danificar o óxido enterrado, ainda observa-se a tensão de limiar negativa, em valores muito deslocados em relação ao projeto 
inicial. O gráfico da Figura 49 a) mostra o comportamento da corrente de dreno em função da tensão $V_{G S}$ para diversos comprimentos de porta. $E$ na sequência, o gráfico da Figura 49 b) mostra os valores de tensão de limiar destes transistores.

O valor da tensão de limiar diminui com o aumento das cargas no óxido de porta, conforme a equação (2.5), e pode até atingir valores negativos se a concentração de cargas for alta o suficiente. Este fato permite elaborar a hipótese de que há uma concentração elevada de cargas no óxido de porta, e por isto, a tensão de limiar ficou tão diferente do projeto inicial.

Figura 49 - Amostra L31 antes da sinterização: a) Gráfico loxVGs para diversos comprimentos de porta e b) Comparação entre a tensão de limiar dos transistores da amostra L31 em relação ao projeto inicial.

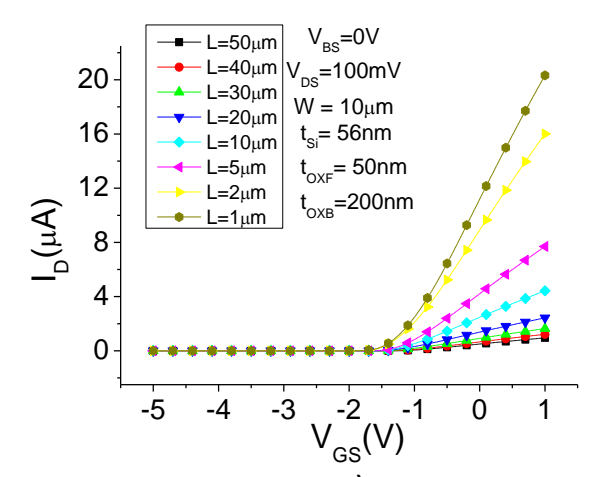

a)

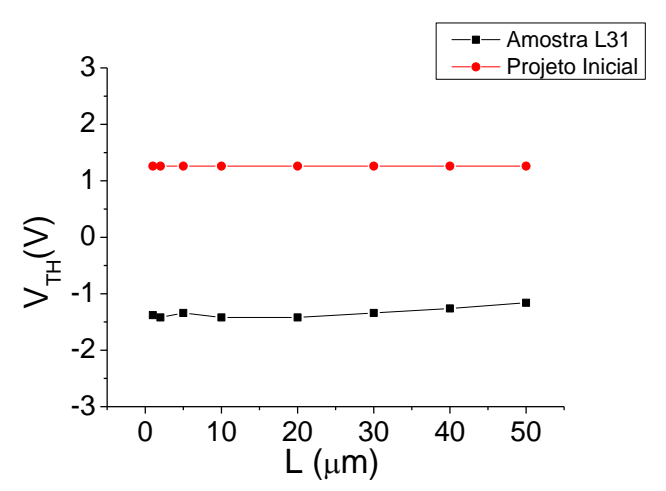

b)

Fonte: Autor.

No entanto, esta hipótese provoca a dúvida sobre o que aconteceu durante a fabricação que elevou as cargas no óxido de porta. Durante as simulações de projeto do processo adotou-se o valor de cargas no óxido $4.5 \times 10^{11} \mathrm{~cm}^{-2}$. Este valor (aproximado) foi obtido em outros processos de oxidação, antes e depois da execução de oxidação de porta na amostra L31. Portanto, é pouco provável que estas cargas tenham se formado durante a oxidação, provavelmente formaram-se em etapa posterior à oxidação de porta no processo de fabricação.

A maior diferença entre o processo de fabricação das amostras L29 à L32, em relação ao processo nMOS convencional com tensões de limiar próximas ao projetado, é a etapa de óxido PECVD com TEOS. Portanto, a 
hipótese inicial é que esta etapa causou as cargas no óxido de porta que provocam o deslocamento da tensão de limiar.

Além disso, a amostra L31 mostrou ser possível ter um processo SOI sem este óxido de silício para posterior abertura de contatos, uma vez que o óxido enterrado da lâmina SOI permite isolar os terminais dos dispositivos do substrato.

Foi proposto então um novo processo, no qual será suprimida a etapa de deposição de óxido de silício para posterior abertura de contatos, e com isto, espera-se que a tensão de limiar dos transistores desta nova rodada de fabricação fique próxima ao projeto inicial.

Entretanto há ainda outras informações que a amostra L31 pode fornecer, como por exemplo, a inclinação de sublimiar. E, ainda mais, qual o efeito da sinterização sobre estes parâmetros dos dispositivos.

A inclinação de sublimiar dos transistores da amostra L31, antes da sinterização, pode ser observada no gráfico da Figura 50, a) $I_{D} \times V_{G S}$ em escala logarítmica e, b) os valores das inclinações de sublimiar para cada comprimento de canal.

Figura 50 - Amostra L31 antes da sinterização: a) Gráfico lDXVGs na região de sublimiar, para diversos comprimentos de porta e, b) Inclinação de sublimiar para diversos comprimentos de canal.

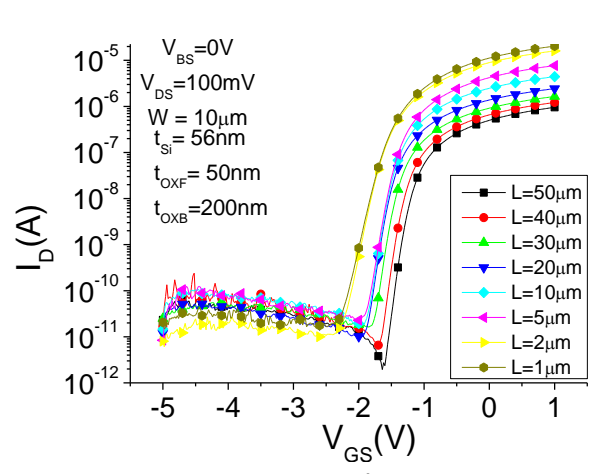

a)

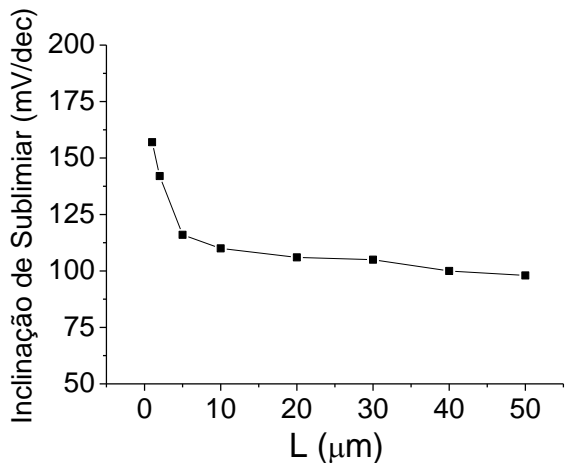

b)

Fonte: Autor. 
Os valores das inclinações de sublimiar, para cada comprimento de canal mostrados na Figura 50 b), são valores altos para dispositivos FD SOI, mas é importante lembrar que esta amostra ainda não sofreu a sinterização. $O$ processo de sinterização tende a diminuir as cargas de interface ( $\mathrm{N}_{\text {itt }}$ ), e estas são significativas para a inclinação de sublimiar conforme as equações (2.14) e (2.19). Portanto, este é um parâmetro que deve ser fortemente alterado após a sinterização.

Após a sinterização a amostra L31 apresentou uma redução na tensão de limiar. Ou seja, o valor da tensão de limiar ficou mais negativo. O gráfico da Figura 51 b) mostra estes valores obtidos.

Figura 51 - a) Corrente de dreno em função da tensão de porta; e, b) tensão de limiar em função do comprimento de porta.

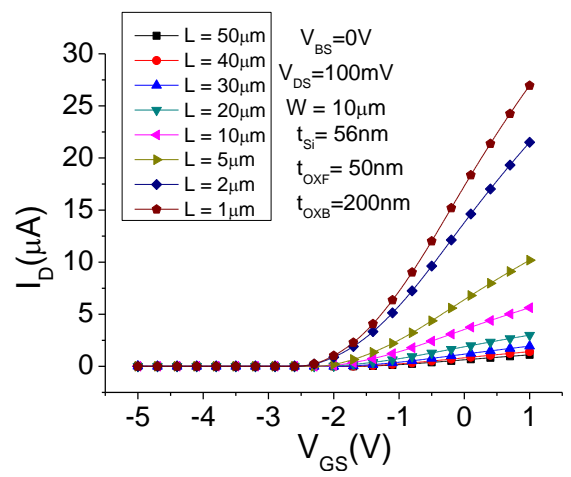

a)

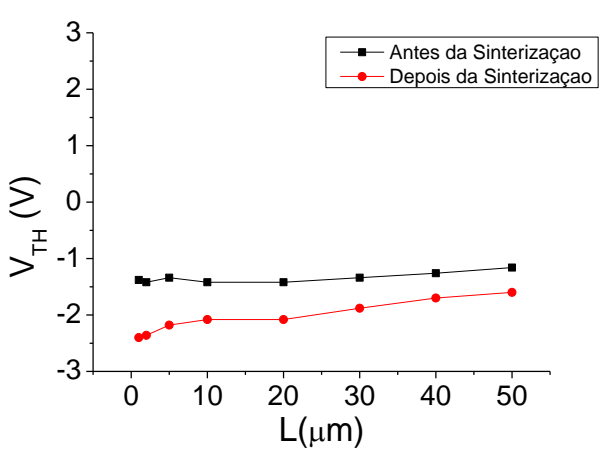

b)

Fonte: Autor.

Esta redução da tensão de limiar deve-se a redução de estados de interface ( $\mathrm{N}_{\text {itt) }}$ devido à sinterização. Na situação de significativas cargas de interface, há um termo adicional na equação da tensão de limiar:

$$
V_{T H 1, D E P 2}=V_{T H 1, A C C 2}-\frac{C_{S i} \cdot C_{O X B}}{C_{O X F} \cdot\left(C_{S i}+C_{O X B}\right)} \cdot\left(V_{G B}-V_{G B, A C C 2}\right)-\frac{Q_{i t f}}{C_{O X F}}
$$

onde:

Qiff é a carga de interface entre o óxido de porta e o silício. 
Esta carga assume valores negativos, devido a polarização, e, portanto o fator "- $\left(Q_{\text {itt }} / C_{\text {OXF }}\right)$ " assume valor positivo. Isto contribui com um aumento na tensão de limiar. Quando o processo de sinterização reduz o valor de estados de interface ( $\left.N_{\text {itt }}\right)$ e, consequentemente, o valor de cargas de interface ( $Q_{\text {itt }}$, a tensão de limiar torna-se mais negativa.

Pode-se constatar a redução dos estados de interface através da comparação dos valores obtidos de inclinação de sublimiar, antes e depois do processo de sinterização. O gráfico da Figura 52 mostra os valores obtidos para a inclinação de sublimiar após a sinterização.

Após a sinterização há a diminuição das cargas de interface e, consequente diminuição do fator de acoplamento capacitivo. Isto reflete na diminuição da inclinação de sublimiar dos transistores.

Figura 52 - a) Corrente de dreno em função da tensão de porta; e, b) inclinação de sublimiar em função do comprimento de porta.

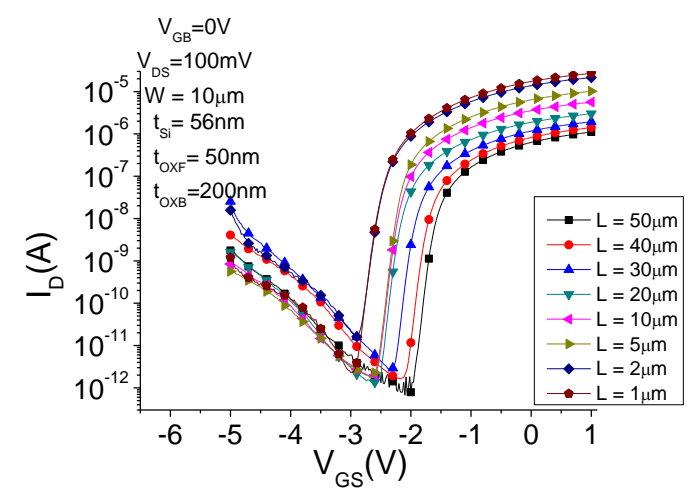

a)

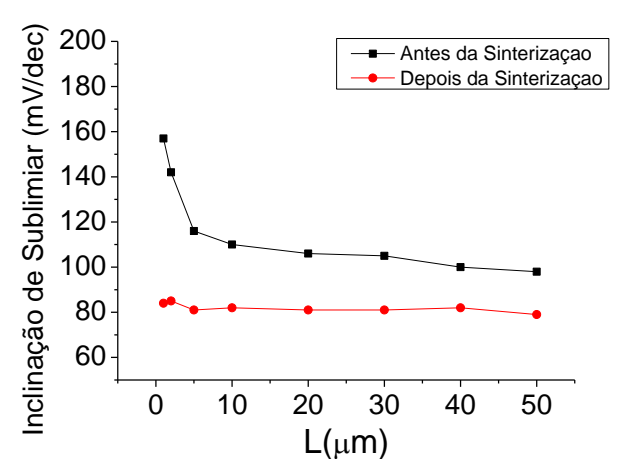

b)

Fonte: Autor.

\subsection{Caracterização elétrica da segunda rodada de fabricação.}

A segunda rodada de fabricação excluiu a etapa de deposição de óxido de silício, pois esta etapa causou problemas na primeira rodada de fabricação e a exclusão desta etapa permite ainda evitar uma etapa de litografia. Deste modo, a segunda rodada de fabricação é ainda mais simples que a primeira. 
Os principais parâmetros elétricos são descritos à seguir.

\subsubsection{Largura de linhas}

A largura efetiva de linhas é um importante parâmetro de processos. Afinal a largura de linha de silício policristalino influencia no comprimento efetivo de porta. Já a largura da região ativa define a largura de canal dos transistores. Há diferenças entre a largura efetiva e a largura de máscara devido a imperfeições nos processos de litografia, na corrosão e em outros processos [29].

Tradicionalmente determina-se a largura de linhas eletricamente, por meio de estruturas cruz-ponte, como as estruturas VDP1, VDP2 e VDP3 do conjunto de fotomáscaras utilizadas.

Primeiramente determina-se a resistência de folha da camada a ser medida, usando a estrutura Van der Pauw [29]. Em seguida determina-se a resistência de um resistor com comprimento conhecido, e preferencialmente longo $(200 \mu \mathrm{m}$, neste caso). Finalmente pode-se calcular a largura efetiva de linha com a equação (5.2):

$$
W_{\text {eff }}=R_{\text {folha }} \cdot \frac{L_{R e s}}{R}
$$

onde:

$$
\begin{aligned}
& R_{\mathrm{folha}} \quad \text { é a resistência de folha da camada a ser medida; } \\
& \text { LRes } \quad \text { é o comprimento do resistor a ser medido; } \\
& \mathrm{R}
\end{aligned}
$$

Calculando chegam-se aos valores apresentados na Tabela 29, à seguir. Entre os resultados destaca-se a largura efetiva de linha da região $\mathrm{N}^{+}$que, em ambas as amostras, ficou cerca de $2 \mu \mathrm{m}$ mais larga. Isto significa que os dispositivos que serão medidos estão mais largos, e, portanto, devem apresentar correntes maiores. 
Tabela 29 - Resultados de resistência de folha e largura efetiva de linha para L41 e L42.

\begin{tabular}{cccccc}
\hline & Camada & $\mathbf{R}_{\text {folha }}(\Omega / \square)$ & $\mathbf{R}(\Omega)$ & $\mathbf{W}_{\text {eff }}(\mu \mathrm{m})$ & $\Delta \mathbf{W}(\boldsymbol{\mu m})$ \\
\cline { 2 - 6 } Amostra L41 & Si-Poli & 13,50 & 280,71 & 9,62 & 0,38 \\
Dose $\left(1,0 \times 10^{13} \mathrm{~cm}^{-2}\right)$ & Região + & 214,06 & $3,495 \mathrm{k}$ & 12,25 & $-2,25$ \\
& Al & $43 \mathrm{~m}$ & $920 \mathrm{~m}$ & 9,40 & 0,60 \\
& Camada & $\mathrm{R}_{\text {folha }}(\Omega / \square)$ & $\mathrm{R}(\Omega)$ & $\mathrm{W}_{\text {eff }}(\mu \mathrm{m})$ & $\Delta \mathrm{W}(\mu \mathrm{m})$ \\
Amostra L42 & Si-Poli & 16,04 & 357,26 & 8,98 & 1,02 \\
Dose $\left(1,2 \times 10^{13} \mathrm{~cm}^{-2}\right)$ & Região N+ & 203,27 & $3,327 \mathrm{k}$ & 12,22 & $-2,22$ \\
& Al & $50 \mathrm{~m}$ & 1,09 & 9,19 & 0,81 \\
\hline
\end{tabular}

Este resultado é consequência da inversão da primeira fotomáscara, processo litográfico diferente do tradicional e que apresentou variações maiores. Outros resultados mostram variações dentro do esperado para processos de corrosão úmida.

\subsubsection{Tensão de limiar $\left(\mathrm{V}_{\mathrm{TH}}\right)$}

A característica de transferência $\mathrm{I}_{\mathrm{D}} \mathrm{XV} \mathrm{V}_{\mathrm{GS}}$ típica dos transistores das amostras L41 e L42 são mostradas na Figura 53, a seguir.

Figura 53 - Corrente de dreno em função da tensão de porta para as amostras L41 (Dose $\left.=1,0 \times 10^{13} \mathrm{~cm}^{-2}\right)$ e L42 (Dose $\left.=1,2 \times 10^{13} \mathrm{~cm}^{-2}\right)$ : a) Escala linear e, b) logarítmica.

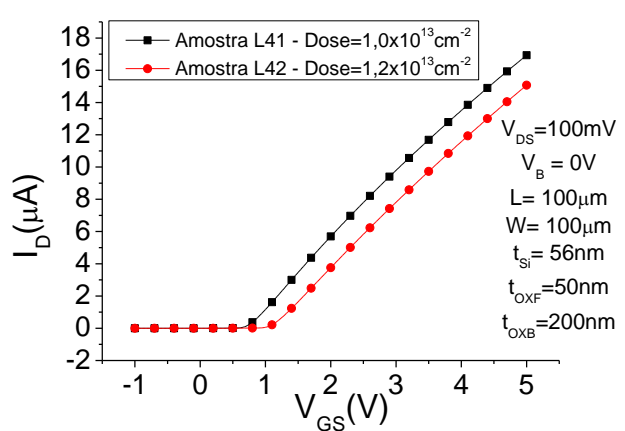

a)

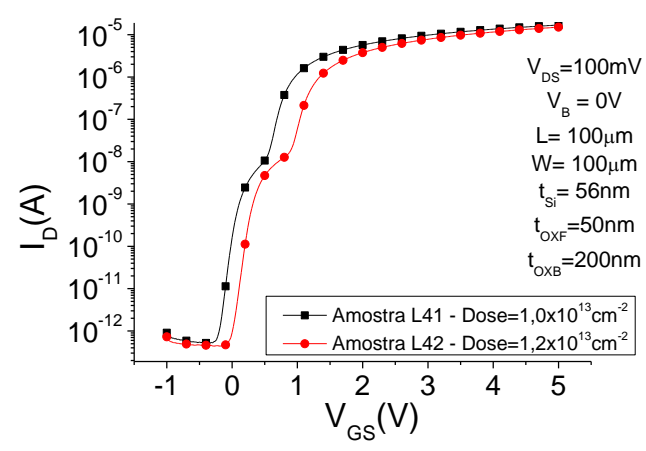

b)

Fonte: Autor.

Ao observar a Figura 53 b) pode-se notar que há um efeito de transistor lateral parasitário nestas amostras. Devido ao processo de fabricação simples implementado, em que não há o conjunto de etapas necessárias para realizar a 
implantação de boro adicional nas laterais dos transistores, este efeito era esperado.

No que se refere à tensão de limiar dos transistores observam-se duas tensões de limiar, ou seja, a tensão de limiar do transistor principal e a tensão de limiar do transistor lateral parasitário.

Aplicando o método da segunda derivada da corrente de dreno em função da tensão de porta têm-se dois picos. A Figura 54 mostra o gráfico de extração da tensão de limiar. Para a análise que será executada considera-se a tensão de limiar dos transistores $\left(\mathrm{V}_{\mathrm{TH}}\right)$ como a tensão correspondente ao maior pico (transistor principal) da segunda derivada de $I_{D S}$ em função de $V_{G S}$.

Os resultados de tensão de limiar estão expressos na Tabela 30, e são muito próximos aos valores projetados inicialmente. Em outras palavras, a dificuldade da primeira rodada de fabricação foi superada ao se suprimir a etapa de deposição de óxido de silício.

Figura 54 - Gráfico da segunda derivada da corrente de dreno em função da tensão de porta.

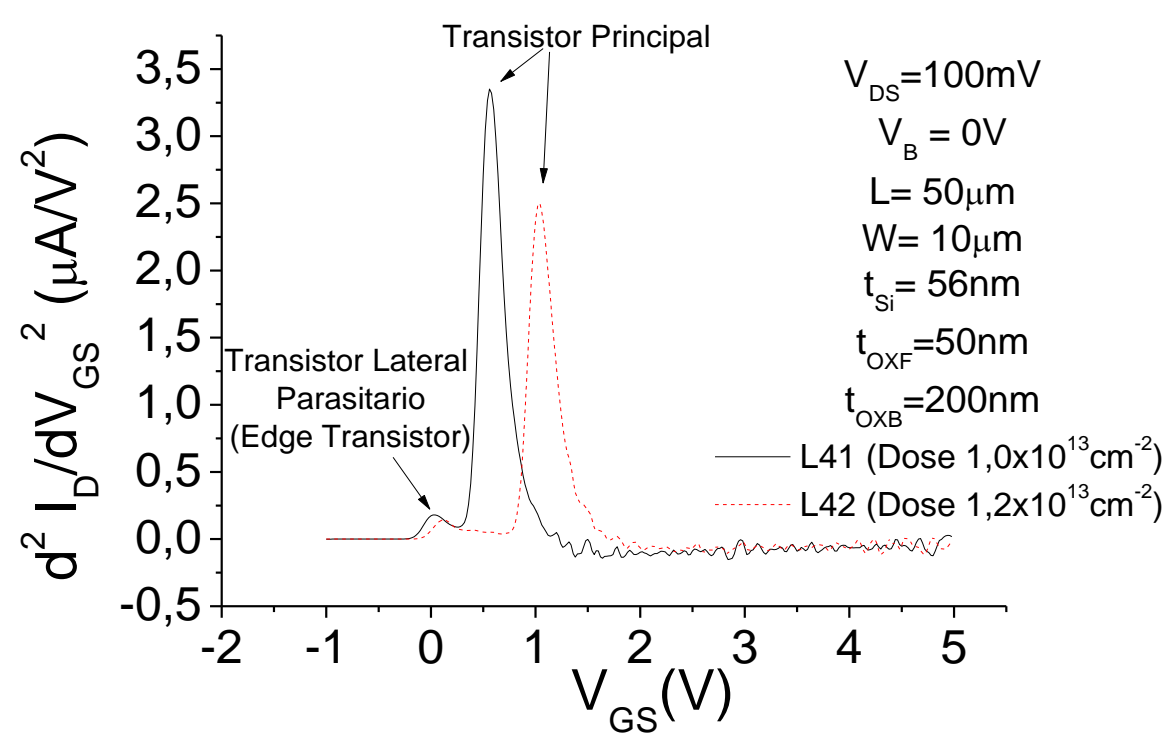

Fonte: Autor.

Os resultados expressos na Tabela 30 , à seguir, foram conseguidos com medidas em 5 transistores isolados de cada dimensão (não entraram neste cálculo os transistores das cascatas), totalizando 15 transistores por amostra. 
Tabela 30 - Comparação entre a tensão de limiar $\left(\mathrm{V}_{\mathrm{TH}}\right)$ obtida experimentalmente e o projeto inicial usando simulação numérica.

\begin{tabular}{ccc}
\hline & $\mathbf{V}_{\text {TH }}(\mathbf{V})$ & \\
\hline Amostra & Experimental & Projeto \\
L41 (Dose $\left.1,0 \times 10^{13} \mathrm{~cm}^{-2}\right)$ & $0,72 \pm 0,07$ & 0,68 \\
L42 $\left(\right.$ Dose $\left.1,2 \times 10^{13} \mathrm{~cm}^{-2}\right)$ & $1,08 \pm 0,09$ & 1,26 \\
\hline
\end{tabular}

No que se refere à tensão de limiar os resultados da segunda rodada de fabricação são compatíveis com o projeto inicial, o que permite concluir que a etapa de deposição de óxido de silício com a técnica PECVD (TEOS), usada na primeira rodada de fabricação, ocasionou alta concentração de cargas no óxido de porta e o consequente deslocamento na tensão de limiar.

A variação em relação ao projeto inicial, de 5,5\% e 16,6\% para as amostras $L 41$ e $L 42$, respectivamente, deve-se a possíveis variações de cargas no óxido de porta, e possíveis variações de dose durante a implantação iônica. Para a aplicação educacional deste processo estas variações são razoáveis.

\subsubsection{Inclinação de Sublimiar (S)}

A inclinação de sublimiar, das amostras da segunda rodada, está prejudicada pelo efeito transistor lateral parasitário. Devido a este efeito não é possível determinar a inclinação de sublimiar do transistor principal. Entretanto, foi possível determinar a inclinação de sublimiar do transistor parasitário. A

Tabela 31 mostra os valores médios e desvio padrão obtidos de medidas de 5 transistores isolados de cada tamanho, totalizando 15 transistores por amostra.

Ao polarizar positivamente o substrato consegue-se diminuir o efeito do transistor lateral parasitário, pois com o aumento da tensão de substrato há uma diminuição da tensão de limiar do transistor principal, como pode ser observado na equação (2.12). 
Tabela 31 - Inclinação de sublimiar do transistor lateral parasitário.

\begin{tabular}{cc}
\hline & $\mathbf{S}(\mathrm{mV} / \mathrm{dec})$ \\
\hline Amostra & Trans. Lateral \\
L41 (Dose $\left.1,0 \times 10^{13} \mathrm{~cm}^{-2}\right)$ & $78 \pm 4$ \\
L42 (Dose $\left.1,2 \times 10^{13} \mathrm{~cm}^{-2}\right)$ & $82 \pm 3$ \\
\hline
\end{tabular}

Observou-se, experimentalmente, que a tensão de limiar do transistor principal é mais sensível a variações de polarização do substrato, em comparação a tensão de limiar do transistor parasitário.

Como a tensão de limiar, do transistor lateral parasitário, é menos sensível a polarização de substrato é possível tornar a tensão de limiar, do transistor principal, menor na condição adequada de polarização de substrato. Isto permite determinar a inclinação de sublimiar do transistor principal, embora para uma polarização de substrato diferente de zero.

A Figura 55 mostra o gráfico da corrente de dreno em função da tensão de porta para diferentes polarizações de substrato.

Figura 55 - Corrente de dreno em função da tensão de porta, em escala logarítmica, para as amostras: a) L41 e b) L42; para diversas polarizações de substrato.

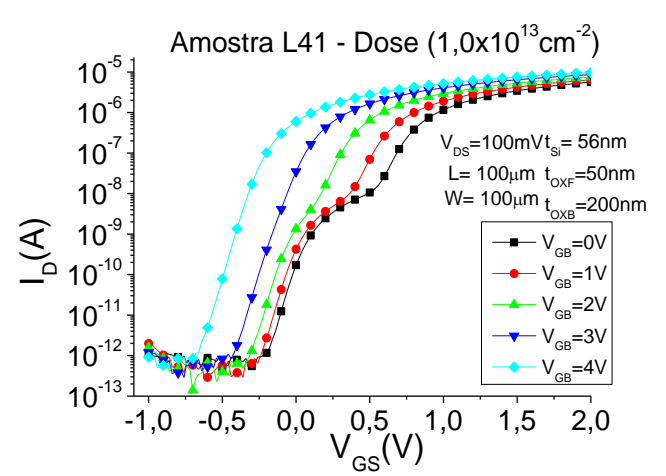

a)

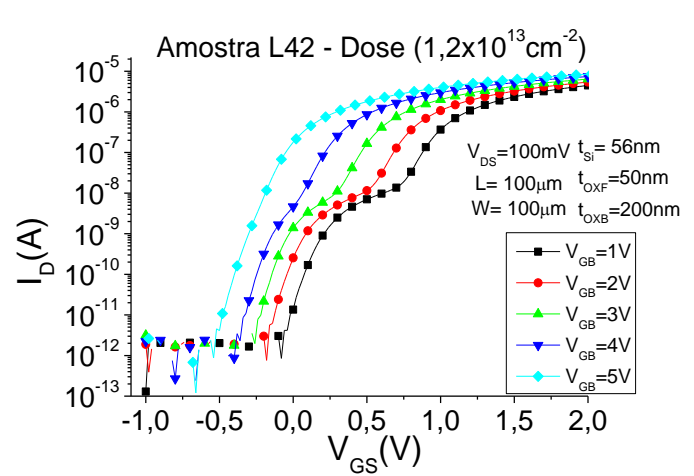

b)

Fonte: Autor.

A partir de certa tensão de substrato o "salto" característico do efeito transistor lateral parasitário desaparece. Isto não implica na solução do problema, afinal o transistor lateral parasitário continua paralelo ao transistor 
principal. No entanto, esta polarização nos permite observar a inclinação de sublimiar do transistor principal, ainda que em uma condição de polarização de substrato não usual.

Medindo a inclinação de sublimiar do transistor principal, para uma tensão de substrato de $4 \mathrm{~V}$, no caso da amostra L41, e de $5 \mathrm{~V}$, no caso da amostra L42; obtêm-se os resultados expressos na Tabela 32. Esta tensão de substrato foi adotada por ser a menor tensão em que o efeito do transistor lateral parasitário não é observado.

Tabela 32 - Inclinação de sublimiar do transistor principal, obtido experimentalmente, para polarização de substrato de $4 \mathrm{~V}$ e $5 \mathrm{~V}$, nas amostras L41 e L42, respectivamente.

\begin{tabular}{cc}
\hline & $\mathbf{S}(\mathrm{mV} / \mathrm{dec})$ \\
\hline Amostra & Trans. Principal \\
L41 (Dose $\left.1,0 \times 10^{13} \mathrm{~cm}^{-2}\right)$ & $77 \pm 3$ \\
L42 (Dose $\left.1,2 \times 10^{13} \mathrm{~cm}^{-2}\right)$ & $79 \pm 3$ \\
\hline
\end{tabular}

A inclinação de sublimiar dos transistores principais apresenta valor razoável, dentro da faixa esperada, já que as simulações executadas durante o projeto mostram inclinação de $73 \mathrm{mV} / \mathrm{dec}$, para ambas as amostras. Além disso a extração deste parâmetro ocorreu em condição de polarização de substrato diferente, devido ao efeito de transistor lateral parasitário.

\subsubsection{Fator de acoplamento capacitivo ( $\alpha)$}

Em transistores construídos em tecnologia convencional (bulk), o efeito de corpo é definido como a dependência da tensão de limiar com a polarização do substrato [29]. Em tecnologia SOI, analogamente, há dependência da tensão de limiar com a polarização do substrato [10]. No entanto, no caso da tecnologia SOI, o substrato comporta-se como uma segunda porta, devido a presença do óxido enterrado. Por isto, em tecnologia SOI define-se o fator de acoplamento capacitivo, que relaciona a dependência da tensão de limiar com a polarização do substrato. 
Um dos métodos para se extrair o fator de acoplamento capacitivo é observar a variação da tensão de limiar com polarização de substrato. $O$ gráfico da Figura 56 mostra curvas da corrente de dreno em função da tensão de porta $\left(\mathrm{I}_{\mathrm{D}} \times \mathrm{V}_{\mathrm{GS}}\right)$ para diferentes tensões de substrato $\left(\mathrm{V}_{\mathrm{GB}}\right)$, de $-15 \mathrm{~V}$ até $15 \mathrm{~V}$ com passo de $1 \mathrm{~V}$; tanto para a amostra L41 quanto L42.

Ao extrair a tensão de limiar para cada polarização de substrato e montar um gráfico de $\mathrm{V}_{\mathrm{TH}} \times \mathrm{V}_{\mathrm{GB}}$ é possível observar três regiões distintas, quando a segunda interface está em acumulação, depleção ou inversão.

A primeira região para valores muito negativos de $V_{G B}$ em que a segunda interface está em acumulação. Nesta situação, segundo o modelo de Lim \& Fossum [30], a tensão de limiar não varia com $\mathrm{V}_{\mathrm{GB}}$. Na prática há uma pequena variação, mas fica evidente a diferença de comportamento quando a segunda interface está em acumulação.

Figura 56 - Corrente de dreno em função da tensão de porta para tensões de substrato variando de $-15 V$ até $15 V$ : a) $L 41\left(1,0 \times 10^{13} \mathrm{~cm}^{-2}\right) ; e$, b) $L 42\left(1,0 \times 10^{13} \mathrm{~cm}^{-2}\right)$.

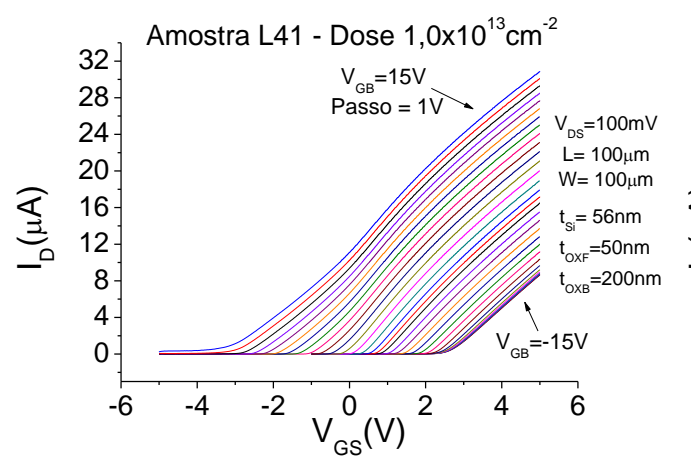

a)

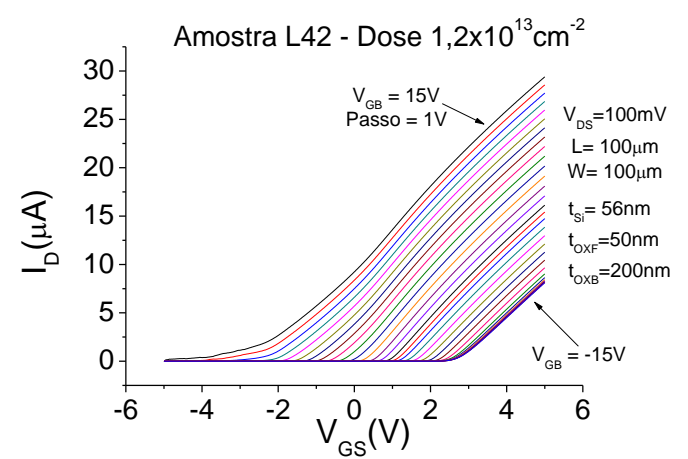

b)

Fonte: Autor.

Há outra região para valores muito positivos de $\mathrm{V}_{\mathrm{GB}}$ em que a segunda interface está em inversão. Nesta situação, a tensão de limiar não varia com $\mathrm{V}_{\mathrm{GB}}$, segundo o modelo proposto por Lim \& Fossum [30], embora na prática se observe uma pequena variação. 
E há também uma região intermediária, em que a tensão de limiar varia linearmente com a polarização de substrato. $O$ coeficiente angular desta região intermediária é igual, em módulo, ao fator de acoplamento capacitivo.

A Figura 57 mostra o gráfico de $\mathrm{V}_{T H} \mathrm{X} \mathrm{V}_{\mathrm{GB}}$ para um dos transistores da amostra L41 e da amostra L42. Neste gráfico pode-se ver ainda a variação da tensão de limiar do transistor lateral parasitário em função de $\mathrm{V}_{\mathrm{GB}}$, e verifica-se que o coeficiente angular é menor para o transistor lateral, ou seja, este é menos sensível a variações de $\mathrm{V}_{\mathrm{GB}}$.

Construindo gráficos como o da Figura 57, e extraindo o coeficiente angular para 5 transistores por amostra, obtêm-se o resultado mostrado na Tabela 33 para o fator de acoplamento capacitivo.

Figura 57 - Tensão de limiar $\left(\mathrm{V}_{\mathrm{TH}}\right)$ em função da tensão de substrato $\left(\mathrm{V}_{\mathrm{GB}}\right)$, para o transistor principal e para o transistor lateral parasitário, nas amostras a) $L 41\left(1,0 \times 10^{13} \mathrm{~cm}^{-2}\right)$; e, b) $L 42\left(1,2 \times 10^{13} \mathrm{~cm}^{-2}\right)$.

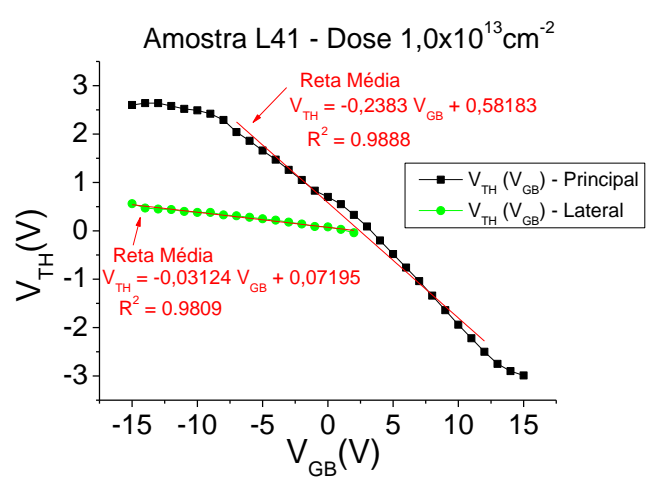

a)

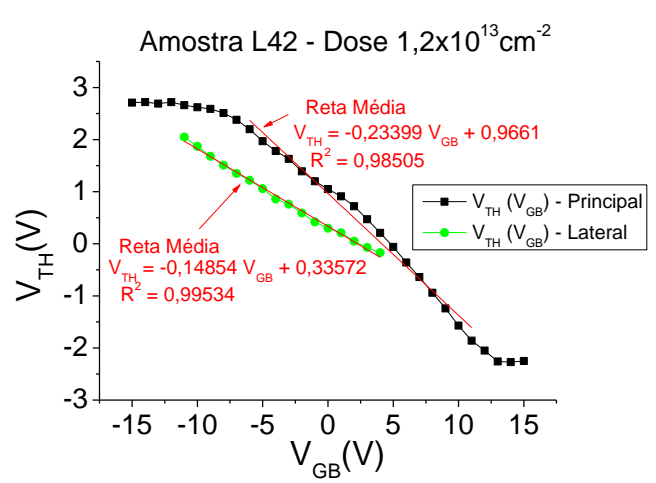

b)

Fonte: Autor.

Tabela 33 - Resultado do fator de acoplamento capacitivo obtido nas amostras L41 e L42, para o transistor principal e para o transistor lateral parasitário.

\begin{tabular}{ccc}
\hline & $\boldsymbol{\alpha}$ (adimensional) \\
\hline Amostra & Trans. Principal & Trans. Lateral \\
$\mathrm{L} 41\left(1,0 \times 10^{13} \mathrm{~cm}^{-2}\right)$ & $0,22 \pm 0,02$ & $0,06 \pm 0,03$ \\
$\mathrm{~L} 42\left(1,2 \times 10^{13} \mathrm{~cm}^{-2}\right)$ & $0,22 \pm 0,02$ & $0,10 \pm 0,04$ \\
\hline
\end{tabular}


Com este resultado pode-se estimar a inclinação de sublimiar do transistor principal para polarização do substrato 0V, usando a equação (2.14). Esta ficaria em torno de $73 \mathrm{mV}$, o que coincide com as simulações do projeto.

\subsubsection{Mobilidade $\left(\mu_{0}\right)$ e Comprimento efetivo de canal ( $\left.L_{\text {eff }}\right)$}

Nesta seção serão extraídos importantes parâmetros para modelagem dos transistores SOI MOSFET como a mobilidade para baixo campo elétrico $\left(\mu_{0}\right)$ e o comprimento efetivo de canal $\left(L_{\text {eff }}\right)$.

Se a tensão de dreno $V_{D S}$ for pequena (de 50 a $100 \mathrm{mV}$ ) e ao considerar o fator de corpo como unitário ( $n=1+\alpha \approx 1)$, chega-se a equação (5.3) [10]:

$$
I_{D S}=\frac{A \cdot\left(V_{G S}-V_{T H}\right)}{1+\theta_{1} \cdot\left(V_{G S}-V_{T H}\right)+\theta_{2} \cdot\left(V_{G S}-V_{T H}\right)^{2}}
$$

Onde:

$$
A=\mu_{0} \cdot C_{O X F} \frac{W}{L_{e f f}} \cdot V_{D S}
$$

E onde $L_{e f f}=L-\Delta L$ é o comprimento efetivo de canal. Ainda $\theta_{1}$, e $\theta_{2}$ são fatores de redução da mobilidade.

Plotando a raiz terceira da segunda derivada do inverso de $I_{D S}$ em função de $V_{G S}$ obtêm-se $V_{T H}$ e $A$ (Figura 58 a). E plotando 1/A para diferentes comprimentos de canal é possível obter $\Delta \mathrm{L}$ e $\mu_{0}$ (Figura $58 \mathrm{~b}$ ).

A Figura 59 a seguir mostra o gráfico de $1 / \mathrm{A} \times \mathrm{L}$, para as amostras $\mathrm{L} 41 \mathrm{e}$ L42.

Com os dados dos gráficos da Figura 59 foi possível obter a tensão de limiar média, pois cada transistor apresentou uma tensão de limiar; obteve-se também a variação do comprimento de canal, e a mobilidade para baixo campo elétrico. 
Figura 58 - Figura esquemática do modo de extração da tensão de limiar $\left(\mathrm{V}_{\mathrm{TH}}\right)$, mobilidade $\left(\mu_{0}\right)$, e variação no comprimento de canal $(\Delta \mathrm{L})$.
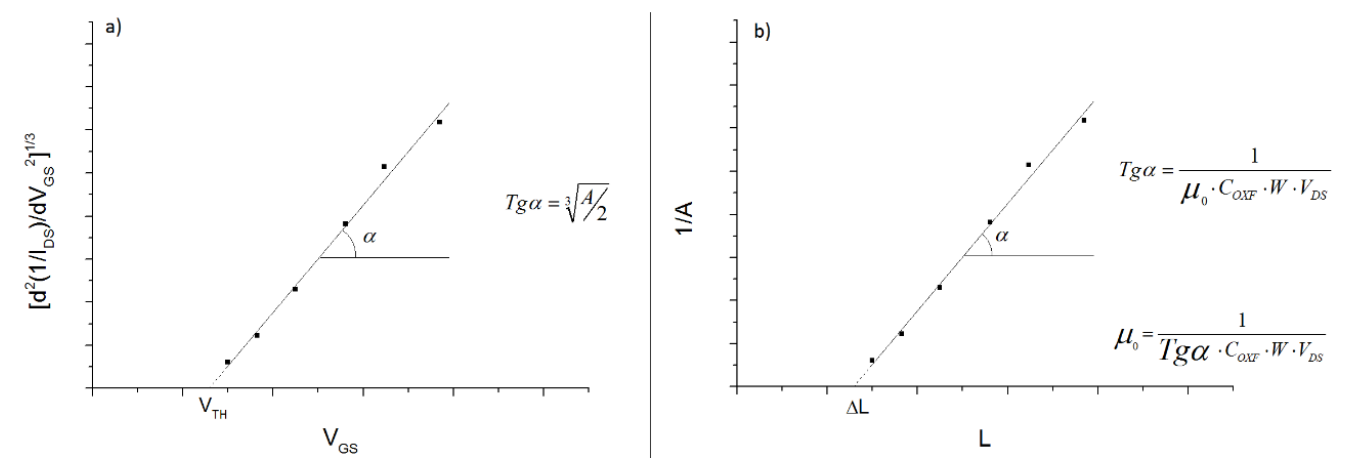

Fonte: Colinge J.P.,Silicon-on-insulator technology.

Figura 59 - Extração dos parâmetros de mobilidade e $\left(\mu_{0}\right)$, e variação no comprimento de canal $(\Delta \mathrm{L})$ para as amostras, a) L41 e b) L42.

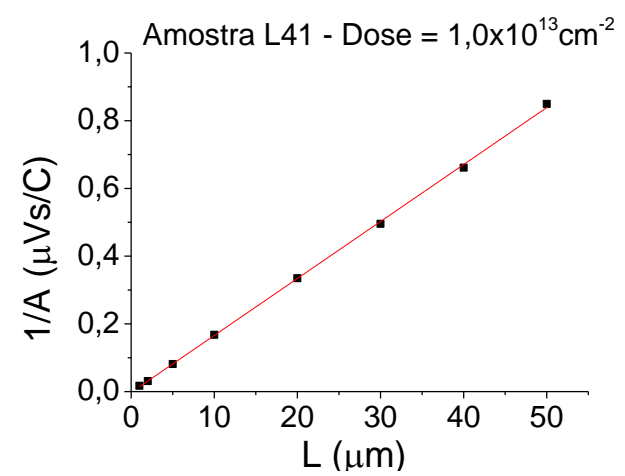

a)

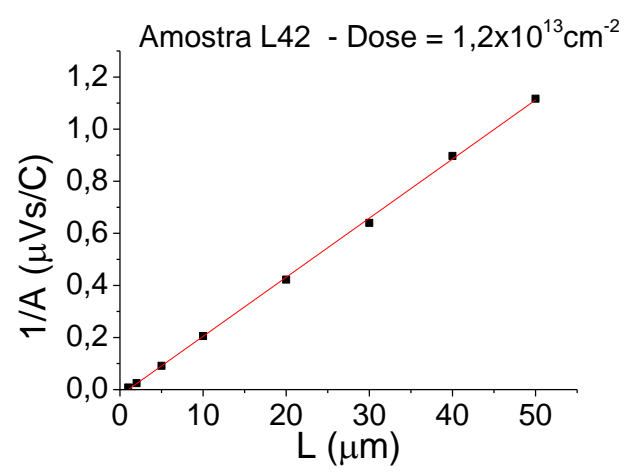

b)

Fonte: Autor.

Para o cálculo da mobilidade considerou-se a espessura do óxido de porta como $44 \mathrm{~nm}$, dado obtido pela medida de elipsometria logo após a oxidação (seção 4.2 Fabricação). Também para o cálculo de mobilidade foi utilizado o valor de largura (W) como sendo 12,2 $\mu \mathrm{m}$; pois é o valor de largura de linha da região $\mathrm{N}^{+}$obtido na seção 5.4.1 Largura de linhas.

Os dados obtidos dos gráficos e cálculos estão resumidos na Tabela 34.

Tabela 34 - Resultados de tensão de limiar, variação do comprimento de canal e mobilidade de elétrons para baixo campo elétrico.

\begin{tabular}{cccc}
\hline Amostra & $\mathrm{V}_{\text {Тн }}(\mathrm{V})$ & $\Delta \mathrm{L}(\mu \mathrm{m})$ & $\mu_{0}\left(\mathrm{~cm}^{2} / \mathrm{Vs}\right)$ \\
\hline L41 (Dose $\left.1,0 \times 10^{13} \mathrm{~cm}^{-2}\right)$ & $0,79 \pm 0,04$ & $0,30 \pm 0,10$ & $620 \pm 20$ \\
$\mathrm{~L} 42\left(\right.$ Dose $\left.1,2 \times 10^{13} \mathrm{~cm}^{-2}\right)$ & $1,10 \pm 0,06$ & $1,00 \pm 0,20$ & $460 \pm 20$ \\
\hline
\end{tabular}


Os resultados da tensão de limiar apresentam muita proximidade com os valores projetados inicialmente, e também com os valores obtidos através da análise da segunda derivada da corrente de dreno em função da tensão entre porta e fonte. Ou seja, há uma confirmação, por outro método, que a fabricação ocorreu atingiu seus objetivos quanto ao projeto da tensão de limiar.

A variação do comprimento de canal $(\Delta \mathrm{L})$ é o resultado final dos processos que tendem a alterar o valor de máscara para o comprimento de canal. Entre os processos que podem alterar o comprimento efetivo de canal destacam-se a litografia e a corrosão do silício policristalino, e a difusão lateral de fósforo (implantado para formar fonte e dreno).

A variação introduzida pelos processos de litografia e corrosão do silício policristalino, foi avaliada na seção 5.4.1. O resultado mostrado na Tabela 34 é um resultado efetivo para os transistores medidos, ou seja, considera tanto os efeitos da litografia e corrosão, como a difusão lateral de fósforo.

É interessante que o resultado efetivo mostre $\Delta \mathrm{L}$ maior na amostra $\mathrm{L} 42$, em acordo com a análise da largura de linha. Pois os processos de litografia e corrosão úmida são extremamente dependentes do operador. Ou seja, são processos cujos resultados variam, significativamente, de uma amostra para a outra.

Por outro lado, a difusão lateral de fósforo é um processo repetitivo e menos dependente do operador. Portanto, devem ser aproximadamente 0 mesmo nas amostras L41 e L42. Assim o resultado efetivo é mostrado na Tabela 34, mas a explicação da diferença entre as amostras está nos processos de litografia e corrosão, como mostra a análise da largura de linha.

A mobilidade para baixo campo elétrico $\left(\mu_{0}\right)$ é maior na amostra $L 41$, com um interessante valor de $600 \mathrm{~cm}^{2} / \mathrm{Vs}$, aproximadamente. Já na amostra L42, o valor menor de $\mu_{0}$ se justifica em função da menor transcondutância dos transistores desta amostra. Nela projetou-se uma tensão de limiar maior, por isso houve implantação iônica de ajuste de $\mathrm{V}_{\mathrm{TH}}$ com dose maior $\left(1,2 \times 10^{13} \mathrm{~cm}^{-2}\right)$, que resulta em menor transcondutância, como mostra a equação (2.23). 


\subsubsection{Transcondutância $\left(\mathrm{g}_{\mathrm{m}}\right)$}

A transcondutância é inversamente proporcional ao comprimento de canal, como mostra a equação (2.23) e como é possível observar na Figura 60, para: a) amostra L41 e b) amostra L42.

A Tabela 35 mostra os valores da transcondutância máxima para cada comprimento de canal. Com estes dados é possível observar a tendência de maior transcondutância máxima para a amostra $L 41$, pois nesta amostra a mobilidade é maior quando comparada à amostra L42.

Figura 60 - Transcondutância em função da tensão de porta para diferentes comprimentos de canal, para a amostra a) L41 e b) L42.

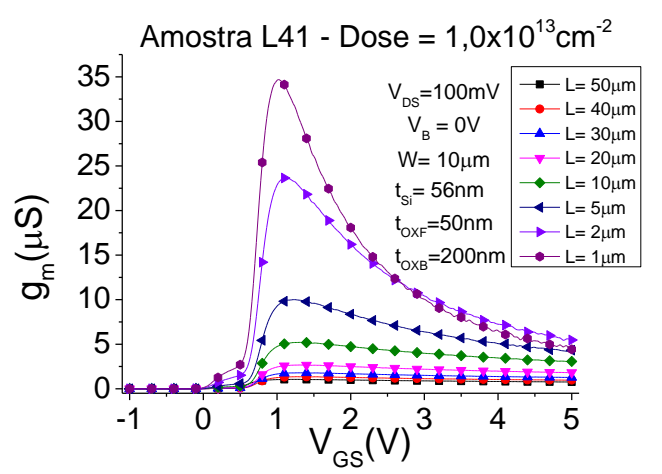

a)

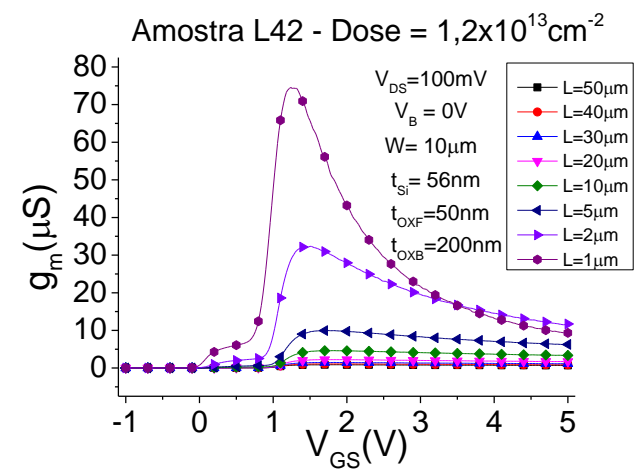

b)

Fonte: Autor.

Tabela 35 - Transcondutância máxima $\left(g_{\operatorname{mmax}}\right)$ em função do comprimento de porta para as amostras L41 e L42.

\begin{tabular}{ccc}
\hline \multicolumn{3}{c}{$\mathbf{g}_{\mathrm{m}}$ máximo $(\mu \mathrm{S})$} \\
\hline Comprimento $\mathrm{L}(\mu \mathrm{m})$ & $\mathrm{L} 41\left(\right.$ Dose $\left.=1,0 \times 10^{13} \mathrm{~cm}^{-2}\right)$ & $\mathrm{L} 42\left(\right.$ Dose $\left.=1,2 \times 10^{13} \mathrm{~cm}^{-2}\right)$ \\
50 & 1,06 & 0,87 \\
40 & 1,35 & 1,10 \\
30 & 1,79 & 1,47 \\
20 & 2,66 & 2,22 \\
10 & 5,20 & 4,61 \\
5 & 10,00 & 9,94 \\
2 & 23,69 & 32,13 \\
1 & 34,70 & 74,57 \\
\hline
\end{tabular}


Entretanto observa-se que para os menores comprimentos de canal, a transcondutância é maior na amostra L42. Isto se deve ao menor comprimento de canal efetivo nesta amostra, que se torna o fator determinante nestas dimensões.

A análise de largura de linha, na seção 5.4.1 Largura de linhas, mostra que a largura de linha do silício policristalino é menor na amostra $L 42$, sendo aproximadamente $1 \mu \mathrm{m}$ mais estreita. Mas é necessário considerar as limitações desta análise. A corrosão úmida do Si-Poli promoveu um perfil isotrópico, e a medida de largura de linha foi realizada a partir da medida de resistência elétrica. Ou seja, a análise de largura de linhas determina a qual seria a largura da linha de Si-Poli caso a corrosão fosse anisotrópica.

Devido a isto, a análise de variação no comprimento de canal, realizada na seção 5.4.5 Mobilidade $\left(\mu_{0}\right)$ e Comprimento efetivo de canal ( $\left.L_{\text {eff }}\right)$, mostra $\Delta \mathrm{L}$ dos transistores praticamente igual à variação na largura de linha do Si-Poli. No entanto, $\Delta L$ é a variação no comprimento de canal dos transistores, ou seja, é a resultante de todos os processos que influenciam o comprimento efetivo de canal, entre eles a variação no comprimento de linha do Si-Poli e a difusão lateral de dopantes (na etapa de ativação dos dopantes implantados).

Portanto, para análise da transcondutância, a variação no comprimento de canal $\Delta \mathrm{L}$, é melhor. $\mathrm{E}$ esta variação é maior na amostra $L 42$. Ou seja, o comprimento de canal efetivo é menor nesta amostra. Em transistores de grandes comprimentos este efeito é secundário e a amostra L41 apresenta maior transcondutância devido à maior mobilidade. No entanto, para pequenos comprimentos de canal, este $\Delta \mathrm{L}$ é significativo para a transcondutância, e a amostra L42 apresenta maior transcondutância $\left(\mathrm{g}_{\mathrm{m}}\right)$.

Entretanto, é inesperado que a amostra $L 42$, cujo $\Delta L=1 \mu \mathrm{m}$, apresente um resultado interessante para 0 transistor de $L_{\text {máscara }}=1 \mu \mathrm{m}$, pois neste caso 0

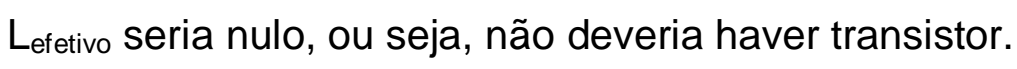


Com o microscópio eletrônico de varredura observou-se que há Si-Poli (porta) nestes transistores, como mostra a Figura 61, e que seu perfil é resultado de uma corrosão isotrópica, como era esperado.

Figura 61 - a) Si-Poli na região de porta do transistor de $L_{\text {máscara }}=1 \mu \mathrm{m}$. Amostra L42 (Dose $=1,2 \times 10^{13} \mathrm{~cm}^{-2}$ ) e b) Perfil esquemático do transistor, destacando a corrosão isotrópica do Si-Poli.

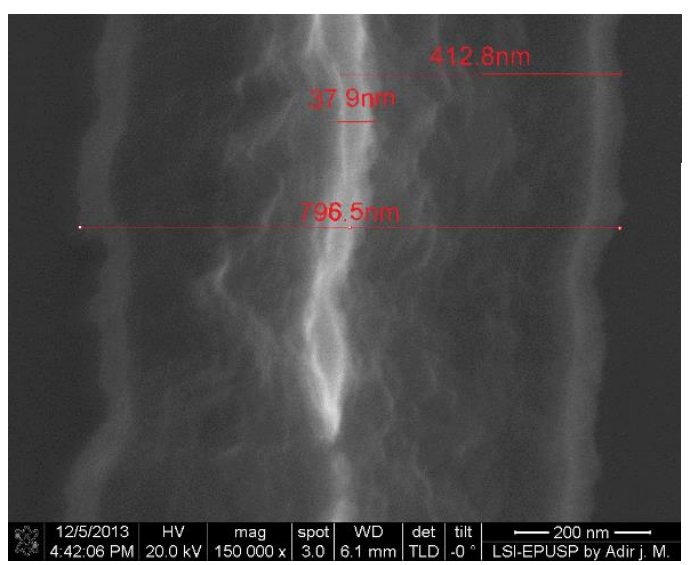

a)

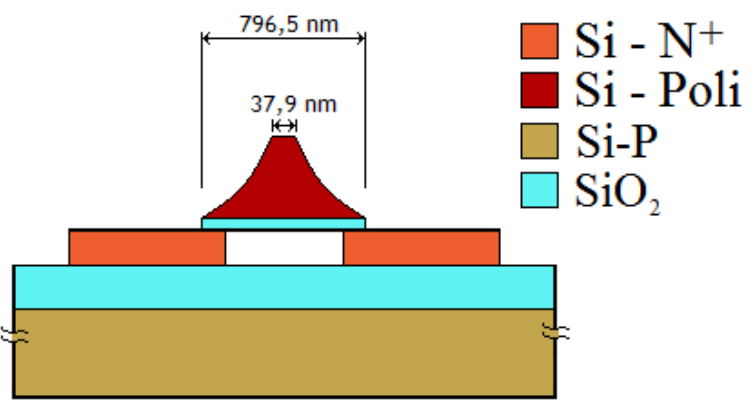

b)

Fonte: Autor.

A não uniformidade da corrosão úmida do Si-Poli, que fica demonstrada nas irregularidades da linha de Si-Poli da Figura 61, justifica um $\Delta \mathrm{L}$ menor para este transistor. $\mathrm{E}$ consequentemente, explica os resultados elétricos interessantes deste dispositivo.

\subsubsection{Resistência de Fone e Dreno ( $\left.\mathrm{R}_{\mathrm{S}}\right)$}

Será considerada a resistência série $\left(R_{S}\right)$ ao transistor a soma da resistência de fonte $\left(R_{F}\right)$ e de dreno $\left(R_{D}\right)$, definida pela equação (5.5):

$$
R_{S}=R_{F}+R_{D}
$$

E admitindo que os dispositivos são simétricos pode-se dizer que a resistência de fonte é igual à de dreno. 


$$
R_{F}=R_{D}
$$

A corrente de saturação de um transistor é dada pela equação (5.7) [10]:

$$
I_{\text {Dsat }}=\frac{K}{2} \cdot\left(V_{G S}-V_{T H}\right)^{2}
$$

sendo $\mathrm{K}$ :

$$
K=\frac{K_{0}}{1+\theta_{1} \cdot\left(V_{G S}-V_{T H}\right)}
$$

onde:

$\theta_{1}$ é o fator de redução da mobilidade e $K_{0}$ :

$$
K_{0}=\frac{W \cdot \mu_{0} \cdot C_{O X F}}{(1+\alpha) \cdot L_{e f f}}
$$

Se a resistência de fonte não é desprezível e se a fonte está no potencial zero, a real tensão entre porta e fonte $V_{G S}$ pode ser calculado pela eq. (5.10) [10]:

$$
V_{G S}=V_{G}-I_{D s a t} \cdot R_{F}
$$

A Figura 62 exemplifica a equação (5.10):

Figura 62 - Configuração para medida de resistência da fonte.

Fonte: Autor.
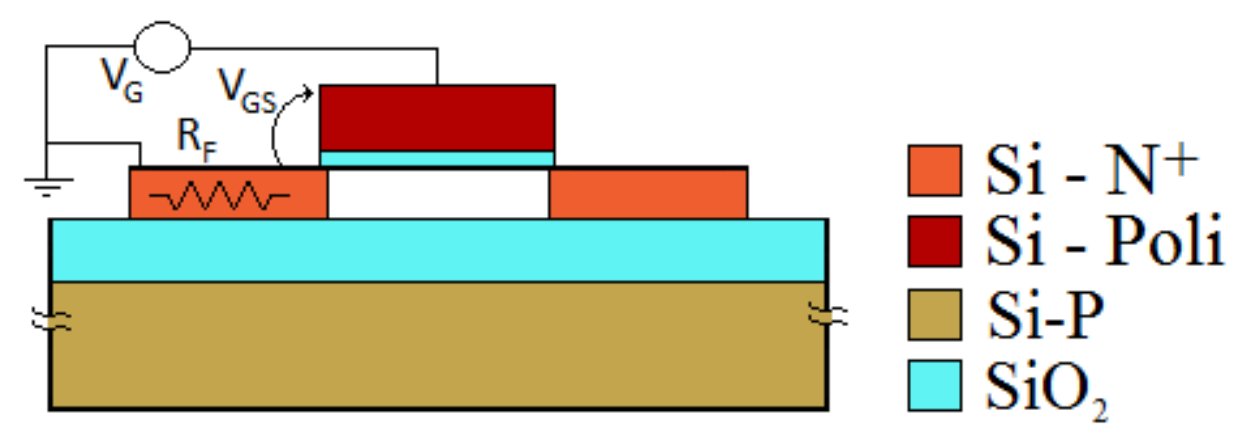

Combinando as equações (5.7), (5.8), (5.9) e (5.10), tem-se [38]: 


$$
V_{G}=V_{T H}+I_{D s a t} \cdot R_{t}+\sqrt{\frac{2 \cdot I_{D s a t}}{K_{0}}}
$$

Onde $R_{t}$ é a resistência de fonte somada à resistência efetiva $\left(R_{\theta}\right)$ devido a degradação da mobilidade no canal [38].

Definindo a função $G_{1}$ pela eq. (5.12):

$$
G_{1}\left(V_{G}, I_{D s a t}\right)=V_{G}-\frac{2}{I_{D s a t}} \int_{0}^{V_{G}} I_{D s a t}\left(V_{G}\right) d V_{G}
$$

A função $G_{1}$ pode ser extraída numericamente das medidas no dispositivo [38]. Solucionando $\mathrm{G}_{1}$, por partes, e substituindo $\mathrm{V}_{\mathrm{G}}$ da equação (5.11), tem-se [38]:

$$
G_{1}\left(I_{D s a t}\right)=V_{T H}+\frac{1}{3} \sqrt{\frac{2 I_{D s a t}}{K_{0}}}
$$

Agora, plotando $\mathrm{G}_{1} \times \mathrm{I}_{\mathrm{Dsat}}{ }^{1 / 2}$, é possível extrair $\mathrm{V}_{\mathrm{TH}}$ e $\mathrm{K}_{0}$, como mostra a a). Uma vez que tenha se extraído $\mathrm{V}_{\mathrm{TH}}$ e $\mathrm{K}_{0}$, pode-se calcular $\mathrm{R}_{\mathrm{t}}$ através da equação (5.14):

$$
R_{t}=\frac{V_{G}-V_{T H^{-}}-\sqrt{\frac{2 I_{D s a t}}{K_{0}}}}{I_{D s a t}}
$$

E com o valor de $R_{t}$ é possível extrair $\theta_{1}$ e $R_{F}$, plotando $R_{t} \times K_{0}{ }^{-1}$, como mostra a Figura 63 b). 
Figura 63 - Gráfico para extração de parâmetros: a) $\bigvee_{T H}$ e $K_{0}$; e b) $\theta_{1}$ e $R_{F}$.

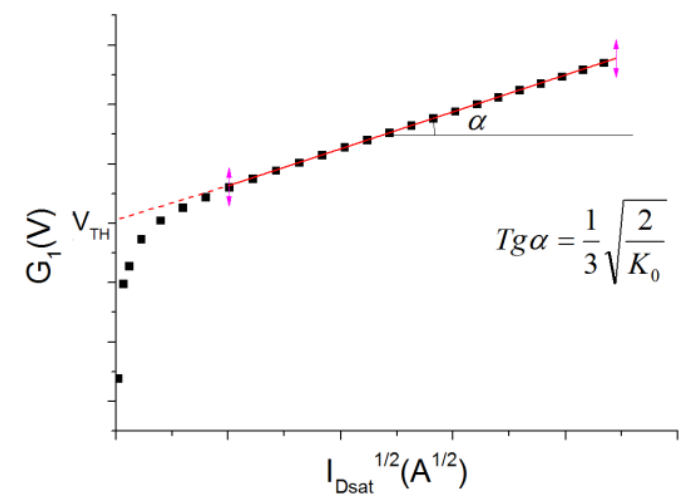

a)

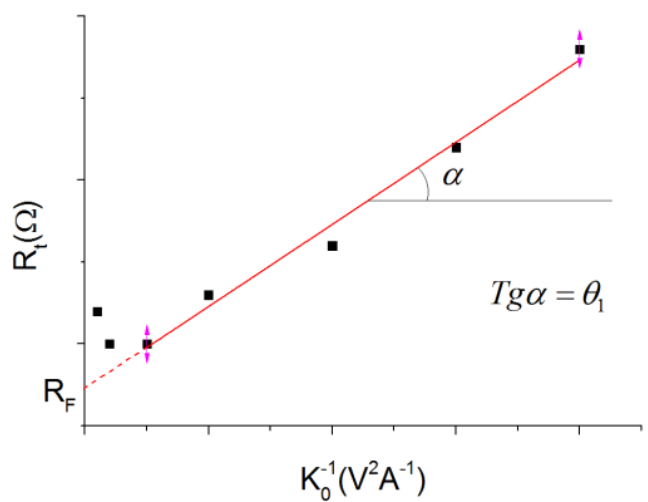

b)

Fonte: Colinge J.P.,Silicon-on-insulator technology.

Aplicando o método descrito [38], chegam-se aos dados apresentados na Figura 64 e na Tabela 36, para as amostras a) L41 e b) L42.

Figura 64 - Gráfico para extração dos parâmetros $\theta_{1}$ e $R_{F}$, nas amostras a) $L 41$ e b) $L 42$.

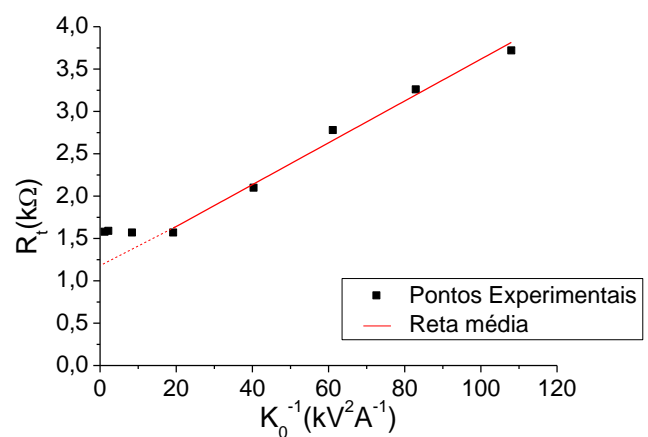

a)

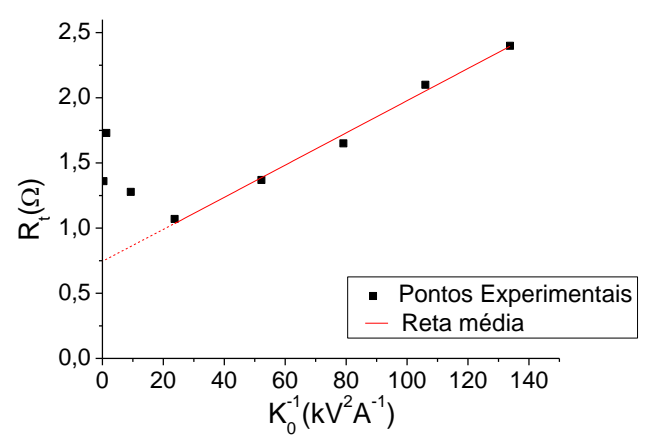

b)

Fonte: Autor.

Tabela 36 - Resultados da tensão de limiar $\left(\mathrm{V}_{\mathrm{TH}}\right)$, da resistência de fonte $\left(\mathrm{R}_{\mathrm{F}}\right)$ e do fator de redução da mobilidade $\left(\theta_{1}\right)$, para as amostras $L 41$ e $L 42$.

\begin{tabular}{cccc}
\hline Amostra & $\mathbf{V}_{\mathrm{TH}}(\mathbf{V})$ & $\mathbf{R}_{\mathbf{F}}(\mathbf{k} \Omega)$ & $\boldsymbol{\theta}_{\mathbf{1}}\left(\mathbf{V}^{-1}\right)$ \\
\hline L41(Dose $\left.=1,0 \times 10^{13} \mathrm{~cm}^{-2}\right)$ & $0,73 \pm 0,08$ & $1,1 \pm 0,2$ & $0,025 \pm 0,009$ \\
L42(Dose $\left.=1,2 \times 10^{13} \mathrm{~cm}^{-2}\right)$ & $1,02 \pm 0,09$ & $0,8 \pm 0,2$ & $0,012 \pm 0,007$ \\
\hline
\end{tabular}


Os resultados da tensão de limiar, avaliados pelo terceiro método, apresentam muita proximidade com os valores projetados inicialmente, e também com as medidas realizadas por outros métodos.

No que se refere à resistência de fonte observa-se um valor alto, o que pode ser explicado pela espessura da camada de silício, que sendo muito fina aumenta a resistência da região de fonte/dreno. Comparando as amostras L41 e L42 nota-se um valor de resistência de fonte maior na amostra L41. Este resultado é coerente com a medida de resistência de folha (seção 5.4.1 Largura de linhas), em que a resistência de folha da amostra L41 é ligeiramente maior.

Quanto à resistência série dos transistores é necessário ter em mente que a resistência de fonte é igual à de dreno, e que, portanto, a resistência série é igual ao dobro da resistência de fonte.

O resultado da resistência série é bastante elevado, principalmente porque neste processo simples não há etapas para reduzir esta resistência, como por exemplo, a formação de silicetos nas regiões de fonte/dreno.

Por sua vez, o resultado do fator de degradação da mobilidade é baixo, para as duas amostras. A explicação para este fato é o baixo campo elétrico vertical, já que a espessura do dielétrico de porta é relativamente grande.

Comparando o resultado entre as amostras nota-se maior fator de degradação da mobilidade na amostra L41, o que é compreensível observando que a mobilidade é maior na amostra $L 41$ e, portanto, sofre maior degradação.

\subsubsection{Condutância de Saída $\left(\mathrm{g}_{\mathrm{D}}\right)$}

A condutância de saída $\left(g_{D}\right)$, representa a variação da corrente de dreno em função da tensão aplicada no dreno, responsável pelo campo elétrico horizontal [39]. A condutância de saída é descrita pela equação (5.15): 


$$
g_{D}=\frac{d I_{D S}}{d V_{D S}}
$$

A condutância de saída tende a atingir seu menor valor quando o transistor está na saturação, tornando o ganho intrínseco maior nesta região de operação.

Medindo a característica de saída (IDS $\times V_{D S}$ ) dos transistores de maiores dimensões (T3) das amostras L41 e L42 tem-se os resultados apresentados na Figura 65.

Figura 65 - Gráfico lDsX $V_{D S}$ dos transistores T3: a) L41 e; b) L42.

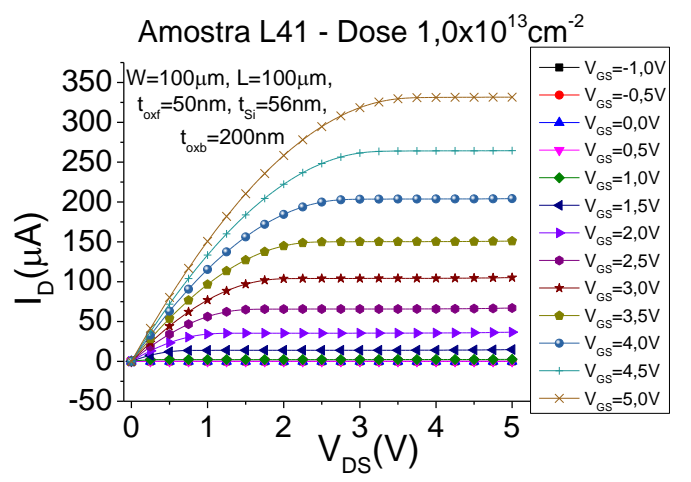

a)

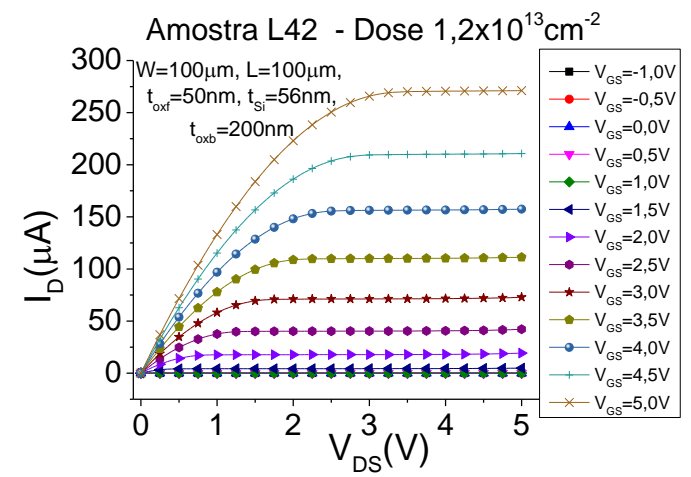

b)

Fonte: Autor.

A característica de saída dos transistores mostrada na Figura 65 apresenta um comportamento adequado, com uma região de saturação bem definida.

Mas quando se observa a característica de saída de transistores de dimensões menores, como na Figura 66, observa-se um aumento da corrente IDS para valores de $V_{D S}$ altos (maiores que $4 \mathrm{~V}$, aproximadamente).

Este efeito demonstra o chamado efeito avalanche [40], ou seja, o campo elétrico lateral fica intenso de modo que ocorre a chamada ionização por impacto. Em termos simples, isto significa que o intenso campo elétrico fornece uma alta energia cinética ao elétron, que ao colidir com átomos da rede cristalina do silício, gera novos pares elétron-lacuna. Os novos elétrons, 
acelerados pelo alto campo elétrico, colidem com átomos de silício, gerando mais elétrons, e deste modo, a corrente cresce.

Figura 66 - Característica de saída dos transistores com comprimento de canal (máscara) variando de $50 \mu \mathrm{m}$ a $1 \mu \mathrm{m}$, nas amostras: a) $L 41$ e; b) $L 42$.

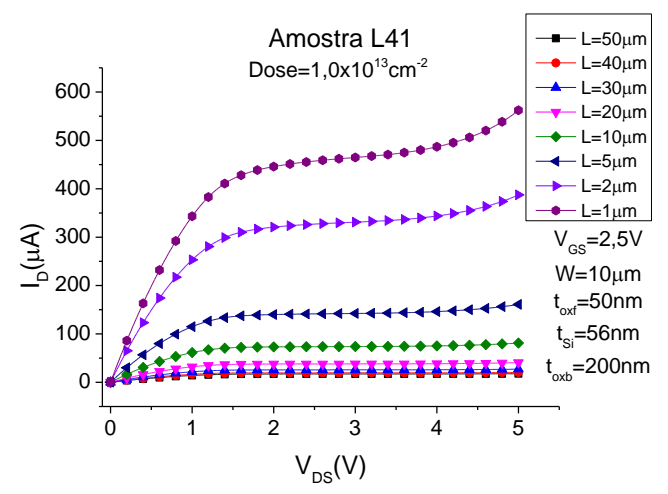

a)

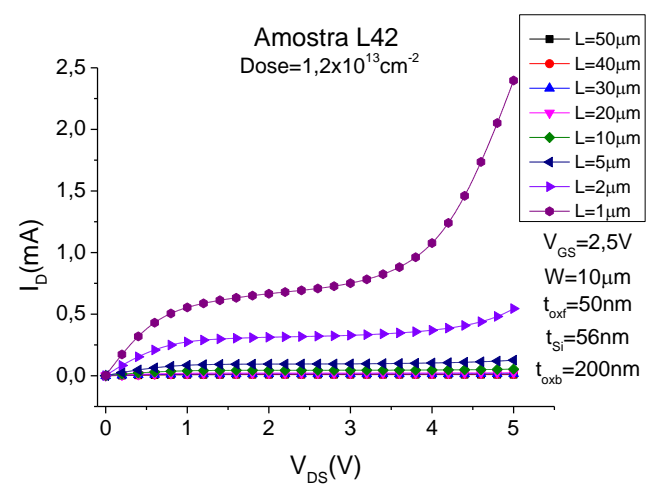

b)

Fonte: Autor.

O efeito avalanche é mais intenso em dispositivos de comprimento de canal menor, pois o campo elétrico lateral é mais intenso.

Calculando a condutância de saída, através da equação (5.15), obtêm-se os resultados mostrados na Figura 67, à seguir.

Figura 67 - Gráficos da condutância de saída em função da tensão de dreno (gDXVDS) para diversos comprimentos de canal, nas amostras: a) L41 e; b) L42.

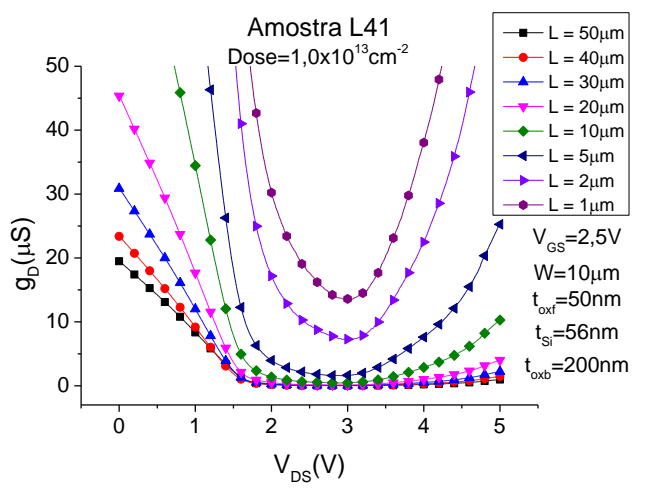

a)

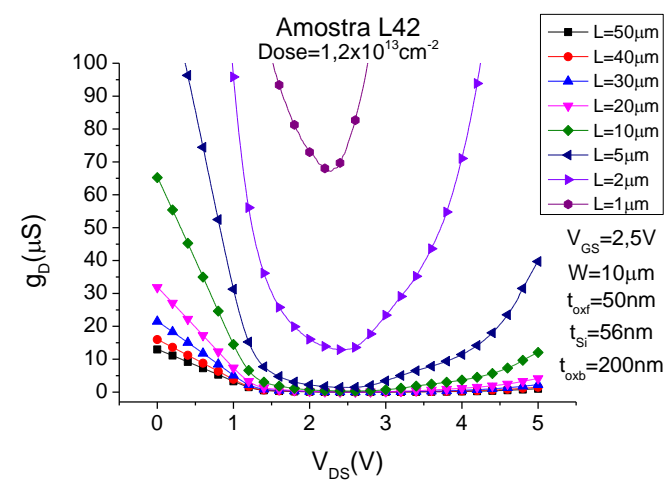

b)

Fonte: Autor.

É facilmente notável, nos gráficos da Figura 67, que a condutância de saída mínima, para todos os comprimentos de canal, ocorre para $V_{D S}$ entre 2,5 
e 3,0V, para tensões mais altas g volta a subir. A condutância de saída sobe, pois, a corrente de dreno não permanecer estável no nível de saturação, e a corrente sobe devido ao efeito avalanche.

Como era esperado, observa-se que a condutância de saída é menor para maiores comprimentos de canal.

Ao observar que a condutância de saída mínima ocorre em certa região da tensão de dreno, optou-se por utilizar dados desta região no cálculo do ganho intrínseco de tensão.

\subsubsection{Ganho de tensão ( $\left.A_{v}\right)$}

O ganho intrínseco de tensão $(A v)$ é um parâmetro muito importante na análise analógica dos transistores e, em consequência, nos circuitos produzidos com estes transistores. Devido ao escalamento, os transistores vêm se tornando menores e operando em velocidades maiores, isto faz com que suas propriedades analógicas degradem-se, devido a efeitos indesejados, como o efeito de canal curto e a degradação da condutância de saída conforme o comprimento do canal é reduzido [39].

Define-se o ganho intrínseco de tensão através da equação (5.16). Devido a valores menores de fator de efeito de corpo $(n=1+\alpha)$ transistores FD SOI MOSFET tem valores de ganho intrínseco de tensão, significativamente, maiores que os transistores convencionais (bulk) [10].

$$
\left|A_{V}\right|=\frac{g_{m}}{g_{D}}
$$

Nas amostras L41 e L42 calculou-se o $A_{v}$ usando a equação (5.16), para uma tensão entre fonte e dreno $V_{D S}=2,5 \mathrm{~V}$, e uma tensão entre porta e dreno $V_{G S}=2,5 \mathrm{~V}$. Os resultados são mostrados nos gráficos da Figura 68 .

O ganho intrínseco de tensão apresentou valores maiores para a amostra L42, como mostra o gráfico da Figura 68, pois a condutância de saída desta 
amostra é menor quando comparada à amostra L41. Quando o comprimento de canal fica menor que $5 \mu \mathrm{m}$ a amostra $L 41$ apresenta maiores valores de $A_{V}$. No entanto, isto deve-se ao $\Delta \mathrm{L}$ da amostra $\mathrm{L} 42$ ser maior, assim, para os transistores menores $(L=2$ e $L=1 \mu \mathrm{m})$, os transistores da amostra $L 42$ tem $L_{\text {eff }}$ muito menor que os da amostra L41, fazendo-os ter um ganho menor.

Figura 68 - Ganho intrínseco de tensão em função do comprimento de canal para as amostras $L 41$ e $L 42$, em uma polarização fixa, $V_{G S}=2,5 \mathrm{~V}$ e $V_{D S}=2,5 \mathrm{~V}$.

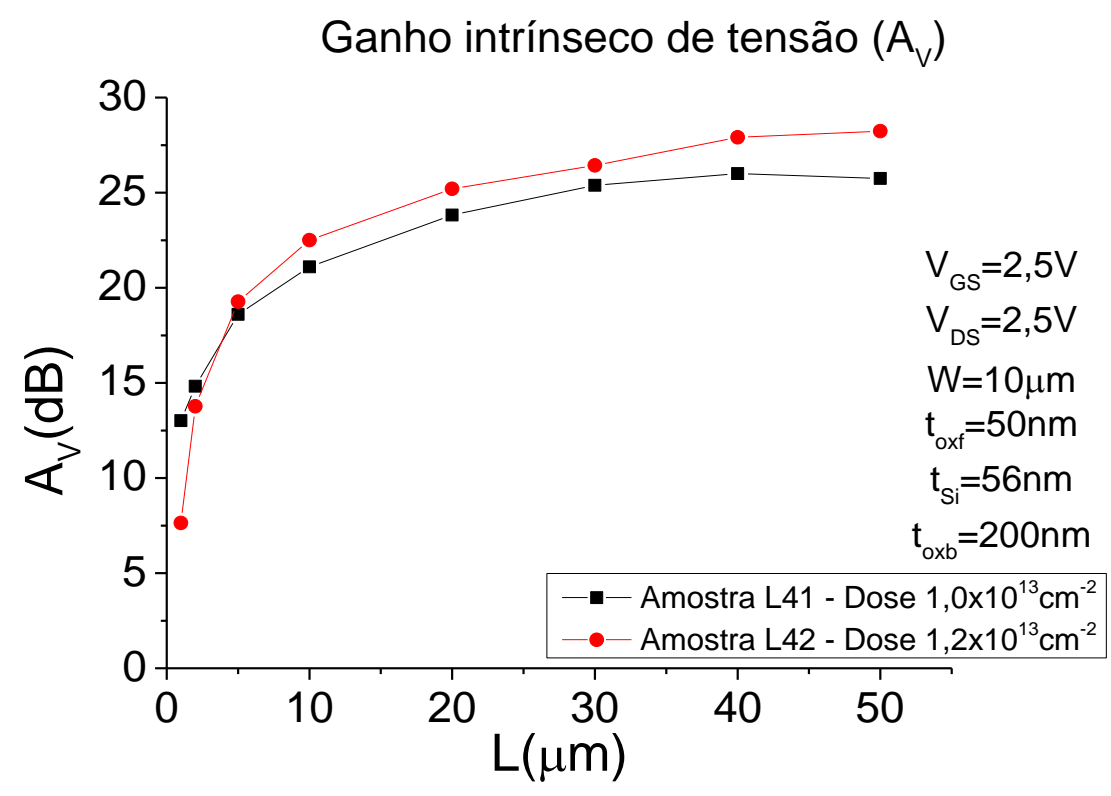

Fonte: Autor.

O resultado do ganho para ambas as amostras mostra valores interessantes para aplicações analógicas, quando o comprimento de canal é grande $(\approx 25 \mathrm{~dB})$.

\subsubsection{Resumo das Características do Processo}

As características da sequência de fabricação executada são:

a) Resistência de folha:

Amostra $L 41$ - Dose $1,0 \times 10^{13} \mathrm{~cm}^{-2}$.

Região $\mathrm{N}^{+}$:

$\approx 214 \Omega / \square$

Si-Poli:

$\approx 13,5 \Omega / \square$

Amostra L42 - Dose $1,2 \times 10^{13} \mathrm{~cm}^{-2}$. 
Região N+:

$\approx 203 \Omega / \square$

Si-Poli:

$\approx 16,0 \Omega / \square$

b) Transistores:

Amostra L41 - Dose $1,0 \times 10^{13} \mathrm{~cm}^{-2}$.

Tensão de Limiar $\left(\mathrm{V}_{\mathrm{TH}}\right)$

$\approx 0,72 \mathrm{~V}$

Mobilidade independente de campo $\left(\mu_{0}\right)$

$\approx 620 \mathrm{~cm}^{2} / \mathrm{Vs}$

Fator de degradação da mobilidade $\left(\theta_{1}\right)$

$\approx 0,025 \mathrm{~V}^{-1}$

Fator de corpo (n)

$\approx 1,22$

Resistência série

$\approx 2,2 \mathrm{k} \Omega$

Ganho de tensão $(A v)^{*}$

$\approx 26 \mathrm{~dB}$

Amostra L42 - Dose $1,2 \times 10^{13} \mathrm{~cm}^{-2}$.

Tensão de Limiar $\left(\mathrm{V}_{\mathrm{TH}}\right)$

$\approx 1,08 \mathrm{~V}$

Mobilidade independente de campo $\left(\mu_{0}\right)$

$\approx 460 \mathrm{~cm}^{2} / \mathrm{Vs}$

Fator de degradação da mobilidade $\left(\theta_{1}\right)$

$\approx 0,012 \mathrm{~V}^{-1}$

Fator de corpo (n)

$\approx 1,22$

Resistência série

$\approx 1,6 \mathrm{k} \Omega$

Ganho de tensão $(A v)^{*}$

$\approx 28 \mathrm{~dB}$

*Polarização $V_{G S}=2,5 V$ e $V_{D S}=2,5 V$, e transistor de dimensões $L=40 \mu m$ e $W=12 \mu \mathrm{m}$.

c) Espessura do óxido de porta (toxf)

$\approx 50 \mathrm{~nm}$

d) Espessura de Silício $\left(t_{s i}\right)$

$\approx 56 \mathrm{~nm}$

e) Espessura do óxido enterrado (toxв)

$\approx 200 \mathrm{~nm}$. 


\section{CONCLUSÕES E PERSPECTIVAS}

Neste trabalho foi apresentada pela primeira vez no Brasil uma sequência simples de fabricação de transistores SOI nMOSFET, utilizando apenas 3 fotomáscaras. Foi elaborado o projeto do processo de fabricação, simulação, fabricação e caracterização elétrica dos dispositivos construídos, utilizando a infraestrutura disponível do Departamento de Sistemas Eletrônicos da Escola Politécnica da USP.

O projeto foi desenvolvido para ser o mais simples possível, utilizando fotomáscaras projetadas para processo MOS convencional. Simulações numéricas foram usadas para projetar características básicas dos transistores como tensão de limiar de $1 \mathrm{~V}$. Devido às possíveis variações na densidade de cargas efetivas no óxido de porta, foram utilizadas duas doses de implantação iônica de boro $\left(1,0 \times 10^{13} \mathrm{~cm}^{-2}\right.$ e 1,2 $\left.\times 10^{13} \mathrm{~cm}^{-2}\right)$, para ajuste da tensão de limiar, de modo a se obter um processo com a tensão de limiar desejada. Posteriormente, o projeto foi aperfeiçoado tornando-se inclusive mais simples que o processo MOS convencional, já que utiliza apenas 3 etapas de fotogravação.

Para a fabricação foi adaptada a técnica de inversão do fotorresiste AZ5214E, procedimento que permitiu reutilizar as fotomáscaras de processo MOS convencional neste processo SOI nMOSFET. A construção dos dispositivos finais foi executada com apenas 18 etapas de processo, graças a simplicidade da sequência proposta e à utilização do próprio óxido enterrado de $200 \mathrm{~nm}$ como região de campo.

A caracterização elétrica permitiu observar a tensão de limiar obtida, $0,72 \mathrm{~V}$ para a dose de $1,0 \times 10^{13} \mathrm{~cm}^{-2}$ e 1,08V para a dose de $1,2 \times 10^{13} \mathrm{~cm}^{-2}$, este último resultado muito próximo do objetivo inicial (1V). Embora a dose mais alta de implantação iônica tenha sido mais eficiente no ajuste da tensão de limiar, a mobilidade independente de campo $\left(\mu_{0}\right)$ foi menor como esperado, devido à maior concentração de dopantes, sendo $460 \mathrm{~cm}^{2} / V s$ contra $620 \mathrm{~cm}^{2} / \mathrm{Vs}$ para a dose menor. Do mesmo modo a transcondutância máxima $\left(\mathrm{g}_{\mathrm{mmáx}}\right)$ apresenta valores maiores para a amostra com menor concentração de dopantes $\left(N_{A}\right)$, por exemplo: $5,20 \mu S$ contra $4,61 \mu S$; no caso de $L=10 \mu \mathrm{m}$. 
Devido a variações durante a corrosão do silício policristalino de porta, a variação no comprimento de canal dos transistores $(\Delta \mathrm{L})$ foi de $0,3 \mu \mathrm{m}$ para a amostra com menor dose e 1,0 $\mu \mathrm{m}$ para a amostra com maior dose, valores

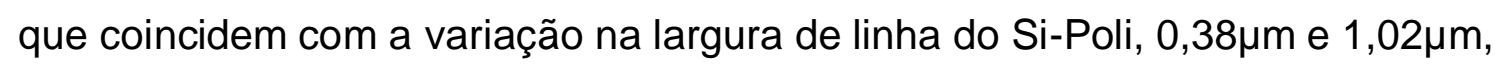
respectivamente. Resultados coerentes com o perfil isotrópico de corrosão do Si-Poli, realizado com corrosão úmida.

A inclinação de sublimiar não pôde ser extraída diretamente devido ao efeito transistor lateral parasitário, efeito esperado em função da simplicidade da sequência proposta. Mas ao obter o fator de acoplamento capacitivo ( $\alpha$ ) 0,22; para ambas as doses, foi possível estimar a inclinação de sublimiar: aproximadamente em $73 \mathrm{mV} /$ déc à temperatura ambiente.

O ganho intrínseco de tensão $(A v)$ mostrou-se maior na amostra com maior dose em função da menor condutância de saída, sendo $28 \mathrm{~dB}$ contra $26 \mathrm{~dB}$ para a dose menor, no transistor com $\mathrm{L}=40 \mu \mathrm{m}$ e $\mathrm{W}=12 \mu \mathrm{m}$. No entanto, para os menores comprimentos de canal o comportamento é o inverso, devido ao menor comprimento efetivo de canal da amostra com maior dose, o que aumenta a condutância de saída e diminui o ganho, sendo $14 \mathrm{~dB}$ contra $15 \mathrm{~dB}$ para a menor dose, no transistor com $\mathrm{L}=2 \mu \mathrm{m}$ e $\mathrm{W}=12 \mu \mathrm{m}$.

Para a sequência deste trabalho é importante estudar de modo mais aprofundado os transistores de pequenas dimensões ( $1 \mu \mathrm{m}$ de máscara) fabricados nesta sequência, pois o fato de um processo simples (sem LDD) gerar um dispositivo submicrométrico ( $L_{\text {eff }}<0,5 \mu \mathrm{m}$ ) funcional, é algo inesperado e não relatado na literatura especializada. Além disso, a continuação natural deste trabalho é aplicar a sequência de fabricação desenvolvida para aprendizado em microeletrônica e sobretudo no ensino de tecnologia SOI. 


\section{REFERÊNCIAS}

1. SWART, J. W. Semicondutores - Fundamentos, técnicas e aplicações. Campinas: UNICAMP, 2008.

2. DRSKA, M. www.valor.com.br. Valor.com.br, 17 dez. 2012. Disponivel em: $<$ http://www.valor.com.br/empresas/2942490/receita-mundial-comsemicondutores-recuara-3-em-2012-preve-gartner\#>. Acesso em: 28 out. 2013.

3. ROCHEL, L. C. E. http://www.abinee.org.br. Abinee, ago. 2013.

em: <http://www.abinee.org.br/abinee/decon/decon10.htm>. Acesso em: 28 out. 2013.

4. AMCHAM Brasil. Disponivel em: $<$ http://www.amcham.com.br/business-in-growth/noticias/paracomprar-uma-tonelada-de-semicondutores-brasil-precisa-exportar14-mil-toneladas-de-minerio-de-ferro-diz-secretario-de-informatica>. Acesso em: 28 out. 2013.

5. CEITEC S.A. Disponivel em: <http://www.ceitecsa.com/pt/apresentacao>. Acesso em: 28 out. 2013.

6. OLIVEIRA M. A. DE, O. F. L. . B. U. Indicadores Internacionais de Evolução Tecnológica e a Importância da Indústria de Semicondutores: 0 Posicionamento Estratégico do Brasil na América Latina. FEA-USP. São Paulo. 2003.

7. RANGEL R. C., C. M. N. P. . M. J. A. Microelectronics Education: Design, Fabrication and Characterization of SelfAligned Silicon-Gate nMOSFET Technology. SEMINATEC. São Paulo: Proceedings of SEMINATEC. 2012. p. 23-24.

8. MARTINO, J. A. Modelagem do Substrato e Novos 
Métodos de Caracterização Elétrica de SOI MOSFET. São Paulo: Tese de Livre Docência , 1998.

9. WIKIPEDIA. Moore's law. Wikipedia: the free encyclopedia, 2013. Disponivel em: <http://en.wikipedia.org/wiki/Moore's_law>. Acesso em: 29 out. 2013.

10. COLINGE, J. P. Silicon-on-Insulator Technology: Materials to VLSI. Berkeley: Kluwer Academic Publishers, 1991.

11. CHEN, H. S.; LI, S. S. Comparison of statistical variation of threshold voltage in bulk and SOI MOSFETs. Solid-State Eletronics, v.35, n.9, p.1233-1239, 1992.

12. SUZUKI, K. et al. Scaling Theory for Double-Gate SOI MOSFET's. IEEE Transactions on Electron Devices, v. 40, n. 12, p. 2326-2329, 1993.

13. ITRS. International Technology Roadmap for Semiconductors 2012. New York. 2012.

14. JONES, H. Advanced Substrate News. Disponivel em: $<$ http://www.advancedsubstratenews.com/2014/03/why-migrationto-fd-soi-is-a-better-approach-than-bulk-cmos-and-finfets-at-20nmand-1416nm-for-price-sensitive-markets/>. Acesso em: 28 mar. 2014.

15. WIKIPEDIA. Julius Edgar Lilienfeld. Wikipedia: the free encyclopedia, 2013. Disponivel em: <http://en.wikipedia.org/wiki/Julius_Edgar_Lilienfeld>. Acesso em: 01 nov. 2013.

16. MELLO, J. http://www.bn.com.br/radios-antigos. Disponivel em: <http://www.bn.com.br/radios-antigos/semicond.htm>. Acesso em: 01 nov. 2013.

17. PLUMMER, J. D.; DEAL, M. D.; GRIFFIN, P. B. Silicon VLSI 
Technology - Fundamentals, Pratice and Modeling. New Jersey: Prentice Hall, 2000.

18. MAFRA JR., J. J. Estruturas de Fonte e Dreno para Transistores MOS Submicrométricos. São Paulo: Dissertação de Mestrado apresentada à Escola Politécnica da USP., 1992.

19. SZE, S. M. Physics of Semiconductor Devices. New Jersey: Wiley-Interscince Publication, 1981.

20. MARTINO, J. A. Um Processo CMOS de cavidade dupla para comprimento de porta de $2 \mu \mathrm{m}$. São Paulo: Tese de Doutorado apresentada à Escola Politécnica da USP, 1988.

21. JASTRZEBSKI, L. E. A. Growth process of silicon over SiO2 by CVD: Epitaxial lateral overgrowth technique. Journal of Eletrochemical Society, vol.130, 1983. 1571.

22. BRADBURY, D. R. E. A. Control of lateral epitaxial chemical vapor deposition of silicon over insulator. Journal of Appl. Physics, v. 55, 1984. 519.

23. MIYAO, M. E. A. Low temperature SOI (Si-on-Insulator) formation by lateral solid-phase epitaxy. Journal of Appl. Physics, v. $64,1988.3018$.

24. HEMMENT, P. L. F. Semiconductor-on-insulator and thin-film transistor technology. MRS Symposium Proceedings, 1986. 207.

25. HILL, D. E. A. The reduction of dislocations in oxygen implanted silicon-on-insulator layers by sequencial implantation and annealing. Journal of Appl. Physics, v. 63, 1988. 4933.

26. BRUEL, M. E. A. Smart-Cut: A New Silicon On Insulator Material Technology Based on Hydrogen Implantation and Wafer Bonding. Japanese Journal os Applied Physics, v.36, 1997. 
1636-1641.

27. CELLER, G. E. A. Smart Cut ${ }^{\mathrm{TM}}$ : A guide to the technology, the process, the products. Parc Technologique des Fontaines. 2003.

28. SOITEC. UNIBOND WAFERS QSE. SOITEC. Grenoble. 2009.

29. MARTinO, J. A.; PAVANELlo, M. A.; VERDONCK, P. B. Caracterização Elétrica de Tecnologia e Dispositivos MOS. São Paulo: Ed. Pioneira Thomson Learning Ltda, 2003.

30. LIM, H. K.; FOSSUM, J. G. Threshold voltsge of thin-film silicon-on-insulator (SOI) MOSFETs. IEEE Transactionon Electron Devices, v. 30, 1983. 1244.

31. COLINGE, J. P.; COLINGE, C. A. Physics of Semiconductor Devices. 1st Ed. Massachusetts: Kluwer Academic Publishers, 2002.

32. SANTOS, L. P. D. Projeto de Máscaras com Dispositivos e Estruturas de Teste usando o Microwind. São Paulo: Trabalho de Conclusão de Curso - FATEC - SP, 2008.

33. FURUKAWA, T. SOI Hybrid Structure with Seletive Epitaxial Growth of Silicon. 6,555,891 B1, 29 Abril 2003.

34. SANTOS, S. G. Aplicação de filmes de siliceto de titânio e do escoamento térmico rápido de camadas de PSG na fabricação de circuitos integrados nMOS. São Paulo: Dissertação de Mestrado apresentada à Escola Politécnica da USP., 1988.

35. CLARIANT. AZ5214E Product Data Sheet. CLARIANT Eletronic Materials. Muttenz. 2010. 
36. NOGUEIRA, W. A. Obtenção de óxidos de porta MOS ultrafinos: Influência da limpeza química e estudo da ruptura dielétrica. São Paulo: Tese de Doutorado apresentada à Escola Politécnica da USP, 2003.

37. CLARIANT. Product data sheet: AZ $\mathbf{1 5 0 0}$ series standard photoresists. Clariant. Muttenz. 2008.

38. SANCHEZ, F. J. G. et al. A Method to Extract Mobility Degradation and Total Series Resistance of Fully-Depleted SOI MOSFETs. IEE Transactions on Electron Devices, 49, 2002.

39. BÜHLER, R. T. Influência de Variações Dimensionais Decorrentes do Processo de Fabricação sobre Parâmetros Elétricos de FinFET. São Bernardo do Campo: Disseretação de Mestrado Apresentada à FEI, 2009.

40. TROUTMAN, R. R. Low-Level Avalanche Multiplication in IGFET's. IEEE TRANSACTIONS ON ELECTRON DEVICES, 1976.

41. ARAÚJO, H. P. Construção e Caracterização de Diodos Controlados por Porta Visando a deteção de radiação luminosa. São Paulo: Dissertação de Mestrado apresentada à Escola Politécnica da USP., 2000. 


\section{ANEXOS}

\section{Anexo A - Lista de Publicações}

[1] RANGEL R. C., CARREÑO M. N. P., MARTINO J. A. Microelectronics Education: Design, Fabrication and Characterization of Self-Aligned SiliconGate nMOSFET Technology. SEMINATEC 2012.

[2] RANGEL R. C., POJAR M., SEABRA A. C., SANTOS FILHO S. G. dos and MARTINO J. A. 3D Transistor (FinFET) Fabricated with Three Lithography. SEMINATEC 2013.

[3] RANGEL R. C., POJAR M., SEABRA A. C., SANTOS FILHO S. G. dos and MARTINO J. A. Fully Electron-Beam-Lithography SOI FinFET. SBMicro 2013. 


\section{Anexo B - Arquivo de Simulação Athenas (Simulação de processos de fabricação do transistor FD SOI nMOSFET).}

go athena

\# Definição da Grade

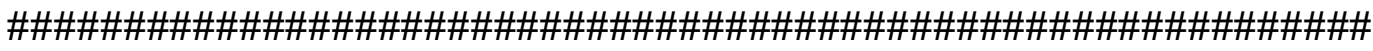

line $x$ loc $=0$ spac $=0.2$ tag $=e s q$

line $x$ loc $=0.5 \mathrm{spac}=0.07$

line $\times$ loc $=2.5 \mathrm{spac}=0.05$

line $\times$ loc $=7.5 \mathrm{spac}=0.05$

line $x$ loc $=9.5 \mathrm{spac}=0.07$

line $x$ loc $=10 \mathrm{spac}=0.2 \mathrm{tag}=\mathrm{dir}$

line y loc $=0$ spac $=0.01$ tag $=$ cima

line y loc $=0.04 \mathrm{spac}=0.005$

line y loc $=0.06 \mathrm{spac}=0.001$

line y loc $=0.08 \mathrm{spac}=0.005$

line $y$ loc $=0.1 \mathrm{spac}=0.01 \mathrm{tag}=$ cimaox

line $y$ loc $=0.3 \mathrm{spac}=0.05 \mathrm{tag}=$ baixox

line y $l o c=1 \mathrm{spac}=0.1$

line $y$ loc $=2 \mathrm{spac}=0.5 \mathrm{tag}=$ baixo

\#Definição da Lâmina

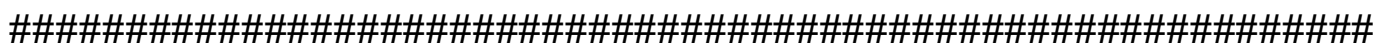

region silicon $x l o=e s q$ xhi=dir $y l o=$ cima $y h i=$ cimaox

region oxide $x \mid 0=e s q$ xhi=dir $y l o=$ cimao $x$ yhi=baixox

region silicon $x \mid 0=e s q x h i=d i r y l o=b a i x o x$ yhi=baixo

init boron $=1 \mathrm{e} 15$ orient $=100$

structure outfile=Lâmina.str two.dim

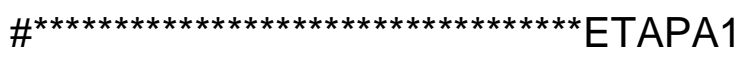

\#Corte e identificação das lâminas\# 


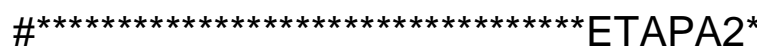

\#Limpeza Química Completa (para minimizar rugosidade)\#

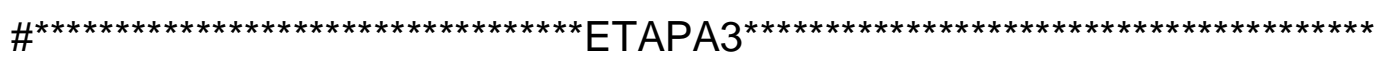

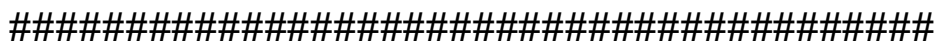

\#Processo de Oxidação p/ Implantação lônica\#

\#\#\#\#\#\#\#\#\#\#\#\#\#\#\#\#\#\#\#\#\#\#\#\#\#\#\#\#\#\#\#\#\#\#

\#Entrada no forno

\#-

diffuse t.rate $=97.5$ temp $=25$ time $=10$ inert

\#Oxidação

\#-

diffuse temp $=1000$ time $=60$ dryo 2

\#Densificação do óxido

\#-

diffuse temp $=1000$ time $=15$ inert

\#Saída do forno

\#-

diffuse temp $=1000$ t.rate $=-97.5$ time $=10$ inert

structure outfile=ApósEtapa3.str two.dim

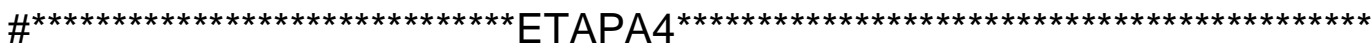

\#\#\#\#\#\#\#\#\#\#\#\#\#\#\#\#\#

\#Implantação de boro\#

\#\#\#\#\#\#\#\#\#\#\#\#\#\#\#\#

Implant boron dose $=1.0 \mathrm{e} 13$ energy $=30$ gauss

structure outfile=ApósEtapa4.str two.dim 
\#Densificação\#

\#\#\#\#\#\#\#\#\#\#\#

\#Entrada

\#-------

diffuse temp $=25$ t.rate $=87.5$ time $=10$ inert

\#Densificação (Propriamente dita)

\#-

diffuse temp $=900$ time $=30$ inert

\#Saída

\#-----

diffuse temp $=900$ t.rate $=-87.5$ time $=10$ inert

structure outfile=ApósEtapa5.str two.dim

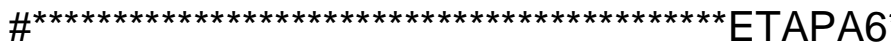

\#\#\#\#\#\#\#\#\#\#\#\#\#\#\#\#\#\#\#\#\#\#\#\#\#\#\#\#\#

\#Litografia: Abertura da Região Ativa\#

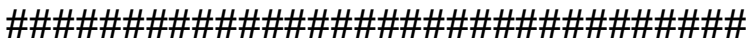

\#corrosão do óxido

etch oxide start $x=0.0 y=-1$

etch continue $x=10.0 y=-1$

etch continue $x=10.0 y=1$

etch done $\mathrm{x}=0.0 \mathrm{y}=1$

\#corrosão do Silício

etch silicon start $x=0.0 y=-1$

etch continue $x=0.5 y=-1$

etch continue $x=0.5 y=1$

etch done $\mathrm{x}=0.0 \mathrm{y}=1$ 
etch silicon start $x=9.5 y=-1$

etch continue $x=10.0 y=-1$

etch continue $x=10.0 y=1$

etch done $x=9.5 y=1$

\#corrosão do Óxido Enterrado

etch oxide start $\mathrm{x}=0.0 \mathrm{y}=-1$

etch continue $x=0.5 y=-1$

etch continue $x=0.5 y=0.2$

etch done $x=0.0 y=0.2$

etch oxide start $\mathrm{x}=9.5 \mathrm{y}=-1$

etch continue $x=10.0 y=-1$

etch continue $x=10.0 y=0.2$

etch done $x=9.5 y=0.2$

structure outfile=ApósEtapa6.str two.dim

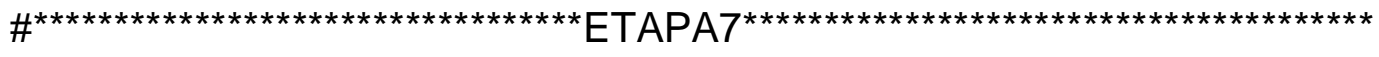

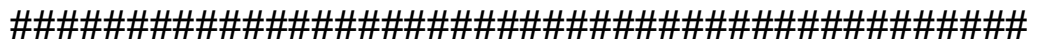

\#Limpeza Química Completa (Redução de $\mathrm{NH} 4 \mathrm{OH}$ )\#

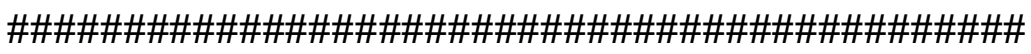

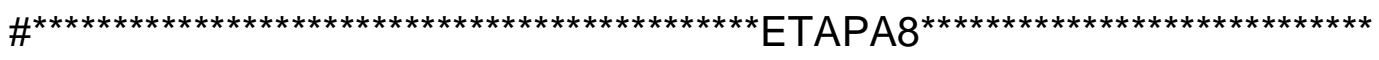

\#\#\#\#\#\#\#\#\#\#\#\#\#\#\#\#\#\#\#\#\#\#\#\#\#\#\#\#\#\#

\#Processo de Oxidação p/ Óxido de Porta\#

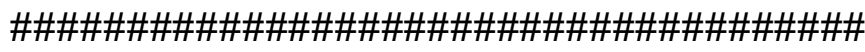

\#Entrada no forno

\#---------------

diffuse t.rate $=97.5$ temp $=25$ time $=10$ inert

\#Oxidação 
\#

diffuse temp $=1000$ time $=60$ dryo 2

\#Densificação do óxido

\#-

diffuse temp $=1000$ time $=15$ inert

\#Saída do forno

\#-

diffuse temp $=1000$ t.rate $=-97.5$ time $=10$ inert

structure outfile=ApósEtapa8.str two.dim

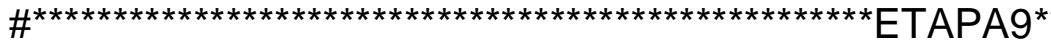

\#\#\#\#\#\#\#\#\#\#\#\#\#\#\#\#\#\#\#\#\#\#\#\#\#\#\#\#\#\#\#\#

\#Deposição de Silício Policristalino Intríseco\#

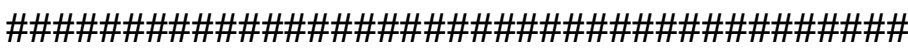

deposit polysili thick $=0.6 \mathrm{div}=10$

structure outfile=ApósEtapa9.str two.dim

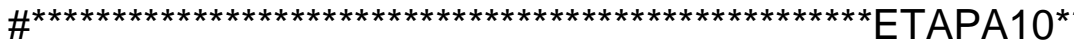

\#\#\#\#\#\#\#\#\#\#\#\#\#\#\#\#\#\#

\#Difusão de Fósforo\#

\#\#\#\#\#\#\#\#\#\#\#\#\#\#\#\#

\#Entrada

\#-------

diffuse t.rate $=90.0$ temp $=25$ time $=10$ c. phosphor $=4.5 \mathrm{e} 19$

\#Processo

\#--------

diffuse temp=925 time=30 c. phosphor $=4.5 \mathrm{e} 19$

\#Saída 
\#-----

diffuse t.rate $=-90.0$ temp $=1150$ time $=10$ c. phosphor $=4.5 \mathrm{e} 19$

structure outfile=ApósEtapa10.str two.dim

\#

\#\#\#\#\#\#\#\#\#\#\#\#\#\#\#\#\#\#\#\#\#\#\#\#\#\#\#\#\#\#\#\#\#\#\#\#\#

\#Litografia: Abertura das Regiões de Fonte e Dreno\#

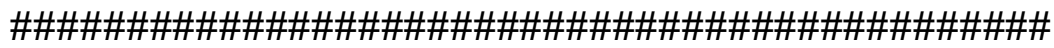

etch polysili start $x=0 y=-1$

etch continue $x=2.5 y=-1$

etch continue $\mathrm{x}=2.5 \mathrm{y}=1$

etch done $\mathrm{x}=0 \mathrm{y}=1$

etch polysili start $\mathrm{x}=7.5 \mathrm{y}=-1$

etch continue $\mathrm{x}=10.0 \mathrm{y}=-1$

etch continue $x=10.0 y=1$

etch done $\mathrm{x}=7.5 \mathrm{y}=1$

structure outfile=ApósEtapa11.str two.dim

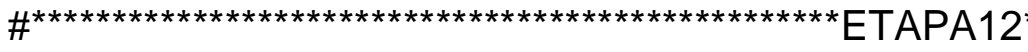

\#\#\#\#\#\#\#\#\#\#\#\#\#\#\#\#\#\#\#\#\#\#\#\#

\#Implantação lônica de Fósforo\#

\#\#\#\#\#\#\#\#\#\#\#\#\#\#\#\#\#\#\#\#\#\#\#

Implant phosphor dose $=5 \mathrm{E} 15$ energy $=40$ gauss

structure outfile=ApósEtapa12.str two.dim

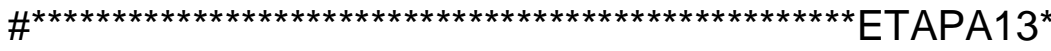

\#\#\#\#\#\#\#\#\#\#\#\#\#

\#Densificação\#

\#\#\#\#\#\#\#\#\#\#\#\#

\#Entrada

\#-------

diffuse temp $=25$ t.rate $=87.5$ time $=10$ inert 
\#Densificação (Propriamente dita)

$\#$

diffuse temp $=900$ time $=30$ inert

\#Saída

\#-----

diffuse temp $=900$ t.rate $=-87.5$ time $=10$ inert

structure outfile=ApósEtapa13.str two.dim

$\#$ \#

\#\#\#\#\#\#\#\#\#\#\#\#\#\#\#\#\#\#\#\#

\#Deposição de Óxido CVD\#

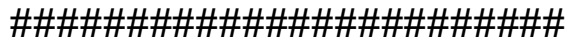

deposit oxide thick $=0.4$ div $=10$

structure outfile=ApósEtapa14.str two.dim

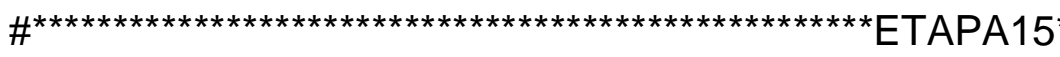

\#\#\#\#\#\#\#\#\#\#\#\#\#\#\#\#\#\#\#\#\#\#\#\#

\#Litografia: Abertura de Contatos\#

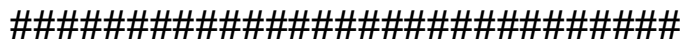

etch oxide start $x=0.7 y=-2$

etch continue $x=1.5 y=-2$

etch continue $x=1.5 y=0.07$

etch done $x=0.7 y=0.07$

etch oxide start $x=3.5 y=-2$

etch continue $x=6.5 y=-2$

etch continue $x=6.5 y=-0.2$

etch done $x=3.5 y=-0.2$

etch oxide start $x=8.5 y=-2$

etch continue $x=9.3 y=-2$

etch continue $x=9.3 y=0.07$ 
etch done $\mathrm{x}=8.5 \mathrm{y}=0.07$

structure outfile=ApósEtapa15.str two.dim

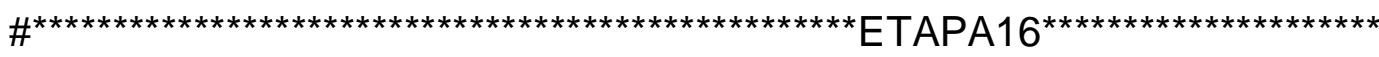

\#\#\#\#\#\#\#\#\#\#\#\#\#\#\#\#\#\#\#

\#Deposição de Alumínio\#

\#\#\#\#\#\#\#\#\#\#\#\#\#\#\#\#\#\#

Deposit aluminum thick $=1$ div $=20$

structure outfile=ApósEtapa16.str two.dim

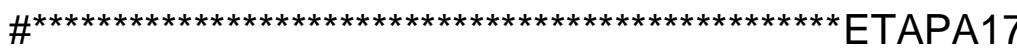

\#\#\#\#\#\#\#\#\#\#\#\#\#\#\#\#\#\#\#\#\#\#\#\#\#\#

\#Litografia: Definição do Alumínio\#

\#\#\#\#\#\#\#\#\#\#\#\#\#\#\#\#\#\#\#\#\#\#\#\#

etch aluminum start $x=0 y=-3$

etch continue $x=0.4 y=-3$

etch continue $x=0.4 y=1$

etch done $x=0.0 y=1$

etch aluminum start $x=2.5 y=-3$

etch continue $x=3.4 y=-3$

etch continue $x=3.4 y=1$

etch done $x=2.5 y=1$

etch aluminum start $x=6.6 y=-3$

etch continue $x=7.5 y=-3$

etch continue $x=7.5 y=1$

etch done $x=6.6 y=1$

etch aluminum start $x=9.6 y=-3$

etch continue $x=10 y=-3$

etch continue $x=10 y=1$

etch done $x=9.6 y=1$ 
etch aluminum start $x=0 y=-3$

etch continue $x=10 y=-3$

etch continue $x=10 y=-0.85$

etch done $x=0 y=-0.85$

structure outfile=ApósEtapa17.str two.dim

structure outfile=Mestrado.str two.dim

quit 


\section{Anexo C - Arquivo de Simulação Atlas (Simulação do Dispositivo FD SOI nMOSFET).}

go atlas

TITLE Transistor

mesh infile=Mestrado.str

electrode name=gate $x \cdot \min =4.8 x \cdot \max =5.2 y \cdot \min =-0.8 y \cdot \max =-0.65$

electrode name $=$ drain $x \cdot \min =8.6 x \cdot \max =8.9 y \cdot \min =-0.5 y \cdot \max =-0.2$

electrode name=source $x \cdot \min =1.1 \times \cdot \max =1.4 \mathrm{y} \cdot \min =-0.5 \mathrm{y} \cdot \max =-0.2$

electrode name=substrato bottom

\# set interface charge separately on front and back oxide interfaces

interf $\quad \mathrm{q}=5 \mathrm{e} 11 \mathrm{y} \cdot \max =0.5$

interf $\quad \mathrm{q}=5 \mathrm{e} 11 \mathrm{y} \cdot \mathrm{min}=0.5$

\#

\# set workfunction of gate

contact name $=$ gate alumin

contact name $=$ drain alumin

contact name $=$ source alumin

contact name=substrato alumin

output minset

impact selb

\#select models

models kla conmob srh auger bgn fldmob print

solve init

\#

\# do IDVG characteristic

\#

method newton trap carriers $=1$

\#

solve prev 
solve vdrain $=0.001$

solve vdrain $=0.01$

solve vdrain $=0.1$

method newton trap carriers $=1$

$\log$ outf=l-17-08-12.log

solve vgate $=-1$ vfinal $=5$ vstep $=0.02$ name $=$ gate

\#

structure outf=dens2.str

\#

quit 